


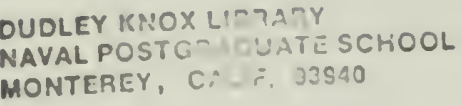






$$
N P G-159
$$





\section{NAVAL POSTGRADUATE SCHOOL Monterey, California}
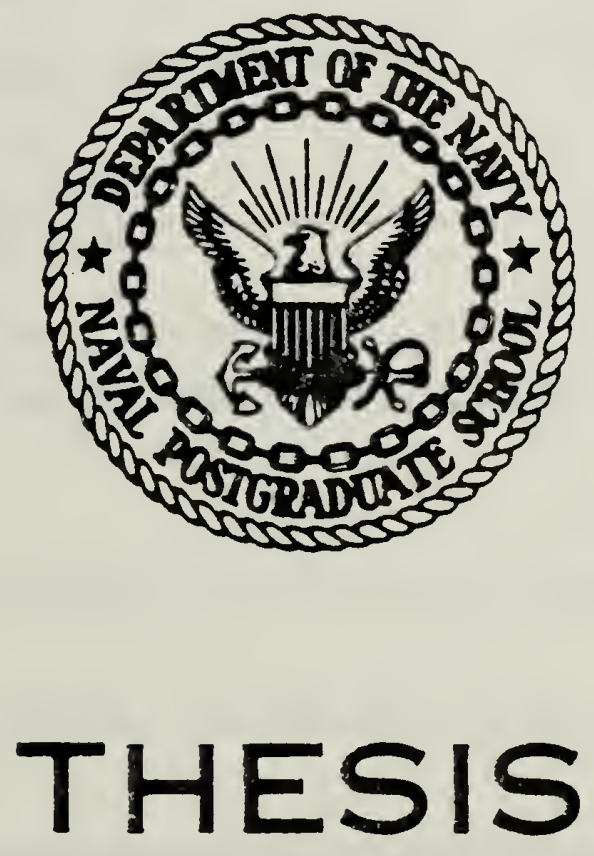

APPLICATION OF THE GLOBAL POSITIONING SYSTEM

TO IIEARSHORE HYDROGRAPHIC SURVEYS

$$
\text { by }
$$

\section{Virginia E. Hewe 11 \\ Donald D. Winter}

\section{September, 1981}

Thes is Advisors:

R. H. Garwood

J. J. Yon Schwind

Approved for public release, distribution unlimited 


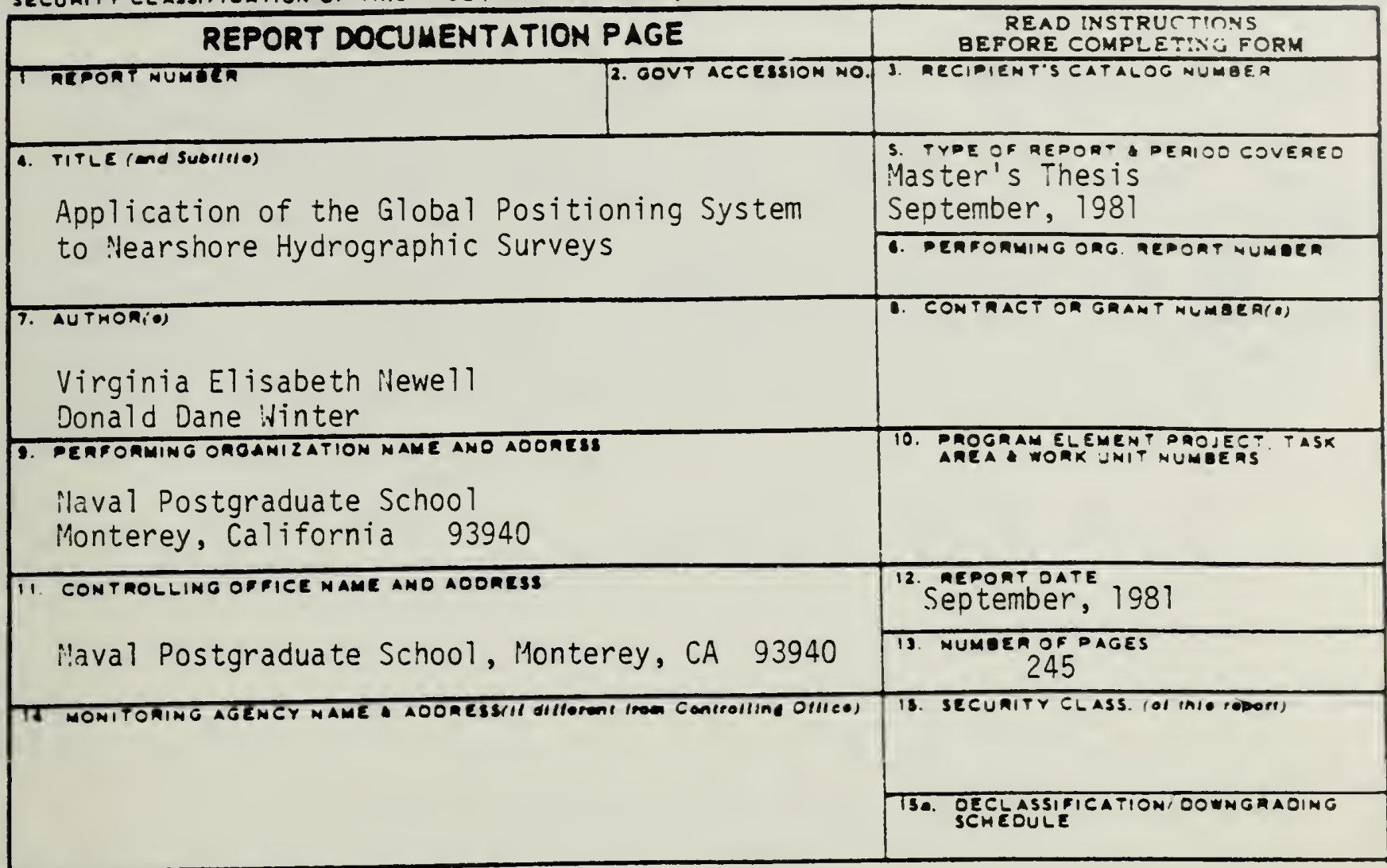

16. OISTRI DUTION STATEMENT (OI IMIO REPOII)

Approved for public release, distribution unlimited

17. OISTRIBUTION STATEMENT (ol ine abelreel enienod In Block 20, Il dilfermi trom Report)

18. SUPPLEMENTAAY NOTES

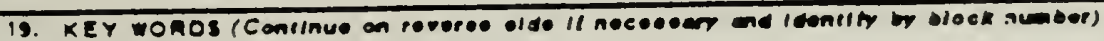

Global Positioning System, hydrography, translocation, ARTEMIS, theodolite

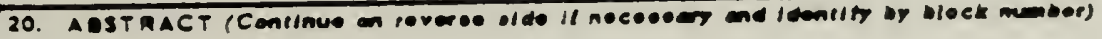

Translocation of the Global Positioning System has proved to be a highly accurate method of position determination for onshore and airborne navigation but it had not been previously evaluated for nearshore hydrographic surveys. The technique of translocation for hydrographic operations involves the simultaneous reception of signals from the GPS satellites by two independent receivers; one receiver onboard the survey vessel and one located at the 

known stationary position. A position correction is obtained at the station ary receiver, which is then applied to the shipboard receiver online or during postprocessing. An accuracy determination of translocated GPS was conducted at the Naval Postgraduate School, Monterey, CA, May, 1981. Two methods of positioning were used for comparison with GPS: 1) a least squares solution of three lines of position observed from three $\|$ ild T-2 theodolites and 2) a position determined from ARTEMIS, a range-azimuth short range microwave positioning system. Translocated GPS accuracies of 10 meters were determined. It is anticipated that greater accuracies will be obtained by using a more sophisticated receiver and more advanced processing methods. 
Approved for public release, distribution unlimited

\title{
Application of the Global Positioning System to \\ Nearshore Hydrographic Surveys
}

\section{by}

Virginia Elisabeth : Vewell

Lieutenant, NOAA

B. 1., University of Maine, 1971

M.S., Virginia Polytechnic Institute

and State University, 1975

\author{
Donald Dane !inter \\ Lieutenant Commander, IOAA \\ B.S., University of llichigan, \\ 1973
}

Submitted in partial fulfillment of the requirements for the degree of

MASTER OF SCIENCE IN OCEAIOGRAPHY (HYDROGRAPHY)

from the

NAVAL POSTGRADUATE SCHOOL

September, 1981 

Translocation of the Global Positioning System has proved to be a highly accurate method of position determination for onshore and airborne navigation, but it had not been previously evaluated for nearshore hydrographic surveys. The technique of translocation for hydrographic operations involves the simultaneous reception of signals from the GPS satellites by two independent receivers; one receiver onboard the survey vessel and one located at a known stationary position. A position correction is obtained at the stationary receiver, which is then applied to the shipboard receiver online or during postprocessing. An accuracy determination of translocated GPS was conducted at the Naval Postgraduate School, Monterey, CA, May, 1981. Two methods of positioning were used for comparison with GPS: 1) a least squares solution of three lines of position observed from three Wild T-2 theodolites, and 2) a position determined from ARTEMIS, a range-azimuth short range microwave positioning system. Translocated GPS accuracies of 10 meters were determined. It is anticipated that greater accuracies will be obtained by using a more sophisticated receiver and more advanced processing methods. 


\section{TABLE OF CONTENTS}

I. INTRODUCTION $\ldots \ldots \ldots \ldots \ldots \ldots \ldots \ldots \ldots \ldots \ldots \ldots \ldots \ldots \ldots \ldots$

II. EQUIPMENT DESCRIPTION AND OPERATIONAL CAPABILITIES..22

A. ARtemis positioning ststem .............23

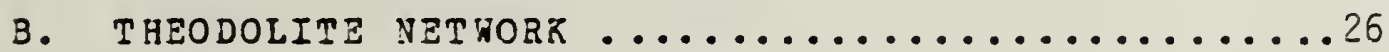

c. TRANSIt POSITIONING STSTEM ................ 30

III. GPS SYSTEM DESCRIPTION A ND OPERATIONAL

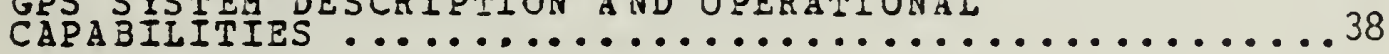

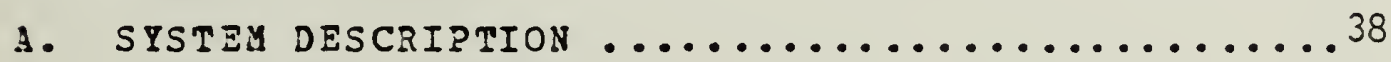

B. MANPACK RZCZIVER .................. 58

c. DIPFERENTIAL GPS .....................57

IV. TEST PROCEDURE ...................... 70

A. POSITIONING NETHORK ..................

B. POSItioning EQUipuent ...................

1. Theodolites $\ldots \ldots \ldots \ldots \ldots \ldots \ldots \ldots \ldots \ldots$

2. GPS and ARTEMIS $\ldots \ldots \ldots \ldots \ldots \ldots \ldots \ldots$

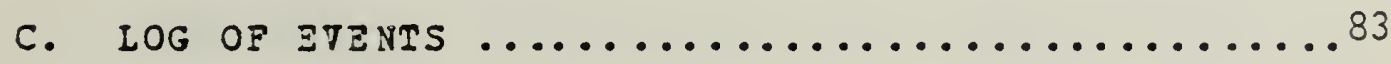

1. Stability Test....................84

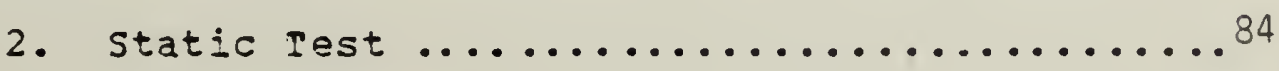

3. Sbipboard Test ...................... 84

7. data processing method ....................88

A. basic surtay computations ..............88 
B. THEODOLITE AND ARTEMIS SHIP POSITION .94

C. DIFFERENTIAL GPS SHIP POSIIION DETERMINATION ...95

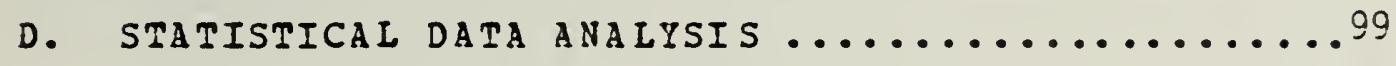

VI. ERROR anALTSIS ...................... 103

A. ARteis positioning ststem ...................

1. Microwave system Errors ..............103

2. ARTEMis system Errors ...............110

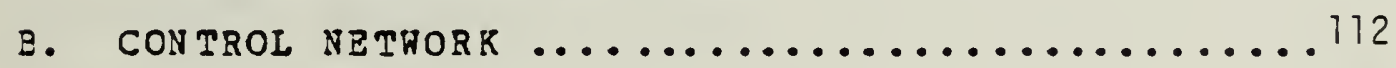

C. THEODOLITE NET חORR .........................

D. TRANSIT POSITIONING SYSTEM ..................

E. GPS ERROR SOURCES .....................121

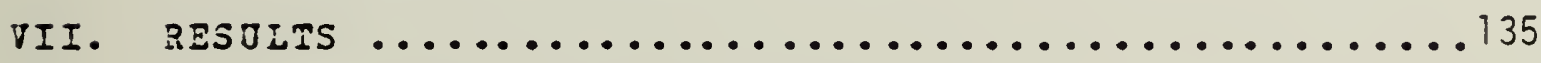

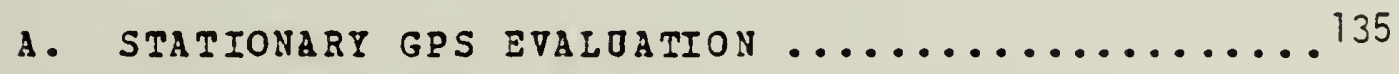

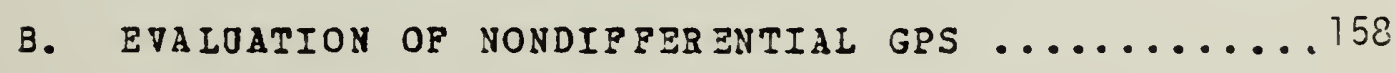

C. DIPFERENTIAL GPS EVALUATION WITH STATIC $\ldots \ldots \ldots 174$

D. ZVALUATION OP DIPRERENTIAL GPS WITHOOT STATIC 181

viri. conciosions ........................221

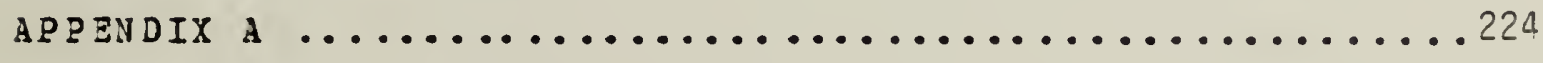

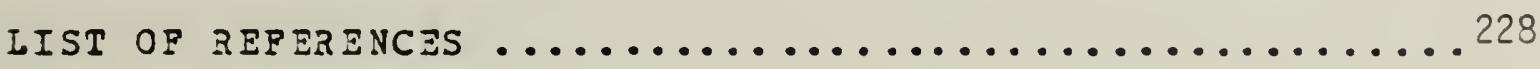

BIBLICGRAPH

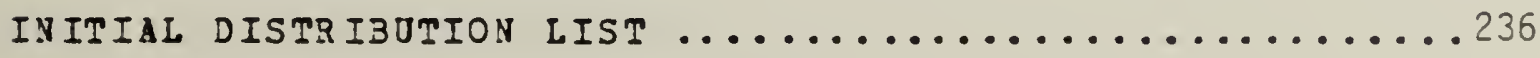





\section{LIST OP TABLES}

I. Ionospheric Group Delay as a Function

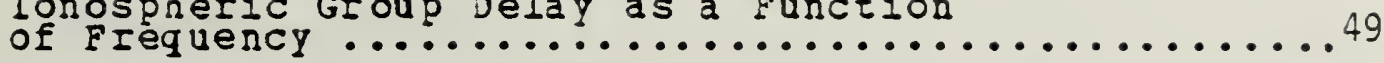

II. yanpack Interface hiring code ..............66

III. Range Error Budget ...................68

IV. Satelite observation rimes ..................

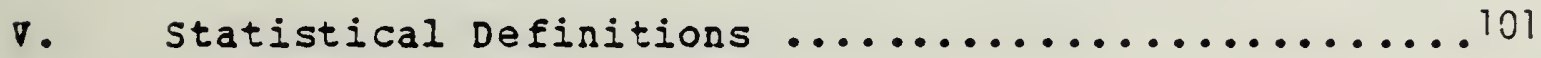

VI. Theodolite Instrument Errors .................116

VII. TRANSIT system Errors ................... 12?

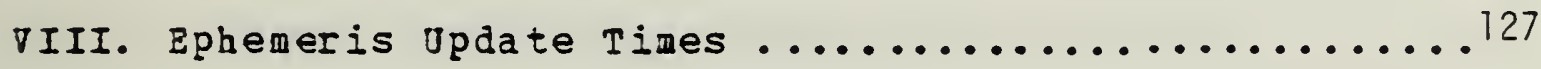





\section{LIST OF FIGURES}

2.1. TRANSIT Satellite $\ldots \ldots \ldots \ldots \ldots \ldots \ldots \ldots \ldots \ldots \ldots$

2.2. TRANSIT Satellite orbital Network ..............33

2.3. AN/PRR 14 Geoceiver Antenna ............. 36

3.1. The Nonuniform 18 satellite Constellation ......45

3.2. Walker $18 / 3 / 0$ Constellation Outages ..........46

3.3. NatSTAR Satellite $\ldots \ldots \ldots \ldots \ldots \ldots \ldots \ldots$

3.4. Pseudo-Range Description ............... 57

3.5. Global Positioning System MVOE Receiver .......59

3.6. MVOE Receiver Face ..................60

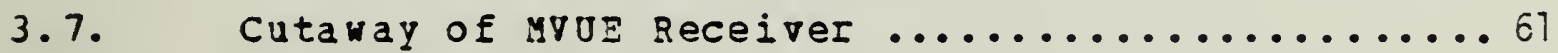

3.8. MVUE CDU Keyboard/Display Layout ...........66

3.9. Circuit Diagram of Receiver Interface ........6 65

4. 1. Test Area with Traverse sketch ............73

4.2. Antenna Tower on Coast Guard pier ..........78

4.3. R/ $\quad$ a CanIa Equipment Layout ............. 81

4.4. Equipment Installation on the B/V ACANIA ......82

4.5. Survey drea and Location of sets by Day ...... 86

5.1. Error Ellipse $\ldots \ldots \ldots \ldots \ldots \ldots \ldots \ldots \ldots \ldots \ldots$

5.2. Differential GPS processing ............. 98

6.1. ARTEMIS Bange Holes ................... 106 

6.2. ARTEMIS systen Error $\ldots \ldots \ldots \ldots \ldots \ldots \ldots$

6.3. Representative Theodolite Intersections for ErTor Ellipse Computations ...................119

7.1. Stability Test Results 9,10 May ...........136

7.2. Stability Iest Results 9,10 May ........... 137

7.3. Stability Test Results 9,10 May ........... 138

7.4. Total User Range Error 9 May ................139

7.5. Total User Range Error 10 May ............... 140

7.6. Static Test Results 11 Yay .............. 142

7.7. Static Test Results 11 May .............. 143

7.8. Static rest Results 11 May ................ 144

7.9. Satellite Elevation Angles .............. 145

7. 10. Satellite azinuth Angles ................ 146

7.11. Total Dser Range Error 11 May ............. 147

7.12. Geoceiver vs. Gps Position Computation ........ 148

7.13. Distance Between Geoceiver and Stationary GPS

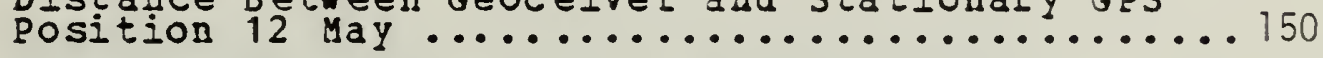

7.14. Distance Between Geoceiver and Stationary GPS

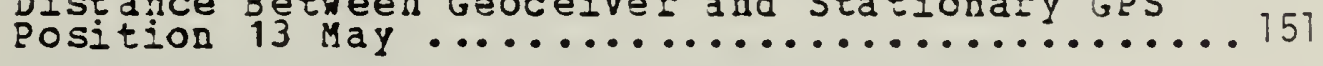

7.15. Distance Between Geoceiver and Stationary GPS 152

7.16. Total Oser Range Error 13 May .............. 153

7.17. Total Oser Range Error 15 May .............. 154

7.18. Azimuth Betyeen Geoceiver and Stationary GPS

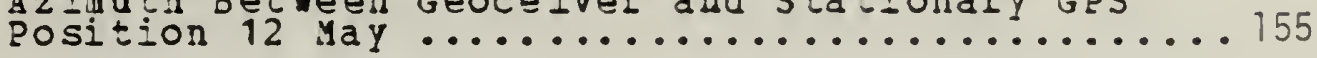




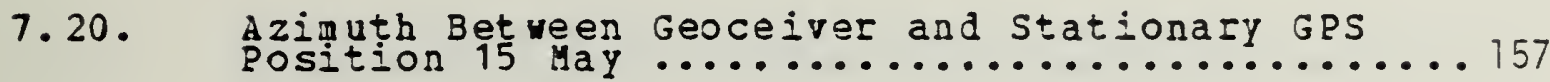

7.21. Distance Between T-2 Ship Position and

Oncorrected GPS position (4 Satellites) set 1 ..159

7.22. Distance Between $T-2$ Ship Position and

Uncorrected GPS position (4 Satellites) set $2 \ldots 160$

7.23. Distance Between $T-2$ Ship Position and

Uncorrected GPS position (4 Satellites) set $3 \ldots 161$

7.24. Distance Between $T-2$ Ship Position and

Oncorrected GPS position (4 Satellites) set 4.162

7.25. Distance Between $\mathrm{T}-2$ Ship position and

Uncorrected GPS position (4 Satelities) set 5.163

7.26. Distance Between $T-2$ Ship Position and

Oncorrected GPS position (4 Sateliites) set $6 \ldots 164$

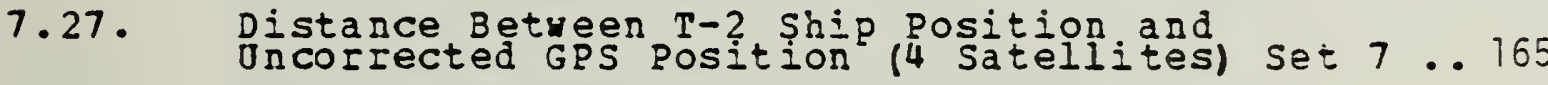

7.28. Distance Between T-2 Ship Position and Uncoriected GPS position (4 Satelites) set 8 . 166

7.29. Distance Between $T-2$ Ship Position and

oncorrected GPS position (4 Satellites)

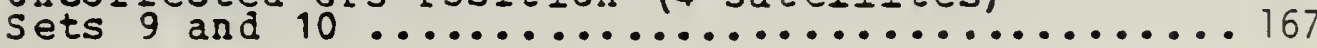

7.30. Distance Between T-2 Ship position and

oncorrected GPS position (4 Sateliites) set 11..168

7.31. Distance Between T-2 Ship Position and

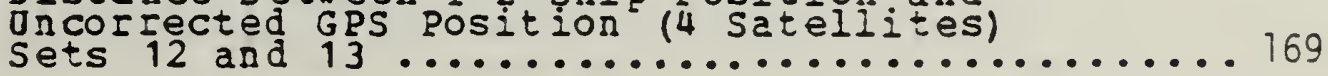

7.32. Total Oser Range Error 12 May ............. 170

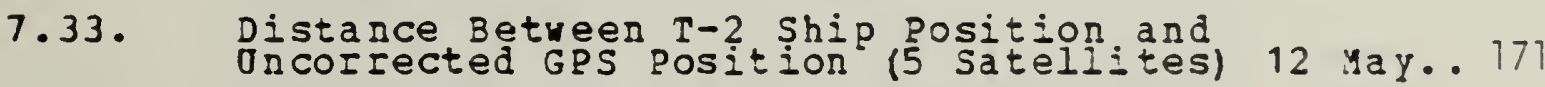

7.34. Distance Between T-2 Ship Position and
Dncorfected GPS Position (5 Satellites) 13 1ay.. 172

7.35. Distance Between T-2 Ship Position and 15 xay.. 173 

7.36. Distance Between T-2 Ship Position and Differential GPS Position with Static Correction

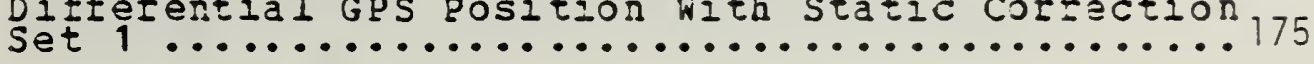

7.37 .

Distance Betveen $T-2$ Ship position and Differential GPS Position Hith Static Corraction

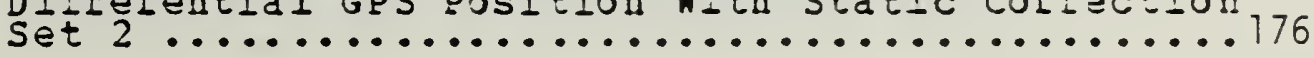

7.38 .

Distance Between T-2 Ship position and Differential GPS position with static Correction

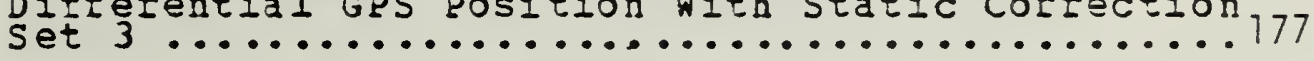

7.39 .

Dista ice Batueen Difierential GPS

T-2 Ship Position and correction set

7.40.

Distance Between $T-2$ Ship Position and Differential GPS Position yithout static correction set 2

Position *ithout Static

..........................178

7.41. Distance Between T-2 Ship Position and correction set 3

7.42. Azinuth Between $\mathbf{m}-2$ Ship position and

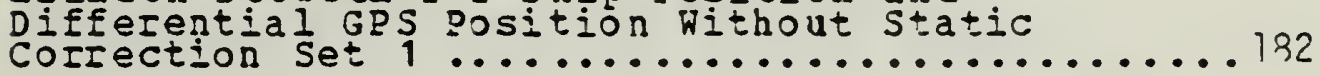

7.43.

Azinuth Between $T-2$ Ship position and Differential GPS Position Hithout Static 183

7.44.

dzinuth 3 etween $T-2$ Ship position and Differential GPS Position Without static Correction set 3 185

7.45.

Distance Between $T-2$. Ship position and Differential GPS Position without static correction set 4

7.46.

Azinuth Betyeen $T-2$ ship position and Differential GPS Position Mithout Static Correction set

7.47. Distance Between $T-2$ Ship Position and Differential GPS Position kithout static Correction set 5

7.48. Azinuth Between $T-2$ ship position and Differential GPS Position Without Static Correction set 5 


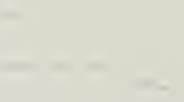


7.49. Distance Between T-2 Ship Position and Differential GPS Position hithout Static Correction set 6

7.50.

Azimuth Between $T-2$ shị position and Differential GPS Position Hithout static correction set 6

7.51. Distance Between T-2 Ship Position and Differential GPS Position without Static correction set 8

7.52

Azinuth Between $T-2$ Ship position and Differential GPS POsition Without Static

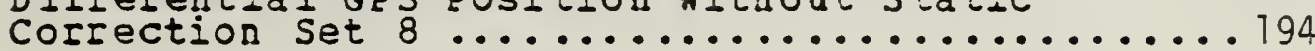

7.53. Distance Betreen T-2 Ship position and Dorrection Sets 9 \& 10 .......................... 196

7.54.

Azimuth Between $T-2$ ship Position and

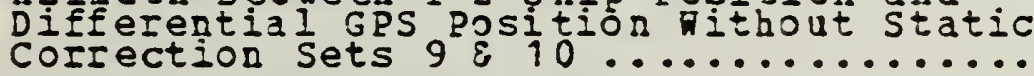

7.55.

Distance Between $T-2$ Ship position and Differential GPS Position nithout static Correction set 11 .

7.56.

Azimuth Between $T-2$ șhip Position and Differential GPS POSition Mithout Static Correction set 11

7.57.

Distance Between $T-2$ Ship Position and Differential GPS Position nithout Static Correction sets 12 \& 13

7.58.

Azimuth Between $T-2$ ship Position and Diferential GPS Position Without static correction sets 12 \& 13

7.59. Distance Betyeen $T-2$ Ship position and Differential GPS Position Without static Correction (5 satelites) $12 \mathrm{Ma}$

7.60. Distance Between $T-2$ Ship position and

Differential G?S Position Mithout Static Correction (5 sateilites) 15 May .............. 204

7.61. Latitude Comparison sets 1, 2............206

7.62. Longitude comparison Sets $1.2 \ldots \ldots \ldots \ldots$......... 

7.63. Latitude comparison set $3 \ldots \ldots \ldots . \ldots . \ldots 208$

7.64. Longitude Comparison set $3 \ldots \ldots \ldots . \ldots 209$

7.65. Latitude Comparison sets 4, $5 \ldots \ldots \ldots \ldots \ldots$

7.66. Longitude Comparison sets $4.5 \ldots \ldots \ldots \ldots \ldots \ldots 11$

7.67. Latitude Comparison sets $6,7 \ldots \ldots \ldots \ldots \ldots . \ldots 212$

7.68. Longitude Comparison Sets $6,7 \ldots \ldots \ldots \ldots . \ldots 213$

7.69. Latitude comparison sets $8.9 \ldots \ldots \ldots \ldots . \ldots 214$

7.70. Longitude Comparison Sets $8,9 \ldots \ldots \ldots \ldots \ldots . \ldots 215$

7.71. Latitude Comparison sets $10,11 \ldots \ldots \ldots \ldots$

7.72. Longitude comparison sets $10,11 \ldots \ldots \ldots \ldots . . \ldots 217$

7.73. Latitude Comparison sets $12,13 \ldots \ldots \ldots \ldots . \ldots 218$

7.74. Longitude Comparison Sets $12,13 \ldots \ldots . \ldots \ldots$ 



\section{LIST OF ABBREVIATIONS}

BPS

$C / A$

$\operatorname{CDO}$

CMAS

DMA

GMT

GPS

aTC

LMT

$\operatorname{MCS}$

MIS

MTOE

NA PSAT

NAVSTAR

OTES

p

$P \nabla C$

SAYSO

URE

JSAP

NGS 1972
Bits per second

Coarse Acquisition Code

Control Data Unit

Circular Map Accuracy Standard

Defense Mapping Agency

Greenuich Mean Time

Global positioning system

Hydrographic/Topographic Center at DMA

Local Mean Time

GPS Master Control Station

MYOE Instrumentation system

MANPACR Vehicular User Equipment

Nary Narigational Satellite system

Global Positioning system

YOAA Office of Ocean Technology and Engineering support

Precision Code

Polyvinyl Chloride Pipe

Space and Missile Systems ogganization

Oser Range Error

Onited States Air Force

WoIld Geodetic System of 1972 



\section{ACKNO!!LEDGEMENTS}

We would like to thank all the NPS students and other individuals who contributed their time and expertise during the long nights at the T-2 locations--without their support this thesis would not have been possible. Thaniss go to: Ilarjorie Amazeen, Bill Anderson, Gene Brown, Bob and Mac Clark, Ron Dickerman, Barry Donovan, Pat Eaton, Mike Ellett, Jerry and B.J. Hills, Dave Hinkel, Roger Parsons and Annette Parsons, Alan Shaffer, Keith Toepfer, Gerry theaton, and Jon Winter.

Special thanks also to Ted Calhoon for his cooperation and to the Captain of the ACANIA, Hoody Reynolds; and the crew members who contributed their ideas for the equipment installation onboard the ship. lle would like to thank Mr. Knute Berstis and Mr. Gary Uhitsell from OTES for their time and efforts in making the thesis possible, and Cdr. A. Durkee, of the Joint Programs Office, for his interest and support in providing the GPS receivers. 



\section{INTRODJCTION}

Shipboard operations for the purpose of oceanographic research, commercial transport, tactical operations, or hydrographic surveying require accurate and dependable positioning systems. The operation of most electronic positioning systems is hampered by atmospheric effects on the propagated signal and design limitations which restrict operating ranges, positional accuracy and dependability. A universal positioning system that provides accurate information to the user regardless of atmospheric conditions and that is free of range limitations is desirable. With the advent of satellite positioning techniques, such a system is now available.

The Nary Navigation Satelite System (NavSar), or TRANSIT, has been operational since 1964 and has proved dependable and sufficiently accurate for certain users. Although developed for military uses, the application of TRANSI in the civilian commuity has continued to expand at an exponential rate. The system, however, is limited by the time interval between fixes, which is 90 minutes on the average, and the requirement for precise knowledge of the ship's velocity. Although the system does not provide 

one method of improving system accuracy is by using two receivers simultaneously in a technique termed translocation, or differential mode. The method is based on the assumption that signal propagation errors to two proximate receivers are nearly the same. One receiver is placed over a known position, and the variation of the observed position vith time is determined relative to the absolute position. This variation is applied to the observed positions determined by a simultaneously operating receiver located at another location--on a survey vessel. for example. The assumption underlying this technique is that the distance betreen the two units is not sufficient to introduce a significant additional propagation error. The resulting position of the translocated receiver should be more accurate than the position obtained using a single receiver.

For hydrographic operations, the translocated Global positioning system (GPS) provides an alternative to presently used positioning systems. The satellites orbit at $20,000 \mathrm{~km}$, which theoretically would allow receiver separation of as much as $500 \mathrm{~km}$ without causing significant additional system error. Mith this flexibility, ore 


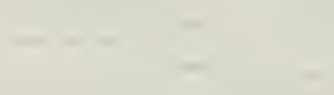


sufficient positional accuracy for hycographic surveying, it has been used for geodetic application by the Defense Mapping Agency (DMA) using fixed shore-based zeceivers to establish positioning networks in inaccessible areas worldwide. [Ref. 1]

The Global positioning system, or NAVSTAR, is a more sophisticated system designed to replace TRAySI in the mid-1980s. Six satellites are currently in orbit with trelfe more to be launched before the operational date of 1987. The 18-satellite orbit configuration will provide a multi-user, passive system yith 24 -hour availability, global coverage, and possible fix intervais of less than one second. The operational netrork consists of three elements--the satellites, the ground-based control seguent, operated by the space and Missile systems organization (SAMSO), and the user's receiver. Prototype receivers have been tested under optimum conditions by samso at the ruma proving Ground, Arizona, on both mobile and stationary platforms. Results show excellent system stability and accuracy when compared to currently used positioning systems. [Ref. 2] 
shorebased receiver could be placed at a central location and a survey of several hundred kilometers of coastline or offshore area could be completed with only one aditional receiver on the survey vesse1. [Ref. 3] The value of this flexibility would be realized in the significant decrease in survey planning, cost, and time compared to that spent presently in conducting hydrographic operations.

The accuracy of the system would be sufficient for all survey scales. The National Ocean Survey (Nos) defines the reguired accuracy of a positioning systen to be no nore than one-third of the survey accuracy, which is 1.5 millimeters at the scale of the survey. [Ref. 4] Non-translocated GPS has been shown to be of sufficient accuracy for 1:80,000 scale surveys and smaller. [Bef. 5]

The object of our research is to deteraine whether GPS at the present operational level is adequate for 1:10,000 scale surveys. To do this, a position determined by two GPS receivers in the translocated mode is compared to the same position determined by two other methods. If translocated GPS can be show to achieve specified iashore survey accuracies, the system would provide sufficient accuracies at all smaller scale surveys. 

Part of the difficulty in determining this level of accuracy concerns the reference system used. Most geodetic positions published by the National Geodetic Surrey (NGS) are based on the North American Reference Datum of 1927 (NAD-27) and the Clarke 1866 Ellipsoid, the best approximation to the shape of the earth for the continental United states. The satellite systems, hoverer, use a Ieference system which is not based on a portion of the earth's surface. A mass-centered ellipsoid referenced to the earth's center of mass has been computed using observed gravity and astronomical data. The best fit to this global ellipsoid is the rorld Geodetic system of 1972 (WGS-72). which is utilized by both, TRA NSIT and GPS. Transformation equations exist which convert NAD-27 coordinates to aGS-72 coordinates, but uncertainty in the gravity model produces errors as large as 10 meters due to the transformation process alone. [Ref. 6]

To establish a 11 positions on the same reference ellipsoid for this research, a TRANSI receiver was acquized frcm DMA and a first order Doppler station was established at the central location of the test area. A third order geodetic survey was conducted from the TaASIT station to 
$-2+2$ 
establish two additional stations on the MGS-72 ellipsoid. Two single channel Manpack GPS receivers were obtained from SAMSO. Stability testing and a receiver comparison test were conducted prior to shipboard testing to determine a quantitative measure of receiver performance. Ona of the receivers was then placed orer the TRANSIT station mark and the other aboard a survey vessel which waneuvered along predetermined track lines. Data were recorded via an interface to an HP-9825 computer and printer at each site. simultaneously, two additional independent measurements were made of ship position--one using a range-azimuth short range microwave positioning system (ARTEMIS) and the other a position determined by a least squares solution of three lines of position observed from thrae 1-second theodolites set on the three pre-established WGS-72 1ocations. The comparison of the ARTEMIS and theodolite-derived ship positions with the translocated GPS ship position provided the test results. 


$$
-x-2+2
$$




\section{EOOIPMENT DESCRIPIION AND OPERATIONAL CAPABILITIES}

Two positioning systems were chosen for comparison with the Global positioning system: a theodolite network and a microvave positioning system. The theodolite network consisted of three shore-based units so as to provide three lines of position. The microwave positioning system prcvided a range and an azimuth from a known location on shore. Both systems are accurate at short ranges and represent two contrasting methods of positioning--visuai and electronic. The theodolite method of positioning at short range has been and continues to be used for hydrographic operations as an alternative to electronic systems when gecmetry and system accuracy 1 imitations impose the need for a more flexible positioning system. The requirement for experienced theodolite observers as well as the comanication and logistics difficulties involved liait the use of this method to special cases.

This chapter describes the ARTEMS short-range electronic positioning system, the operation of the theodolite network as used during the comparison test, and the TBANSIT satellite system. 

ARTEMIS POSITIONING SISTEM

The ARTEIS position fixing system is a short-range licrowave system (to $30 \mathrm{~kg}$ ), built by christiaan iuygenslaboratorium B. $\nabla .$, in the Netherlands. It has been lsed operationally (primarily in Europe) since 1972, when :he system was introduced at the International Hydrographic :onference in Monaco. At the present time, fifty systems re in use. The systen is unique in design, is highly ccurate at short ranges, and is particularly useful for small barbor surveys, river surveys and relative positioning 1ses. Por this study, the ARTEMIS system, along with technical assistance, was obtained froll the Anerican Aistributor, MARINAP Corporation of Houston, TEXAS.

ARTEMIS is a range-azimuth positioning system which engloys a unique tracking method.

A stationary or fixed unit is placed over a known position on shore. Using a telescope that is mounted on the antenna, the antenna is sighted onto another known point and the known azimuth between the two locations is entered into the system via a digital display on the fixed unit. The unit is then locked into place for operation. A mobile unit is placed on the vessel whose position is desired. 

The mobile and fixed antennas resemble radar antennas which, while operating, track each other so that the two antennas are always parallel to each other and perpendicular to the line of position between them. A microwave link is established between the two antennas during periods of measurement and information is relayed between the mobile and fixed units. (A voice link is also available during operation.) The fixed unit provides the direction and the azimuth of the mobile unit with respect to the point sighted on by the telescope. At the same time, the mobile unit transmits a coded interruption of the signal to the fixed unit, which replies with the same interruption. The time difference between the transmission and reception at the mobile unit determines the distance between the two a ntennas.

Distance accuracy is determined by the number of measurements averaged over time and is available in two modes--a dynamic mode which arerages 1000 measurements or a static mode wich measures 10,000 measurements per displayed distance. The azimuth and distance information is displayed by the mobile unit so that personnel are not required at the stationary unit once operation has begun. The systan can be 

operated in long or short-range modes, which determine the amount of porer output for the system.

The microvave Erequencies used are 9.2 and 9.3 GHz. Problems arising with signal interference, observed with all microware positioning systems, therefore can occur with ARTEMIS. The regions of range holes, or multipath interference, can be computed for up to $10 \mathrm{~km}$ range by prior knowledge of the antenna elevations above sea level and the operating distance fron the shore-based antenna. [Ref. 7]

Each antenna is designed with a $22^{\circ}$ vertical beam width and a $2^{\circ}$ horizontal bean width. A power source of 22 volts DC per unit is required, With. an average curzent load of 2.5 amps.

The accuracy of the system depends on both the distance and the angle measured. The angle measurement has a $2 \sigma$ probability of measuring within $2^{\prime}$ of arc $\left(0.033^{\circ}\right)$. The distance measurement has a $2 \sigma$ probability that the mean distance value will vary within \pm 1.5 meters.

one of the advantages of ARTEMIS over other electronic systems is that the tro lines of position defining the fix always intersect at $90^{\circ}$. A unique advantage is that the coverage around the fired unit can be circular, with a 


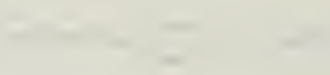


maximum range of operation to $30 \mathrm{~km}$, dependent on antenna heights. The short range applications of the ARTEMIS fill a need not provided by many currently used positioning systems.

For this study, the ARTzMIS was used in conjunction with the fositions derived from the theodolite netyork to determine the best estimate of the ship's position. The accuracy of the ARTEMIS was more than adequate for the ranges encountered during the test, and the ease of use and operational versatility of the systen made its use very advantageous.

B. TBEODOLITE NETHORK

A network of three fild $r-2$ theodolites was used as the control positioning system. The theodolite is widely used for surveying as a deans of measuring angles between two observational locations--either in a horizontal plane for traverse or triangulation surveys, or a rertical plane for astronomical observations.

The use of three theodolites as a short-range positioning system was an accepted method of positioning prior to development of electronic distance measuring systens. There remain disadrantages when using electronic 
positioning systems for hydrographic operations at short ranges $(1-2 \mathrm{~km})$. Most short-range electronic systems are designed for neasurement of position at line-of-sight ranges. This region includes a large portion of inshore hydrographic surveys. Inshore positioning involves more thorough planning to obtain the required accuracy for the scale of the survey. For example, in a harbor or core it may be difficult to place two range-range electronic units so that the area to be surveged is not within the region of positioning system uncertainty, or $30^{\circ}$ (radially) on each side of the baseline between the two units. To reposition the electronic units as often as is required to obtain optimum geometry is time-consuming and fequires manpower and extensive planning, and can result in operational delays. Interference of the signal due to reflection from a caln sea surface, or multipathing, is also a problem at short ranges for microwave systems.

Theodolites can be set at any intervisible location with preplanned geometry and can be used for the entire region to be surveyed. This method requires less expensive equipment (three theodolites), more manpowar (a recorder and an observer at each site), communication between the three 

locations (via portable radio, for example) and reasonable weather conditions. The basis of this procedure is that three angles observed from known locations to a predeternined point on the ressel constitute three lines of position. After removing all possible systematic errors and through a least squares solution of the three lines of position, the position of the vessel is determined. A major disadvantage is that observational errors are not determined in real time because the data cannot be processed immediately.

The basic procedure for the method requires predetermined sites which are known relative to each other. This may be achieved by using published geographic positions or by conducting a local plane survey to establish new positions using preestablished stations nearby. Zither way, all three locations must be based on the same datum and preferably permanently positioned by $a$ disk or a station mark.

Each theodolite was aligned using a plumb bob or optical plummet orer one of the known station marks or disks. By a predetermined scheme, each site was marked so as to be clearly visible to the other sites (lights were used for 
this study). The telescope of each theodolite was sighted onto one of the other sites and the horizontal circle set to read an arbitrary value ciose to $0^{\circ}$. The crosshaizs in the telescope were set to intersect the mark. When the theodolite was exactly sighted, the horizontal cizcle was read and recorded. (At this time the lights were turned off.l The operation began when all three sites completed this step, called the "initialliag procedure", or "initial pointing". The instrument was sighted on a point on the survey ressel that was visible to all operators. The ship was tracked by the operators by using the micrometer wheels on the instrument until a "mark" was called over the radio by the recorder at the control theodolite location. At that instant, the operator stopped tracking and the horizontal circle was read and recorded. This observation constituted a fix. After a series of fixes were racorded, or when the survey vessel reached a predetermined location, a set of fixes was completed. The lights were then reactivated at each site, each observer intersected the original mark, the horizontal circle was again read and the "final pointing" was recorded. If necessary, the instrument was zelevelled. The process was then repeated by starting with the ミnitialling procedure. 


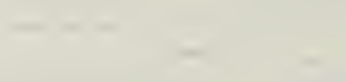


It was assumed that the theodolites vere in good operating condition. Collimation error had previously been determined. The observers were kept at the same locations throughout the test to minimize the error due to individual observer variations. Since only one portion of the hcrizontal circle was used, and no reverse readings observed, a systematic error vas introduced. This was assumed to be minimized during computation of the vessel position.

The observations were corrected for collimation error and for pointing error by evenly distributing the difference between the initial and final pointing values. The resulting angles yere processed using an intersection computation with a least squares fit applied to optimize the result. The computations for this study yere processed using an HP-9815 computer and software prepared by $C d=$ Ludvig Pfeifer, NOAA. The resulting position was used as the best estimate of the position of the ship.

C. TRANSIT POSITIONING SYSTEA

The TRANSIT, or Nary Navigation Satellite system, is the most widely utilized satellite positioning systen at the present time. The network of satellites and ground tracking 

stations has been in operation since 1964 and is becoming widely used by both the military and civilian commuities. It is expected to continue operation until at least 1995 , When the Global positioning syste is expected to replace it.

The system consists of $\geqq$ series of TaAsIT satellites (fig. 2.1.) in fired polar orbits of $1095 \mathrm{~km}$ elevation, forming a network within which the earth rotates (fig.2.2.). The orbits are spaced so that satellite passes occur, for a given ground location, at intervals of between 35 and 100 minutes. Each satellite travels an observable distance of between 4400 and $7000 \mathrm{~km}$ per pass, providing a sufficient time interval and baseline orer which the user can record data.

The idea of positioning an observer on the earth's surface by using the satellite as a reference systex originated from observation of sputnik 1, launched by the Soviet onion in 1957. By recording the change in Erequency of the satellite signal as the satellite passed overhead, a Doppler shift could be measured. The Doppler shift gives a spatial relationship as a function of tine between the observer and the satellite. If the position of the 



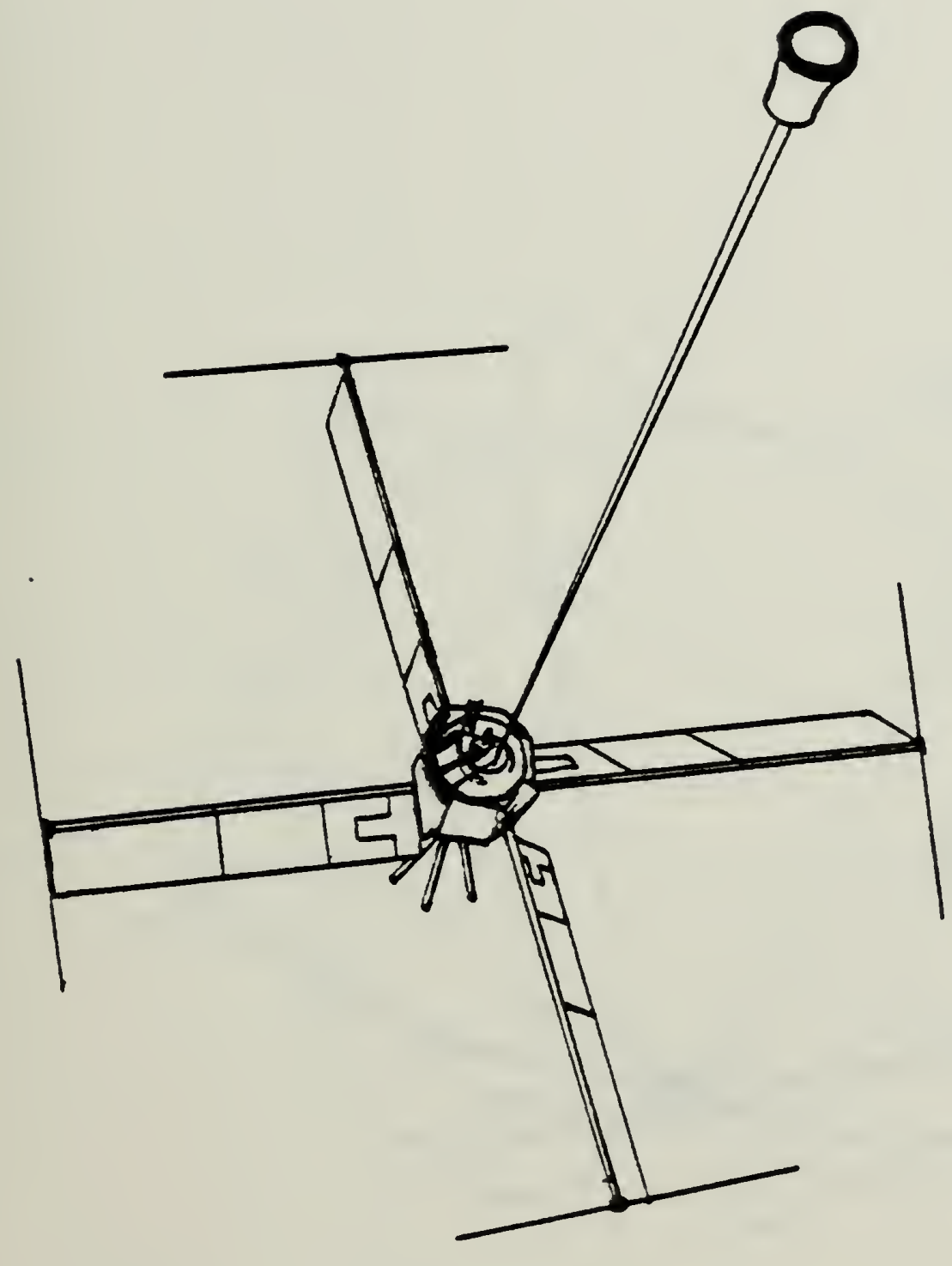

Fig. 2.1. TRANSIT Satelitite 


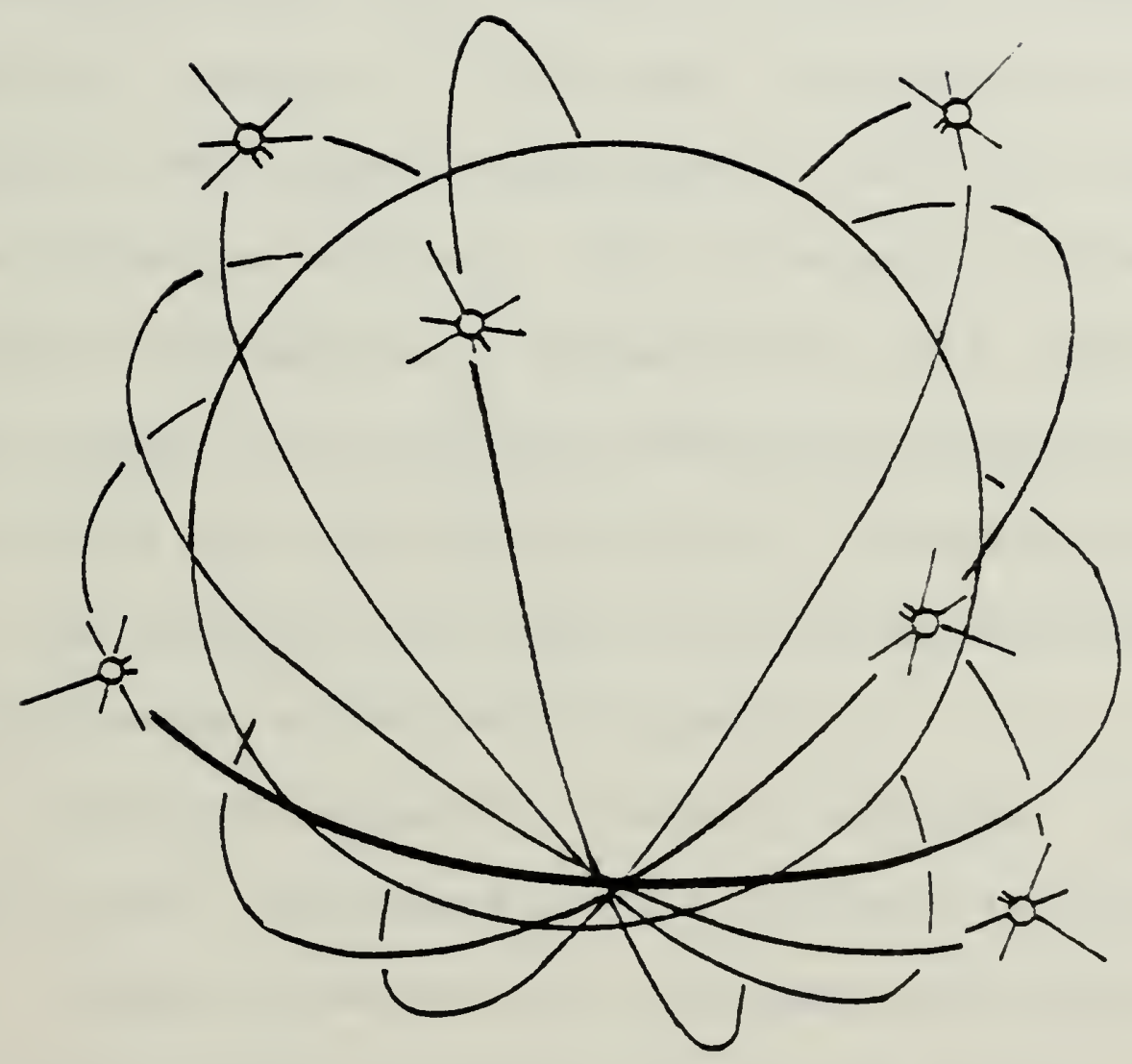

Fig. 2.2. Transit Satelitite Jroital ietwork 


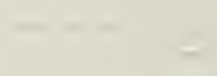


satellite is known at the time of observation, the observer's position can be determined.

In the TRANSIT system, the satellite positions are precisely determined by tracking stations located at Prospect Harbor, Maine: Rosemount, Minnesota; and Mahiawa, Hawaii. The tracking information (in the form of the Doppler frequency shift as a function of timel is relayed to the computing center at the Naral astronautics Group Headquarters, Pt. Mugu, California. Here the actual satellite orbits are computed. This information is used to predict orbit information. Parameters of this predicted orbit are relayed to two injection stations at rosemount and pt. Mugu. During the next satellite pass, the information is relayed to the satellite as part of the ravigation ressage, with new updates occurring every 12 hours.

The satellites therefore contain predicted orbit information which is received by the user via a satellite receiver. Several receivers are arailable with complexity and positional accuracy dependent upon the needs of the user. a computer is normally required to determine the user's mobile or fixed position in real time from a single satellite pass. 

Por many users having a dual channel receiver and known velocity, this method of positioning provides sufficient accuracy with typical error of 27 to 37 meters root sum square. Optimum accuracy is obtained, hovever, if the receiver position is fixed, and sereral consecutive passes of the same satellite are recorded. Juring each pass, lasting from 10 to 16 minutes as the satellite travels from one horizon to the other, many Doppler counts lobservations of shift in frequency as a function of time) are recorded. After a predetermined number of passes are stored, the data can be forwarded to the Defense Mapping agency in Brookmont, Maryland. There the precise ephemeris data from the ground tracking systen is applied to the data from the recorded passes to provide the optimum solution. The resulting position has a typical error of 6.3 meters root mean square for a series of passes, with a 3 -dimensional result of 1.5 meters per axis repeatability after 25 precise ephemeris passes. This method is used to determine positions in Iemote areas by DMA geodetic survey groups using the Magnavox AN/PRR-14 Geoceiver (fig.2.3.). [Bef. 8]

The TRANSIT system uses the Horld Geodetic system of 1972 (WGS-72) reference ellipsoid which is based on the 



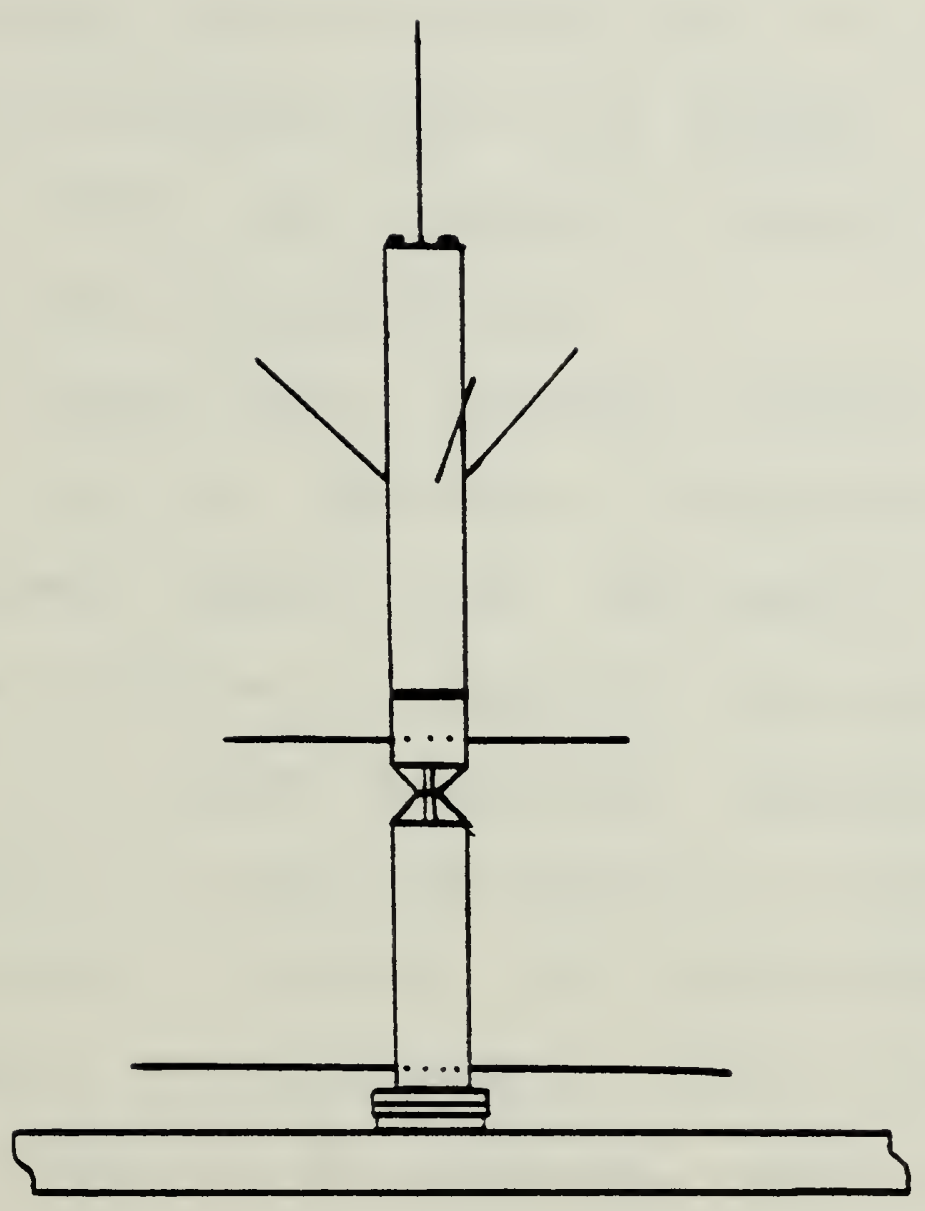

AN/PRR-14 GEOCEIVER

ANTENNA

Fig. 2.3 . 
$-$ 
Universal space Rectangular Coordinate system--an earth, mass-centered coordinate system. The MGS-72 ellipsoid describes the best fit of the entire earth to a mathematical model. The satelite orbits are computed using this geopotential model, the accuracy of which is based on gravitational and astronomical data.

Por the present study, a Magravox AN/PRR-14 Geoceiver was acquired from the Department of Satellite Geophysics, Satellite Tracking Branch, DMA. The receiver was placed over a fixed point and 40 passes of one satellite were observed. The procedures described previously for an optimum solution of point positioning were followed. The resulting latitude, longitude, and height zelative to the WGS-72 ellipsoid are coordinates of a first order TRANSIT position as defined by DMA standards. This position was used as the basis for horizontal control for the study (see test procedures). 

III. GPS STSTEY DESCRIPTION AND OPERATIONAL CAPABILITIES

A. SYSTEM DESCRIPTION

NATSTAR, or the Global positioning system, was designed for maximum operational capability--high accuracy, twenty-four hour access, passive user, and world-wide coverage. A brief description of the GRS, and the satellites (NAVSTARS), will serve as a background for the more in-depth discussion immediately following.

GPS navigation is based on the measurement of four Ianges, or pseudo-ranges, from each of four satellites with known, or predicted, positions. Each range determination is computed using the propagation velocity of the signal multiplied by the satellite-to-user travel time. Satellite transmission time is included as part of the navigation signal message. Prom the four known ranges, the user position and user clock error are computed on a three-axis, orthogonal coordinate system. This computation is then used to transform the user position onto the NGS-72 ellipsoid.

The remainder of this chapter will provide the background for GPS development and the three najor system segments of the GPS: the space system segment, the control 
$-2$ 
segment, and the user system segment. Included in the user system segment will be a discussion of the yanpack receiver as developed by rexas Instruments corporation used for this study.

With the successful operation of the TRANSIT system in the early 1960's, the Department of Defense (DOD) began to consider the specifications of, and the technology required for, the development and implementation of a second generation system. On 17 April, 1973, the Deputy secretary of Defense stated that a Defense Narigation Satellite System was to be dereloped. [Ref. 9] Using the new synthetic oscillator technology, and the Department of Defense surface and nearsurface navigation objectives and requirements, a DOD interdepartmental task force developed the GPS as the second generation satellite navigation system. Nith the United States Air Porce (USAP) as the managiag agency, the GPS became a joint service program, with representatives from the DMA, Army, Navy, Marines, Coast Guard, and the North Atlantic Treaty organization. [Ref. 10] The Joint Programs office was established vithin the Air Force space and Missile systems organization to design, develop, and inplement the GPS program. 
$-+2-1$ 
GPS was conceived and designed to provide continuous. real-time, vorld-wide navigation coverage for subsurface, surface and aearsurface operational vessels, vehicles, and aircraft. Accuracy of better than 10 meters was desired under all conditions, with navigational capabilities to update and interface with other forns of existing and projected navigational systems. Another requirement of the GPS satellites was nearly trouble-free and simple user operation, even in low signal-to-noise environments. An encoded signal structure was required for the satelitte system for security reasons. In addition, the signal transuitted by the NAVSTAR satellites had to include other operational information in conjunction with the navigational message. To provide for narigational requirements in event of hostilities, the GPS was designed to permit the use of redundant satelites.

To achieve these objectives and requirements, the GPS program was organized according to three developmental tasks: concept validation, full-scale engineering derelopment and systems tests, and production and operation. Starting in 1974, the concept validation task was initiated with the nerger of the IIMATION series satellite program and 
$-x+2-x+2$ 
the USAF system 21B (a highly accurate three-diaensional navigation system) program. Tests with the Navigation Technology Satellite, NTS-1, utilizing two Iubidium clocks (accuracy 5-10 parts per $10^{13}$ ) and an orbit 7500 nautical miles ( $\mathrm{nm}$ ) above the surface and three ground based IÆceivers (called inverted range) provided concept verification. [Ref, 11] Additional tests were conducted with an impored NTS- 2 satellite positioned at an altitude of $10,980 \mathrm{~nm}$ and containing two cesium clocks faccuracies on the order of 1 part per $10^{13}$ ). [Ref. 12] orbital height of $10,980 \mathrm{am}$ permitted the evaluation of the effect of the planned GPS constellation altitude on navigational accuracies using the improved cesiun frequency standards. In 1980, NTS-3 was launched and the ddranced Developmental yodel (ADM) hydrogen maser frequency standard evaluated for use on the GPS (providing an expected frequency accuracy of 1 part per $10^{13}$ ). [Ref. 13] The results obtained from the NTS-3 satellite have not yet been released. Since 1978, additional satellites have been orbited to provide the six-satellite constellation required to fully evaluate the first development task--concept ralidation, Phase I. 
$-1-$ 
During Phase I, user requirements were consolidated to allow the development and construction of four basic types of test receivers: continuous tracking receivers, sequential tracking receivers, I cw cost receivers, and the Manpack Ieceivers. [Ref. 14] These receiver types were then constructed for $P$ hase I testing by various contractors and their performances evaluated aboard helicopters, aircraft, ships, vehicles and personnel at the Joint Programs office's testing facilities. Phase I, concept validation, was completed in late 1979 and Phase II testing was begun in early 1980 with full scale engineering, developmental, and systems tests.

phase II tasks, finishing the operational and control segments of the testing, are scheduled for completion in mid-1983. The operational control station will be relocated at a central continental onited states site during this phase. Additionally, all satellite monitor receivers at the remote monitoring stations will be updated to operational status. User equipment and receiver selection will be made in two increments. gour contractors will be asked to coupete for the second increnent of the receiver selection process by providing upgraded and refined user receivers for 


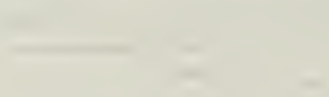


extensive testing and evaluation. Tro of the four contractors will then be selected to continue the competition and will provide additional receiver design, refinement and modificaticn, leading to prototype production and extensive field testing.

When Phase II is completed in mid-1983, Phase III. production, will commence with the selection of one of the two contractors to produce the user receivers. Manufacture of these receivers will comence shortly after selection. and commercial availability of receivers is expected in 1985. [Ref. 15] The GPS should be fully operational with world-wide coverage using a constellation containing a total of eighteen satellites in 1988. [Ref. 16, 17]

The GPS is considered to be composed of three inter-related system segments: the space system segment, the control segment, and the user system segment. Of these, the space system segment may be considered the most iaportant since the other two require the space segment to be operational at all tines. operationally, the space system segment consists of 18 satellites placed in orbits at altitudes of 10,898 nm and having orbital periods of about 12 hours. [3ef. 18] 

The original plan for the satellite constellation consisted of 24 satellites in three planes of 8 satellites each. These three planes were to be placed $45^{\circ}$ of longitude apart and at an inclination of $63^{\circ}$ to the equator. [Ref. 19] As a result of 1980 budget cutbacks the space system segment has been reduced to a total of 18 satellites. [Ref. 20] Several different types of 18 satellite constellations have been proposed, but all have drawbacks. One which appears the most promising is the 'yonuniform 18 ' constellation containing 6 planes, each of which contains 3 satellites spaced $120^{\circ}$ apart (fig.3.1.). The areas of user outages (fig.3.2.) are a disadrantage of this configuration. The user outages are indicated by the darker areas shown on Pigure 3.2. These outage areas will appear to rotate about the globe at the indicated latitudes, and positioning with the GPS will be intermittent, or of decreased accuracy for users at these latitudes. The Einal constellation ronfiguration is to be selected early in 1982. [Ref. 21]

Bach NAVSTAR satelitte bas the Eollowing characteristics: weight of 982 pounds, length of 17.5 feet from tip to tip of the 5 square solar parels, three atomic 
$-$ 


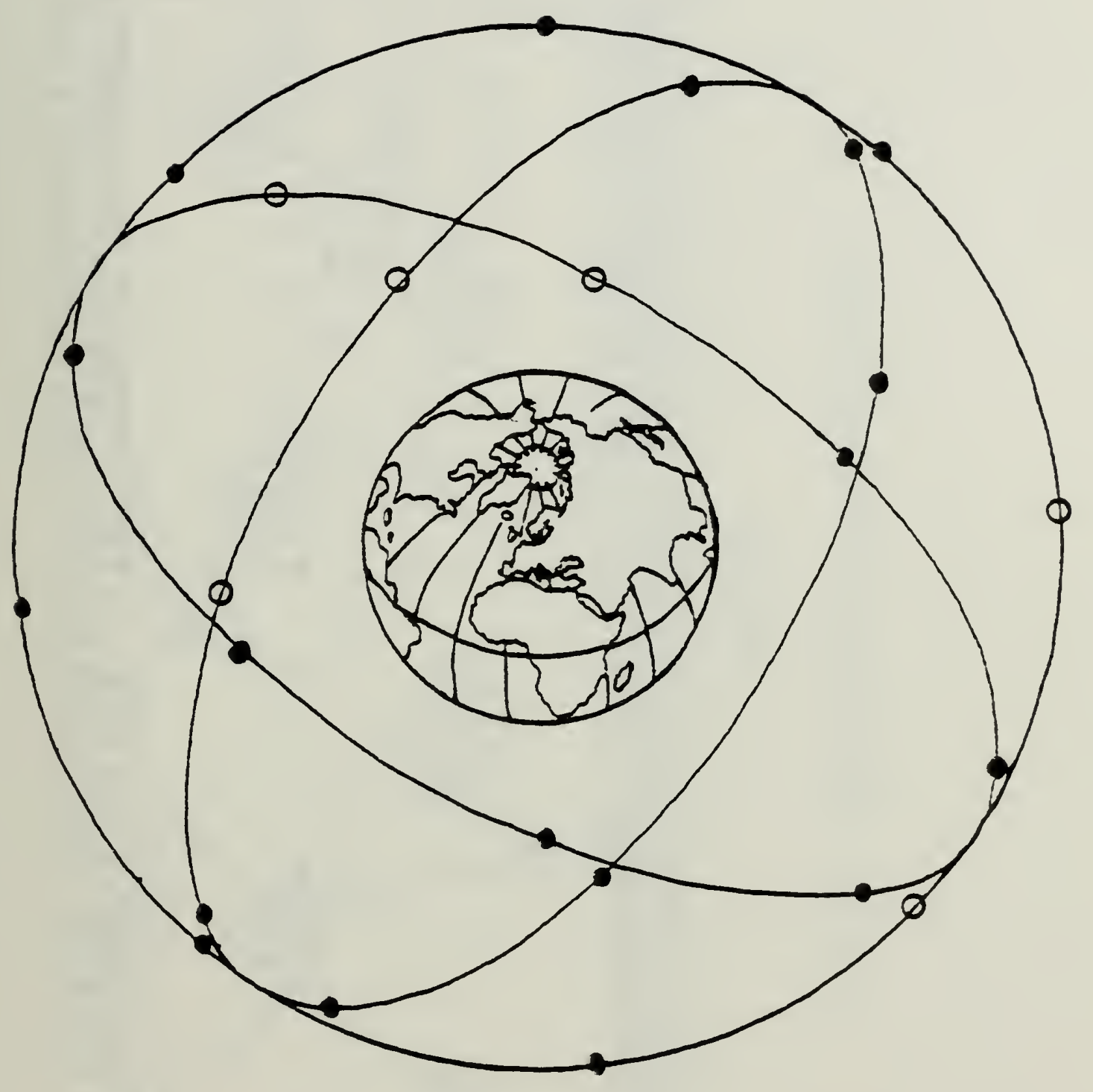

- Proposed Satellite

- Deleted Satellite

Fig. 3.i. The Ilonuniform 18 Satelitite Consteliation 


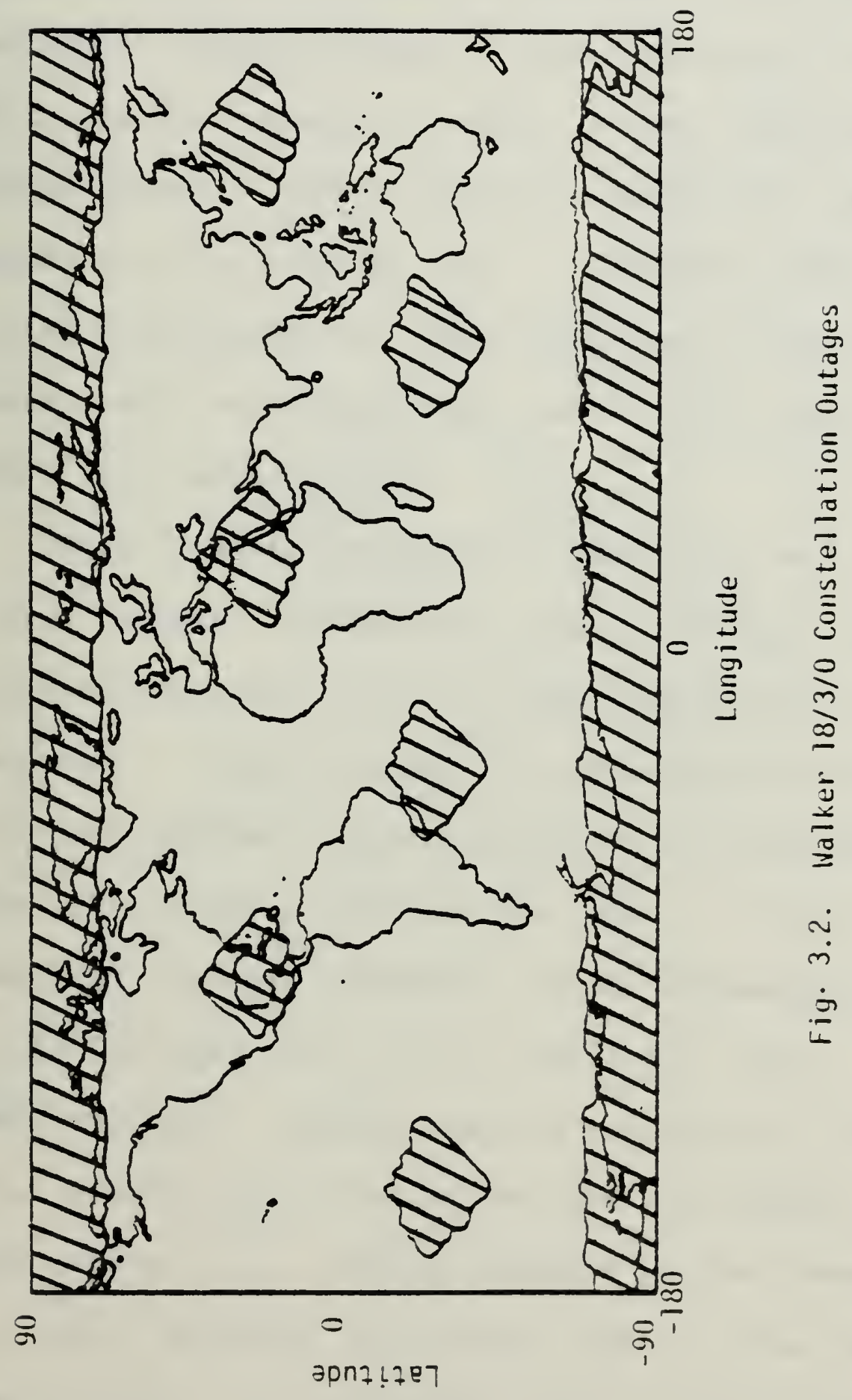




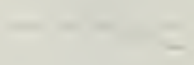


frequency standards (clocks), and three nickel-cadmium batteries for operations in darkness and during peak load periods. Stabilization of each varSTAR is maintained by four skewed reaction wheels which produce three-axis stabilization. NAVSTAR station-keeping and momentum damping capability is provided by a hydrazine propulsion system within each satellite. Life expectancy of each unit is five years, and expendables are expected to last for up to 7 years with normal usage.

Figure 3.3. illustrates the parts of each NAVSTAR. A twelve element shaped-beam helix antenna transmits the navigation message on two L band frequencies to user system segments. Simultaneously it receires satellite status, clock corrections, ionospheric data, and ephemeris constants frcm the control segment on two $S$ band frequencies. [Ref. 22] The two coherent I band frequencies are centered on $1227.6 \mathrm{MHz}$ (L1), and 1575.4 MHz (L2). [Ref. 23] [Ref. 24] Both frequencies are necessary to determine the total ionospheric delay correction for signal propagation tiae (Table I ). Errors produced by the ionosphezic delay in signal velocity contribute most of the error in the pseudo-range. By utilizing the I1 and L2 frequencies and 


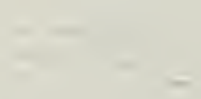




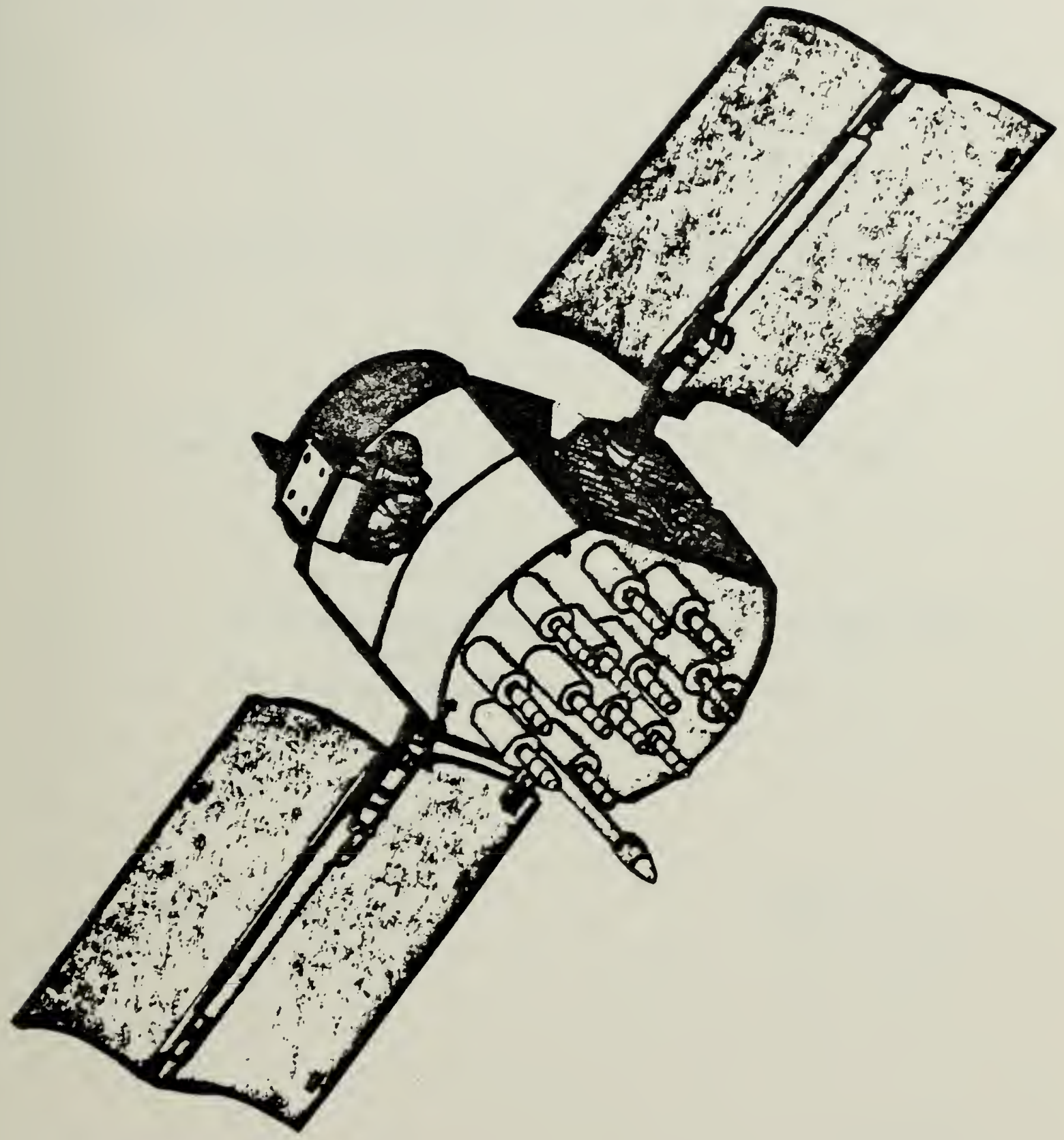

Fig. 3.3. NAVSTAR Satellite 


\section{$-x-2+2$}


TABLE I. Ionospheric Group Delay as a Function of Frequency

$$
\tau=\frac{R}{C}+\frac{A}{f^{2}}+\frac{B}{f^{3}}+\frac{C}{f} \ldots .=\frac{R}{C}+\frac{A}{f^{2}}
$$

(neglecting third order and higher terms which contribute minimal error)

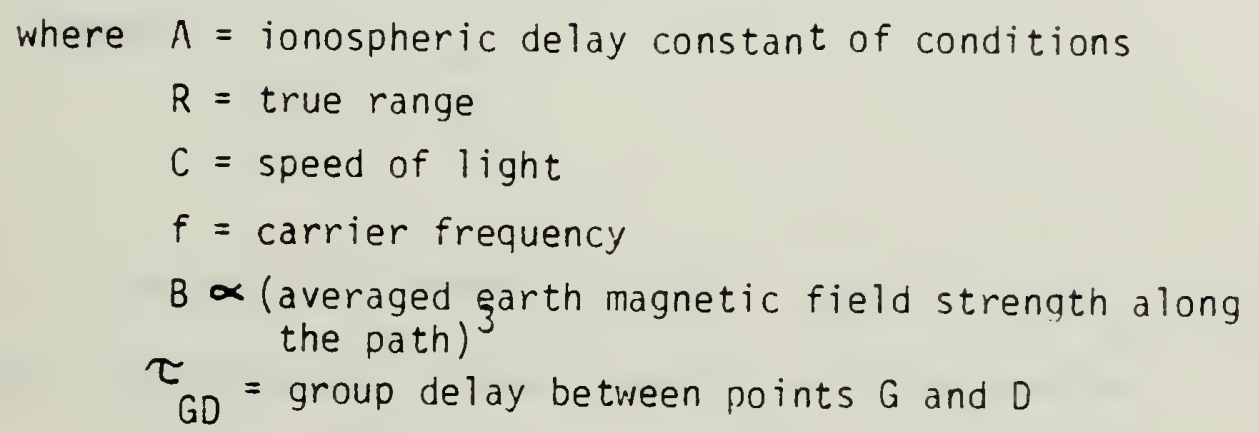

Term lleglected:

B
$f^{3}$
$C$
$f^{4}$
Range Error at

$f=1.5 \mathrm{GHz}$

$\leqslant 1$ inch

$\leq 3$ inches 

the following algorithm, the error is decreased but not totally eliminated. [Ref. 25]

$\tau_{\mathrm{GOL}} \cdot \tau_{\mathrm{GOL}}=\Delta \tau$

$$
\begin{aligned}
& =A\left[\frac{1}{f_{L_{2}}^{2}}-\frac{1}{f_{L_{1}}^{2}}\right] \\
& \left.=\tau_{G D L}\left[\frac{f_{L_{1}}}{f_{L_{2}}}\right)-1\right]
\end{aligned}
$$

Where:

$$
\tau_{G D L_{1}}=\frac{A}{f_{L_{1}}^{2}}
$$

where $A=$ ionospheric constant and ${ }^{\tau} \mathrm{GOL}_{1},{ }{ }_{\mathrm{GDL}_{2}}$ are the respective ionospheric group delays at frequencies $I 1$ and L2. Both frequencies are also modulated to transmit the GPS time codes and the navigation message.

GPS time is transmitted using two pseudo-random noise chip codes--the Coarse acquisition ( $C / A)$ and the Precision (P) codes. Modulation on the L1 frequency carries both the $C / A$ and $P$ codes in phase quadrature. While the l2 frequency carries only the $p$ code. These codes identify each acquired satellite by matching the unique pseudo-random noise code pattern generated by each satellite with simila = user generated codes. 

Both codes are required to mea sure the navigation signal propagation time. The phase shift is measured and used to match the user generated signal with the incoming satelite signal. [Bef. 26] The C/A code has a repetition period of one millisecond and has a short code stream, transmitting 1.023 million bits per second (bps). This code is easily acquired and matched with the user generated pseudo-random noise code but only provides a coarse time signal for computing the pseudo-range. However, the $P$ code has a long code strean, repeating only every seren days, and it is transmitted at the higher rate of 10.23 million bps. With this higher data transmission rate and iong repetition period, a more accurate time signal is available for pseudo-range determination. However, the long period and high data rate makes the $\mathrm{P}$ code difficult to match $w i t h$ the user-generated pseudo-randow noise code pattern unless the receiver has a highly accurate time standard, and the approximate receiver location is known. In lieu of this, the usual method of acquiring the $P$ code is by matching the C/A code of the desired MAVSTaR, then using the Handover Nord (HOW), to locate the correct $P$ code sequence within the 7-day pseudo-random noise code. GPS time is transmitted 
With the HOH every six seconds and provides very accurate GPS time to the user. Both of these codes provide the proper time reference for computation of the pseudo-range. The C/A code provides a less accurate time reference than the $?$ code. The selection of the code depends only on the navigational accuracy desired.

The navigation message is also moduiated on frequencies I 1 and I 2 but at a much slower rate (only 50 bps) than either the $C / A$ or $P$ code. On both frequencies, the navigation message is identical and consists of 5 subsets of 6 seconds duration each. Each navigation message begins with the telemetry message (TLM) and the How message, which are used to transfer from the $\mathrm{C} / \mathrm{A}$ to 2 codes. The remainder of the entire navigation message allocated to each subsection is transmitted after the TLI and HoW messages. Information in the narigation message includes approximate satellite ephemerides, status of other NAPSTAR satellites, parameters for clock corrections, atmospheric signal delay corrections, satellite performance status, momentum dump status since last upload, time since last upload, almanac and identification codes for all satellites, and provisions for inclusion of any special or important nessages from the 
$-$ 
control system segment to the user. [Bef. 27, 28] Navigation is thus achievabie by combining the information transwitted by the space system segment in the form of the $C / A$ and $P$ codes and the navigation message.

Accuracy and proper function of GPS are governed by the second segment--the control segment. The control segment monitors and uploads the individual NAVSTAB satellites, checks operational characteristics, determines the ephemeris and almanac data and corrections required, computes the time delay and clock corrections for each satellite atomic standard, determines the atmospheric delay corrections for pseudo-range computations and includes special messages in the body of the navigational message. These functions are under the command and operational control of the Master Control Station, currently located at vandenberg AFB, California. Four unmanned remote monitor stations, located in Havai, Guam, Elmendorf AFB, Alaska, and Vandenberg AFB, collect the pseudo-ranges to each satellite, the change in pseudo-range of each satellite signal, local meteorological data, and the remote monitor station atomic standard parameters. Each set of data is transmitted, on request, to the Master control station, where all the data is combined 


\section{- n-}


and the satelite upload corfections and parameters are computed. These corrections and parameters are then Ielayed to the Opload Station, Vandenberg AFB, for transmittal to the respective NAVSTAR sateliites. The uploads occur when the satellites are first visible to the upload station and when the Dser Range BIIor exceeds 4 meters, as computed by the Master Control Station. [Ref. 29, 30, 31]

The last segment, the user system segment, combines the information provided to the space system segment (by the control segment) with the information received from the space system segment to obtain the pseudo-ranges from four NAVSTAR satelitites. These ranges are computed using the following algorithms:

$$
\mathbf{R}_{i}=c\left(t_{R}-t_{t_{i}}\right)-c \Delta t_{A_{i}}
$$

where $R_{i}=$ true slant range to satellite $i, c=$ speed of light in a vacuum, $t_{R}=$ time of received GPS signal by user receiver (assumed to be simultaneous from all satellites), $t_{i}=$ time of transmission at satellite $i$, and $\Delta t_{A_{i}}=$ atmospheric propagation delay time from satellite i 
$=$ 
(fig.3.4.). Assuming a user clock error, the true zange can be expressed in terms of a pseudo-range:

$$
R_{P_{i}}=R_{i}+c \Delta t_{A_{i}}+c\left(\Delta t_{i}-\Delta t_{S_{i}}\right)
$$

where $R_{P_{i}}=$ pseudo-range including clock error, $\Delta t_{R}=$ time delay in the user receiver cf the received signal, and $\Delta t_{S_{i}}=$ time delay in satellite transmission from satellite i.

To determine the slant ranges:

$$
\begin{gathered}
R_{i}=\sqrt{\left(x_{S_{i}}-x\right)^{2}+\left(y_{S_{i}}-y\right)^{2}+\left(z_{S_{j}}-z\right)^{2}} \\
R_{i}=\sqrt{\left(x_{S_{i}}-x\right)^{2}+\left(y_{S_{i}}-y\right)^{2}+\left(z_{S_{i}}-z\right)^{2}}+c \Delta t_{A_{i}}+c\left(\Delta t_{R}-\Delta t_{S_{i}}\right)
\end{gathered}
$$

The following quantities are known: $x, y, z$ obtained Eron navigation ephemeris data; $\Delta t_{A_{i}}$ computed using the icnospheric delay correction obtained from observing frequencies $L 1$ and $L 2$ (tropospheric delay neglected): $\Delta t S_{j}$ obtained from the navigation aessage as the satellite clock error. Thus, there are four unknowns: $x, y, z$ (user position coordinates) and $\Delta t_{R}$ ( user clock error or bias). To solve this set of equations, four satellites must be observed simultaneously. [Ref. 32] 
- 
Should only three satellites be observable, the altitude may be assumed and the solutions can be computed for the otber two location variables and the user clock error. sclutions of this type (altitude hold) significantly degrade position accuracy.

The above description is orer-simplified since the relativistic effects of NAVSTAR satellite velocity, as observed by the user, are neglected in terms of the satellite time delay correction and the atmospheric propagation delay correction. The actual user velocity, in terms of relocity in the $x, y$, and $z$ directions, is calculated using the Doppler shifts of the two fiequencies I 1 and $L 2$ and the estimated satellite position taken from the ephemeris data. With the relativistic effects as an integral part of the data set, solution of the navigation position problem becomes more complex. Phase I receiver manufacturers have included them in the solution of the problem by several different methods. Methods of solution depend on the usage of the receiver (whether static, high or low dynamicl and the expected cost/benefit ratio for the receiver (in terms of the total cost, veight and size). Curfent state-of-the-art design technology and savigational 


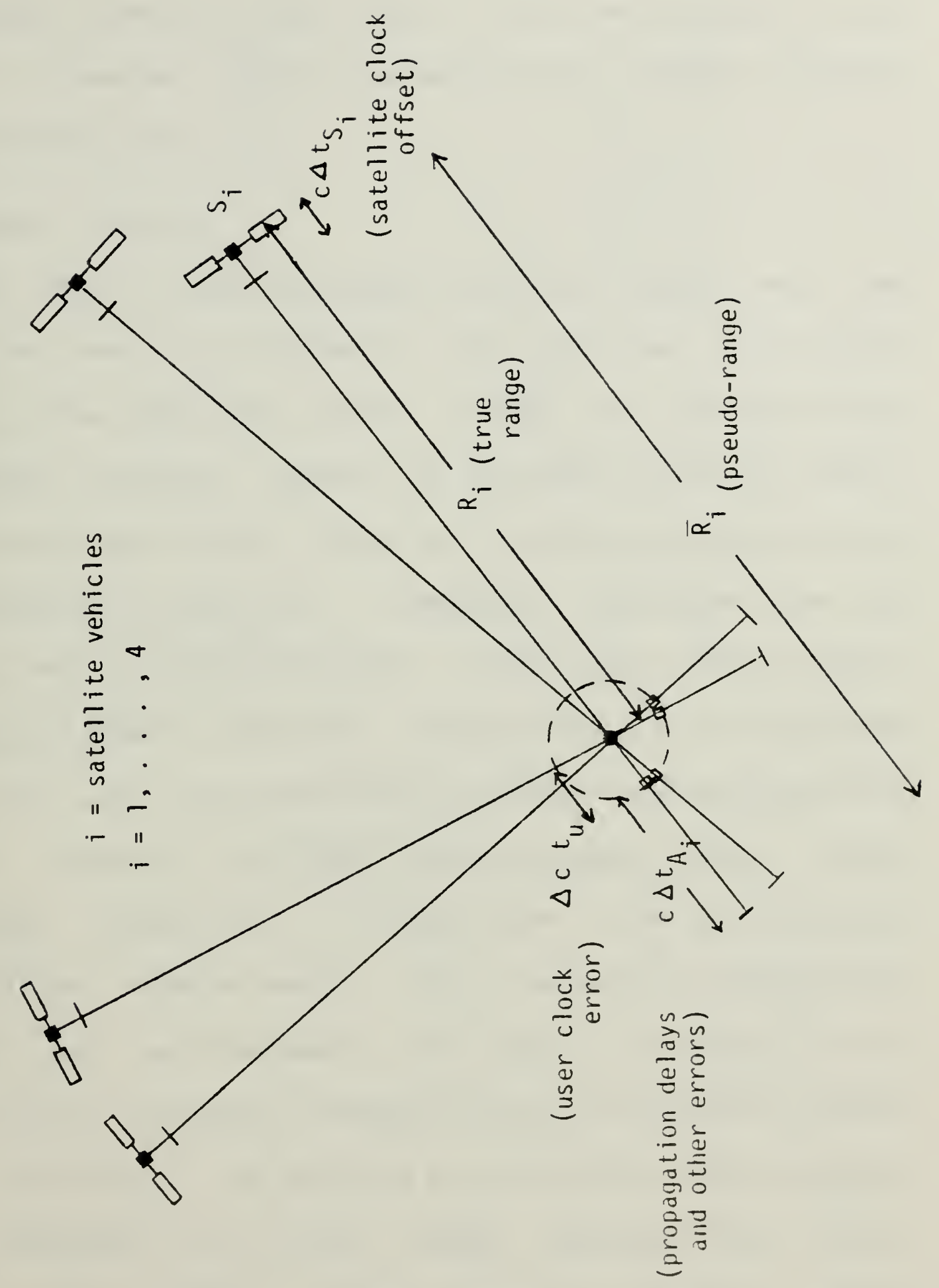

Fig. 3.4. Pseudo-Range Description 
$-$ 
algorithms, developed since phase I, will be included in the Phase II receivers and will significantly improve accuracy of future receivers.

B. MANPACK RECEIVER

The Phase I receiver used for this research was the Texas Instruments GPS Manpack, also known as the Manpack Vehicular User Equipment (MVUE). MVUE is a single channel Low dynamic receiver, usable for receiver velocities from 0 to 25 meters per second. [Ref. 33] system configuration is illustrated by figure 3.5. Composing the system are the Manpack control data unit ( $(D D)$, antenna and rehicle nount, and vehicle power converter. The Manpack is the receiver unit (fig. 3.6.) witb provisions to connect an external data output, through the MVOE Instrumentation system (MIS) interface, figure 3.7. Facilities for an internal preamplified antenna mount, or an external preamplified antenna, and an attachment for either an external power source or the integral battery pack are also shown (figure 3.7). Together, the MVUE and the SBP/9900 microprocessoz data processing unit have storage capacity for 47,360 sixteen bit words. This storage capacity allows interrogation of NAVSTAR satelites sequentially, with the 



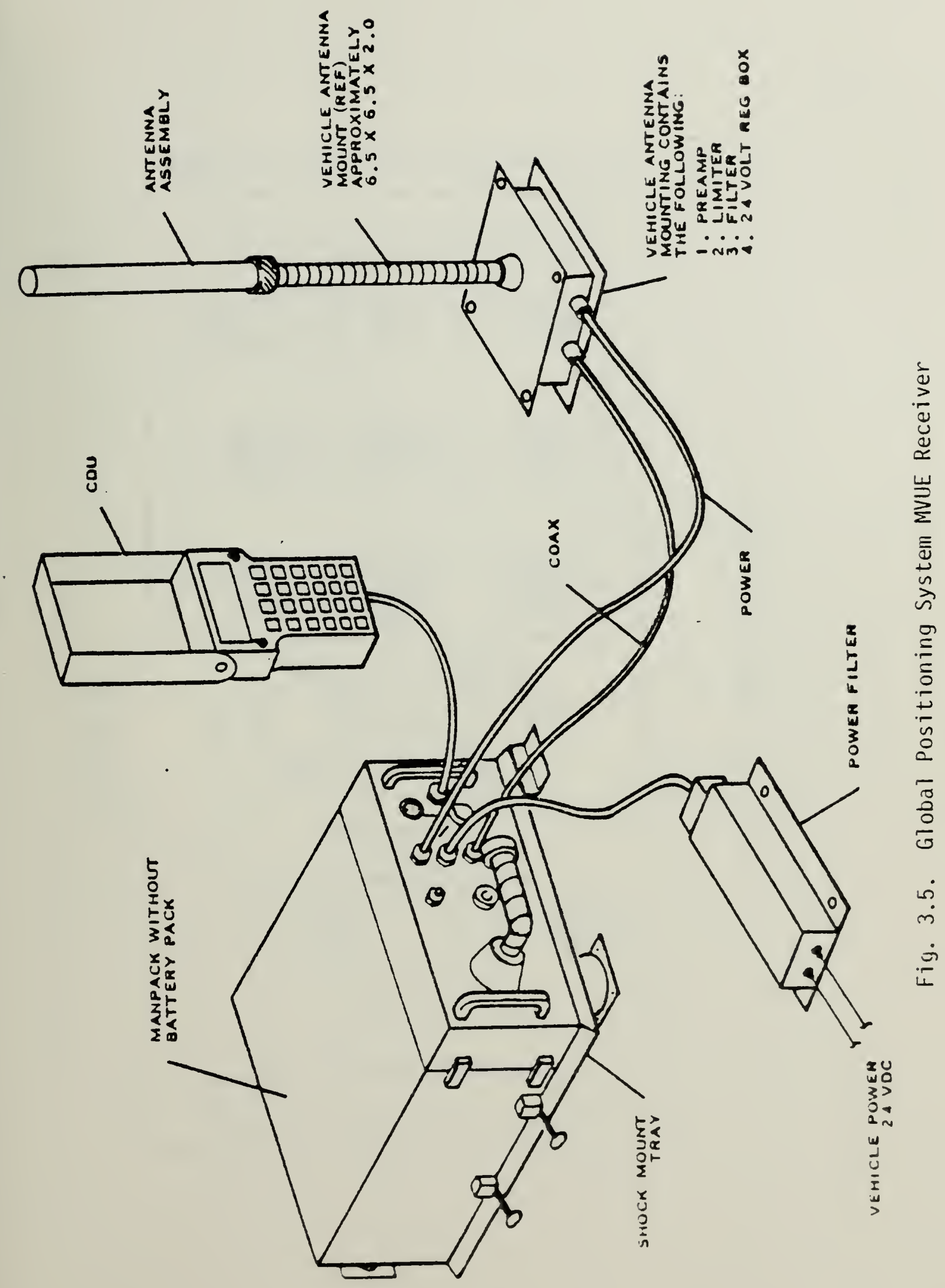




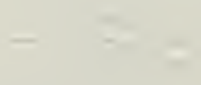




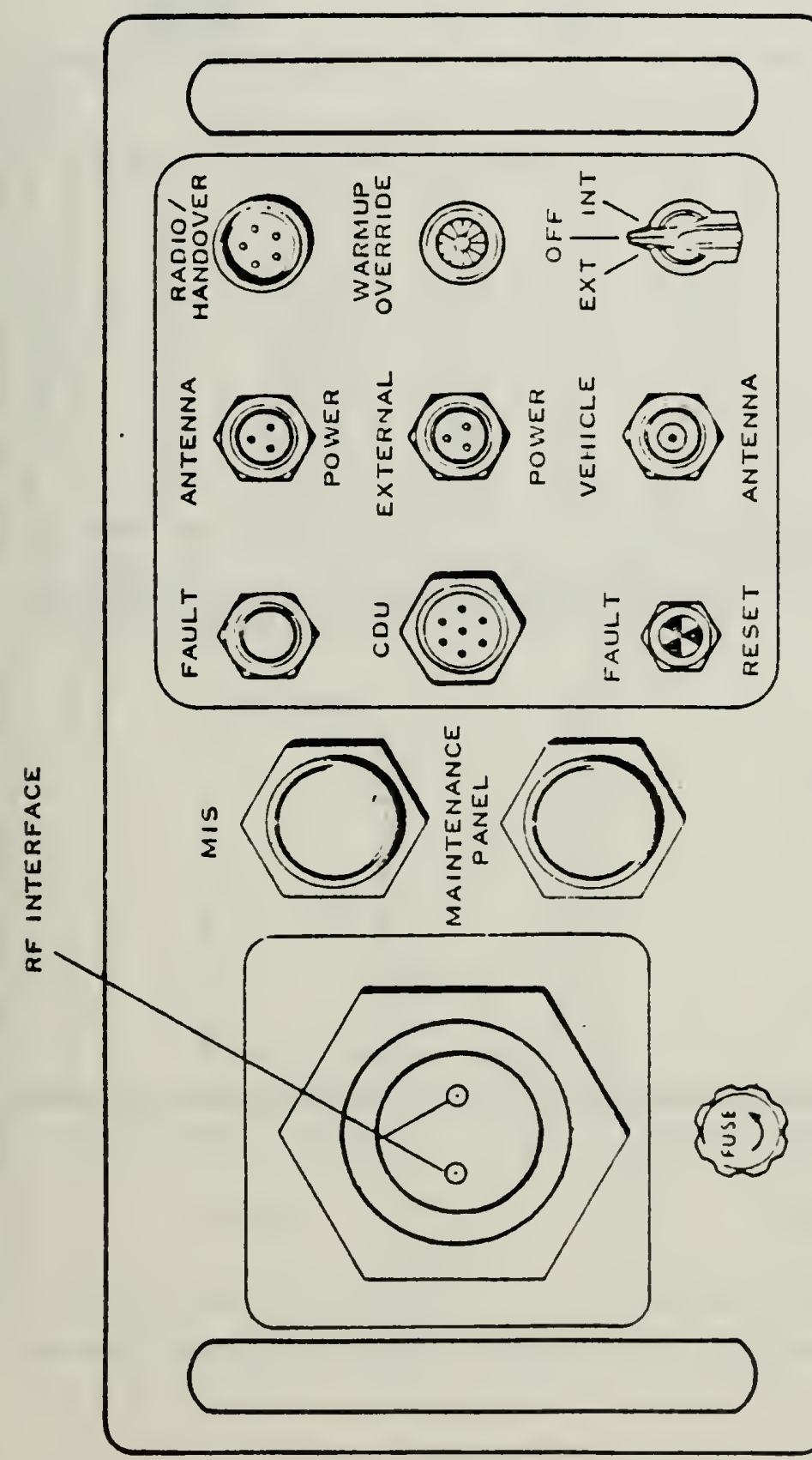

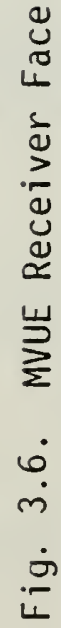


- 


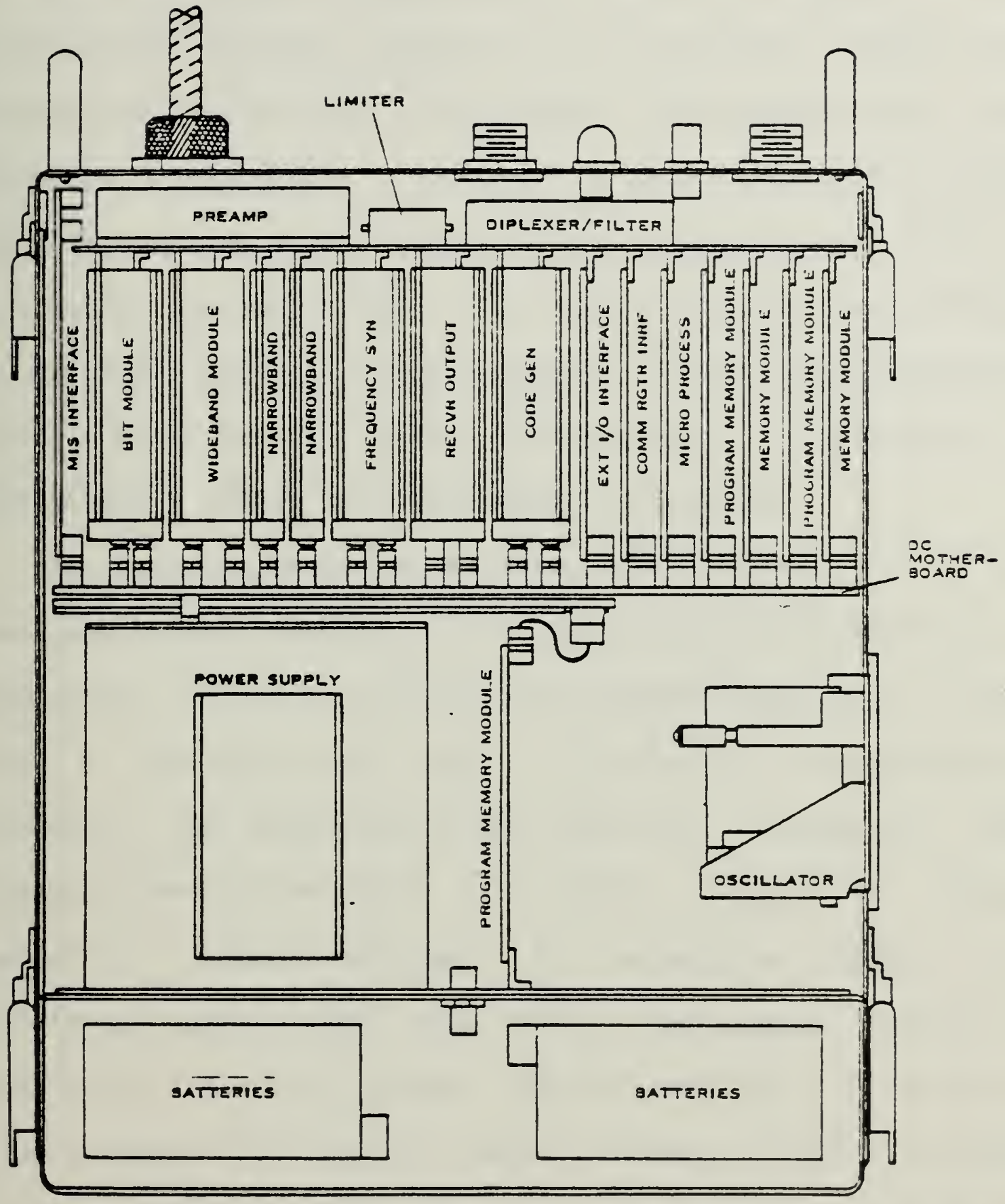

Fig. 3.7. Cutaway of MVUE Receiver 

receiver computing a position fix every 24 seconds. The relativistic velocity effects on the received signals are determined by matching the incoming frequencies with the expected frequencies. The user velocity relative to the satellite is determined from the cbserved frequency shifts. The nominal frequency shift for each satellite transmission is computed using the simultaneously transmitted ephemeris data. Total weight of this receiver unit is 33.5 pounds, and it has a rolume of 17,958 cubic centimeters.

The second element of the MVOE, the CDU (fig. 3.8.), is the input/output derice for the non-automated Manpack user. Inputs are entered by keying the pressure pads set in six rows of four pads per fow. To obtain a navigational position, the approximate user latitude, longitude, and Greenwich Mean Time (GMT) are keyed. After the warmup period of 3 to 5 minutes, the satellite signals are received, and the CDO will display the actual position. Aditional input may include NATSTAR satellite selection, user altitude, and other position datums. Output options include position, GMT time, and systen error nessages. other inputs and outputs are listed in the MroE manual. [Ref. 34] 
- 


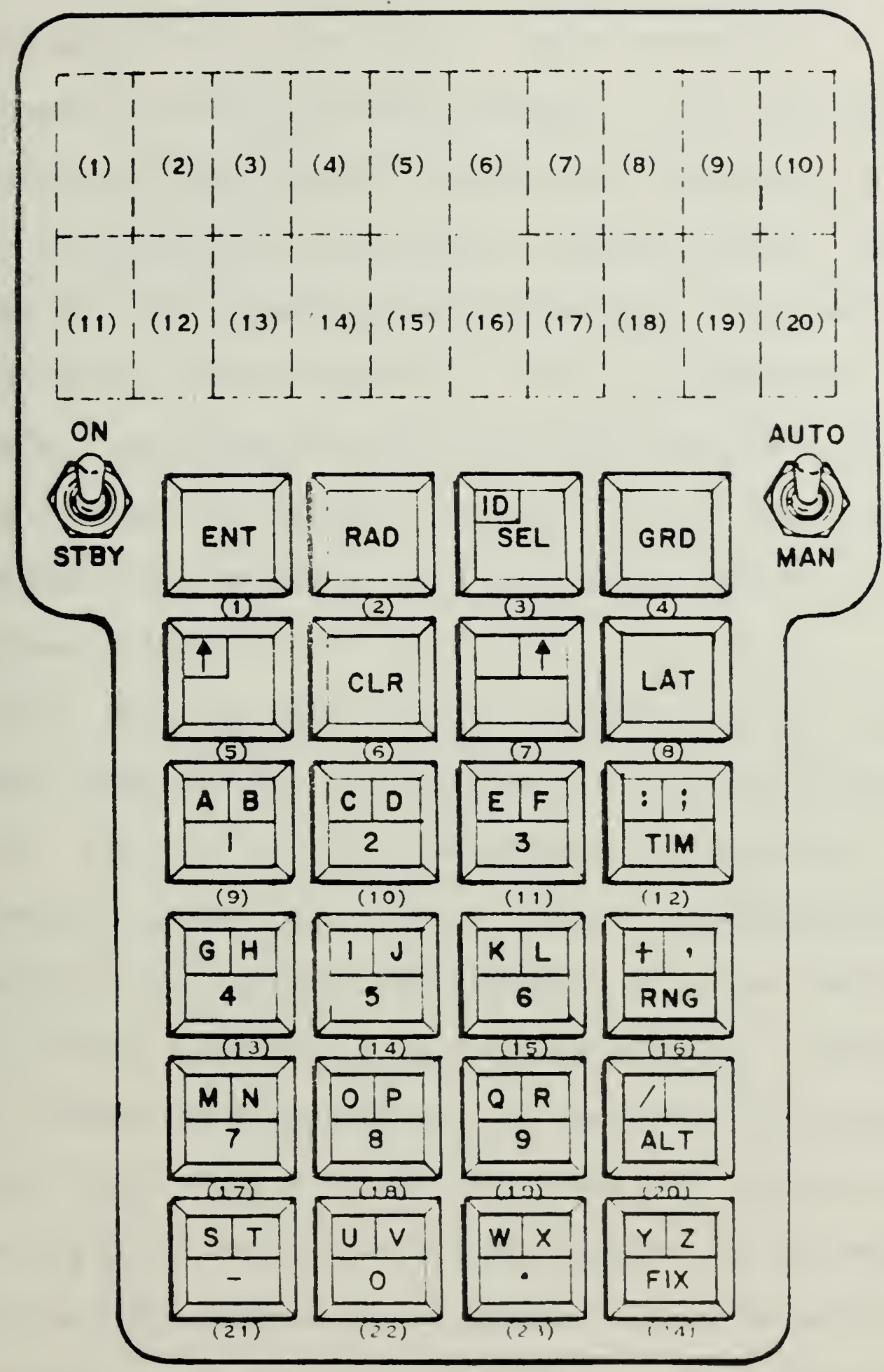

Fig. 3.3. MVUE CDU Keyboard/Display Layout 
Automated users may elect output either to a radio interface or through the MIS interface. Por this research, a special interface unit, designed and constructed at the office of Testing and Evaluation of Systems, MOAA, was used to link the MIS interface board within the receiver with a Heulett Packard $9825 \mathrm{~T}$ computer. With this interface, user latitude, longitude and GPS time were logged onto nagnetic tape for future processing. Pigure 3.9. and Table II are the engineering documents used in construction of the MVUE interface unit.

Other MOE elements are the antenna and the antenna external preamplifier vehicle mount. Located within the antenna are two antenna subassemblies associated with frequencies $L 1$ and L2. Both of the subassemblies are connected to the external preamplifier with two lengths of coaxial cable, enclosed in a flexible conduit. The entire unit, antenna and preamplifier, is connected to the Manpack receiver with a power cable and a coarial antenna cable. Cable length is determined by the location of the external antenna but is limited by the minimum strength required by the Manpack receiver. The combined antenna and preamplifier unit is 36 inches long, and it weighs 1.9 pounds. 


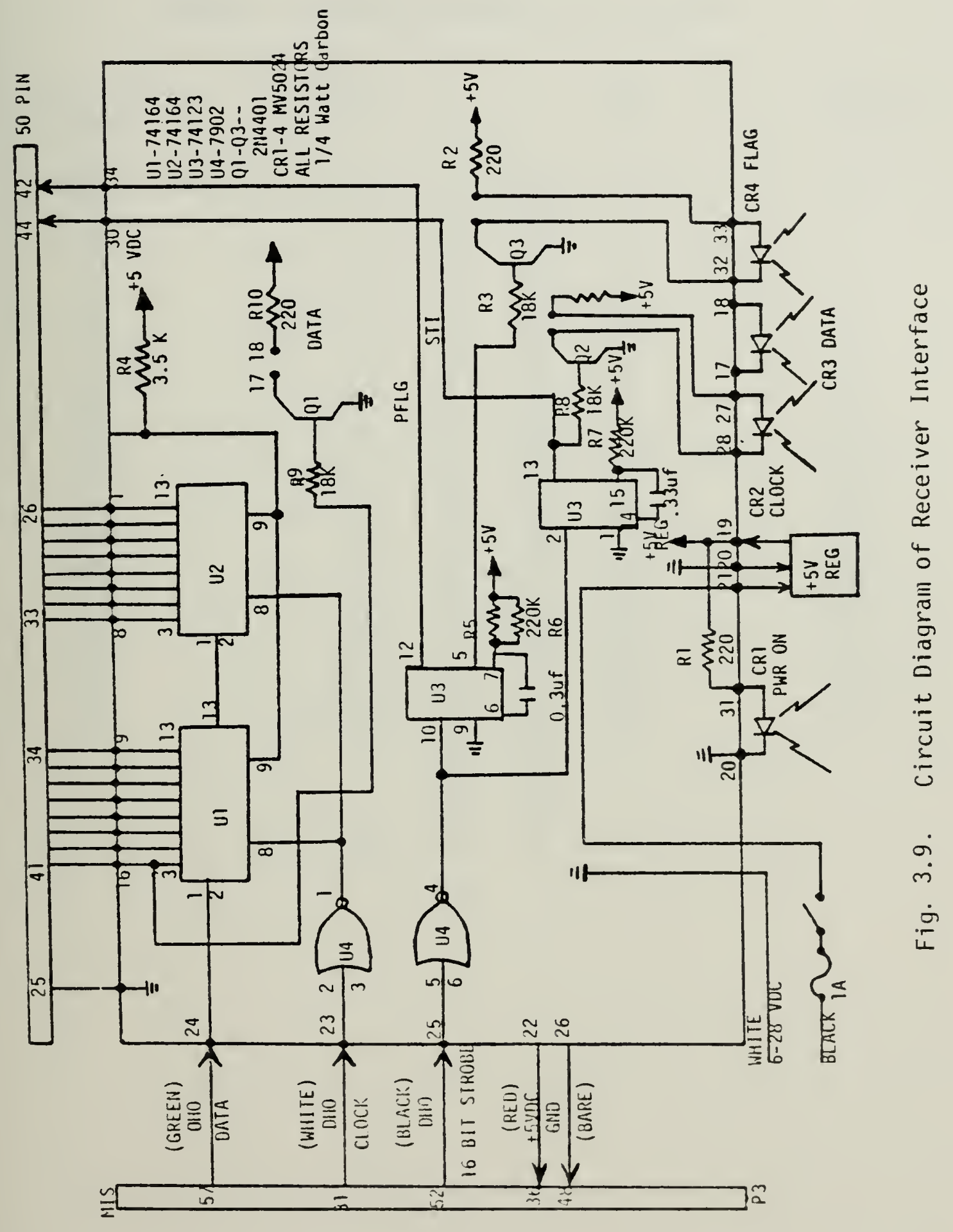


- 
TABLE II. MANPACK Interface Wiring Code

\begin{tabular}{cccccc}
$\begin{array}{c}\text { Wire Color } \\
\text { Code }\end{array}$ & $\begin{array}{c}\text { OUT } \\
\text { BIT }\end{array}$ & & & BIT & $\begin{array}{c}\text { Nire Color } \\
\text { Code }\end{array}$ \\
\cline { 2 - 4 } 90 & 1 & 1 & 26 & 1 & 0 \\
91 & 2 & 2 & 27 & 2 & 1 \\
92 & 3 & 3 & 28 & 3 & 2 \\
93 & 4 & 4 & 29 & 4 & 3 \\
94 & 5 & 5 & 30 & 5 & 4 \\
95 & 6 & 6 & 31 & 6 & 5 \\
96 & 7 & 7 & 32 & 7 & 6 \\
97 & 8 & 8 & 33 & 8 & 7 \\
934 & 9 & 9 & 34 & 9 & 912 \\
935 & 10 & 10 & 35 & 10 & 913 \\
936 & 11 & 11 & 36 & 11 & 914 \\
937 & 12 & 12 & 37 & 12 & 915 \\
945 & 13 & 13 & 38 & 13 & 923 \\
946 & 14 & 14 & 39 & 14 & 925 \\
947 & 15 & 15 & 40 & 15 & 926 \\
948 & 16 & 16 & 41 & 16 & 8 \\
98 & PCTL & 17 & 42 & PFLG & 908 \\
927 & CTLO & 18 & 43 & PSTS & 916 \\
928 & CTLI & 19 & 44 & STIO & 917 \\
901 & BIT I/O & 20 & 45 & STI1 & \\
902 & PRESET & 21 & 46 & EIR & \\
& & 22 & 47 & & \\
& & 23 & 48 & & \\
& & 24 & 49 & & \\
& GND & 25 & 50 & GNO &
\end{tabular}




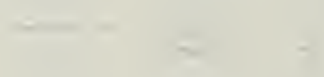


The power converter must supply 24 volts DC to the Manpack receiver. During this research, a power supply which converted 120 volts AC to 24 volts DC was used. This power supply was considered more stable than the power converter provided with the $4 \nabla 0 \mathrm{E}$, and the voltage output and power were controlled and monitored during the testing period.

\section{DIPFERENTIAL GPS}

As mentioned earlier in this chapter, atmospheric propagation delays are the major source of error in the navigational equations because ionospheric propagation is poorly understood. The tropospheric propagation delays are neglected in the narigation equations, and the resultant error is dependent on local temperature, pressure, humidity. and vavSTAR eleration and azimuth. rropospheric corrections are usually neglected if the observed satellite is more than $5^{\circ}$ above the local horizon. [Ref. 35]

Additional error sources are receiver and satellite clock perturbations, lengths of signal paths Erom different satellites, wultipathing delays, satellite ephemeris errors, and receiver noise. Combined, these factors lead to errors of 3.6 to 6.3 meters, as table III illustrates. [Ref. 36] 


$$
-1-
$$


TABLE III. RANGE ERROR BUDGET

Uncorrected Error Source

$$
\begin{aligned}
& \frac{\text { User Equivalent Range Error, }}{(1 \sigma)} \\
& \text { feet }
\end{aligned}
$$

SV Clock Errors

Ephemeris Errors

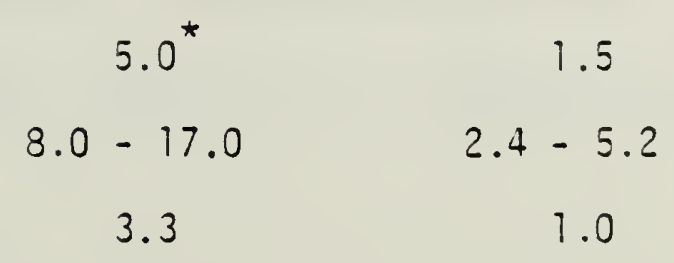

Group Delay (SV Equipment)

$4.0-9.0$

$1.2-2.7$

Mut tipath

5.0

1.5

Vehicle Oynamics

and Resolution

5.0

\author{
Multipath
}

Atmospheric Delays

\title{
TABLE III. RANGE ERROR BUDGET
}

\author{
meters
}




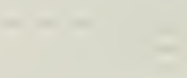


one method used to reduce the magnitude of this error is that cf differential, or translocated, positioning. To use this method, one receiver is positioned over a known geographic position. Pseudo-ranges to each satellite are determined, and a differential correction is obtained for each pseudo-range. These corrections are then applied to the satelitte pseudo-range observed at a second mobile receiver. Hith the differential corrections applied, the net error of the mobile GPS receiver is significantly Ifduced. [Ref. 37] 



\section{TEST PROCEDORES}

A. POSITIONING NETMORK

one of the considerations in planning this test was to examine the various methods of positioning the shore-based equipment. It was desirable to use closely spaced (1-2 km) locations within the immediate surroundings of Monterey harbor for reasons of ready access by personnel during installation of equipment and for optimum accuracy of the positioning systems chosen for control. as mentioned previously, the positioning systems chosen for the comparison ( $t h \in$ three theodolites and the ARTEMIS) give best results at relatively short ranges.

Two predetermined station narks were selected for the test--1) OSE MON 1978, a bronze disk set by the Army Corps of Engineers, located on a sand dune on the Naval Postgraduate School property 400 meters from the ocean at an elevation of 40 meters above sea level and 2) MOSSEL 1932, a bronze disk set by the coast and Geodetic survey in a rock outcrop 7 meters above sea level at the shoreline on the property of the Hopkins Marine Laboratory of stanford University. The third station mark was set in the center of 


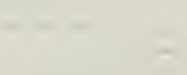


the Monterey Coast Guard Pier for purposes of the test. This was a DMA bronze disk stamped GEOCEIVER STA 31370. This location was chosen for access to pover facilities available at the pier and because of central location to the test area.

The position of the Geoceirer station was established using a Magnarox Geoceiver (Model AN/PRB 14) obtained from the Department of Satellite Geophysics, Satellite rracking Branch, DMA/Hydrographic Topographic Center. The equipment was operated in accordance with DMA requirements to obtain a documented first order station. The data were submitted to, and processed by, DMa/HTC in Brookmont, Maryland, using precise ephemeris information to provide the wGS-72 position. Michael ellett of DMA provided the technical expertise for acquisition of the data and maintenance of the gecceiver during the test period.

A third order, Class I, closed traverse was conducted following the standards of the National Geodetic survey (NGS), using a Hild $\mathrm{r}-2$ theodolite to seasure angles and a Motorola MRA V Tellurometer to measure distances. The TRANSIT position computed by DMA/HTC was used for the initial position of the survey, and a polaris observation 
using the theodolite provided the initial azinuth (fig. 4.1.1. A total closure error in distance of 0.061 neters and angle of 5.4" was achiered. The positions determined Erom the traverse and used for the control netuork are as follows:
OSE MON
$36^{\circ} 36 \cdot 08.4241 \mathrm{x}$
$121^{\circ} 52 \cdot 40.301 "$ प्र
MUSSEL
$36^{\circ} 37 \cdot 21.882 " \mathrm{~N}$
$121^{\circ} 54 \cdot 16.048 "$ "ृ
GEOCEIVER STA 31370
$36^{\circ} 36 \cdot 36.246 " \mathrm{~N}$
$121^{\circ} 53 \cdot 29.693^{\prime \prime}$

B. POSITIONING EQUIPMENT

As previously described, three positioning systems were used during the test--the three theodolites, the GPS, and the ARTEMIS. In addition, the geoceiver was set to acquire data during the shipboard portion of the test. During the time of day that the GPS satellites were available (Table IV) only one or two observations per day of the same TRANSIT satelite were possible. The geoceiver data were recorded but were not used for this study. 


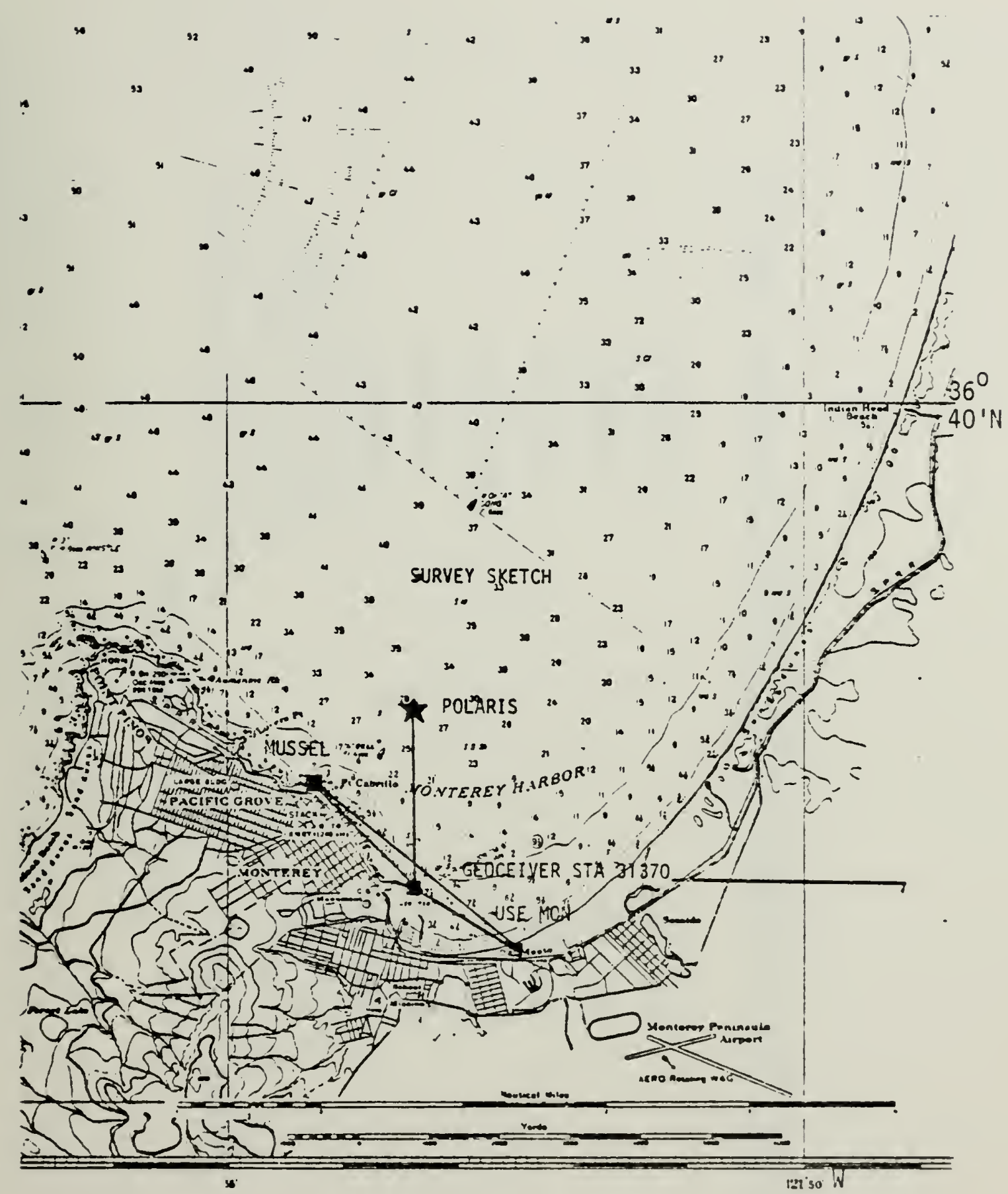

Fig. 4.1. Test Area with Traverse Sketch 


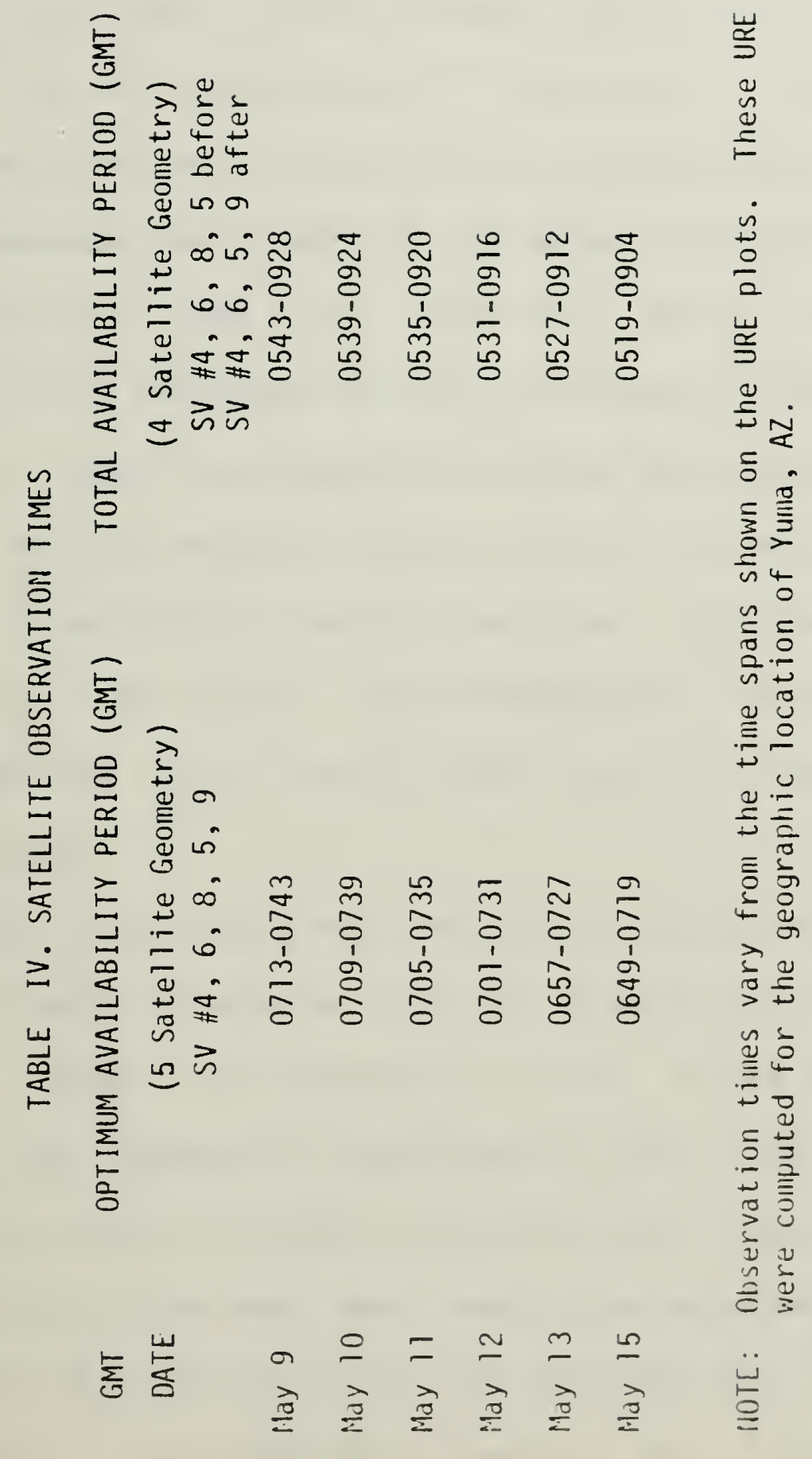





\section{Theodolites}

This section describes the placement and operation of the equipment during the test. One theodolite was set on a tripod at each of the three stations, and each was occupied by an observer and a recorder. commuication betreen stations was maintained via portable radios.

Because tests could be conducted only between 10 PM and 2 aM local mean time (LMT) due to GPS availability times, it was necessary to plan a systems of lights for the stations. The three theodolite sites were made visible by placing battery powered lights directly over the station marks. In addition, battery operated light packs for the theodolites were used. All shorebased lights and light packs for the test were provided by the Pacific Marine Center, NOAA.

The ship system was designed with an omnidirectional pair of lights anchored around the support pipe for the GPS antenna. Also, the equipment shelter on the boat deck of the ship was lighted by spotlights so that the GPS antenna was easily seen by the shorabased theodolite operators.

During the test, each theodolite observer initialled on one of the other stations and recorded the reading on a log sheet. The theodolite operztors then intersected the 
lights on the ship GPS antenna using the theodolite telescope and tracked the ship until a 'mark' was called over the radio from the personnel aboard the ship. The angle measured at this time was recorded on the $\log$ sheet as a fix. The time interval between fixes was approximately one winute. Each series of approximately twenty fixes constituted a set. At the end of each set, a final reading was made of the angle to the reference station. The fixes were numbered consecutively throughout the test, and the Greenwich Mean Time (GMT) of each fix was recorded on the ship log sheets. The length of the sets depended on the ship position and heading.

To correct the observed theodolite angles, the mean of the final pointing and the initial pointing was determined for each set and for each station. This value was assumed to be a constant throughout the set and was Iemored from each angle. A collimation erfor for each theodclite was also removed from each theodolite observation. The same observers and theodolites vere used Dightly at all stations except MoSSEI, where two different individuals observed over the test week. This continuity of personnel and equipment was designed to reduce operator and instrument error to a minimum. 



\section{GPS and ARTEMIS}

To colocate the different pieces of equipment at the GEOCEIVER STA 31370, a wooden tower was built as shown in figure 4.2. This tower was set over the station for the period of the test. An NPS equipment vehicle was parked as close as possible to the tower. Electrical power yas obtained from the Monterey coast Guard facility.

Prior to the ship test, both GPS antennas were placed on the tower and centered over the station mark. For the first two nights, 9 and 10 may, equipment problems allowed the use of only one system each night and data were acquired only to determine the stability of each systen. During the next night, 11 May, position outputs for the two simultaneously operating GPS receivers were recorded. This static test gave a determination of any difference between the two receivers under almost identical conditions.

Por the ship test, the GPS antenna was centered over the mark and was anchored at the top of the torer: the geoceiver antenna was centered over the mark and anchored at the middle level; and the theodolite on the tripod was set over the mark at ground level. This arrangement provided colocation of all three systems. It das assuned that no 


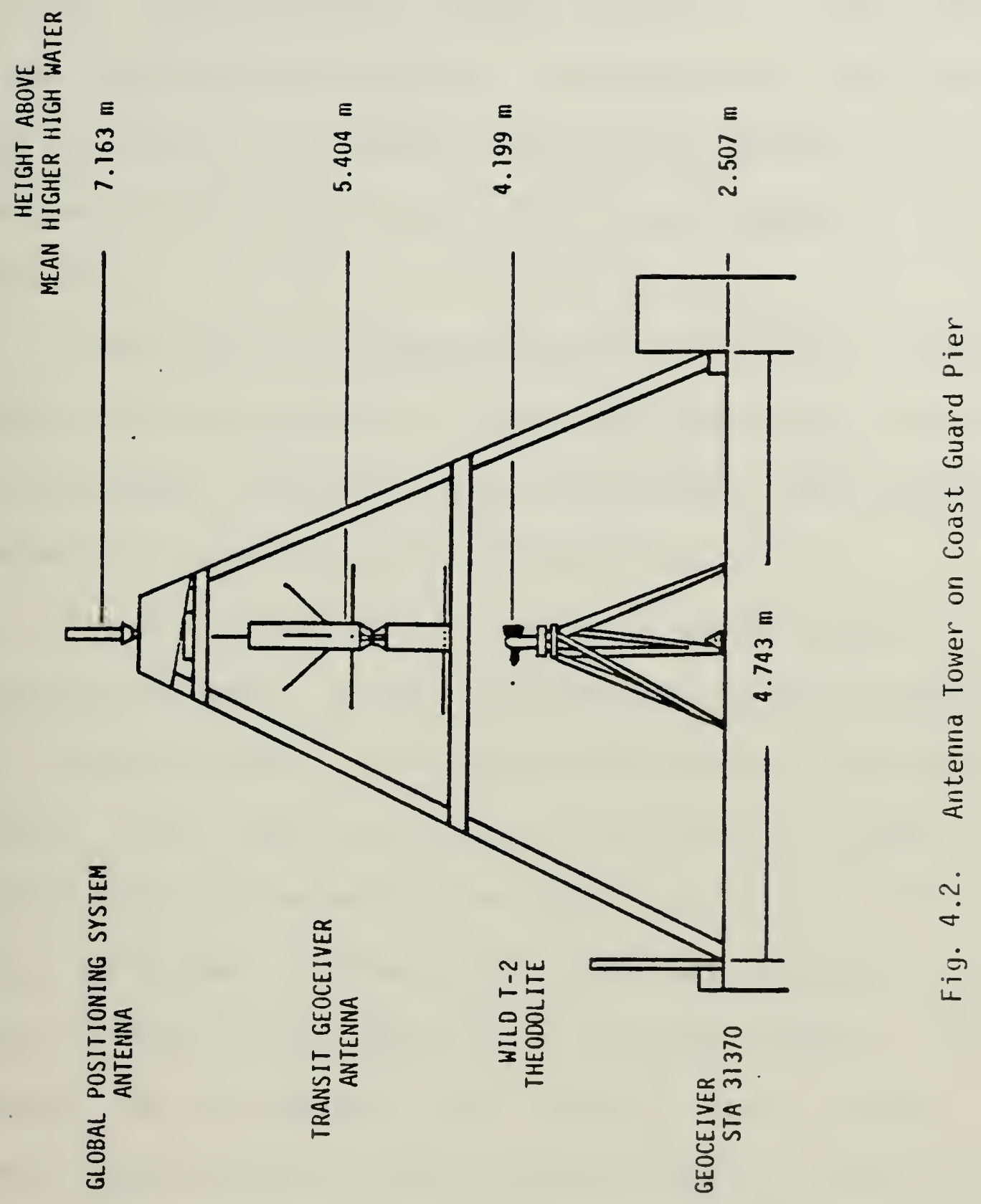


error was introduced by the presence of the wooden structure. The shorebased ARTEMIS antenna unit was offset from the theodolite to eliminate interference in the signal due to the tower. An offset position was computed relative to the station mark and was used in postprocessing of the ARTEMIS data.

Except for the antennas for the GRS, the ARTEMIS, and the geoceiver systems, all other equipment was installed in the equipment vehicle, where an operator was stationed throughout the test to monitor the data quality.

The GPS Manpack is a manually operated system. As mentioned previously, it vas decided that manual operation of GPS was detrimental to the goal of the test, and that an interface that would provide an automated printout of positions from the lanpack as well as a printout of GPS time would be desirable. Knute Berstis and Gary Hitsell of the office of Testing and Evaluation of systems (OTES), NOAA, assembled two interfaces that provided data storage on cassette tapes as well as the desired printout. Each system operated in conjunction with a HP-9825 computer and a HP-7845 printer/plotter. Software was provided by omEs, NOAA. This arrangement permitted storage of the satellite 
messages for further processing and provided an automated printout of the ARTEMIS data. A GPS Manpack had been sent to ores for testing during the construction of the interface. Technical expertise and operation of the interface during the test were provided by OTES.

The data from the GPS receiver were printed at an interval of 24 seconds, and consecutive data were continually recorded on tape and printed during the test periods. In addition, a manual record of the GPS position from the CDO was logged as the 'marks' vere called via the radios.

The ship positioning systems were installed as shown in figures 4.3. and 4.4. An equipment shelter was secured to the boat deck of the $R / \nabla$ ACANIA. A length of six-inch diameter polyvinyl chloride (PVC) pipe was attached to the aft wall of the building on the centerline of the ship. The GPS antenna and the system of lights previously mentioned were set on top of the pipe.

The artemis mobile antenna unit was set on a platform located on the centerline of the ship and at the top of the building high enough to not interfere with the signal from the ship radar beam. Por the period of the 


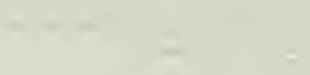



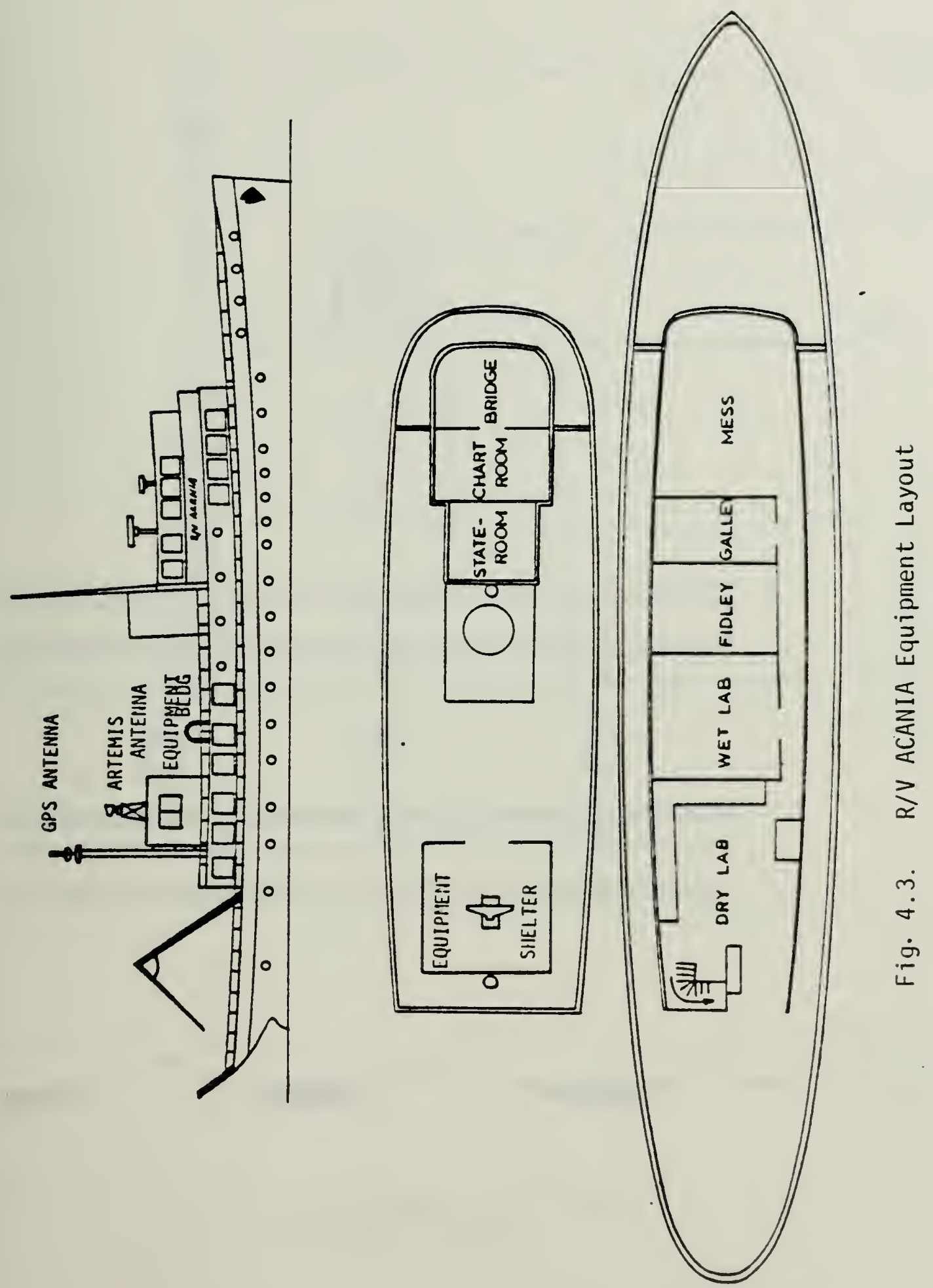


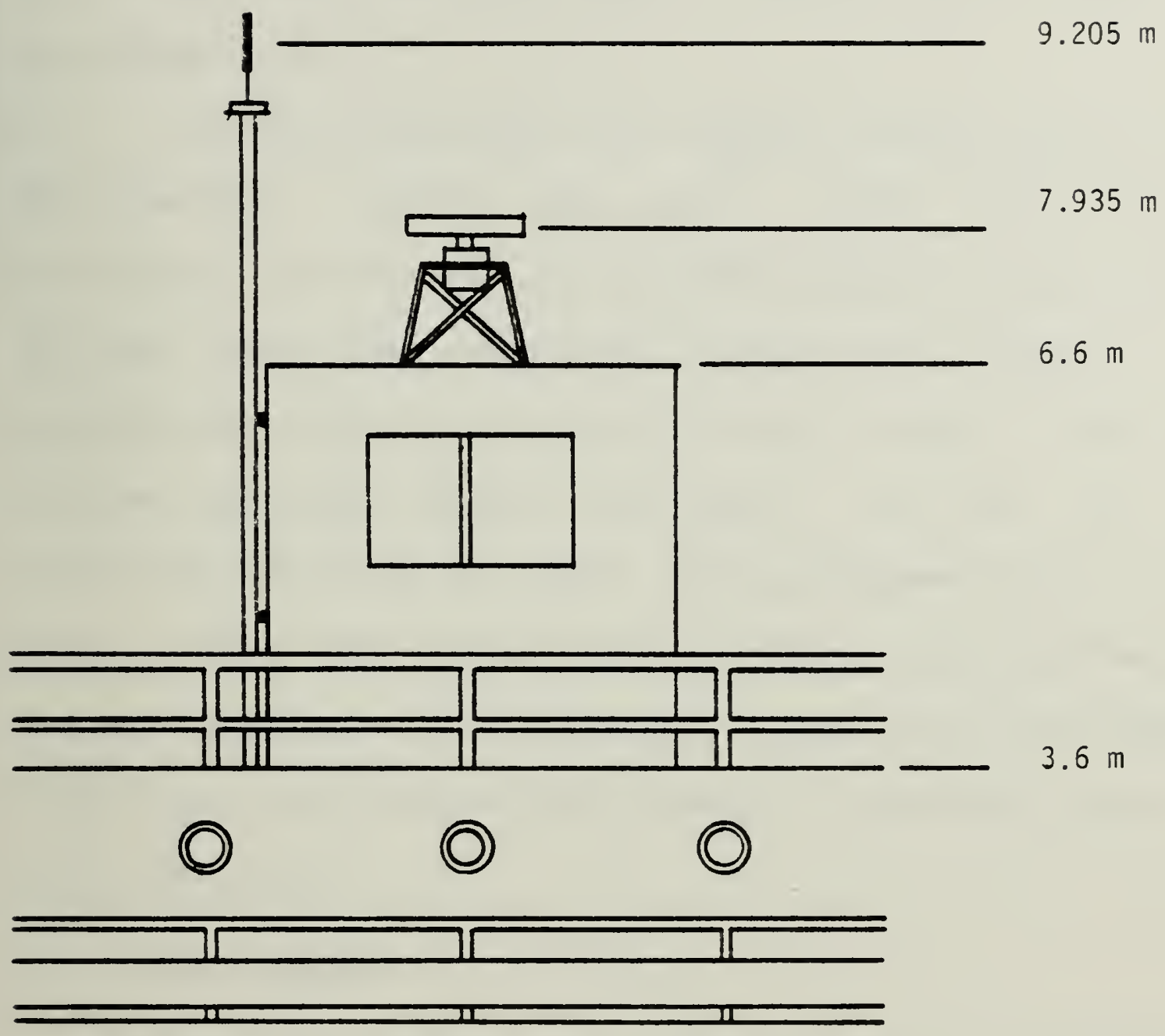

Mean Higher High Water Level

Fig. 4.4. Equipment Installation on the R/V ACANIA 
test, the weather conditions allowed ship operations without use of the radar, thus there was no possibility of damage to the ARTEMIS unit.

All other equipment--the aRTEMIS receiver unit, the GPS receiver, control data unit, power filter, and interface, the HP-9825, the HP-7845 plotter/ printer, and the real time clock--was placed inside the building. An operator monitored the equipment during the ship tests and another individual radioed the 'mark', or fix, to the theodolite operators on shore. The equipment used at the shore location was installed in $a$ vehicle and consisted of the same components as on the ship. operation of equipment during the siptests was monitored by an individual located in the rehicle.

C. LOG OF EVENTS

The test was divided into two portions--1) a shorebased test which consisted of tro nights of stability testing, and one night of receiver comparison tests, and 2) the ship test consisting of three nights of shipboard operation. The $R / \nabla$ aCanI from the Naral postgraduate school was the platform used for the shipboard tests. 
$-$ 


\section{Stability rest}

operations began on 9 ray, 1981, GMT. One of the GPS systems was placed over the station mark, and continuous data yas recorded during the satellite availability periods. In this manner, system 1 was tested on 9 May, and system 2 was tested on 10 May. A position was defined as a quality observation if four or more satellites vere used by the receiver to obtain the output.

\section{Static Test}

Both GPS antennas were centered over GEOCEIVER STA 31370. and data from simultaneous operation of both receivers were recorded at the equipment vehicle. One antenna was placed on top of the wooden structure and the other immediately beloy it on the middle level. The vertical displacement vas assumed to cause negligible error in the horizontal positions. Data were acquired on 11 May fIcm both receivers with a quality observation defined as a position determined from four or more satellites.

\section{Shipboard rest}

Por the entire period of shipboard testing, the wind speeds were less than 5 knots and the seas were calm with 12 feet or less of swell. Visibility was excellent throughout 
n- 
the test week. The ship track for each set is shown in figure 4.5. A $\log$ of subsequent operations follows:

12 May---The GPS Manpack Ieceiver was installed on the $R / P$ ACANIA and GPS and theodolite operations were conducted. The ship was allowed to drift during sets $1-3$ (fix 1-69) With 23 fixes per set, in a east-northeasterly direction.

13 May---The ship cruised at 4 knots on track lines from south to north for sets 4 and 6 , and lines from north to south for sets 5 and 7 . During fixes 139 through 157 the radio at the coast Guard pier was disabled, and no data were acquired by either the theodolite observer or the operator in the equipment vehicle.

14 May---The shipboard GPS system was inoperable. The trouble was traced to a Eaulty antenna cable, requiring replacement. No data were acquired.

15 May---The ARTEMIS, the GPS and the theodolite network were all used for this test period. Data from sets 8 through 13 were acquired (fixes 165-262).

16 May---The control data unit on the shore based GPS system failed before the start of ship operation and could not be repaired wi thout factory maintenance. 



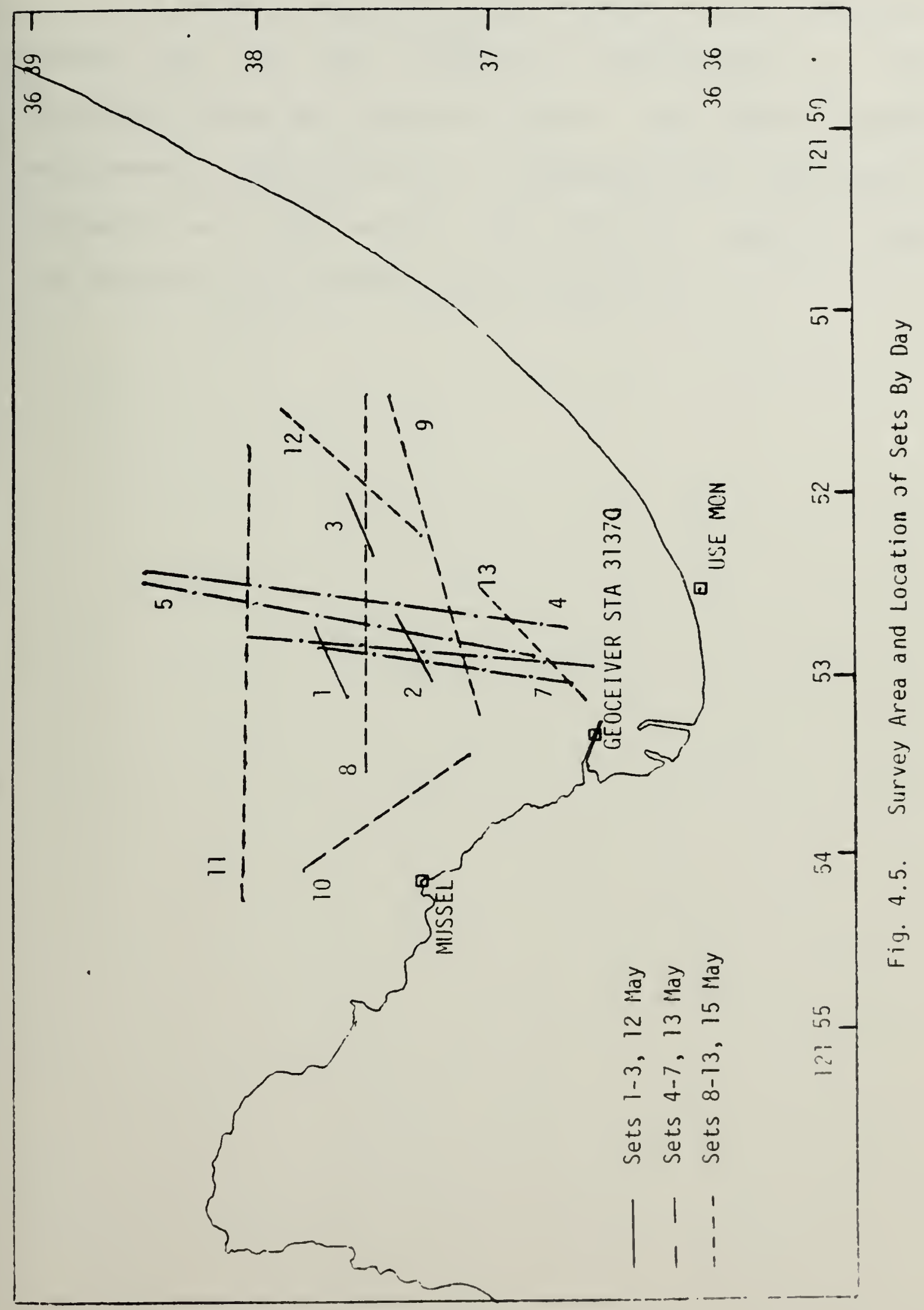



a total of 252 fixes vere recorded by the theodolite network and all GPS positions corresponding to the theodolite fixes were manually logged. The arTeMIs azimuth and distance information and consecutive GPS positions on the ship and in the vehicle were stored on cassette tapes and printed by the HP-7845 printer/plotter. 



\section{DATA PROCESSING METHODS}

Processing of the thesis data was divided into four interrelated, but separate, tasks. These tasks were the basic geodetic survey, theodolite and ARTEMIS ship position determination, differential GPS ship position determination, and the statistical analysis of the ship position ccmparisons. Each task will be discussed separately.

\section{A. BASIC SURVET COMPOTATIONS}

As described earlier in the rest procedures, a basic geodetic survey of the test area was conducted to place the theodolite control stations on the Norld Geodetic system of 1972. or MGS-72. To begin the survey, a Magnavox AN/PRR 14 Geoceiver was placed over the center survey disk, GEOCEIVIR STA 31370 1981, and the digital Doppler data, Erom TRANSIT satellite 68, were recorded onto paper tape. Thirtp-three passes, over a period of two and one half weeks, were recorded, but analysis of the equipment maintenance diagnostics indicated a possible error in the records. These data were therefore discarded.

A second set of forty satellite passes of TRANSIT satellite 68 were recorded over a ten day period and were determined to be of acceptable quality according to the 
standards of the DMA Department of Geodasy. This second set of data was then subritted to DMA, Department of Geodesy, Computation section, for analysis. Also submitted were meteorological data taken during the passes and additional information required for documentation of a first order TRANSIT position. Satellite 68 Doppler data for the survey was then processed in conjunction with the tracked satellite position by DUA computer facilities. A final geodetic position on the MGS-72 ellipsoid was obtained for GEOCEIVER STA 31370. Coordinates of the station are listed in the Test procedures section. The computed height relative to the ellipsoidal surface is $\mathbf{- 3 3 . 3 9}$ meters. Computation of the geographic position utilized a minimum of 38 individual TRANSIT satellite passes recorded for GEOCEIVER STA 31370. This provided for an accuracy of one part in $10^{5}$ (first order accuracy standard). [Ref. 38]

To orient the positioning network, an initial azimuth fIOM GEOCEIVER STA 31370 to station MOSSEL 1932 was computed from two sets of observations of polaRIS. All observations and computations of the star sighting utilized procedures outlined in the National ocean survey Photogrammetric Instructions Number 4, Revision $1,4 / 24 / 73$, the Hydrographic 
- 
Manual, and the Manual of Geodetic Triangulation, SP-247. [Ref. 39,40$]$

Having the initial azinuth, distances were measured betveen all three control stations using a Tellurometer MRA 5 microvave distance measuring unit. Twenty observations of distance were made for each of the three lines measured: GEOCEIVER STA 31370 to MUSSEL, GEOCEIVER STA 31370 to USE MON, and MOSSEL to OSE MON. The average of the distance for each line vas then corrected for instrument error and meteorological conditions following the instructions contained in the operators Manual and the rellurometer Manual. [Ref. 41] Resulting slope distances were then reduced to geodetic distances using the respective corrections for slope to horizontal distance, reduction of elevation to sea level, and the chord to arc distance. These corrections were computed using the nGS 1972 ellipsoidal parameters and the methods outlined in the Hydrographic Manual, the Manual of Geodetic Triangulation, and Introduction to surveying. [Ref. 42] The resulting geodetic distances neet third-order, class I specifications for traverse accuracy, 1:20,000. In addition, angles to the other stations were observed at each control station, giving 

a total of three sets of angles. Each set was comprised of four direct and four reverse plate observations with a wild T-2 theodolite. Each pair of direct and reverse observations was corrected for initial pointing errors. observations and computations were made using the methods detailed in the Hydrographic Manual, the Manual of Geodetic Triangulation, and the Manual of second and Third-order Triangulation and Traverse. [Ref. 43] The resulting closure meets the specifications for traverse accuracy of three seconds per traverse station or a closure of 6 seconds.

With the geodetic position of GEOCEIVER STA 31370 known. as vell as the azimuth from GEOCEIVER STA 31370 to MOSSEL and the distance fIOm GEOCEIVER STA 31370 to MUSSEL, the gecgraphic position of MOSSEL was computed on the MGS 1972 ellipsoid using the direct geodetic computation. This computation used the Rainsford's method modified by $r$. vincenty and including the Helmert's elliptical terms. [Ref. 44]

Next, using the azimutb from MOSSEL to OSE yON, the geodetic distance, and the results of the direct geodetic computations, the geographic position of USE MON was 
determined. Also, the ARTEMIS geographic position was calculated as an offset using an azimuth and distance from GROCIIVIR STA 31370. With these computations, the geodetic survey was completed.

Positioning of the ship, $R / \nabla$ ACANIA, required one azimuth, or line- of-position, from each of the control stations MUSSEL, GEOCEIVER STA 31370, and OSE MON. These lines of position were used to triangulate the vessel position. Angles from each of the three theodolite locations were observed as described in the Test procedures. Each of the three angular mezsurements were then corrected for wean pointing errors and the individual theodolite collimation errors. Each corrected angle was then adjusted, by control station, to obtain an azimuth from south, as required to triangulate the ressel position. The three resulting azimuths and the corresponding control station latitude and longitude were then used in a least squares three line of position intersection computation. Results of the computation were a vessel position in latitude and longitude, error ellipse semi-major radius, error ellipse semi-minor radius, azimuth from south of semi-major radius, and circular standard error. [Bef. 45] Figure 5.1 illustrates these error ellipse parameters. 
$x^{-2}=$ 
The mean displacement of a point to be expected in the direction of the two coordinate axes, $X$ and $Y$, due to measuring errors, can be expressed by the quantities $\sigma_{x}$ and $\sigma_{y}$.

When the north-south axes are rotated, two axes ( $X$ and $Y$ ) perpendicular to one another are obtained. corresponding to the maximum and minimum values of $\sigma$ and $\sigma$. The maximum and minimum values of $\sigma$, and the clockwise rotation angle $(\alpha)$ of the major axes of the error ellipse are included as part of the output of the Geodetic Package and can be used as input if desired.

The circular standard error (CSE) is also included in the output with the error ellipse parameters. The value of CES is the radius of a circle whose area is equal to the area of the error ellipse. That is:

$$
C S E=\sqrt{\sigma_{\max } \sigma_{\min }}
$$

EXAMPLE: Error Ellipse

$\begin{array}{ll}\text { Az-Max } & 144.9^{\circ} \\ \operatorname{Max} & 0.235 \mathrm{~m} \\ \text { Min } & 0.211 \mathrm{~m} \\ \text { CSE } & 0.223 \mathrm{~m}\end{array}$

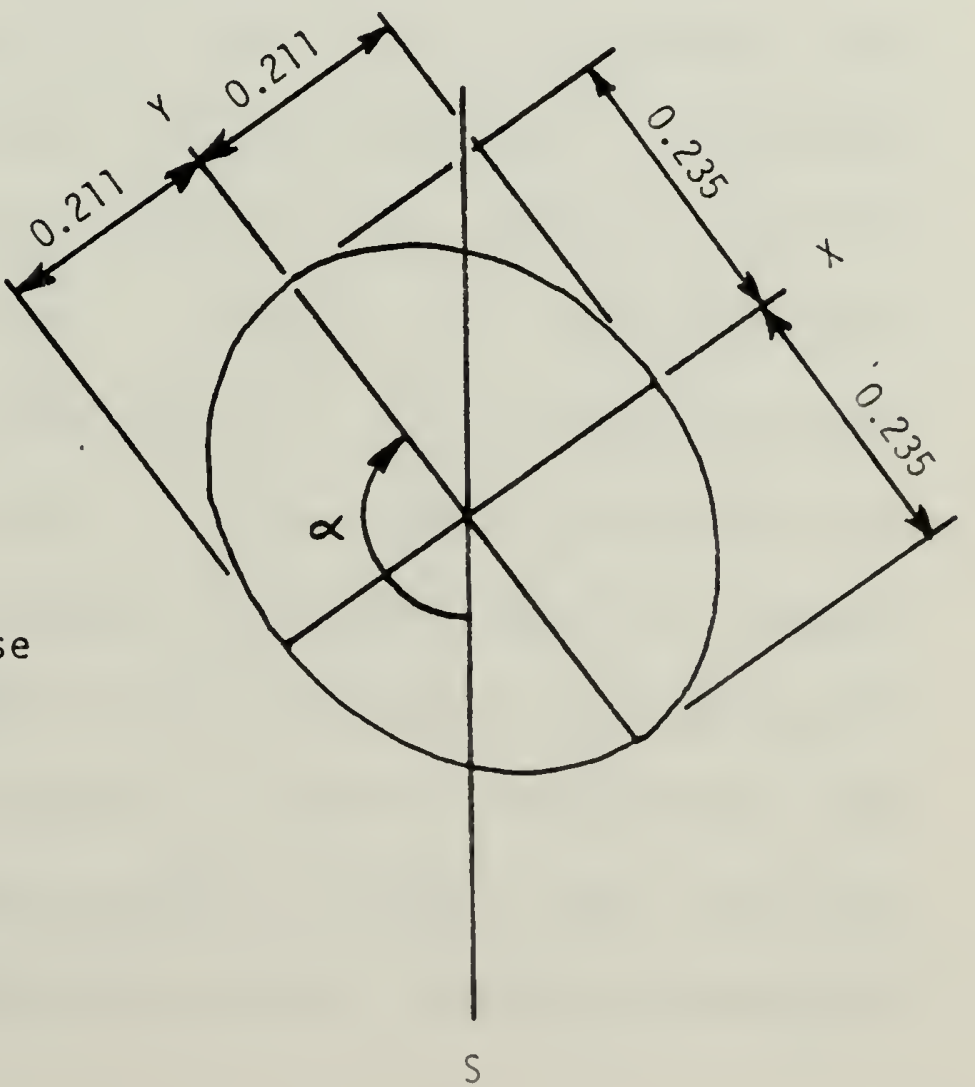

Fig. 5.1. 


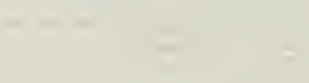


For this study, 262 vesse 1 positions, or fixes, were observed and recorded. On examination during processing, 51 fixes were found to contain errors and data omissions which rendered the vessel positioning computation invalid or indeterminate. The remaining 211 fixes comprised the data set which was then broken down into smaller sets for analysis and comparison. These sets were number 1 through 13 and categorized according to vessel track. All sets were then processed using several differant methods to determine the most accurate approach.

B. TREODOLITE AND ARTEMIS SHIP POSITION DETERMINATION Before processing the GPS Manpack data, the ARIEMIS data were processed to ensure the vessel positions, as obtained by theodolite, were correlated with the correct automated and hand recorded GPS data. ARTEMIS data consisted of an angle, MOSSEL-ARTEMIS OFFSET-vessel, and distance from the ABTEMIS OFBSET to the ressel. The angular measurement was first converted to an azimuth from south using the azimuth of ARTEMIS OPESET to MOSSEL as the correction and adding the measured angle. Vessel position based on ARTEMIS was then computed using the direct geodetic program lalso used for the basic survey). Comparisons of the resulting geographic 
positions and the theodolite derived geographic positions, were made for corresponding fix numbers using the inverse geodetic computation on the HGS-72 ellipsoid. The inverse computation utilizes two geographic positions as inputs for calculating the forward and back azimuths and the distance betwe $\in$ n the positions. [Bef. 46] For comparison, if the tyo positions differed by more than 20 meters, the ARTEMIS positions on either side of the suspect ARTaMrs fix were then used to compute the inverse computation to the theodolite ship position. In seren fixes, the fix position values vere changed in the May 15 GPS data to give more accurate results.

\section{DIFEERENTIAI GPS SHIP POSITION DETERMINATION}

With the check and adjustnent of the GPS data and the theodolite determined vessel position complete, the first GPS data processing was the comparison of the uncorrected, non-differential ship GPS Manpack receiver data to the theodolite computed ship position. Using the inverse geodetic computation, the forward azimuth and the distance between the theodolite computed ship position and the ncn-differential GPS ship position were completed. These results were then used in the analysis of the differential 
processing to examine the stability of the shipboard ranpack receiver compared to the GPS Manpack receiver located over GEOCEIVER STA 31370.

There were two nethods of analysis of the differential GPS. The first of these was the determination of a static correction to be applied to all the GPS data. This static correction in the differential GPS computations was to account for a suspected bias between the two similar, but not identical. Manpack receivers. A mean static correction was computed for the most stable reception period during the static tests on 11 May. Mith the two Ieceivers colocated Orer the GEOCEIVER STA 31370, a mean correction of -0.954 seconds of latitude and -0.307 seconds of longitude was found between GPS Manpack System 1 and system 2 during times 07:16:00 GMT and 07:25:12 GMT. This static correction was then added to the latitude and longitude of GPS ranpack System 1 (located orer GEOCEIVER STA 31370) data.

The second method of analysis or processing in the differential mode used the latitude and longitude obtained directly from the GPS Manpack receivers. In either processing method, the computation of the differential corrector to the shipboard GPS Manpack receiver data vas the 

same. An explanation of the computations and processing of the differential correction for both methods follows. Computation of the differential corrector for each GPS fix position was accomplished by using the geographic position obtained with the stationary Manpack receiver, located over GEOCEIVER STA 31370, and the geographic position of GEOCEIVER STA 31370 . These two positions were then used in the inverse geodetic computation to obtain a differential correction vector (forward azimuth, and distance) from the stationary GPS receiver to GEOCEIVER STA 31370. In figure 5.2, the differential correction vector is labelled "âa". Osing the direct geodetic computation, the differential correction vector was applied to the corresponding shipboard GPS Manpack receiver position, and the differential-GPS position was obtained. These resulting positions were computed on a one-to-one basis using the fix numers as identifiers. Vector "Â", the differential corrector $v \in c t o r$ which is identical to the vector "Â" in figure 5.2, is applied to the shipboard GPS Manpack receiver and results in the differential GPS ship position.

Comparison of the differential GPS ship position with the theodolite-computed ship position was accomplished using 


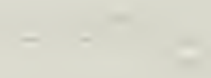




\section{T-2 COMPUTED}

SHIP POSITION

$\diamond$

DIFFERENTIAL GPS SHIP
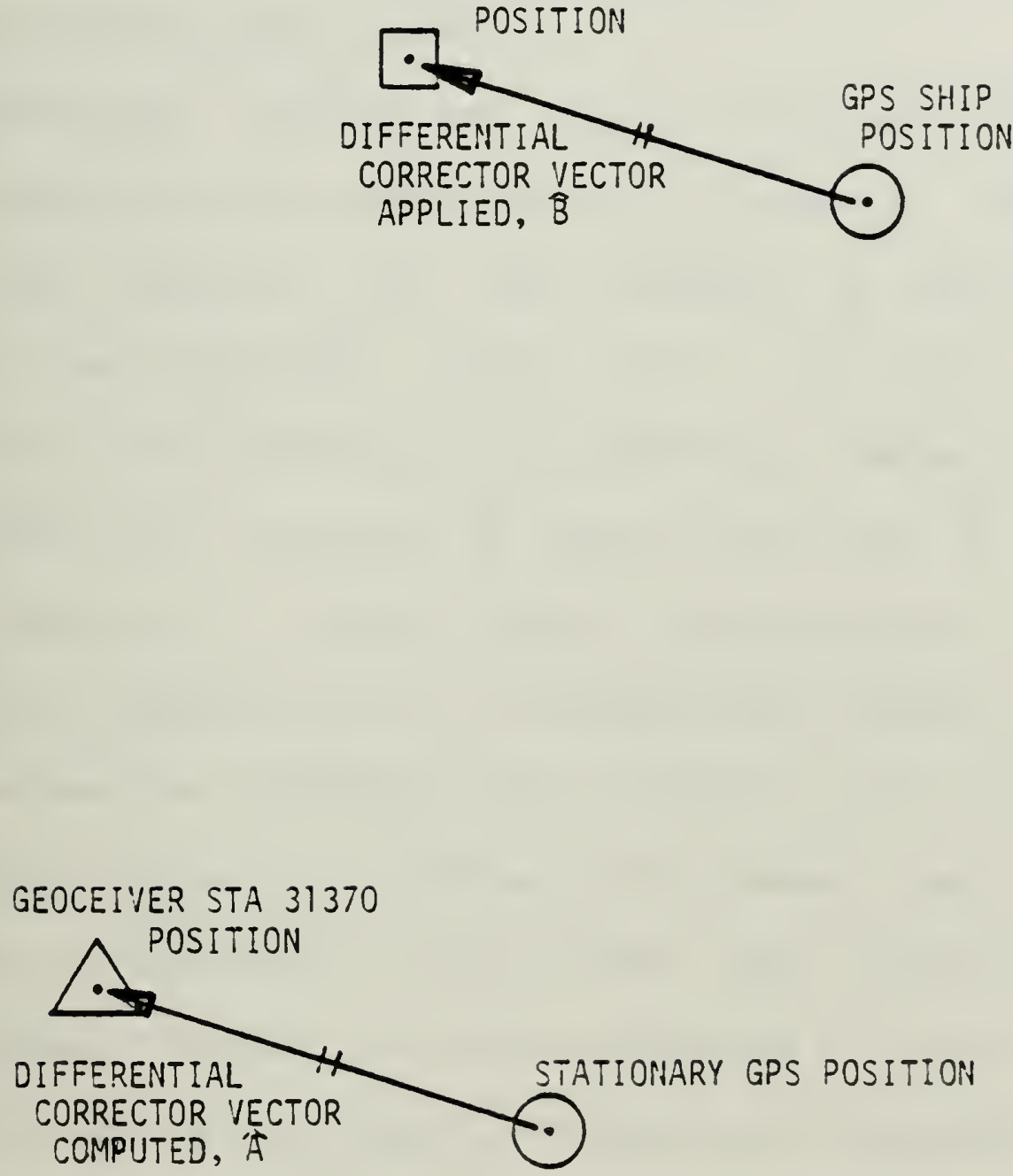

Fig. 5.2.

DIFFERENTIAL GPS PROCESSING 


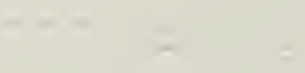


the inverse geodetic computation for both methods of differential GPS processing. The resulting forward azimuth and distances for both processing methods were used in the statistical analysis.

\section{Statistical data anALYSis}

Statistical analysis yas done on data separated into sets according to the method of data processing. The static data and stability data were graphed as functions of latitude and longitude versus time. User range error, furnished by the space Division, GPS/OL-AQ, Vandenburg, AFB, was plotted as a function of time for each day of the test (see Results). Other graphed relationships are the gecgraphic positions of the stationary GPS Manpack receiver data versus the GEOCEIVER STA 31370 and the theodolite semi-major radius as a function of fix number (see Results). other statistical data analyses were represented by histograms. plotted on these histograms are the relative frequency on the left margin, variable bar increments scaled on the bottom, number of variable observations in each bar increment on the top, and the total sample size on the top margin. Within the histogram the frequency bars are denoted by asterisks, the mean by a capital $M$, the quartiles by 
periods and the empirical density function by the capital $F$ curve. The empirical density function was computed using:

$$
F(z)=\frac{1}{N(B(N))} \sum_{i=1}^{N} \frac{\left(x_{i}-z\right)}{B(N)}
$$

[Bef. 47] where: $F(z)=$ the empirical density function, $z$ = the frequency of observation, $x$ = individual observation, $N=$ the total number of observations, $W=$ yeight function, $B$ $=$ banduidth,

$$
\begin{gathered}
N=1-2 \\
B(N)=\text { range of } a 11 \text { observations } / \sqrt{N}
\end{gathered}
$$

The statistical values listed beloy the histogram are defined in Table $\nabla$. Computed histograms show the distances betyeen: 1) the theodolite-computed ship position and the differential GPS ship position, both with and without the static correction, by set; 21 the theodolite-computed ship position and the differential GPS ship position, without static correction, for five satellite observation periods on each of the three ship test days; 3) the theodolite-computed ship position and the non-differential GPS ship position for the five satellite-observation periods on each of the three 

The definitions of the basic statistics computed by the program are listed below:.

MEAN: Average of the sample

MEDIAN: Mid-Value of the sample, if there are an odd number of sample points, or the average of the two middle values for an even number of points

TRIMEAN: $\quad 0.25 *\left(Q_{1}+2 Q_{2}+Q_{3}\right)$, where $Q_{i}$ are the quartiles MIDMEAN: The average of all sample values lying between the upper and lower quartiles

MIDRANGE: Average of the maximum and minimum

GEOMETRIC MEAN: GM $=\sqrt[n]{x_{1} \cdot \dot{x}_{2} \cdot \cdots \cdot x_{n}}$

HARMONIC MEAN: $\quad H M=n / \sum_{i=1}^{n} 1 / x_{i}$

VARIANCE: Unbiased estimators for variance and standard deviation are used - the square of the standard deviation

STANDARD DEVIATION: $S=\sqrt{i \frac{1}{\sum_{i} x_{i}^{2}-n \bar{x}^{-2}}}$

COEFFICIENT OF VARIATION: Standard deviation / $\mid$ Mean $\mid$ when the mean is less than $10 . * *-30$, the coefficient of variation is set to zero.

MEAN DEKIATION: The average of the sum of the absolute differences between the sample values and the median

RANGE: Maximum - minimum

MIDSPREAD: $Q_{3}-Q_{1}$, also called the interquartile distance

M3: Third central moment. Unbiased estimator is used

144: Fourth central moment. Unbiased estimator is used

COEFFICIENT OF SKEWNESS: M3 / (Standard Deviation) $\star \star 3$

COEFFICIENT OF KURTOSIS: (M4 / (Standard Deviation) $\star \star 4$ ) -3

BETA1: Biased estimate of third central moment; can be used in testing for normality

BETA2: Biased estimate of fourth central moment

MAXIMUM: Largest sample value

MINIMUM: Smallest sample value

QUANTILES: The alpha-quantile, $x$ (alpha), is the solution to the equation:

Probability $(x \cdot 1 e \cdot x($ lpha $))=$ alpha 
ship test days; and 4) the GEOCEIVER STA 31370 position and the uncorrected stationary GPS position for the three days of ship tests. In adition, the azimuths between the theodolite-computed static corrections, for each subset. were graphed as a series of histograms. To illustrate the difference between the GEOCEIVER STA 31370 position and the stationary GPS position, the azimuths between the two positions are graphed on histograms for each of the three test days. 



\section{ERROR ANALYSIS}

The error sources contributed by each positioning system are described. Estimates of the effect of each on the final results are determined were possible.

\section{A. ARTEMIS POSITIONING STSTEM}

The sources of error in the ARTEMIS ship position can be divided into two categories--those sources of error inherent in all microwave positioning systems and those unique to the ARTEMIS system. All are investigated and the contribution of each to the total error is determined.

\section{Microwave System Errors}

Sources of system error include range holes, inaccuracies in calibration, non-ideal geometry of the Iines of position describing the fix, and interference with reflections of the signal from nearby objects.

Range holes are a cause of unreliability in microwave positioning systems. The problem exists when the sea surface is calm enough to reflect part of the transmitted signal. The reflected signal will arrive at the receiving antenna at a later time than the signal which travels directly, causing a phase difference between the two signals. A zone or region of destructive interference of 
the directly transmitted signal and the reflected signal will occur within which the ressel will receive an attenuated signal. Mhen the phase difference of the two paths is exactly $180^{\circ}$, no signal will be received provided the reflected signal is as strong as the direct-path signal. prediction of the range holes, therefore, is useful in survey planning so as to aroid this problem.

The range hole is a function of shore unit and ship unit antenna heights, the vavelength of the system, and the distance from the shorebased unit. If the operating area is known, antenna heights can be determined and equipment can be installed so that no range holes exist in the survey area. If fixed antenna heights are known, the region of uncertainty can be determined from the equation: [Bef. 48] The following equation is used for this computation:

$$
D_{n}=2(h 1)(h 2) / n \lambda \text {. }
$$

where $\lambda$ is the warelength (constant for ARTEMIS at .032 m), h1 and h2 are antenna heights, and $D_{n}$ is the distance from the shore based unit to the nth range hole. For this study, the antenna height of the fixed unit above mean sea level at the GEOCEIVER STA 31370 was 3.8 meters. The mobile antenna was installed on top of the equipment shelter on the boat 
- 
deck of the $R / V$ ACANIA at a height of 7.9 meters above the the waterline. Two range holes within the survey area were determined to be located at ranges of 1876 meters for $n=1$ and 938 meters at $n=2$ (fig. 6.1). These two ranges were computed for the case of mean lower low tide. The change in width of the range hole due to a tidal fluctuation of 1.5 meters during the test is show in figure 6.1. (During the night of 15 May the sea surface was sufficiently disturbed by a two-foot swell and a surface wind of $2-4$ knots such that surface reflection was minimal and no loss of signal was observed at the computed ranges).

Calibration of the ARTEMIS system was accomplished in two stages. As part of the study, the ARTEMIS was obtained for a one reek test of the system from 13 to 17 April. During this time it was calibrated for azimuth and range over the baseline between the GEOCEIVER STA 31370 and MUSSEL. The azimuth readings required no adjustment but the range was reduced by two meters. The equipment was returned to Marinar Corporation to fulfill prior commitments and then was returned to yonterey for the ship test on 15 May. Before the evening operation, the ARTEMIS was used to measure the same baseline as previously. A plus two meter 
- 2- 


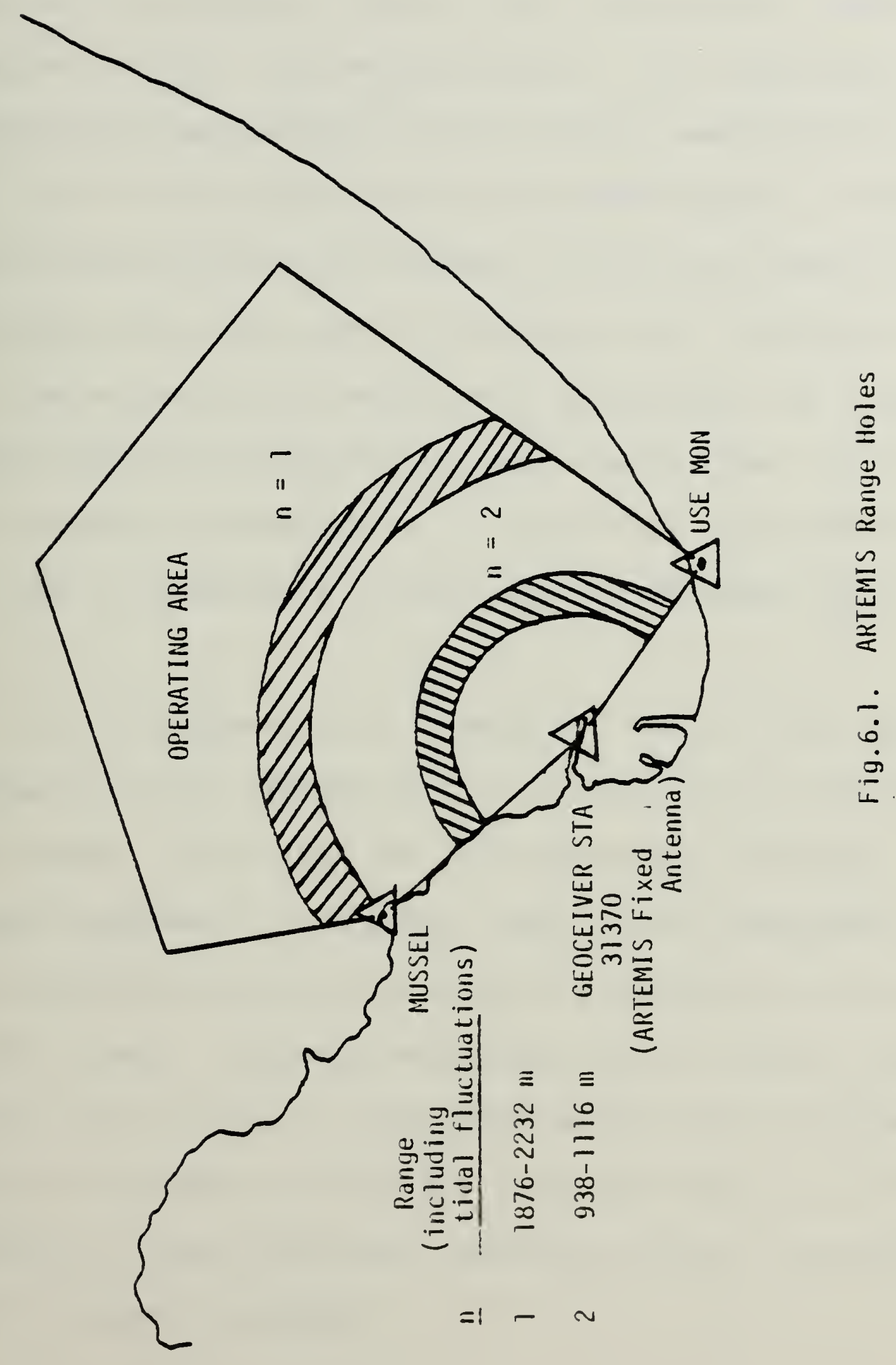


- - n 
bias was observed at this time, but no immediate compensation was made. This error was assumed constant throughout the test and was included in the calculation of the ship-determined ARTEMIS position during postprocessing. One of the advantages of the ARTEMIS system, unlike other microwave positioning systems, is that the geometry is always ideal for the lines of position that determine the fix. The range-azimuth technique of deternining the vessel position defines an uncertainty ellipse having axes that are always mutually perpendicular. This allows prediction of errors as a function of range only. independent of the angle.

The manufacturer's specified error in range measurement of the ARTEMIS is \pm 1.5 meters for all line of sight ranges. One axis of the uncertainty ellipse is therefore constant. The other axis, that describes the error introduced by the system azimuth uncertainty, is $60 \mathrm{~cm}$ per 1000 m range. (This is determined from an angular error of $0.033^{\circ}$ or $2^{\prime}$ of arc). Both system error values represent an accuracy of twice the standard deviation value, or a $95 \%$ probability of the true value occurring within the margin allowed by these parameters. 
$-$ 
The positional uncertainty can be expressed in terms of the radius of a circle of equivalent probability within which the true fix is expected to occur. The method of computation of this radius is described in Appendix A. The technique allows the conversion of uncertainty ellipses to radii of circles of equivalent probability. values from this computation for the radii of circles of $90 \%$ probability at different ranges used in the survey area for 15 May are displayed in figure 6.2 along with the circles of $90 \%$ probability, the magnitude of the radii at the ranges used for the study do not exceed 5.4 meters. One goal of tin is study was to measure the difference in positional accuracy between ARTEMIS and GPS. A maximum error of 1.0 meters, an order of magnitude smaller that the tested system accuracy, is desirable. At the present time, however, there are few systems that can provide the order of accuracy system for the position of a moving vessel, so the 5.4 meter error observed at 4000 meters had to suffice.

Error caused by reflection of the signal from nearby objects is difficult to measure. To minimize this problem, the offset position for the ARTEMIs unit was planned so as to be clear of possible interference from the wooden 


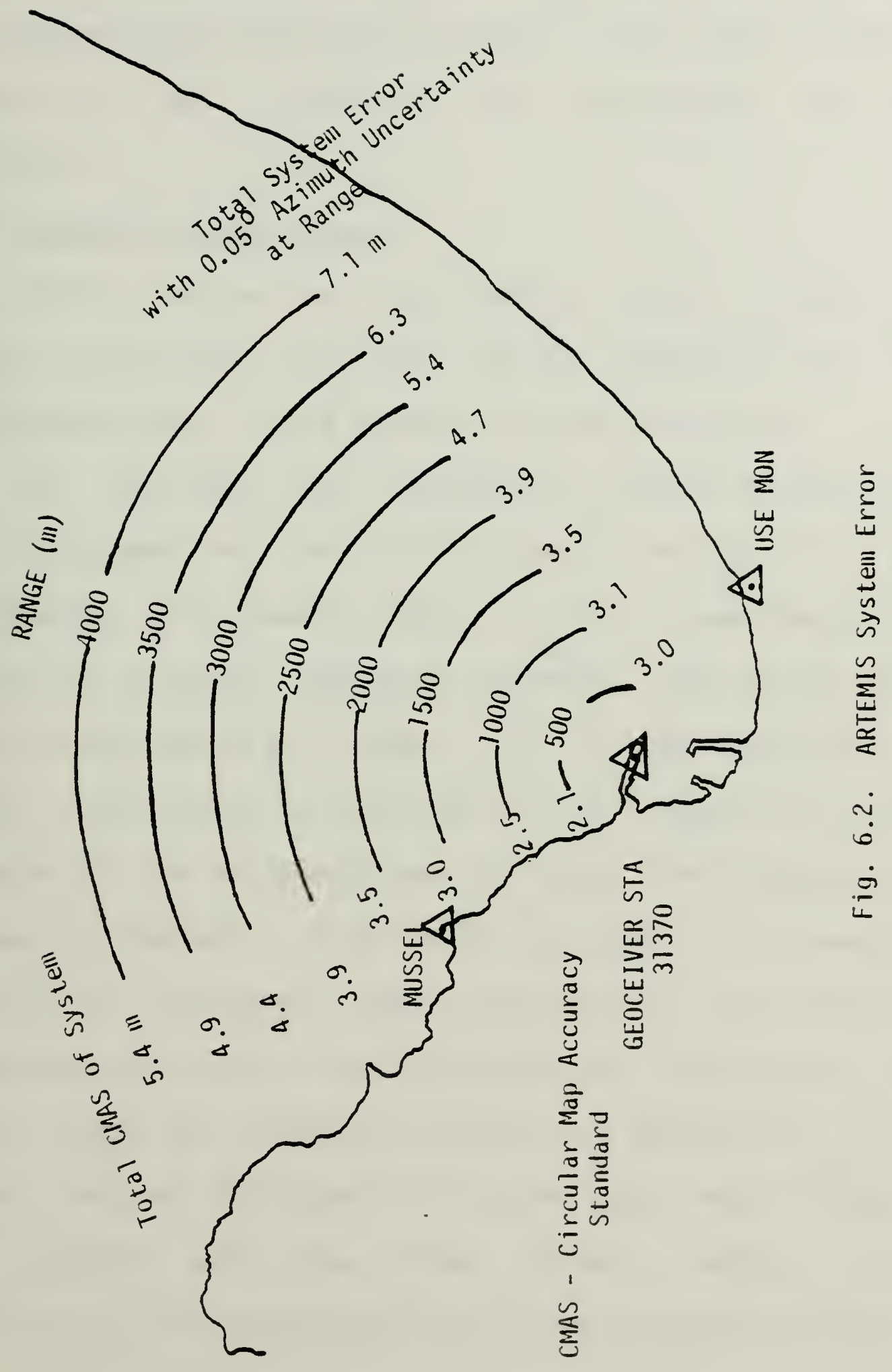


structure and the eluipment vehicle. No signal interference was observed despite the ship's motion. This source of data unreliability was therefore not considered to be significant.

\section{ARTIMIS System EIIOIS}

Errors unique to the ARTEMIS system include a pointing error source and the lack of resolution of the azimuth measurement in the dynamic mode of operation.

The operation of the ARTEMIS system requires a manual alignment of the fixed antenna so that it is perpenaicular to a known object. This is necessary to establish an original reference direction upon which all angular measurements are based. It is possible that a pointing error could be produced by the operator if the crosshairs of the telescope used to align the antenna are not exactly sighted. This yould introduce a systematic error into all subsequent angle measurements. To minimize this source of error, the alignment of the antenna was checked before and after the period of operation. The original azimutb displayed on the antenna unit display agreed exactly with the final azimuth value. Any contribution to ship position error was considered minimal. 
The ARTeurs was operated using the dynamic mode option (see Equipment Description--ARTEMIS). The resolution of the system in this mode is 1 meter for displayed range and $0.1^{\circ}$ for azimuth values. This resolution limit introduces an uncertainty of \pm 0.5 meters in range and $0.05^{\circ}$ in angle measurements. The computed uncertainty ellipse as expressed by radii of circles of equivalent probability, is shown in figure 6.2. The system error and all other errors mentioned above are assumed to occur within the scope of this resolution uncertainty.

Another source of system error has been proposed in a study conducted in June, 1980, by NOAA. [Ref. 49] The test compared the ARTEMIS system with two ranges measured by two Del Norte Trisponders (a short range microwave range/range positioning system) and two lines of direction measured by two shore-based theodolites. The results described an underway bias of $-0.05^{\circ}$ of unknown origin in the angle measurements. This discrepancy has not been resolved. The preliminary test conducted in Monterey in april, 1981 compared the ARTEMIS system with three lines of direction determined by three theodolites. The purpose of the test was to resolve the underway bias problem. Results are enclosed in a separate report. [Ref. 50] 
$-5=$ 
B. CONTROL NETMORK

The entire survey was oriented relative to the TRANSIT position on the coast Guard Pier (GEOCEIPER STA 31370 ). Therefore, errors inherent in the position of this station mark affected all results. Assuming that the geographic coordinates published by DMA/HTC represented the best estimate available of the GEOCEIVER STA 31370 , the remaining significant sources of error affecting all results were survey errors. The control network for the study was determined from the traverse and it was assumed that all positions used in the study vere oriented relative to each other on the rGs-72 ellipsoid. A change in the ellipsoidal surface within the area encompassed by the traverse was assumed to be insignificant.

survey errors stem from the methods used for obtaining the initial azimuth for orientation of the survey, the type of traverse chosen, and the geometry of the traversed triangle.

To obtain a starting azimuth for the traverse, two sets of observations on polaris vere recorded at the GEOCEIVER STA 31370. A striding level attachment to the theodolite vas not used. The instrument level bubble was observed 


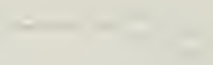


receatedy during the observations to ensure constant instrument alignment with the vertical. Failure to keep the instrument level could have introduced a \pm 30 " uncertainty into the starting azimuth of the survey. [Ref. 51] To consider the significance of such an error, all stations were recomputed using a deviation of $\pm 15^{\prime \prime}$ from the computed azimuth. The resulting shift in the positions of MOSSEL and OSE MON are listed:
US E HON
0.133 distance at $230^{\circ} 36 \cdot 47.16 \prime$ azimuth
MOSSEL
0.132 m distance at $230^{\circ} 33^{\prime} 4.08^{\prime \prime}$ azinuth

The change is considered insignificant relative to the other errors described above.

The survey was a closed loop traverse using GEOCEIVER STA 31370 as the origin and closing position. The weakness in this method involves the measured distances. A method of checking the observed angles in the triangle exists via the angular closure if a significant deviztion in one of the angles can be detected. The distance measurement, however, can produce an undetected bias in the survey if the distance measuring instrument contains a systematic error. This error would shift all the surveyed positions. Correct 
$-1$ 
measurement of distance by the MRA $V$ reliurometer, therefore, was important. The equipment was calibrated over a known baseline and the errors were within the centimeter range. This error was therefore negligible.

The geometry of the triangle was not optimum. Ideally. the triangle would have been equilateral to minimize the source of observing error. The choice of traversed points was based on the location of preexisting station marks and the desired geometry of the theodolite fixes to the ship. The closures computed for the traverse met third order specifications for accuracy, and the survey was not adjusted to remove the closure error. [Ref. 52, 53]

The survey errors were considered to be within the uncertainty of the TRANSI station location and were therefore not considered significant for the study.

\section{TBEODOLITE NETPORK}

The errors generated by the theodolite network are divided into equipment errors, operator related errors and system errors, of which the latter is the most significant.

The equipment used for the theodolite network were three 1-second theodolites which have a measurement resolution of t0.5". All theodolites were in good condition. 
Instrumental errors of a theodolite are listed in rable VI. [Ref. 54]

The major source of equipment error was introduced by not changing face, the process of observing angles a second time with the telescope reversed. Due to the nature of the test coupled with 1-minute fix intervals, it was not possible to observe all the fixes in both the direct and reversed modes. As an example of the magnitude of this error, the horizontal collimation errors were determined for each theodolite prior to the study. The results are listed below:

Theodolite

$\# 14405$

\# 14482

\# 14452

\section{Collimation Error}

$-1.011$

$+2.711$

$-0.71$

all the measured angles were adjusted for this error as described in the processing section. The largest influence on the remaining instrumental errors was the non-verticality of the main axis. If the non-verticality were large (for example, one division off-level in the lowe spirit level bubble). the angle measured could be in erzor by $7 "$. [Ref. 55] To minimize this error, each theodolite was 

TABLE VI. Theodolite Instrument Errors

ERROR

Eccentricity, misplaced indices

Graduation of circles

Micrometer run and vernier error

Non-verticality of main axis

Bad setting of the upper spirit level

Verticality of cross wires

Horizontal collimation

Vertical collimation and index setting error
ELIMINATED BY:

Reading both sides of circle and changing face

Changing zeros

Selection of suitable zero setting

Error is not cancelled by any observing procedure

Correct setting or application of correction

Changing face and using same part of wire

Changing face

Changing face 


$$
-+
$$


Iflevelled if necessary between sets of observations. The magnitude of this and the collimation errors were considered to be insignificant relative to the system errors discussed later in this section.

The operator-related errors are a function of the individual performance of the observers. The experience and personal comfort of the observer, for example, are two najor factors which can influence the observed angles. An observer's performance and resultant impact on the quality of the results depend on the judgment and reaction time of the observer and are influenced by variables such as fatigue and age. The subjective nature of the problem makes an estimate of the error difficult, therefore, for this study the error was considered random.

The major source of error in the theodolite positioning system dealt with the timing of the fix.

A delay existed between the time the 'mark' was called over the radio and the actual time the angle was observed. The timing problem was most critical wen the ship was close to one of the three observer locations because the rate of change of the bearing of the ship was greatest at this time. Hence a small delay generated a large amount of error in the angle 
- 
recorded. To indicate the effect this error source may have had on the position of the ship, two fixes vere chosen arbitrarily--one at close range to each of MUSSEL and GEOCEIVER STA 31370. A one minute value was added to the angle which was most affected by the timing error and the fixes vere recomputed. The same process was repeated for the three fixes with the one minute value subtracted from the critical angle in each fix. The results follow:

Numer Original Pix + 1 Minute - 1 Minute

$210 \quad 36^{\circ} 37 \cdot 20.62282^{\prime \prime} \quad 36^{\circ} 37 \cdot 20.61468^{\prime \prime} \quad 36^{\circ} 37 \cdot 20.63081^{\prime \prime}$ $121^{\circ} 53 \cdot 41.97184 " 121^{\circ} 53 \cdot 41.96933^{\prime \prime} 121^{\circ} 53 \cdot 41.97426^{\prime \prime}$

259 $36^{\circ} 36 \cdot 45.88048^{\prime \prime} 36^{\circ} 36 \cdot 45.87574 " 36^{\circ} 36^{\prime} 45.89082^{\prime \prime}$ $121^{\circ} 52 \cdot 54.05062 " 121^{\circ} 52 \cdot 54.04635 " 121^{\circ} 52 \cdot 54.05459 \prime$ No significant error was generated from this source.

Another source of system error was associated with the geometry of the fix. Ideally, the three theodolite angles yould describe tro equilateral triangles to the ship: however, within the operating area, the geometry varied. As an indication of the size of this error, representative fixes were chosen and the circular map accuracy standards (cras) of each of the combinations was determined. Pigure 6.3 illustrates the approximate error caused by variations 


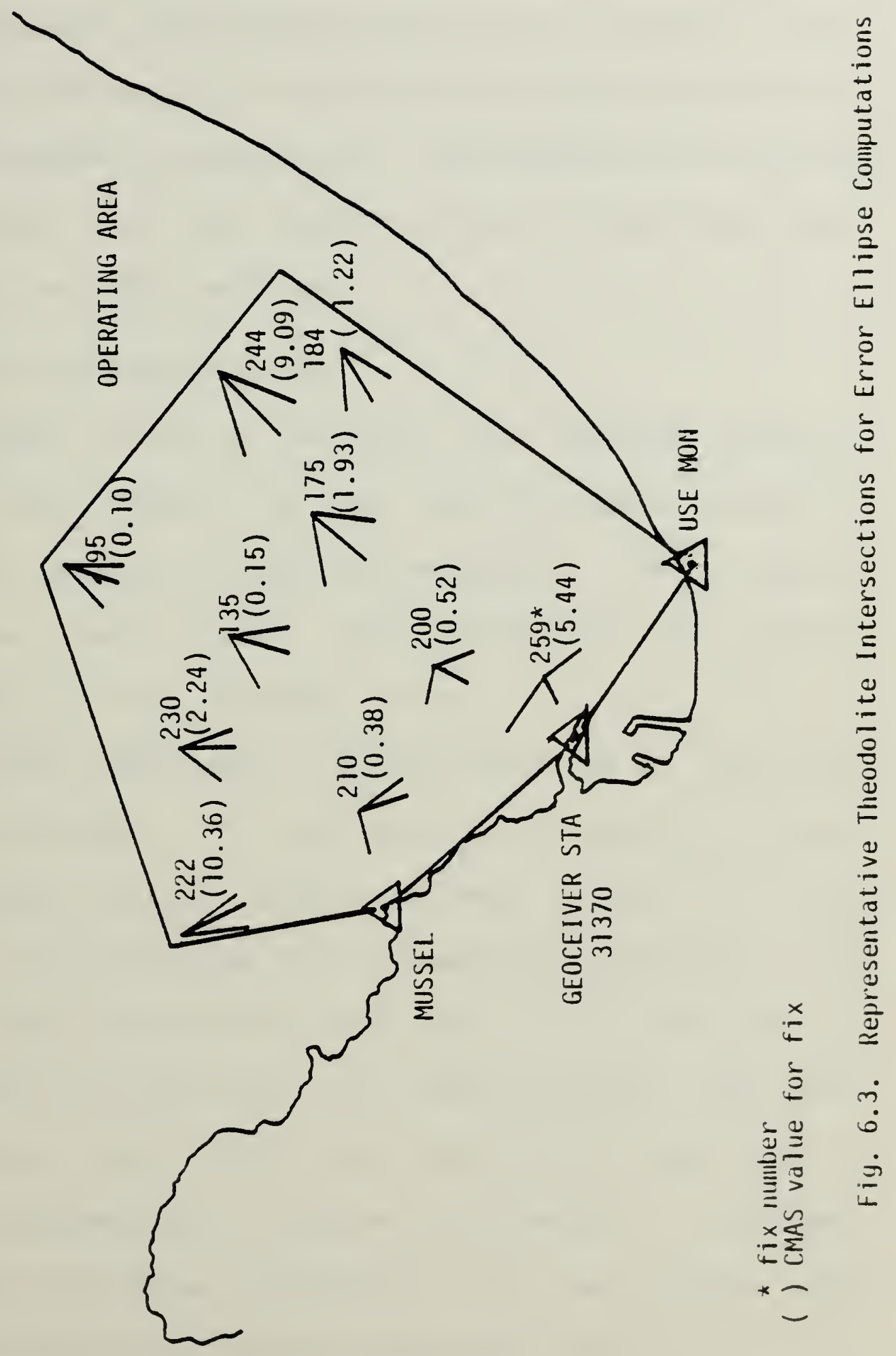



in the geometry. Mithin the area outlined in the figure the gecmetry creates a cMas of not more than 10.4 meters. This is therefore the source of the largest probable error in the theodolite method of positioning. Nevertheless, this method in combination with the ARIEMIS system provided the best estimate of the ship location.

\section{TRANSIT POSITIONING SYSTEM}

The method used to determine the TRANSIT position (GEOCEIVER STA 31370 ) is the most accurate satellite positioning technique presently available.

Error sources are reduced both during data collection and during postprocessing of the recorded values.

DMA places requirements on the collection of data that will minimize error. Por this study, only satellite passes whose maximum altitude ranged between $10^{\circ}$ and $80^{\circ}$ were recorded. Meteorological data (temperature, pressure, and humidity) were collected for each pass, and a deternination of the receiver clock drift was computed after each pass. The amount of clock drift as a function of time gave a real-time indication of receiver performance. Equipment checks were conducted routinely, and the results were included with the data package submitted to DMA. 


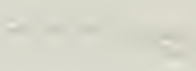


An error budget of the TRANSIT systell for point positioning is listed in Table VII. [Ref. 56] The precise ephemeris method of postprocessing accounts for all of these errors: 1) for each pass the tropospheric correction is computed fron the meteorological data; 2) the ionospheric correction is determined by observing the shift in frequency between the two transmitted frequencies; 3) the receiver clock error is known: 4) the satellite orbits are observed by the tracking stations so that precise satellite positions are known; 5) errors due to uncertainties in the geopotential model and surface drag forces are accounted for during computation; and 6) the receiver altitude relative to the ellipsoidal surface is computed approximately from the given MSL elevation.

The accuracy of the computed TRANSI position is stated as 1.5 meters per axis within a $90 \%$ confidence interval. This is assumed to provide the best estimate possible of the GEOCEIVER STA 31370 Ielative to the HGS-72 coordinate systex.

E. GPS ERROR SOURCES

Global positioning Systen error sources are separated into tro main categories, the space vehicle systam errors 

TABLE VII.TRANSIT System Errors

\section{SOURCE}

Uncorrected propagation effects

(ionospheric and tropospheric effects)

Instrumentation and measurement noise

(local and satellite oscillator phase jitter, navigator's clock error)

Uncertainties in the geopotential model used in generating the orbit

Incorrectly modelled surface forces

(drag and radiation pressure acting on the satellites during the extrapolation interval)

Uncertainties in navigator's al titude

(results in a bias in longitude)

Ephemeris rounding error
$\underline{E R R O R ~(m) ~}$

$1-5$

$3-6$

$10-20$

$10-25$

10

5 

and the GPS user receiver errors. There are seven possible sources of error in the space rehicle system--errors associated with satellite equipment, satellite clock, ephemeris, atmospheric delays, signal multipath effect, satellite update, and satellite propulsion firing. Table III lists these error sources and the approximate user equivalent range error for each. [Ref. 57]

The satellite equipment error, also termed the group delay, is caused by differences and uncertainties in processing and transmission of the message through the individual satellite's circuitry. Each satellite has the group delay calibrated prior to launch and this known group delay is included in the satellite time corrector within the navigation message. However, unknoun delays in signal processing and circuitry not accounted for by the corrector contributes an estimated one meter to the error budget.

Satellite clock error is caused by variations in each satellite clock. Satellite clock time may depart by up to 976 microseconds from the correct GPS time. Corrections for the predicted clock variations are included in the navigation message. Residual clock variations contribute to the error budget and are included in ephemeris erzors since 


$$
3-x-1-x
$$


the clock errors are small and have the same effect as ephemeris errors.

Ephemeris errors are the result of satelite clock variations, drift by the monitor station clocks, monitor station signal processing delays. lack of precise nonitor station geodetic positions, solar yind and pressure paraneter variations, and earth gravity model error. These sources all contribute to the ephemeris error buaget. The ephemeris error budget is monitored over long time periods and translated by the Master control station into an Oser-Equivalent Range Error (URE). When the URE exceeds the prescribed value of 4 meters the satellite ephemeris data is uploaded to zeduce the URE. [Ref. 58] Most of the ORE is included into the user clock corrector obtained in the GPS position computation. Howerer, not all of the ephemeris error is removed during the position computation, and the Iesidual error has been estimated to be approximately 1.5 meters. See rable III.

Atmospheric delays in signal propagation are the Iesult of tro effects, ionospheric delay and tropospheric delay. of these, the ionospheric delay. which depends on the frequency of the transmitted signal, is greater. Nith the 


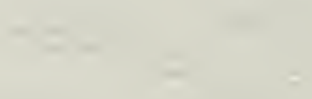


two frequencies, I1 and L2, transmitted by each satellite to the user receiver, the ionospheric propagation delay can be modelled. Osing this model, the majority of the propagation delay is accounted for, but a residual delay results in an error. The other part of the atmospheric delay error defends on the tropospheric propagation delay. propagation delay in the troposphere is a function of signal path length through the layer, the receiver air temperature, and air pressure and humidity. Since the tropospheric delay is not a function of frequency and is highly localized, the tropospheric delay corrector has not been incorporated into the atmospheric correction computation and is therefore an aditional source of error. These two error sources combine to yield an atmospheric delay error estimated to have a magnitude of between 2.4 to 5.2 meters.

Ionospheric scintillation of the GPS signal, in addition to the ionospheric propagation delay, cause errors in positioning. Scintillation has the effect of random interference with the propagated signal as the signal is transuitted through the upper ionosphere. [Ref. 59] Interference caused by scintillation combines with the GPS user raceiver processing noise to cause a random ranging 

error and, if the interference is severe, interruption of the pseudo-random number binary code causes loss of signal. Errors and signal losses caused by scintillation cannot be predicted or estimated.

Signal multipath errors result from the reception of a satellite's signal transmitted via different propagation paths. Received signals thus may have been distorted or reduced in strength to a sufficient degree so as to affect the range determination from the satellite. Error due to multipathing is highly localized and cannot be modelled. Estimates of the error magnitude are between 1.2 and 2.7 meters.

The last two space vehicle system error sources are attributable to the Master Control station (MCS) satellite accuracy and maintenance functions. Usually the Mcs uploads each satellite at a given time each day and the ephemeris data is changed(Table VIII). Should the user not be aware of occurrence of upload and if the receiver therefore does not obtain the new ephemeris data, ranging to the satellite in question will contain a possibly very large erzor. In addition, if the MCS, through the Remote stations, determines that the four skewed reaction wheels cannot 



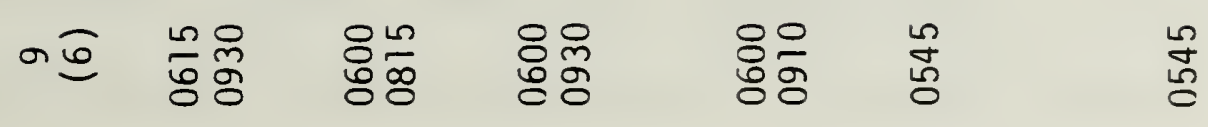

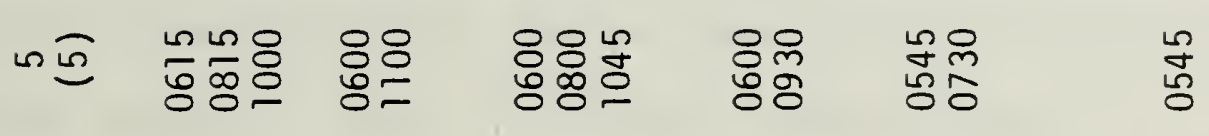

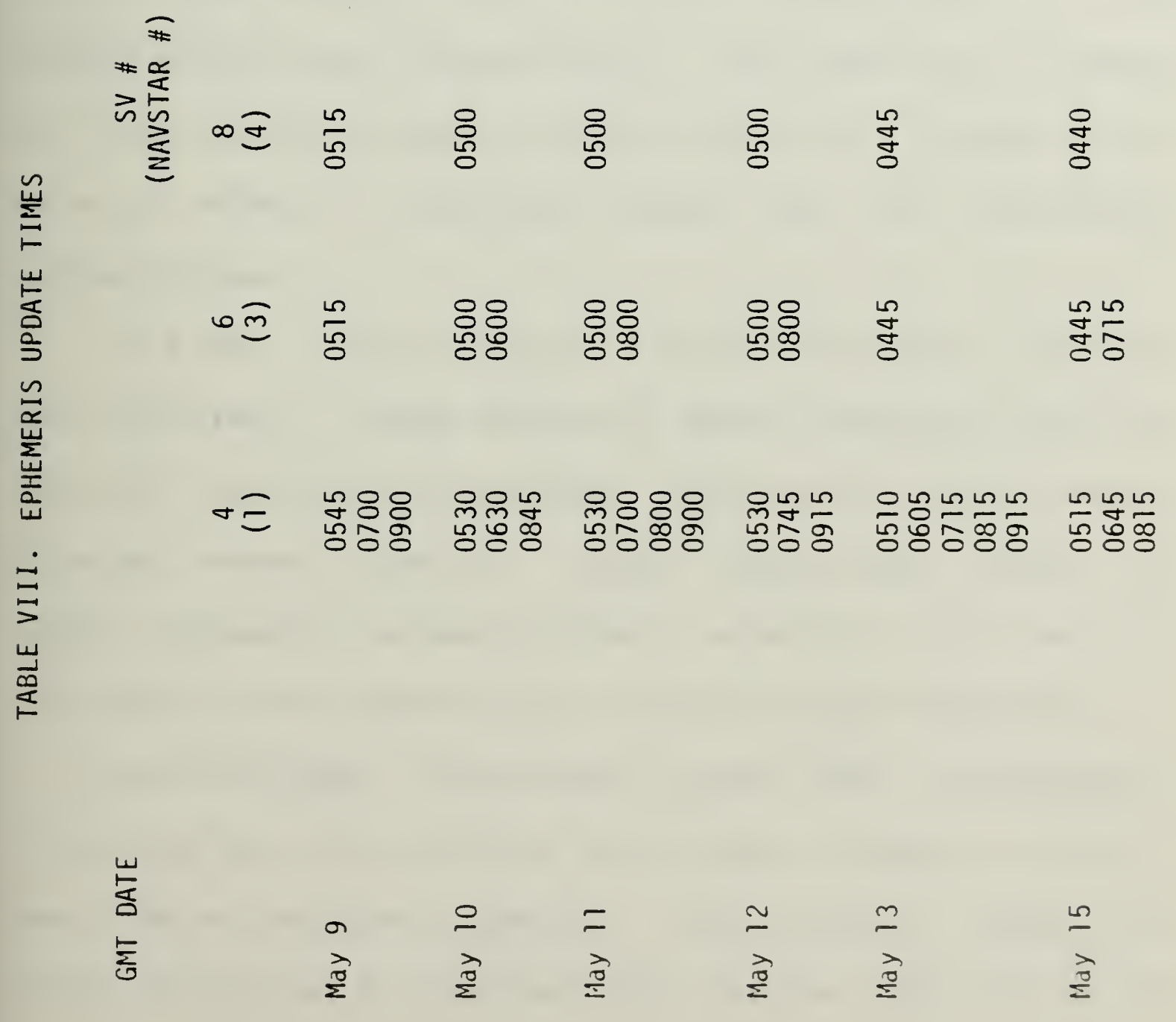



maintain satellite antenna alignment with earth, the hydrazine propulsion system is activated and the satellite is rotated. Once the propulsion system has used, the satellite orbit cannot stabilize immediately, and the ephemeris data will be inaccurate. A period of up to several hours may be required for orbit stabilization and for the new ephemeris data to be computed and uploaded. During that period, the ranging computations to the satellite will have large errors. The magnitude of these tyc error sources cannot be estimated but is assumed to be several orders of magnitude larger than the previously stated errors.

The second error category is that related to the GPS user receivers. These sources of error associated with the user GPS receiver, the Manpack, are receiver signal noise, receiver vessel velocity, signal resolution, method of signal processing, ephemeris update capability, and, for the differential GPS computations, system accuracy comparison.

Received signal noise errors result from interference introduced into the receiver GPS signals through processing and internal receiver circuitry. Additionally, quality of signal resolution is dependent upon receiver type and can be 

a source of error. The combined errors from these two sources are estimated to be 1.5 meters. [Ref. 60] Estimates of these error sources for the MvUE have not been made but are estimated to be of the same magnitude.

Velocity of the receiver vessel results in GPS errors of varying magnitude. The higher the velocity, the larger the error. This error is due to the time lag required to obtain and process each NAVSTAR satelite range with the MVOE siagle channel receiver, to compute the average vessel velocity and to use the average velocity for positional computations. The Manpack requires a six second time interval to obtain and process the pseudo-range from each satelite used. Thus the fix position is an extrapolation of the four satellite ranges to obtain a convergent fix position. At one knot, the vessel travels 0.51 meters in one second. During the full twenty-four seconds required to obtain four satelite ranges, the vessel would have travelled 12.24 meters. With the vessel travelling at four kncts, the distance travelled during the total time interval required for a GPS fix position would be 48.96 meters. Processing the pseudo-ranges from four satellites reguires the solution including the average vessel velocity during 
the 24-second ranging period. Ose of this average neglects the relative velocity of the receiver antenna which is mounted on the mast. During this test, the GPS antenna was mounted 9.06 meters above the waterline of the $R / V$ ACANIA. Assuming fire degrees of pitch and $=011$ and a vessel roll period of 15 seconds, relative average antenna velocity was 0.16 meters per second. The antenna velocity error translates in to a random error of 0.16 meters. The other velocity errors have not been estimated but are assumed to be less than one meter for the low vessel velocities used in the test.

one error source mentioned previously requires further clarification: error due to the relative position at the time of the fix. The Manpack requires up to twenty-four seconds to obtain and process the satellite ranges. The position of the fix and the associated time of fix are then recorded. However, the time of the fix may not have been the same time the computational results were printed. Thus the output position may not have been correlated with the correct theodolite computed ship position since the theodolite lines of position were observed when the GPS position was printed. Errors from this bias source may 

Iange from 12.24 meters at one knot of vessel velocity to 48.96 meters at four knots. This erfor varied with the processing time required to obtain a convergent position. An estimate of this error magnitude was not made because of its wide variability.

The type of receiver and the method of signal processing also contributed to the error. ultichannel receivers designed for phase I testing have a lower magnitude error for satelite signal reception and processing than do the single channel receivers, such as the Hanpack. In the multichannel receivers, four or more satellite pseudo-range data are taken simultaneously. The single channel receiver sequentially receives each satellite and computes the pseudo-range data. Simultaneous data reception reduces the user velocity error and therefore has less position aliasing than that found in the single channel receivers.

The method of signal processing may induce positional errors through the use of non-optimal weighting functions in the position computation. Should the ephemeris or Ianging data change significantly, as happens during uploading, signal processing using kalman filters as used in the ilanpack do not change the computed position rapidly enough 
to reflect the large changes in $r$ anges and result in a slow change drift of the GPS position. Estimated time requirements for user receivers to stabilize after an upload are up to two hours. [Ref. 61]

The capability of the user GPS Ieceiver to receive ephemeris data immediately after upload reduces the ephemeris errors caused by using an outdated ephemeris. The ephemeris data is repeated every thirty seconds and its length requires sections of two message subframes. [Bef. 62, 63]. The use of current ephemeris data in the computations reduces the error for the ephemeris to the value shown in table III. The Manpack has the capability to accept ney ephemeris data immediately, but during the test large errors were introduced into the computation on satellite ephemeris upload because this selected optional function either did not operate properly or was neglected by the operators.

Por the differential GPS user, an additional error source is introduced into the error budget: the assumption that both GPS receivers will observe, obtain the pseudo-ranges, and compute the position solution in exactly the same manner. If this were true then both receivers 

should be able to compute the identical position if placed at the same position at the same time. Hith the Manpacks, the assumption that the units were identical and the position solutions were identical was not made because prior testing established that the receivers differed in position computations by as much as 3.08 meters. [Ref. 64]

For the static testing on 11 May. one error source not previously discussed was the vertical separation of the two Manpack antennas, colocated over the GEOCEIVIR STA 31370 control station, and the possible interference of the uppermost antenna, System 1, with the GPS signals received by the lower system 2 antenna. Separation of the two antennas was 2.1 meters. Calculations using the speed of propagation in a vacuum and the two GPS frequencies produce vave lengths of 0.19 meters and 0.24 meters. Since separation of the antennas was much greater than either varelength theoretically there should have been no positional errors due to antenna interaction or interference. Differing elevations of the antannas above the ellipsoidal surface also may have induced errors in the position computation. Estimated errors for the elevation differences are less than 0.1 meters. Total errors for the 
antenna vertical elevation separation and antenna interference or interaction have not been estinated.

Thus, the error budget for the Global positioning system suggests a combined error of up to 57.35 meters. Using the differential technique, the bias errors can be reduced in magnitude or eliminated. These bias errors include ionospheric propagation delays, tropospheric propagation delays, variations from predicted ephemerides, and satellite clock perturbations. Teasley, Hoover, and Johnson (1980), evaluated the error budget for a more 3 dvanced GPS receiver and found the predicted filtered solution error was reduced from approximately 11 meters to approximately 3 meters with differential GPS processing. [Ref. 65] Error budgets for the Manpack and the differential correction vector processing method used in this test did not attain the four meter accuracy but were not expected to because the receivers used were less accurate, and of different types. 



\section{RESULTS}

Results of the GPS tests have been separated into four sections: stationary GPS evaluation, evaluation of nondifferential GPS, differential GPS evaluation with static correction, and evaluation of differential GPS without static correction. Tables IV and VIII list the optimum satellite observation periods and the NAVSTAR upload times for each day of the testing period.

A. STATIONART GPS EVALUATION

Stationary GPS receiver evaluation was separated into the stability tests, the static tests and the tests of the stationary GPS receiver used during differential testing. Pigures $7.1,7.2$, and 7.3 illustrate the results for the stability test conducted on 9 and 10 May. The receiver vas less stable than expected and depended to a great extent on the VATSTAR uploading times and the URE of NAVSTAR 1 (fig. 7.4 and 7.5). Correlation between tines for the NAVSTAR upload and changes in the stability can be observed at 0620 on 9 May (fig. 7.1), 0655 on 9 May (fig. 7.2), 0815 on 10 May (fig. 7.3), and 0845 on 10 May (fig. 7.3). The Iflationship betreen stability and URE is illustrated by comparison of the URE fOr NATSTAR 1 at 0640 on 9 May (fig. 



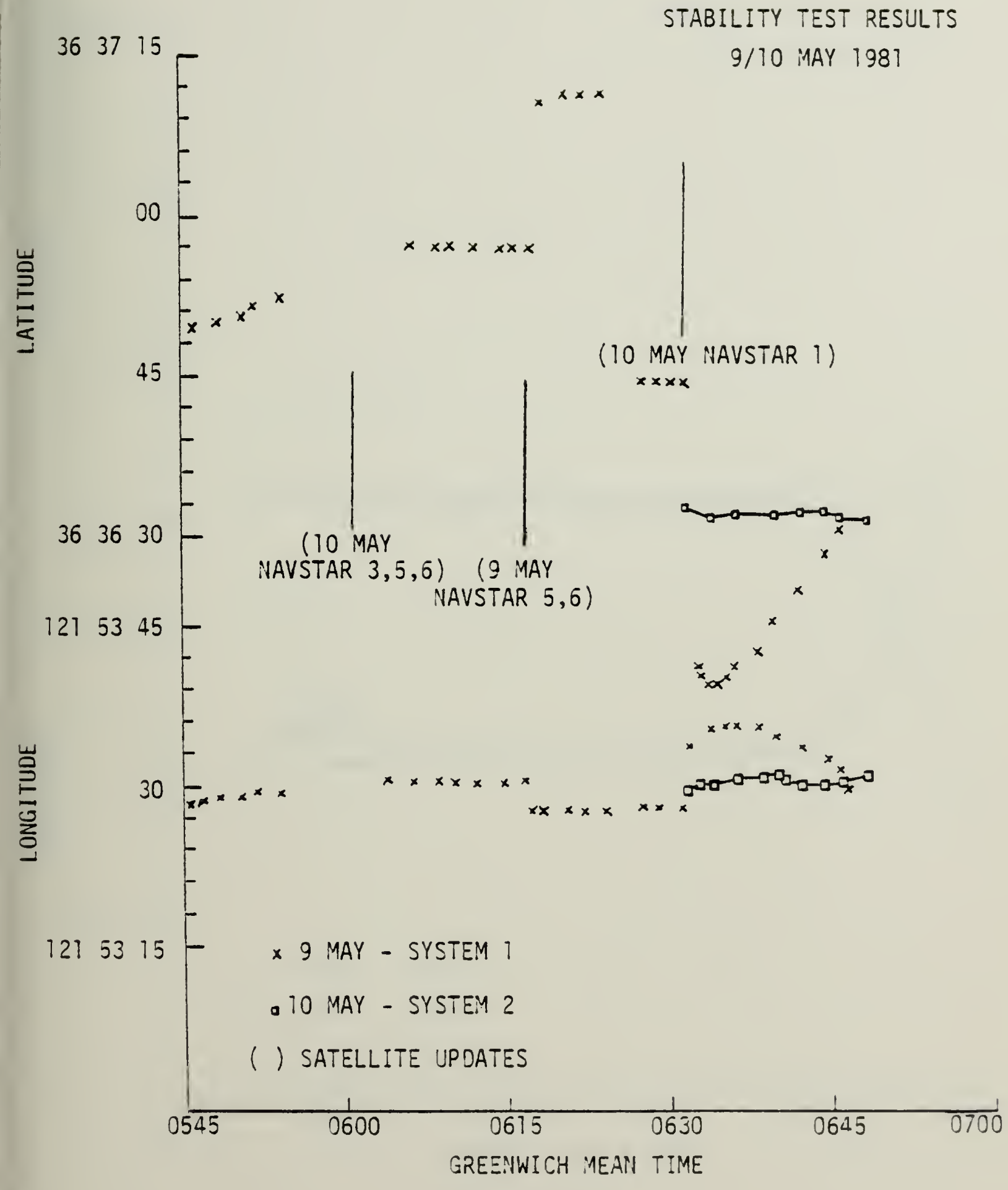

Fig. 7.1. 
$-$ 


$36 \quad 3715$

崖

$1215315-$

12153

363630
STABILITY TEST RESULTS

9/10 MAY 1981
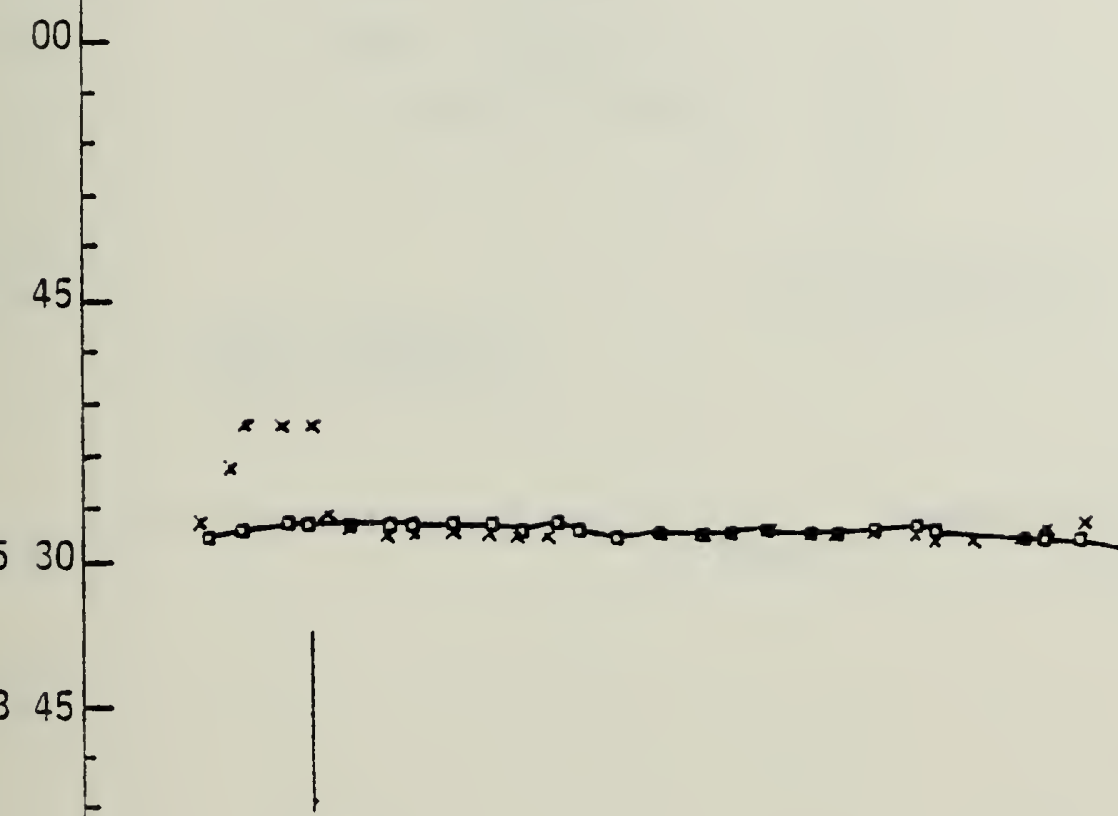

(9 MAY

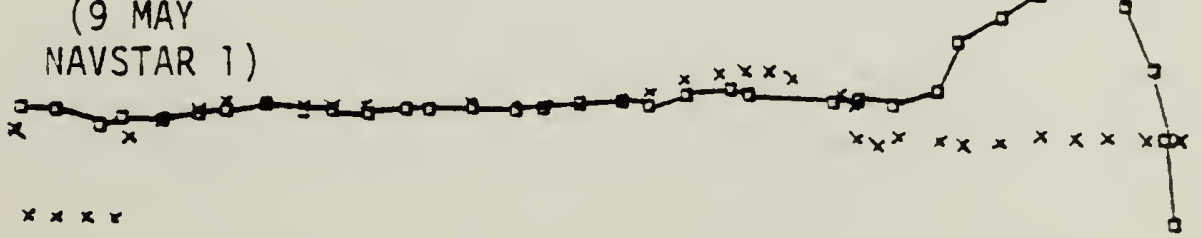

NAVSTAR 1)

* 9 MAY - SYSTEM 1

- 10 MAY - SYSTEM 2

( ) SATELLITE UPDATES

\begin{tabular}{ccccc}
\hline & 1 & 1 & 1 & 1 \\
0645 & 0700 & 0715 & 0730 & 0745
\end{tabular}

Fig. 7.2. 



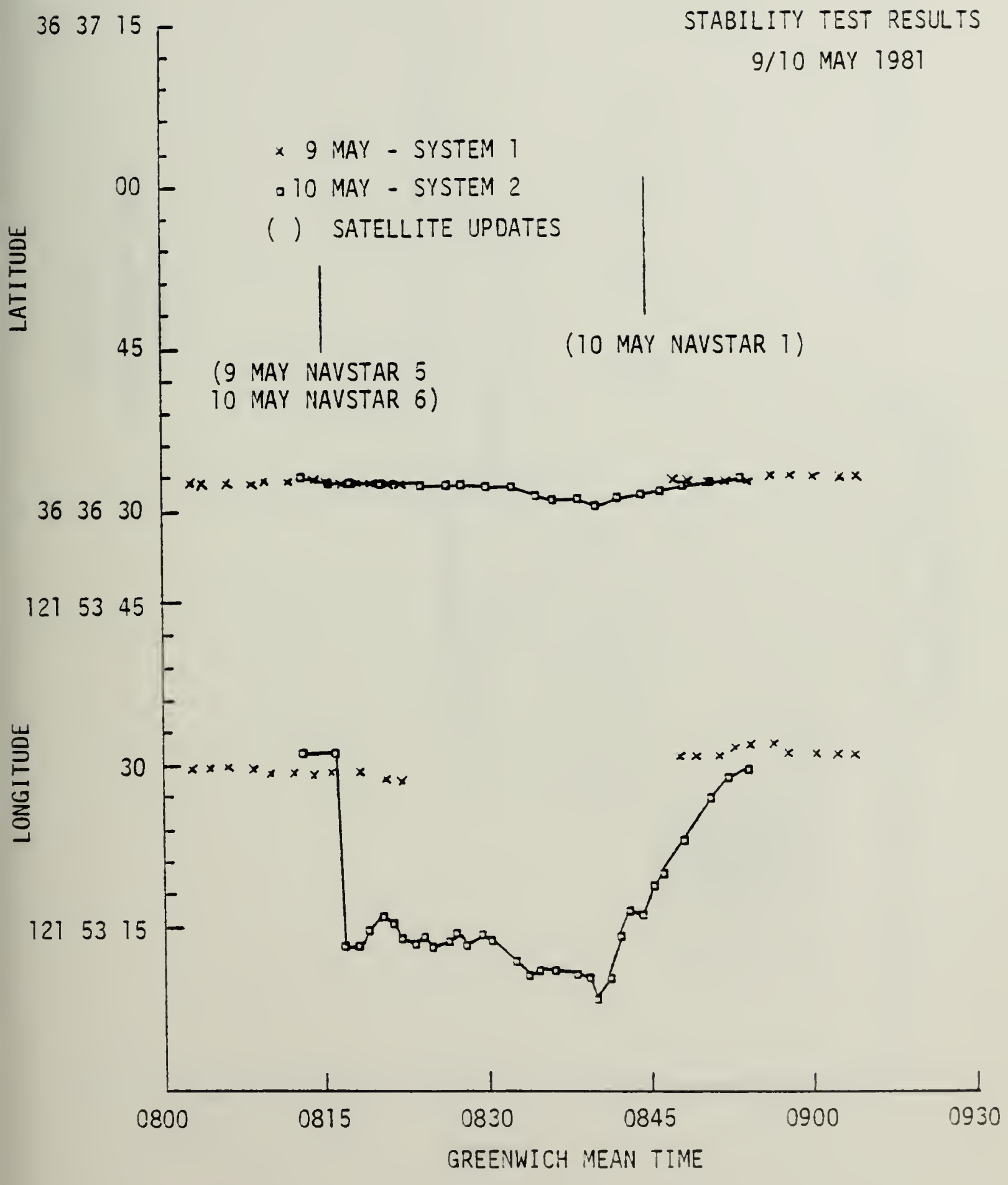

Fig. 7.3 . 


$$
=
$$



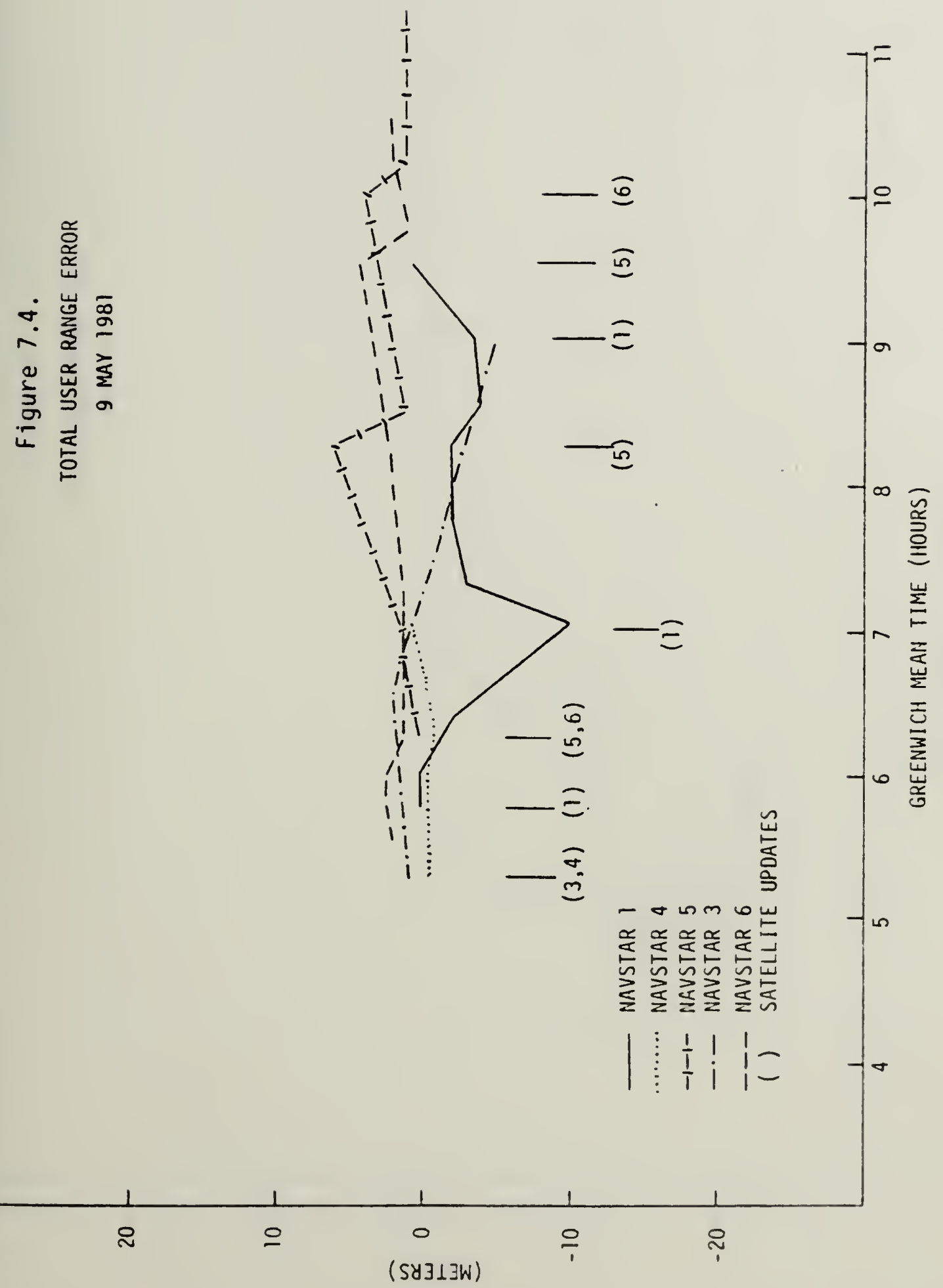



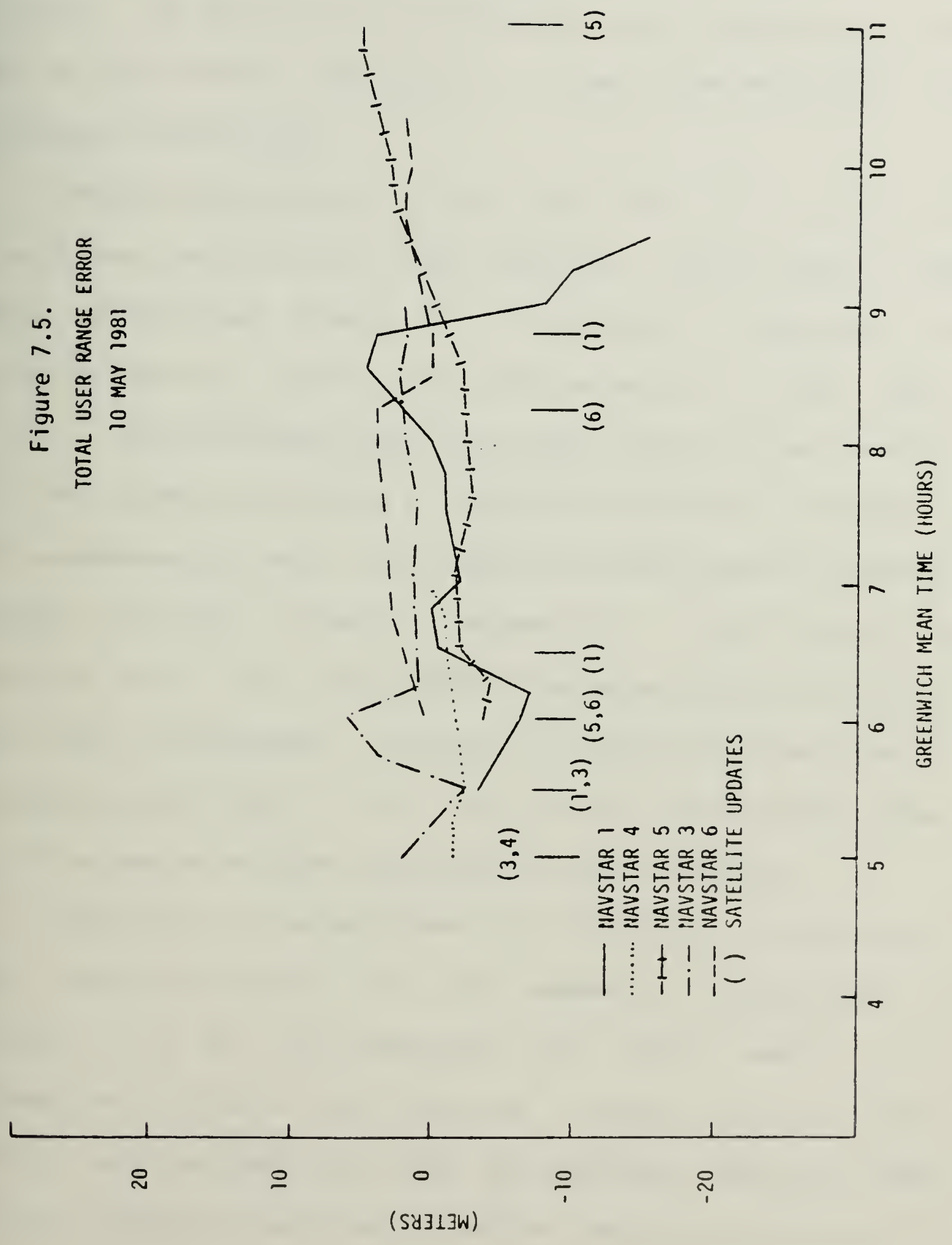



7.4) with the stability plot on figure 7.1 for the same time period. On figure 7.2 the stability plot variation at 0745 on 10 May remains unexplained but may have been due to a receiver malfunction.

Results for tests on 11 May (fig. 7.6, 7.7, and 7.8), exhibited less stability than expected. Also, system 2 was less stable than system 1 . The largest difference in reading between the two receivers occurred at 0750 (fig. 7.7). This difference may have been caused by the location of the antenna of system 2 under the antenna of system 1. At approximately 0800 , the satellite constellation elevation angles were the largest, between $56^{\circ}$ to $80^{\circ}$ above the borizon (fig. 7.9), and antenna interference may have led to the large differences. Neither the satellite constellation azimuth angles (fig. 7.10) nor the user range errors (fig. 7.11) appeared to have any effect on the stability.

Comparison of the stationary GPS receiver positions with the position obtained with the geoceiver is depicted in figure 7.12 for the stability and static tests. The comparison indicates that there is a nearly constant offset of the two positions with the GPS position almost due south of the geoceiver position. Purther comparisons between the 
$--1=$ 
- SYSTEM 1

- SYSTEM 2

( ) SATELLITE UPDATES
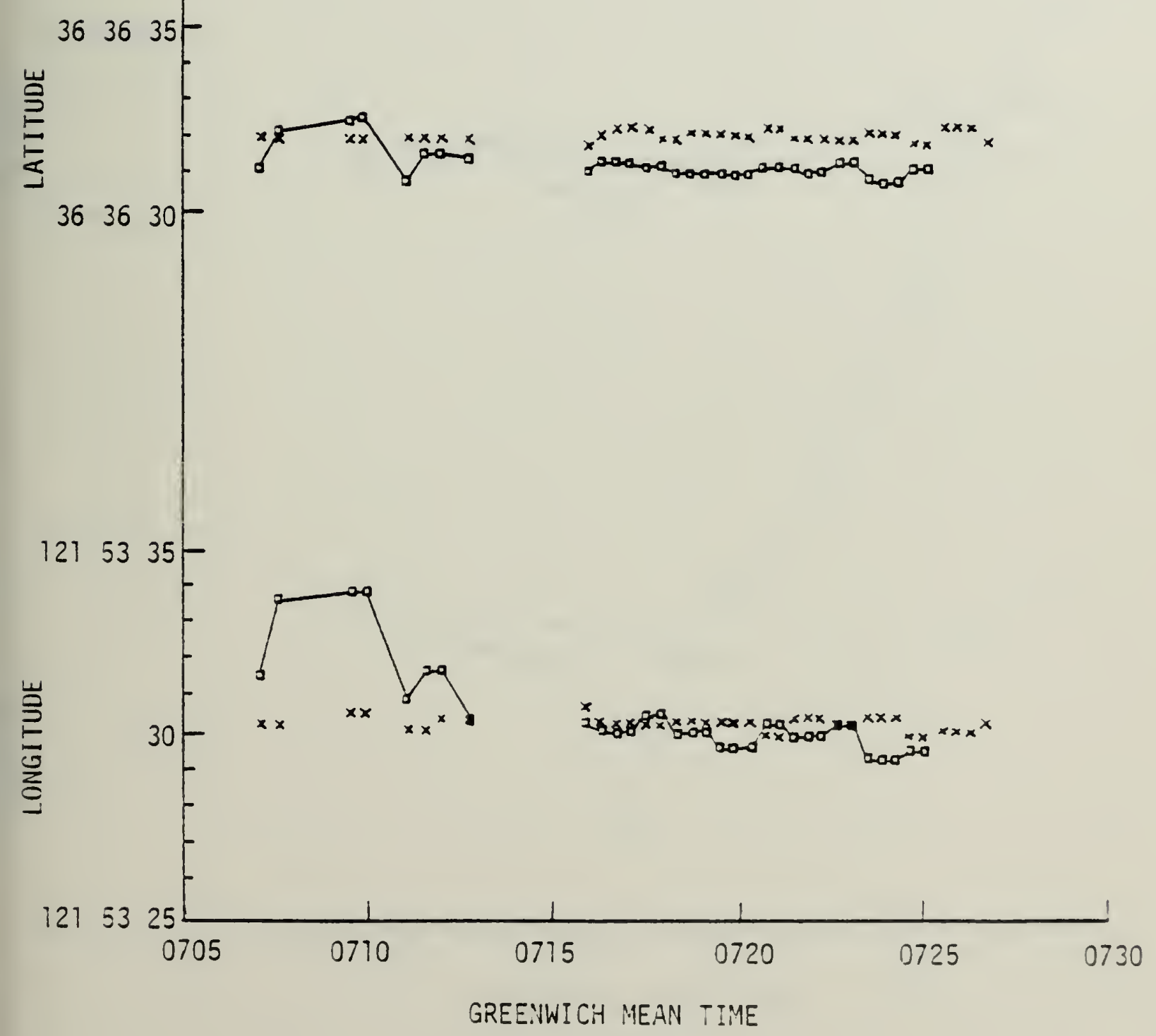

Fig. 7.6.. 


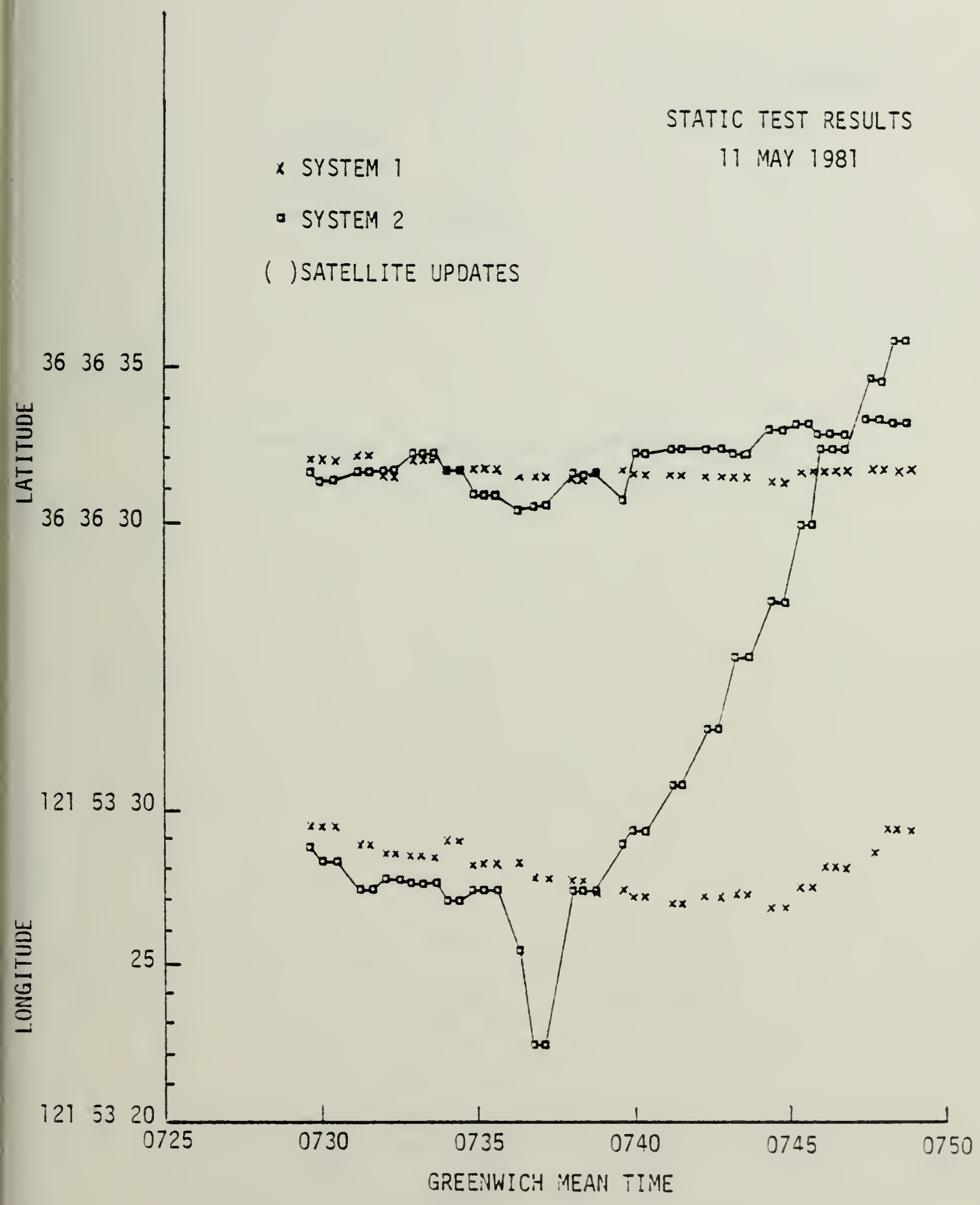

fig. 7.7 . 


\section{STATIC TEST RESULTS}

* SYSTEM 1

11 MAY 1981

- SYSTEM 2

( ) SATELLITE UPDATES

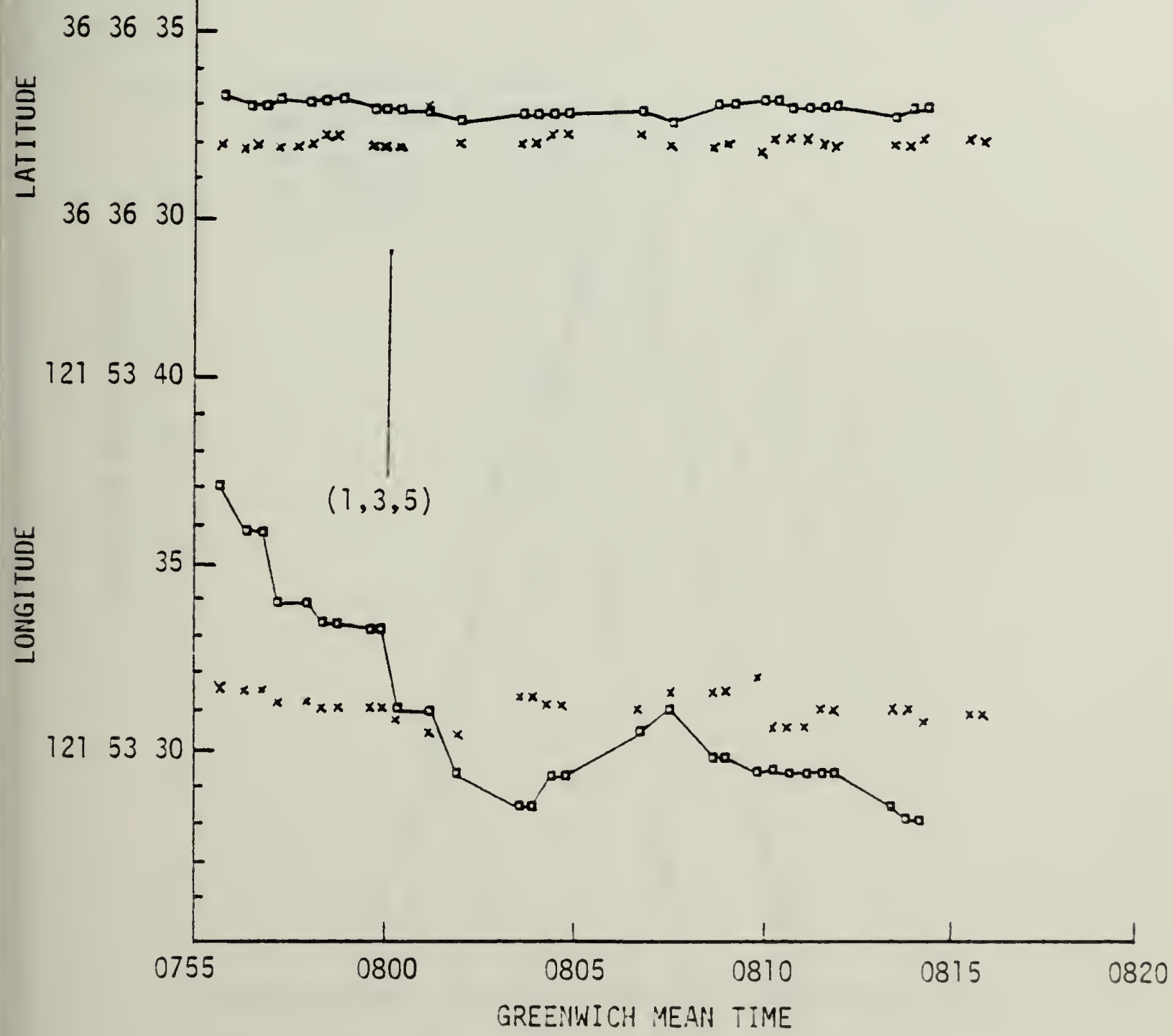

Fig. 7.8. 



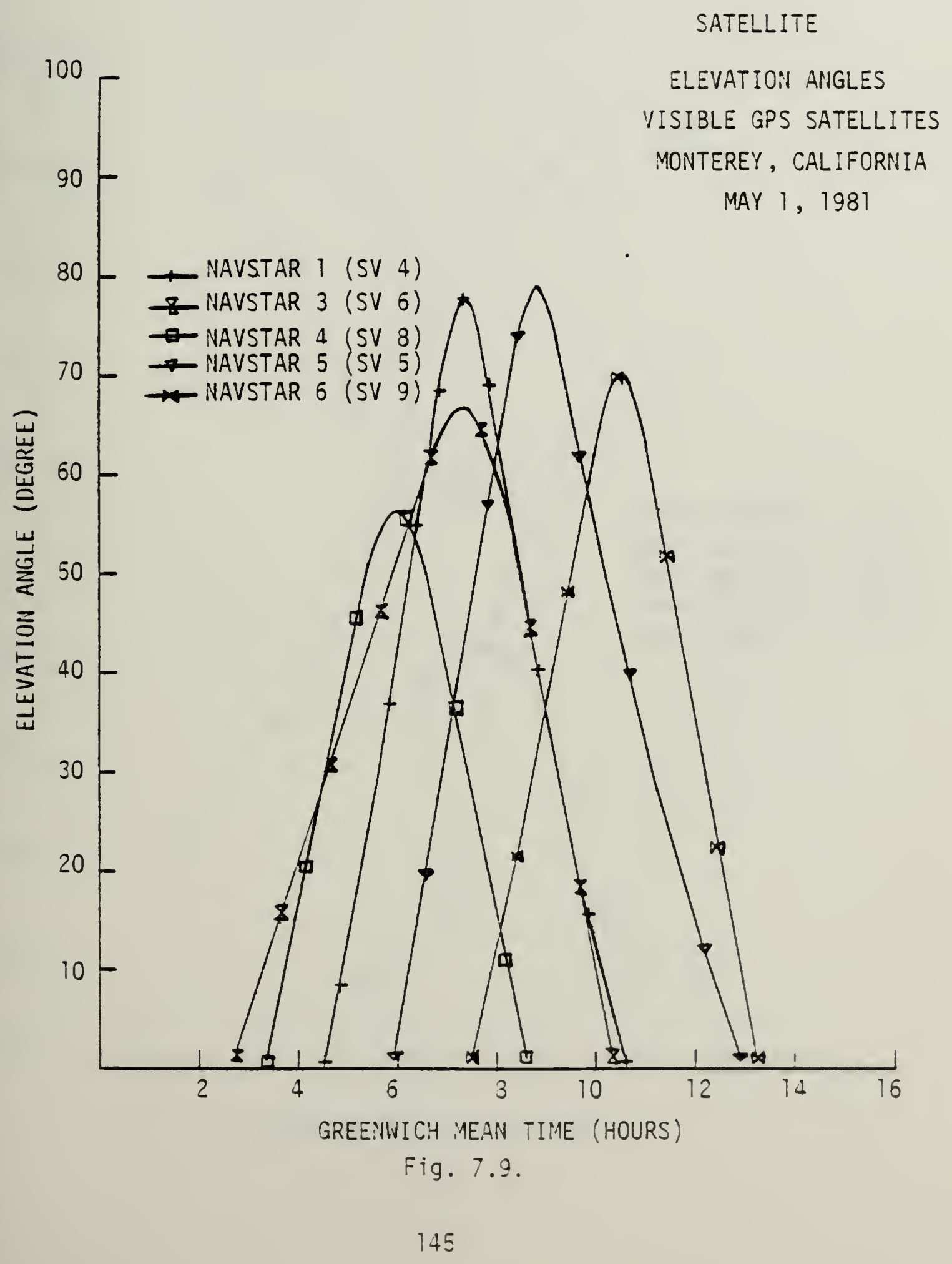





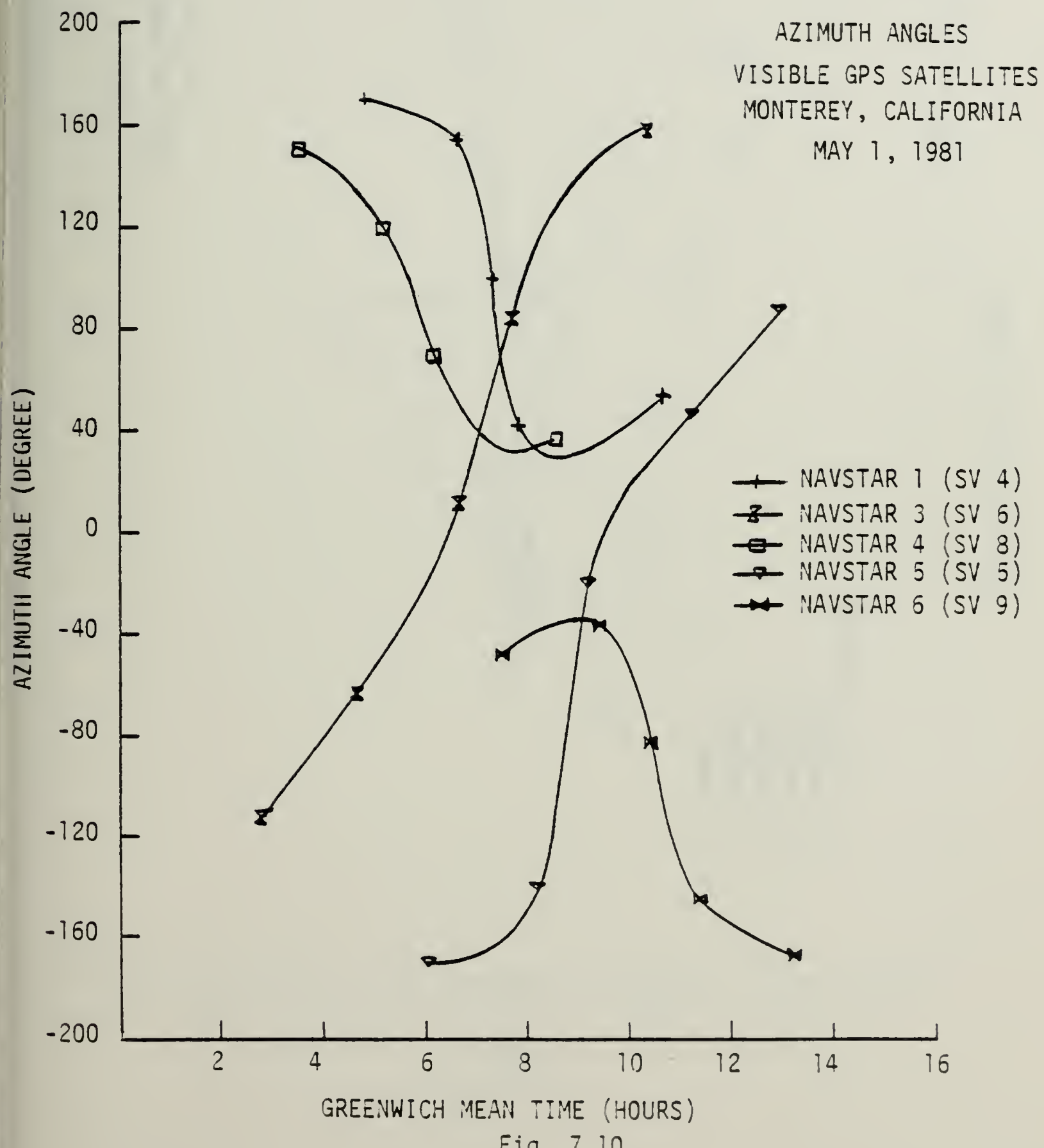

Fig. 7.10. 



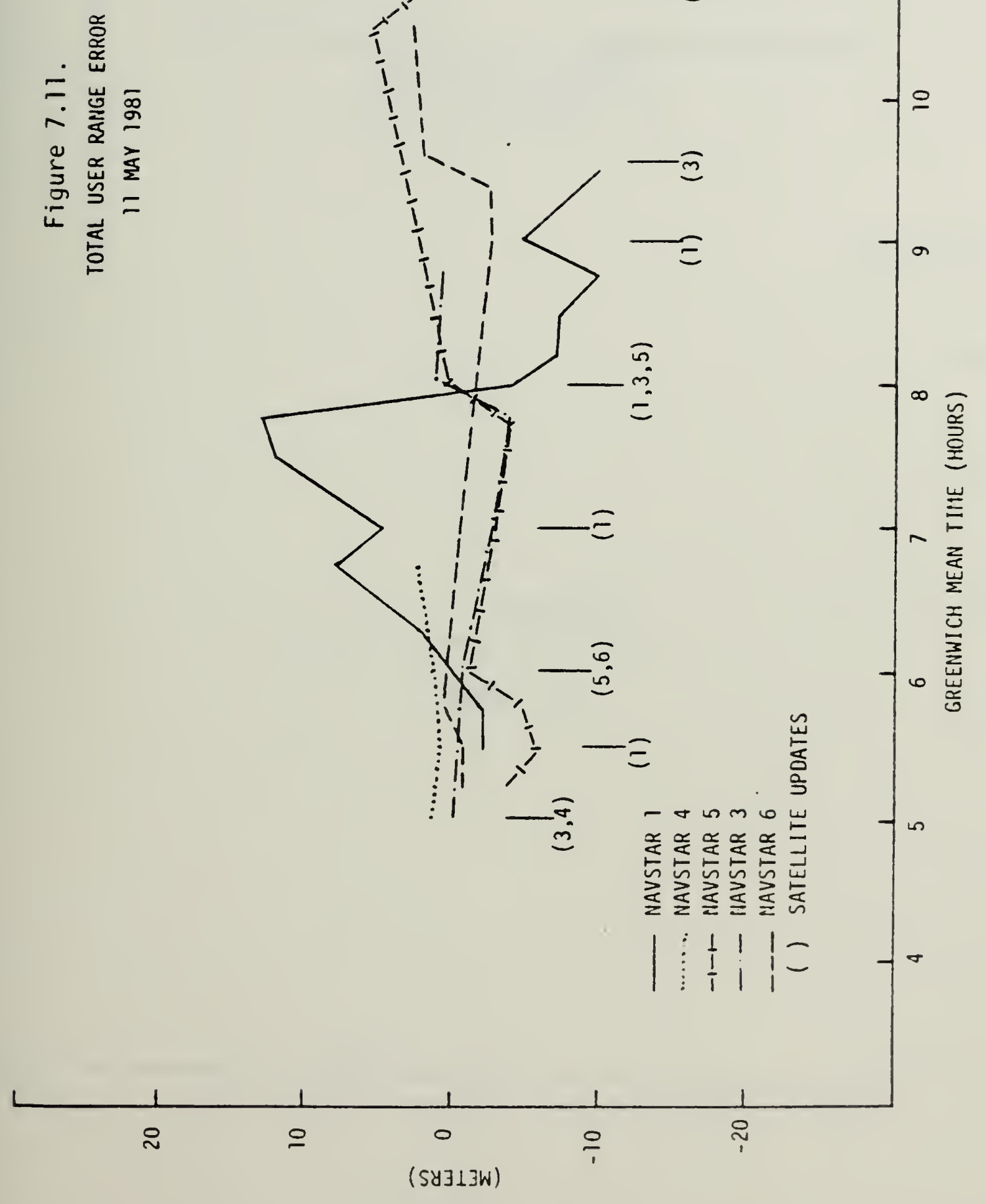



GEOCEIVER VS. GPS POSITIOH COMPUTATIOH
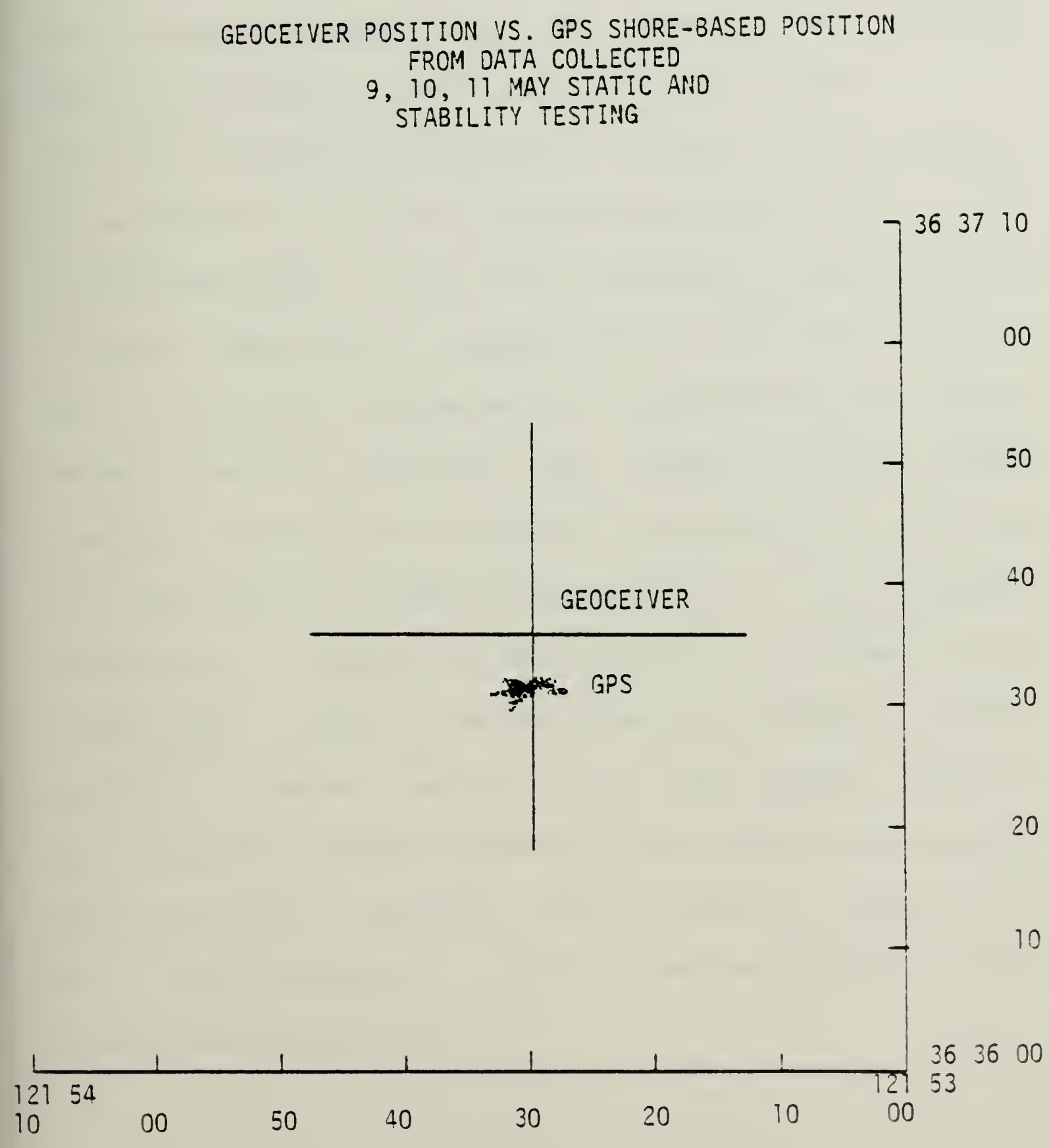

Fig. 7.12 . 

stationary GPS receiver position and the geoceiver pcsition reinforce this conclusion. In figures $7.13,7.14$, and 7.15 , the mean distances between the two positions are 127,173 and 143 meters, respectively. The higher means for the data shown in figures 7.14 and 7.15 are due to the URE (fig. 7.16 and 7.17) for those dates and the NATSTAR upload frequency. If the data from 13 May is deleted because of the high ORE for that date (fig. 7.16), and the median distance used for 15 May is taken to be a representative value (130 meters on fig. 7.15), The difference is approximately 128 meters Between the two positions. The azimuth was also nearly constant with the observed median values of $181^{\circ}, 207^{\circ}$ and $178^{\circ}$ from south as shown in figures $7.18,7.19$, and 7.20 respectively. Neglecting the data on 13 May because of ORE values (fig. 7.16), the remaining two values are nearly identical and have a mean of $179.5^{\circ}$ from south. Thus the data indicates a nearly constant offset between the position obtained with the geoceiver and the position obtained with GPS. This difference is about 130 meters and has an almost north-south orientation. 

Figure 7.13.

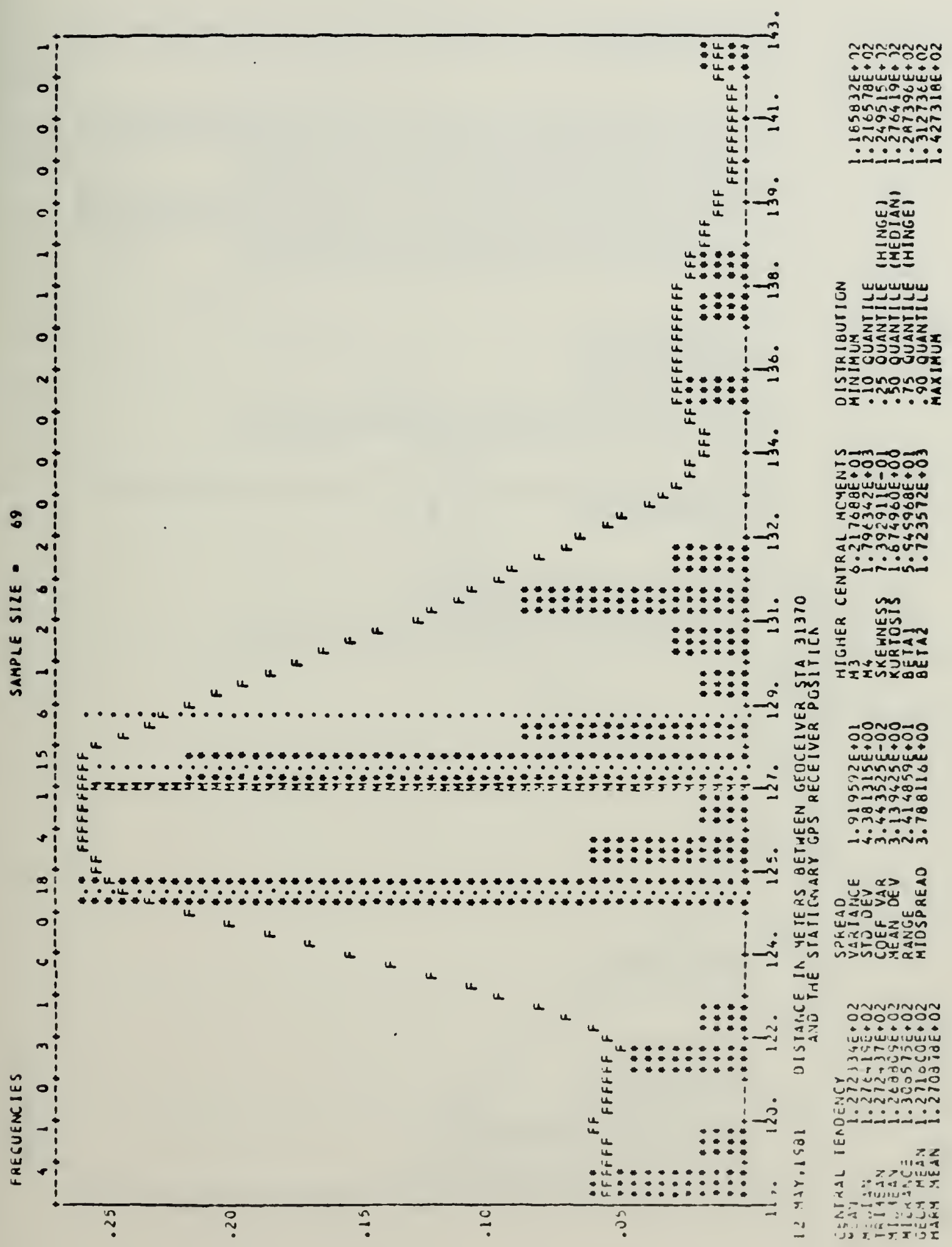



Figure 7.14 .

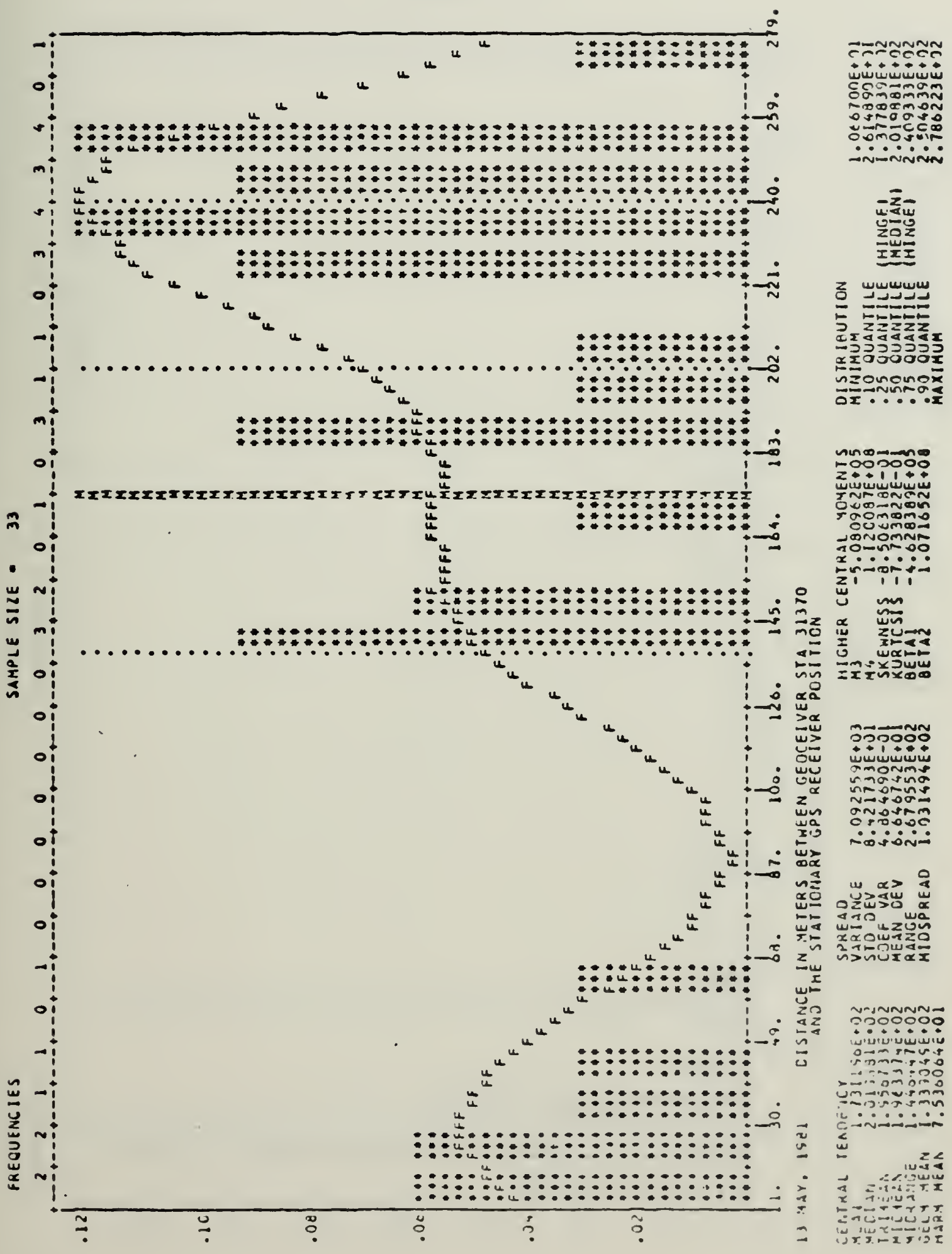


Figure 7.15.

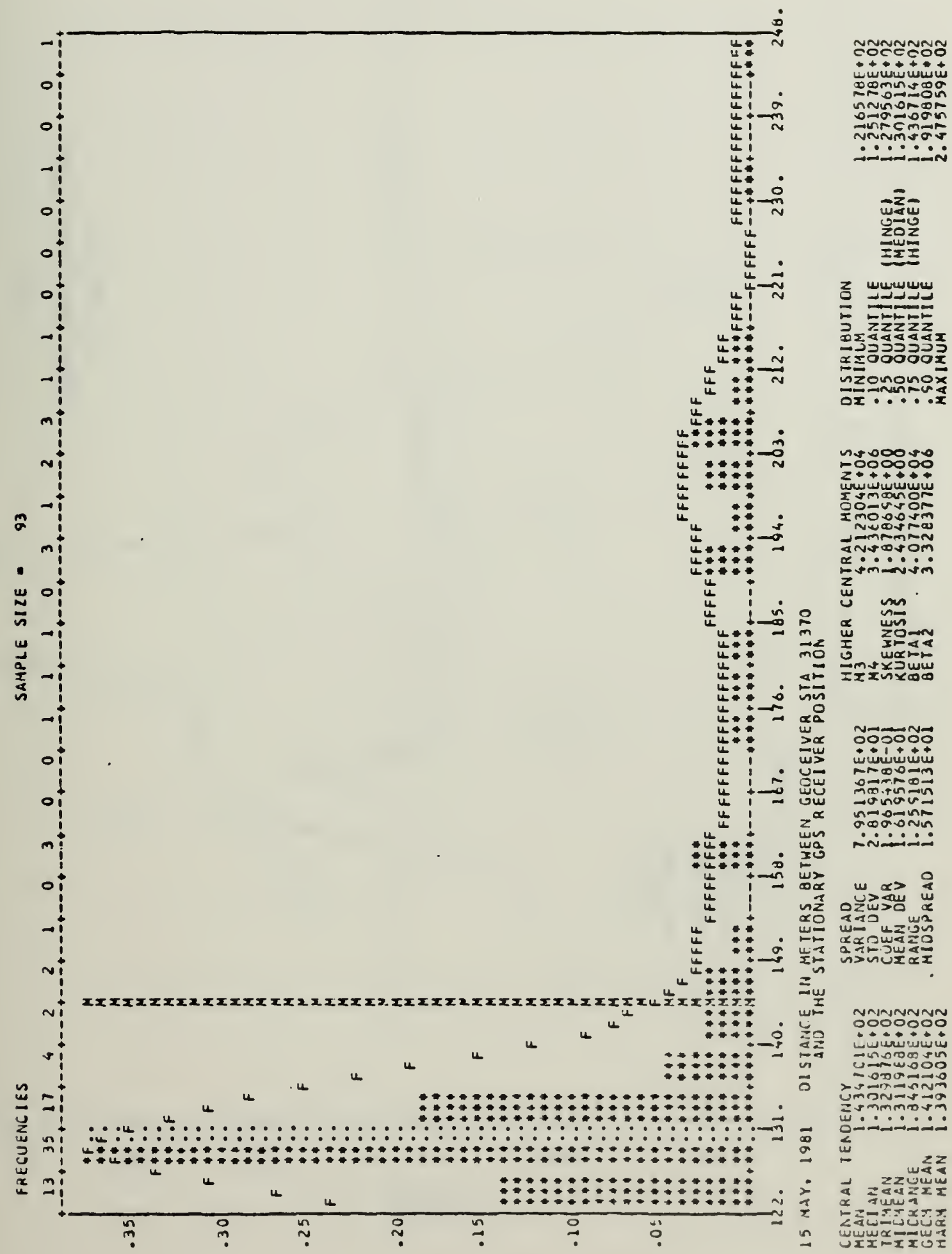





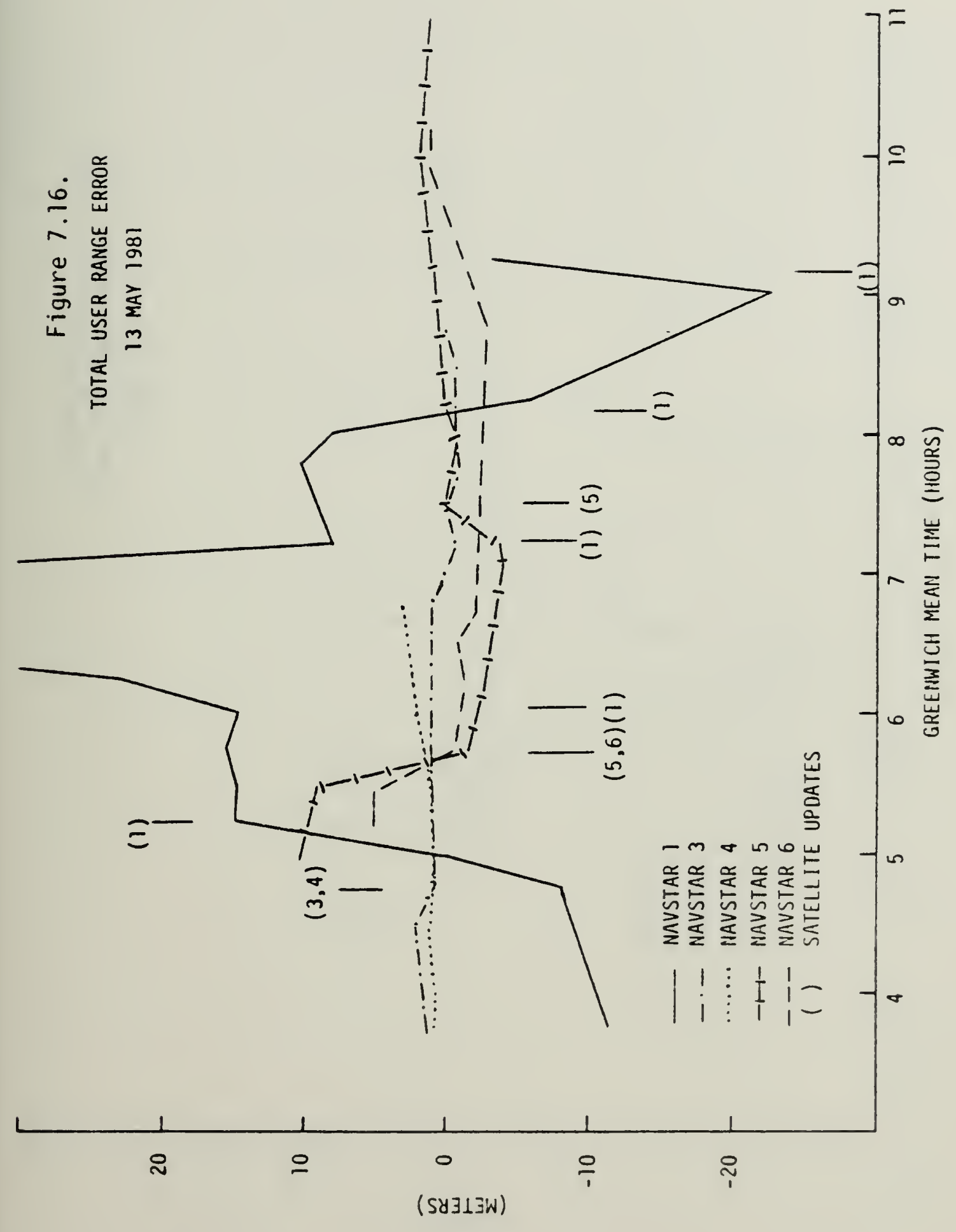



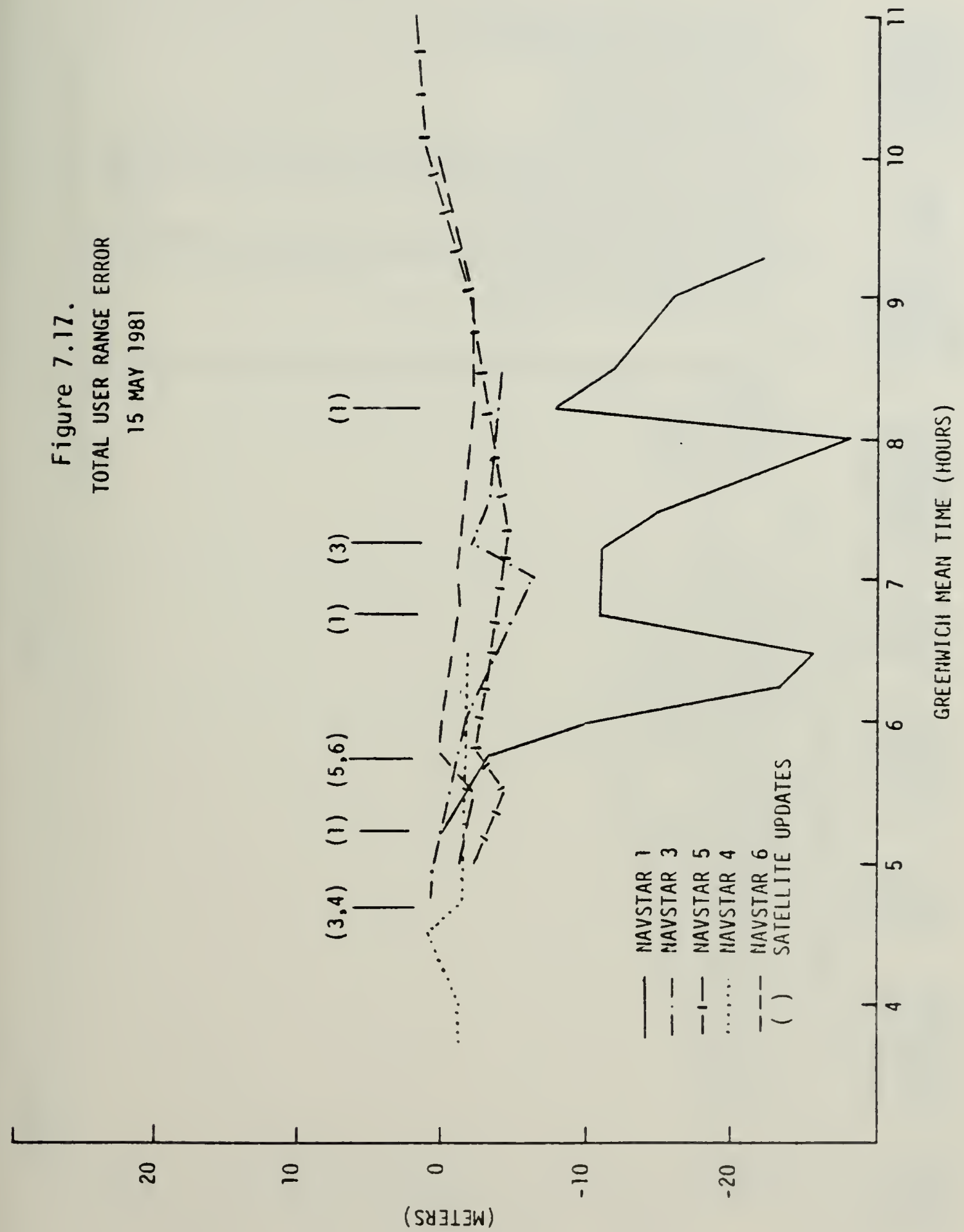


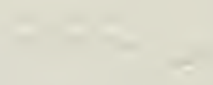


Figure 7.18 .

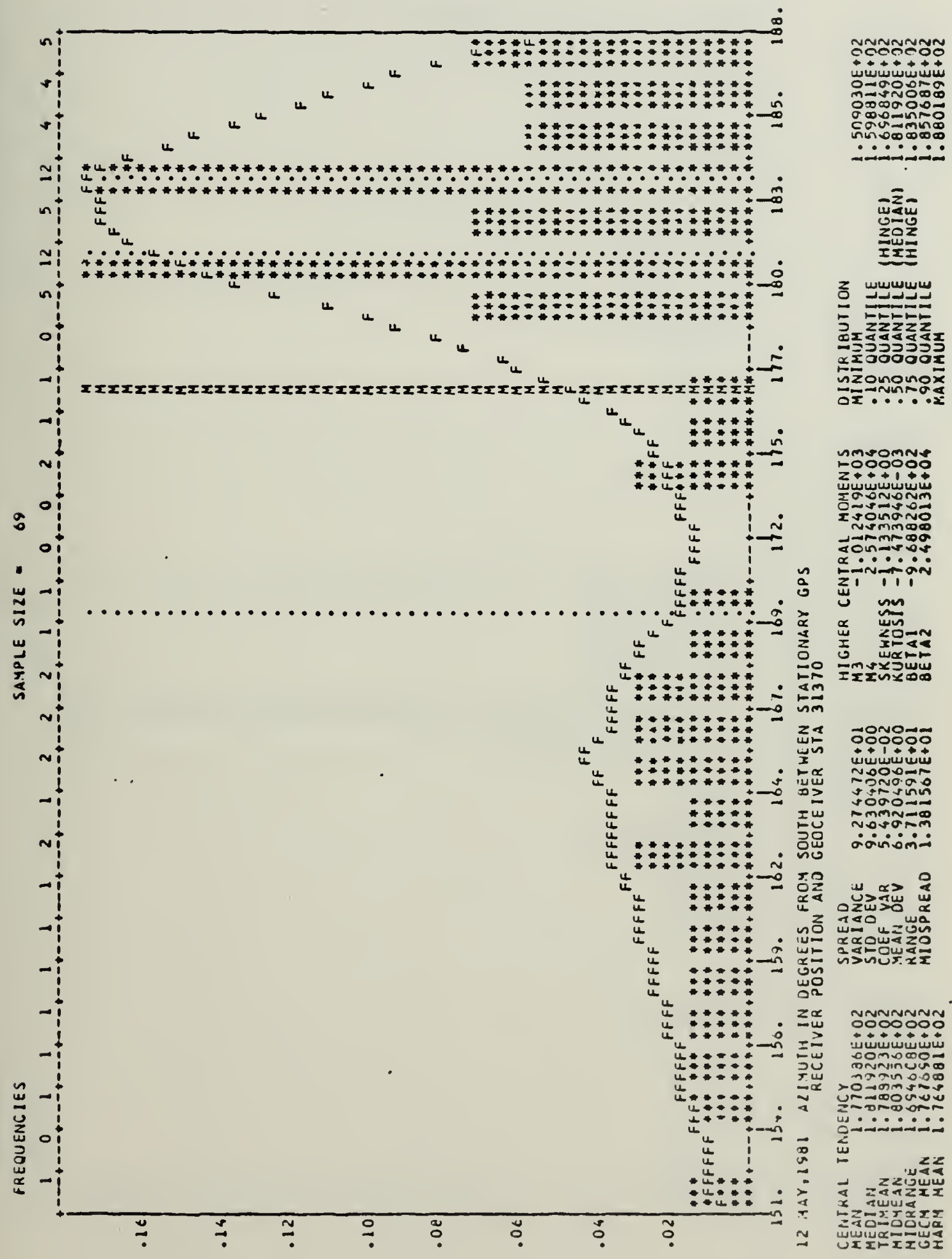



Figure 7.19.

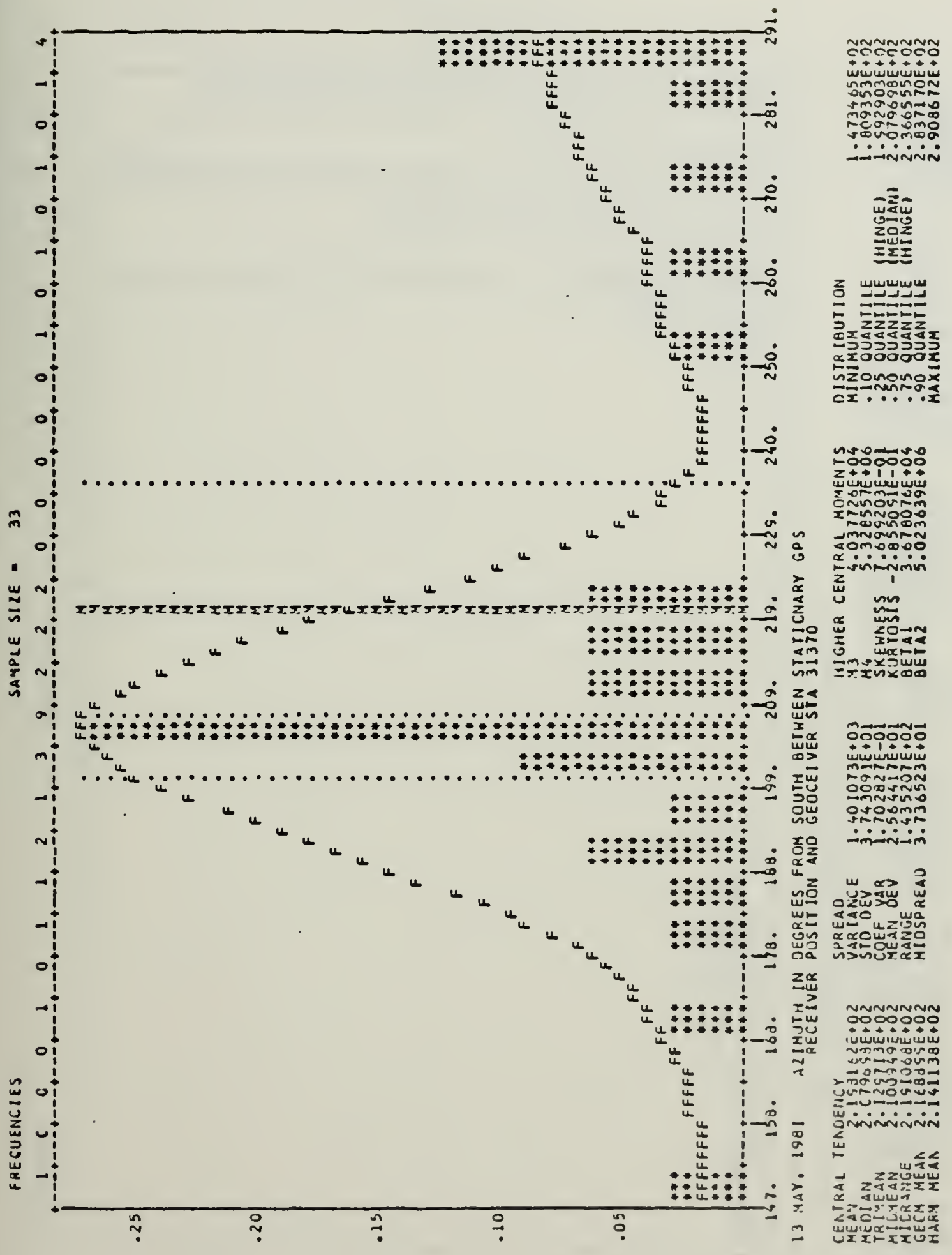



Figure 7.20 .

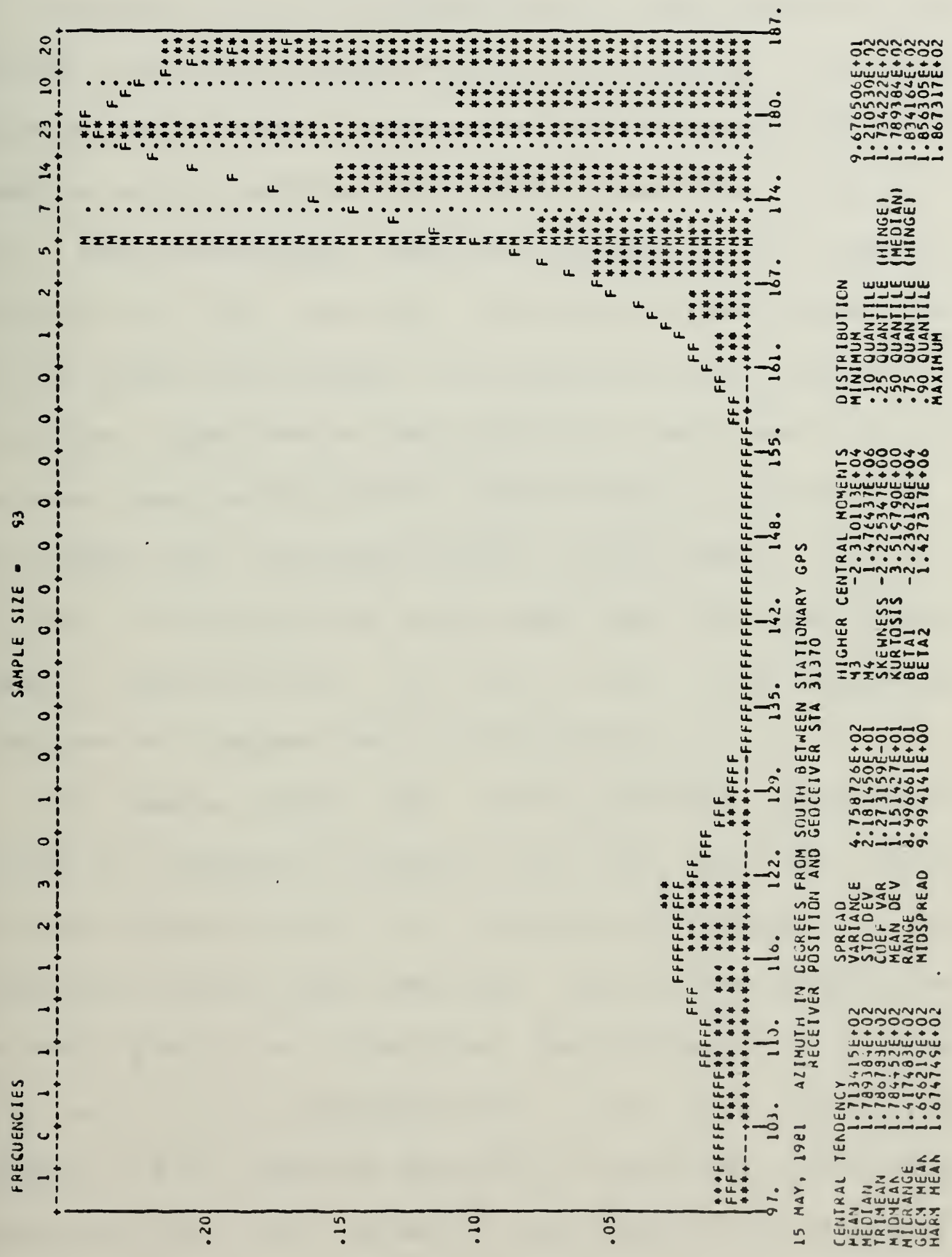





\section{B. ETALJATION OP NONDIFFERENTIAL GPS}

Evaluation of the non-differential GPS positions was done on a set by set basis. Figures 7.21 through 7.31 depict the distance in meters between the theodolite-computed ship position and the shipboard GPS receiver position. sets 1, 2 and 3 have the smallest distance difference, as shown in figures 7.21, 7.22, and 7.23, with mean values between 118 and 133 meters and standard deviations ranging from 7.45 to 16 meters. These smaller mean distances are a result of the loy user range errors for 12 Mag as shown on figure 7.32 . The highest mean distances occurred during sets $4,9,10$, 12. and 13 when the ORE values were high and the NAVSTAR uploads occurred (fig. 7.16 and 7.17). The remairing distances vary between 144 and 278 meters.

The results during the best satellite observation periods are depicted in figures $7.33,7.34$, and 7.35 , where the non-differential GPS ship position was compared to the theodolite-computed ship position, the distance between the tro being plotted as a histogram. Mean distances on figures 7.33 and 7.35 are representative of the five satellites observed and the improved accuracy of the system, with mean distances of 134 and 149 meters and standard deviations of 

Figure 7.21.

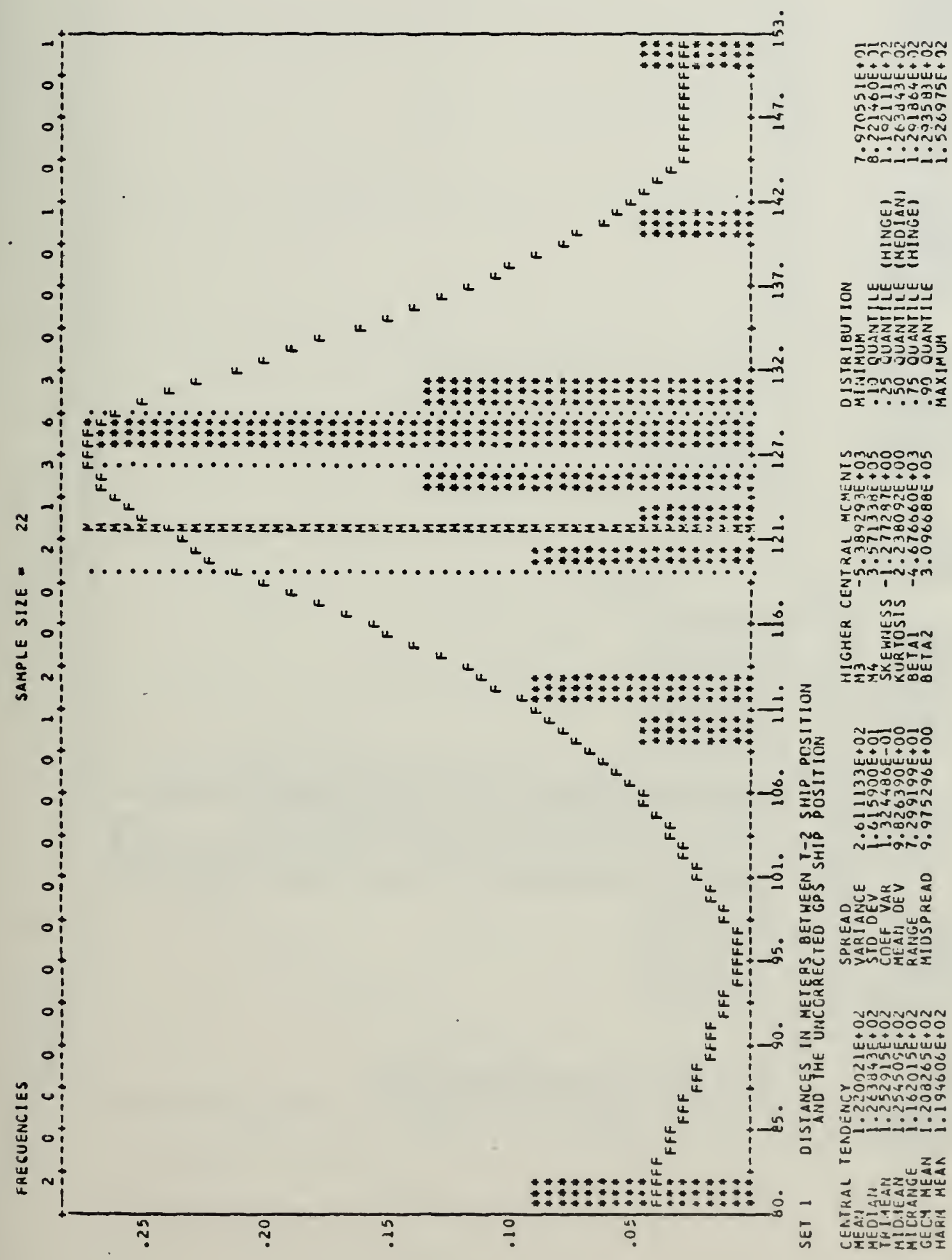



Figure 7.22 .

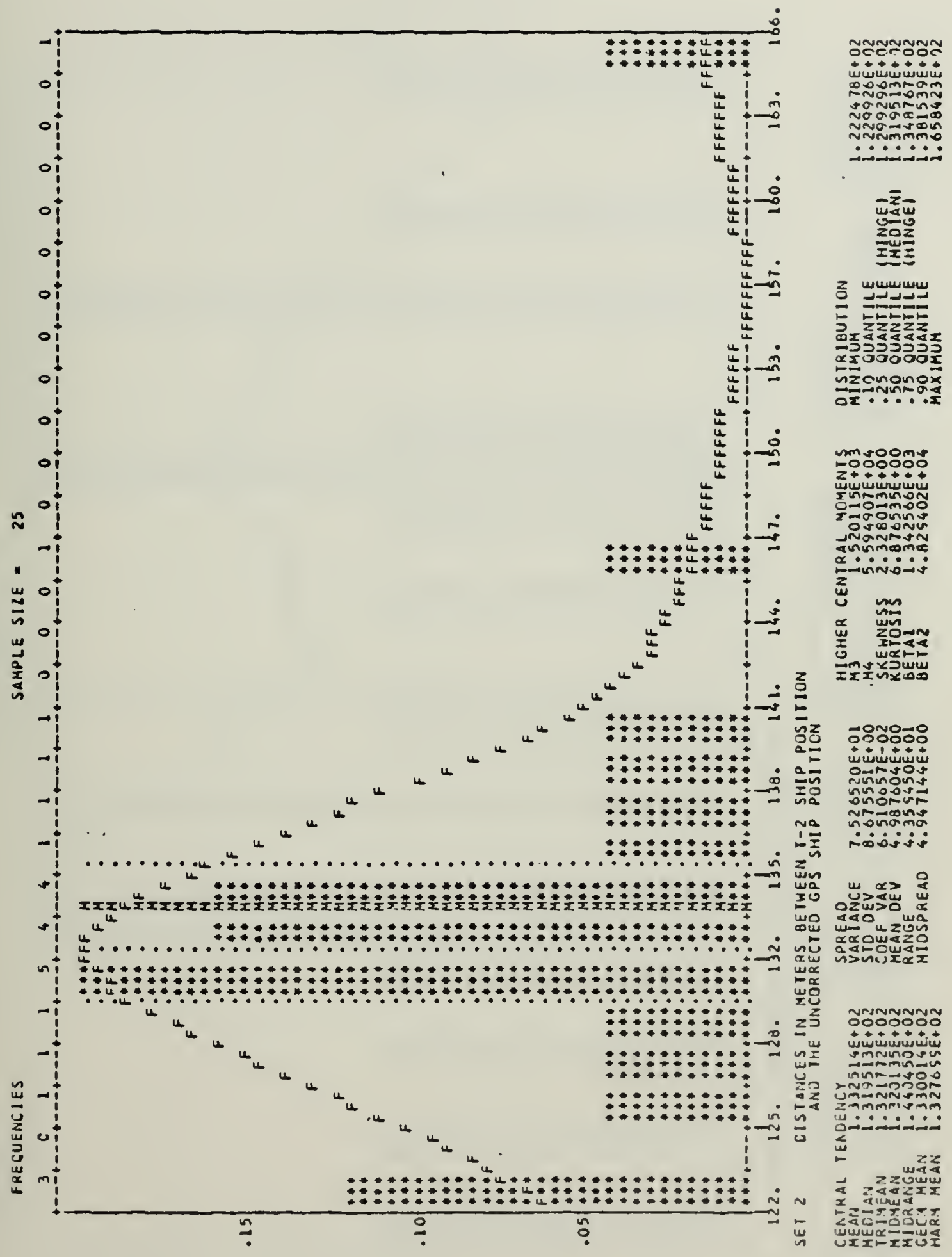



Figure 7.23 .

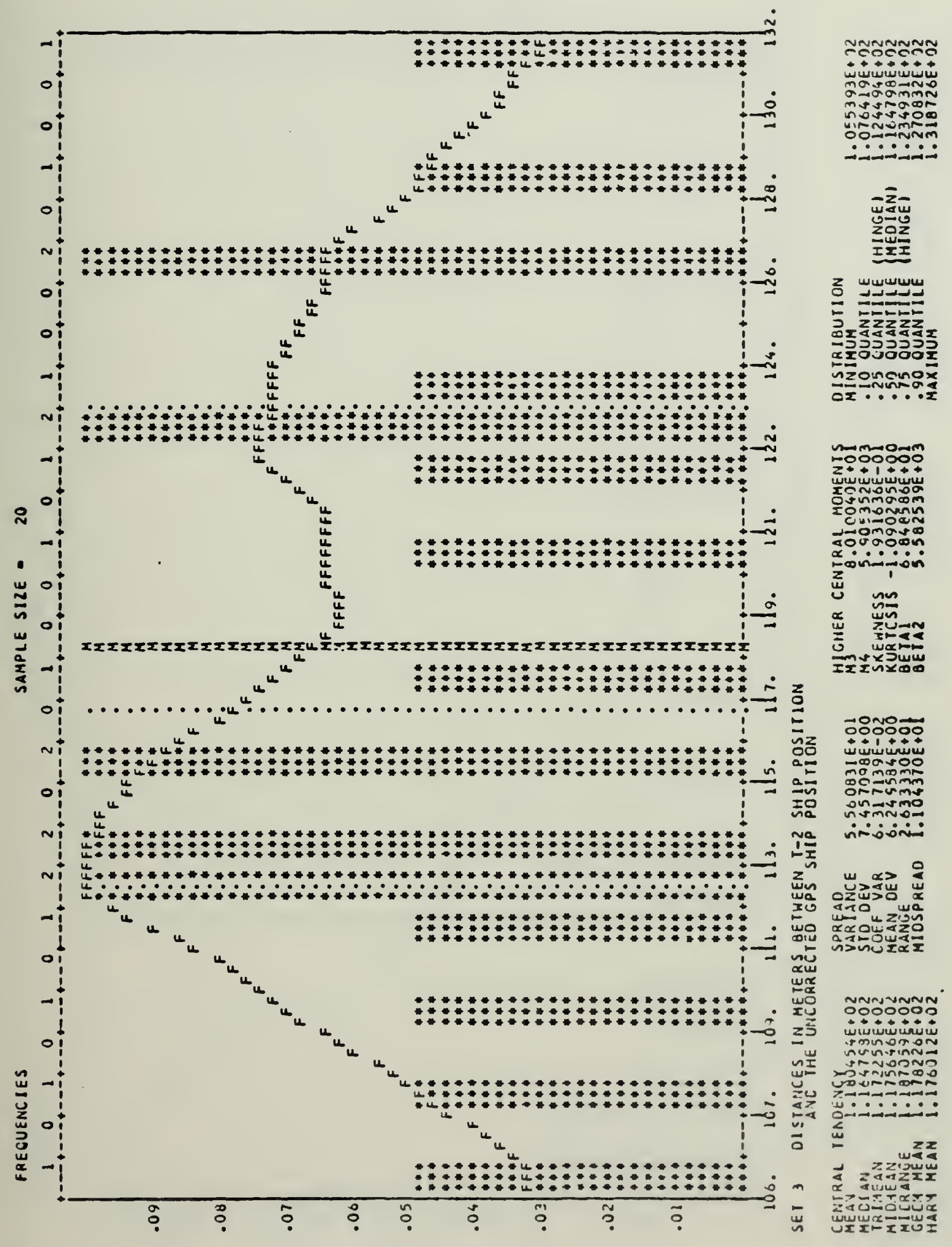


$-5$ 
Figure 7.24.

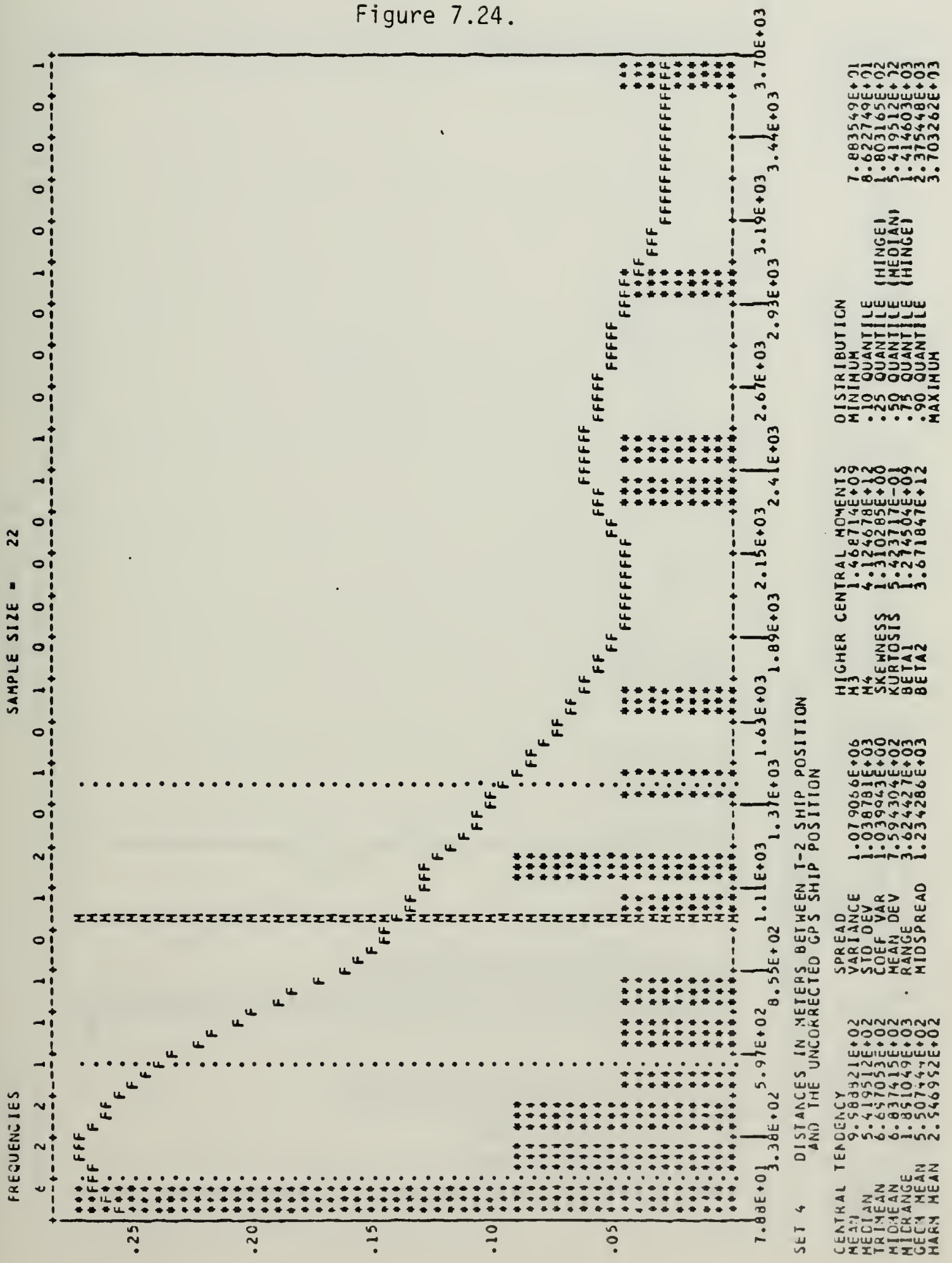



Figure 7.25

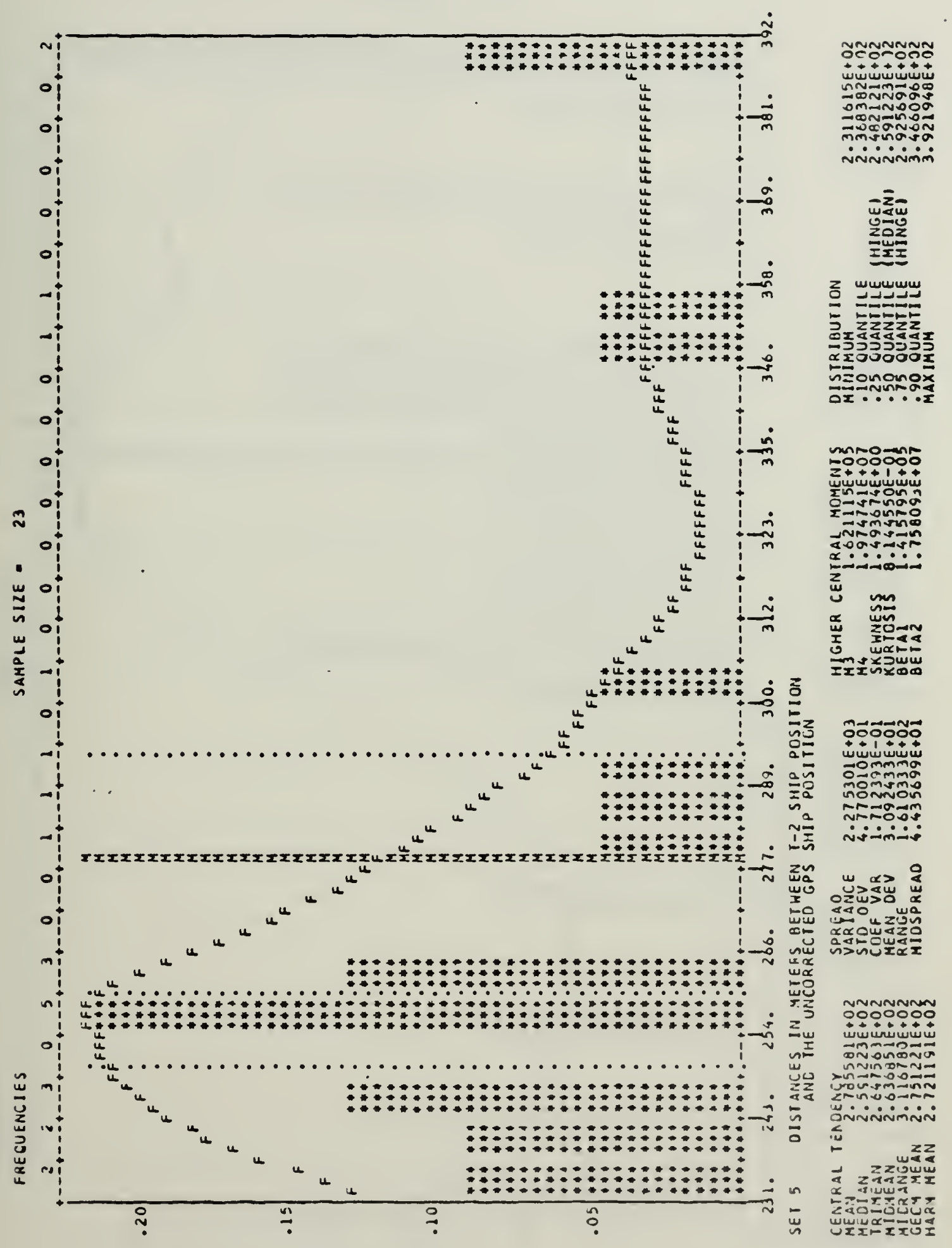



Figure 7.26.

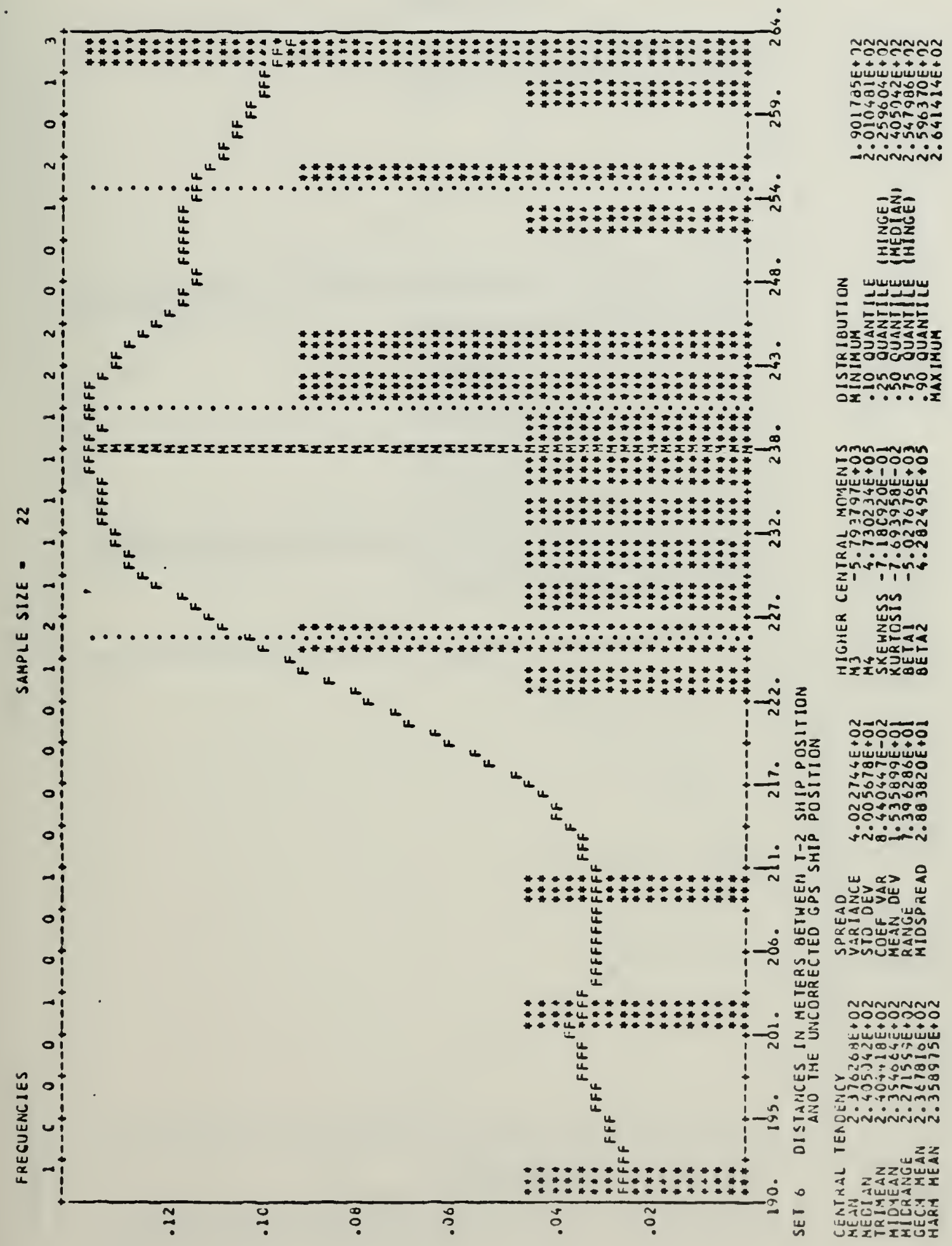



Figure 7.27 .

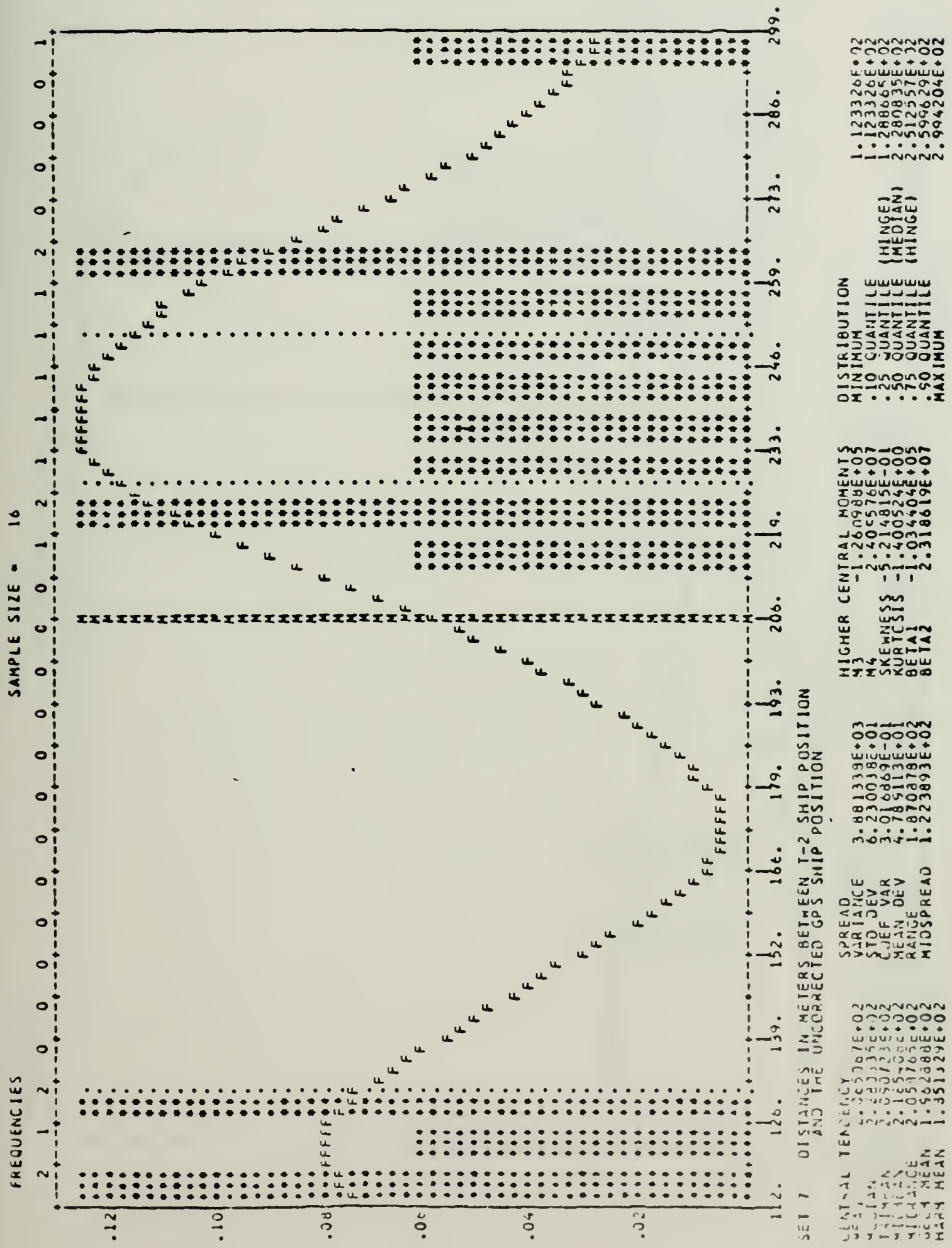


Figure 7.28.

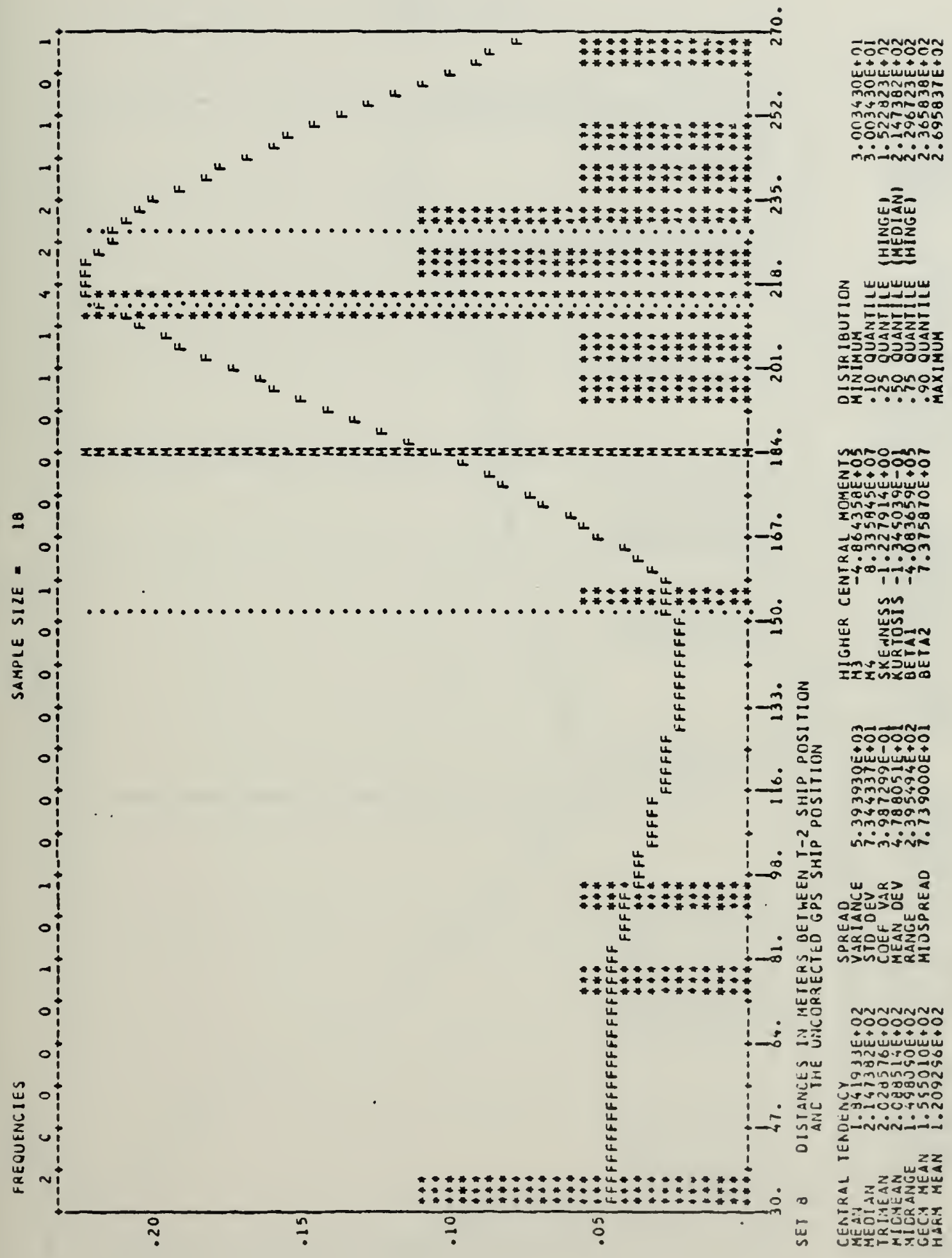



Figure 7.29 .

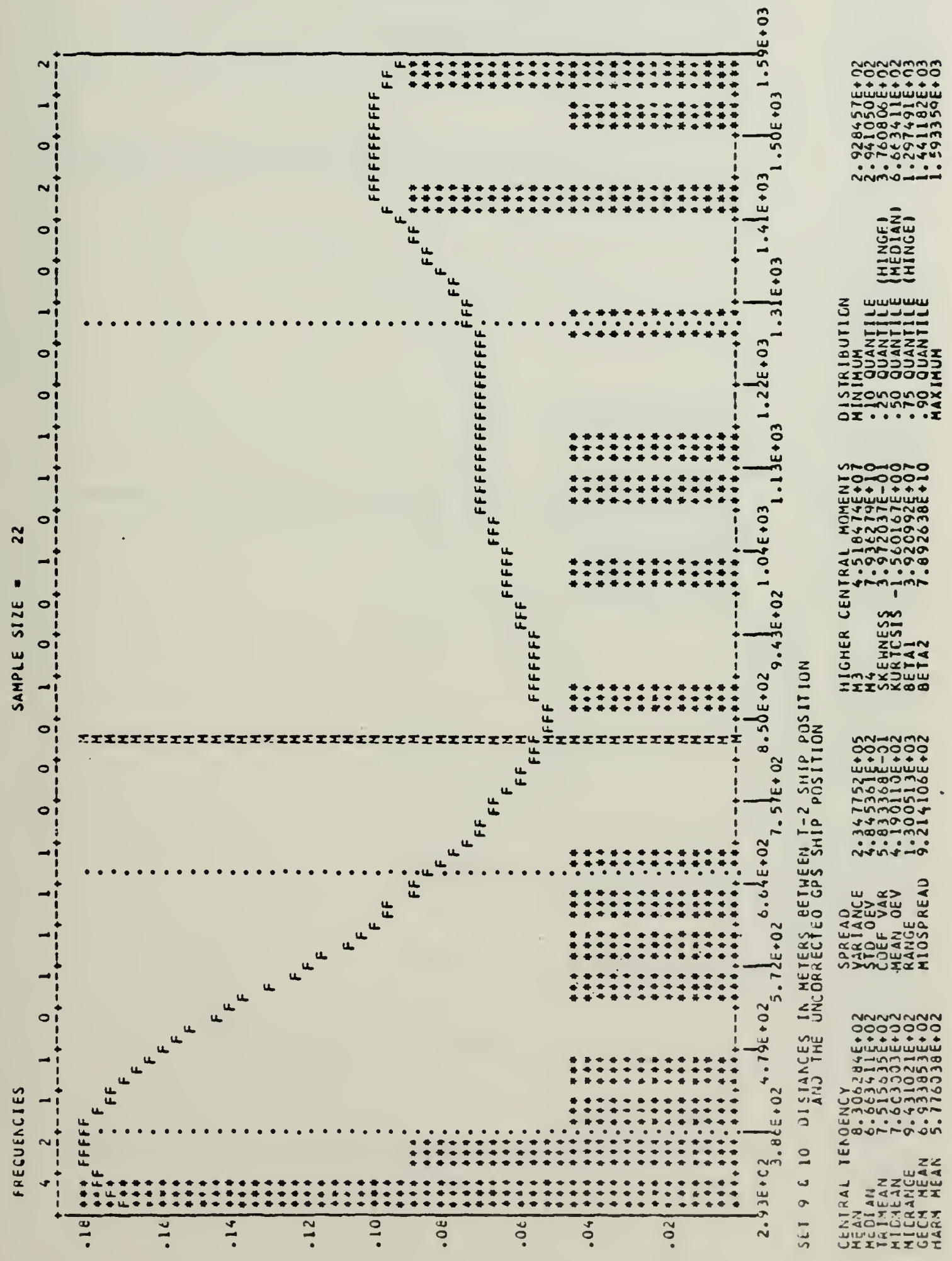


Figure 7.30 .

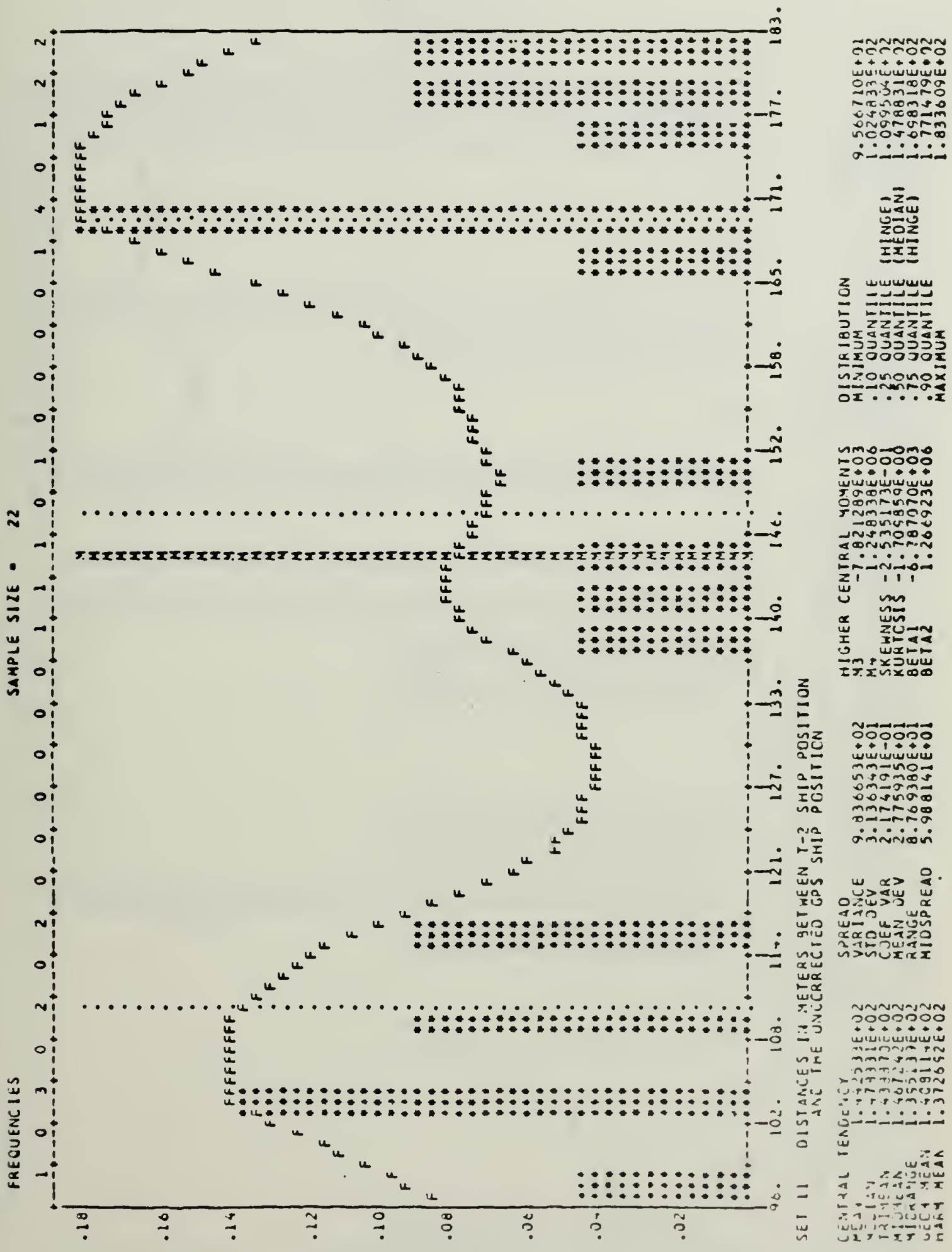



Figure 7.31 .

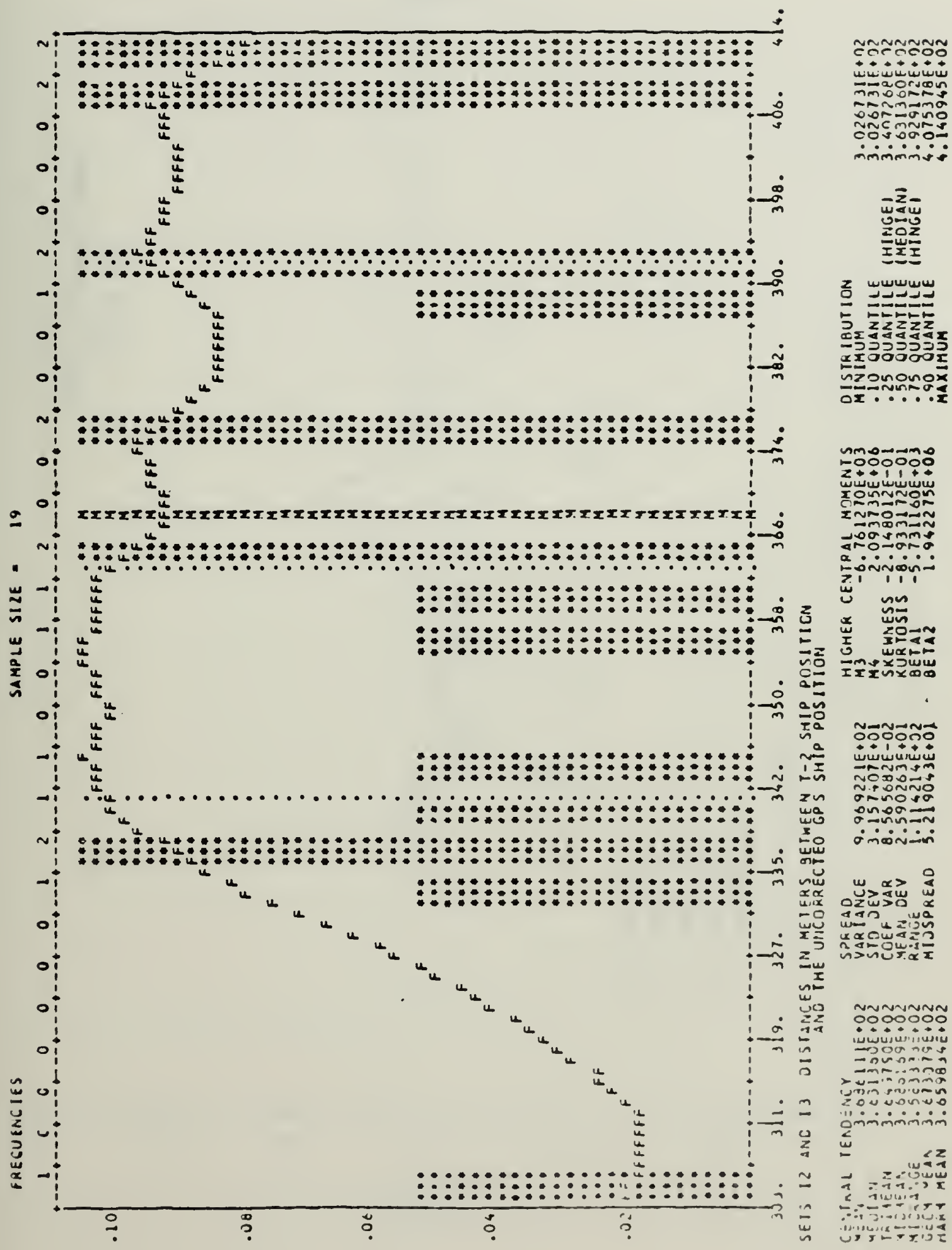




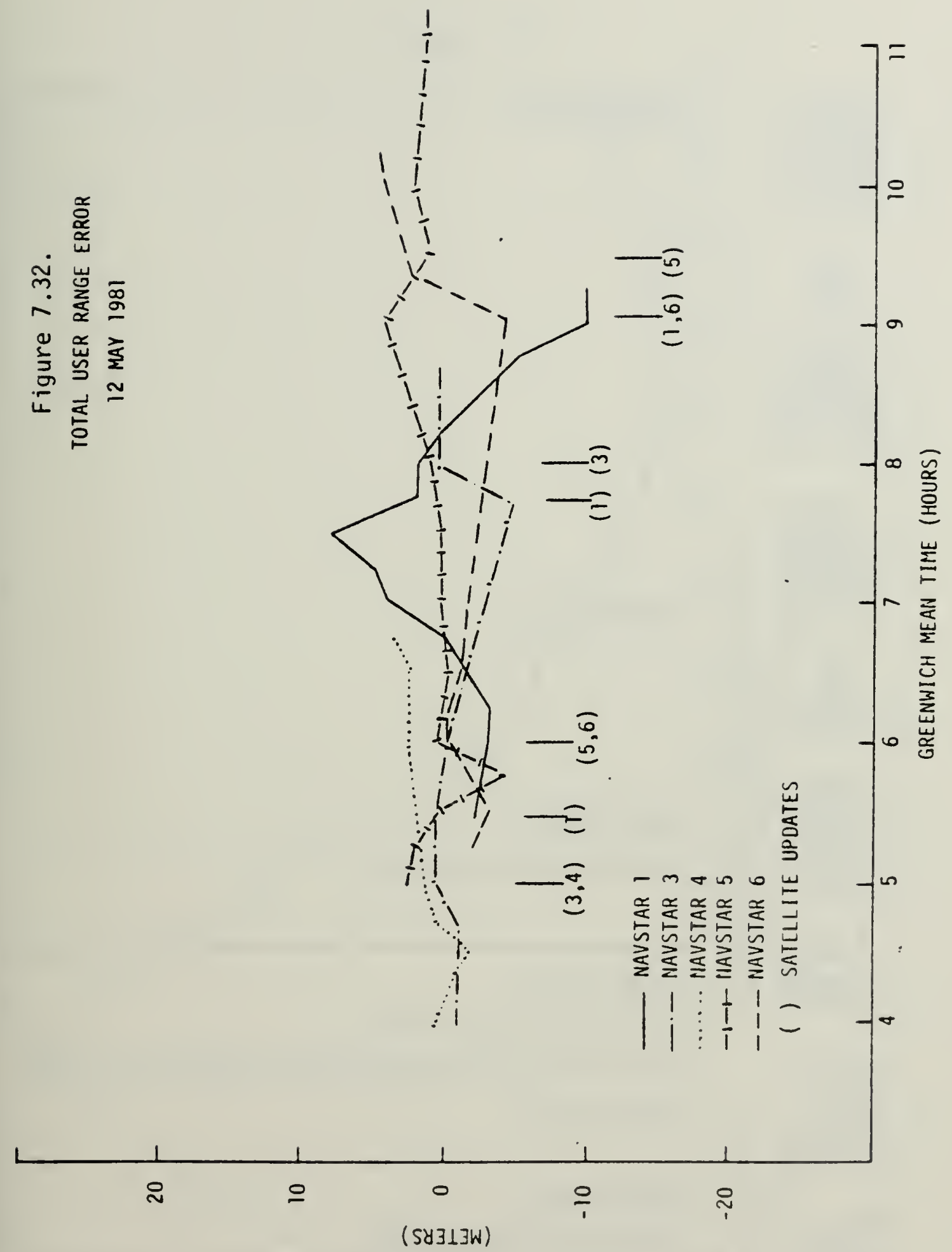

Figure 7.33 .

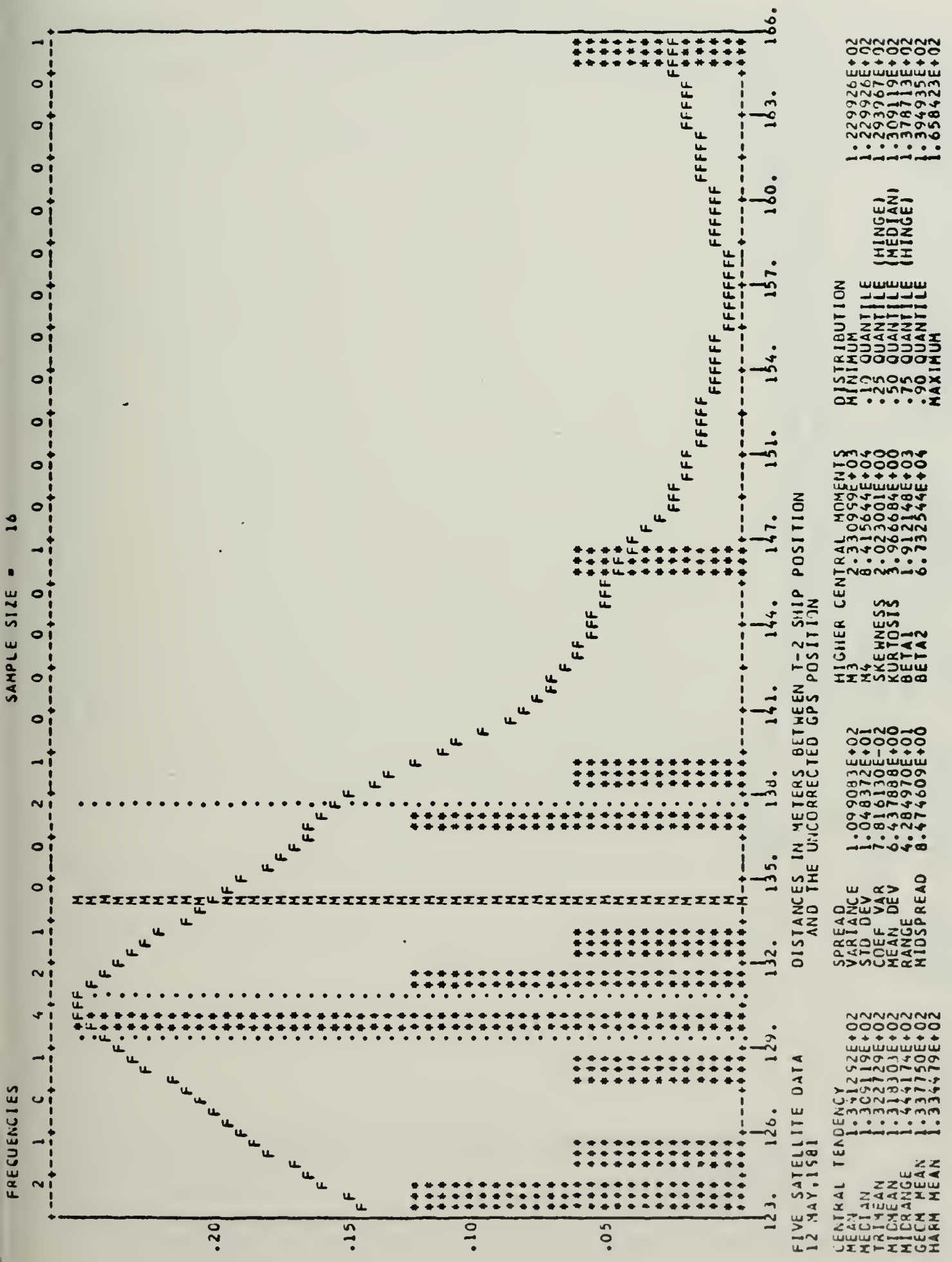


Figure 7.34 .

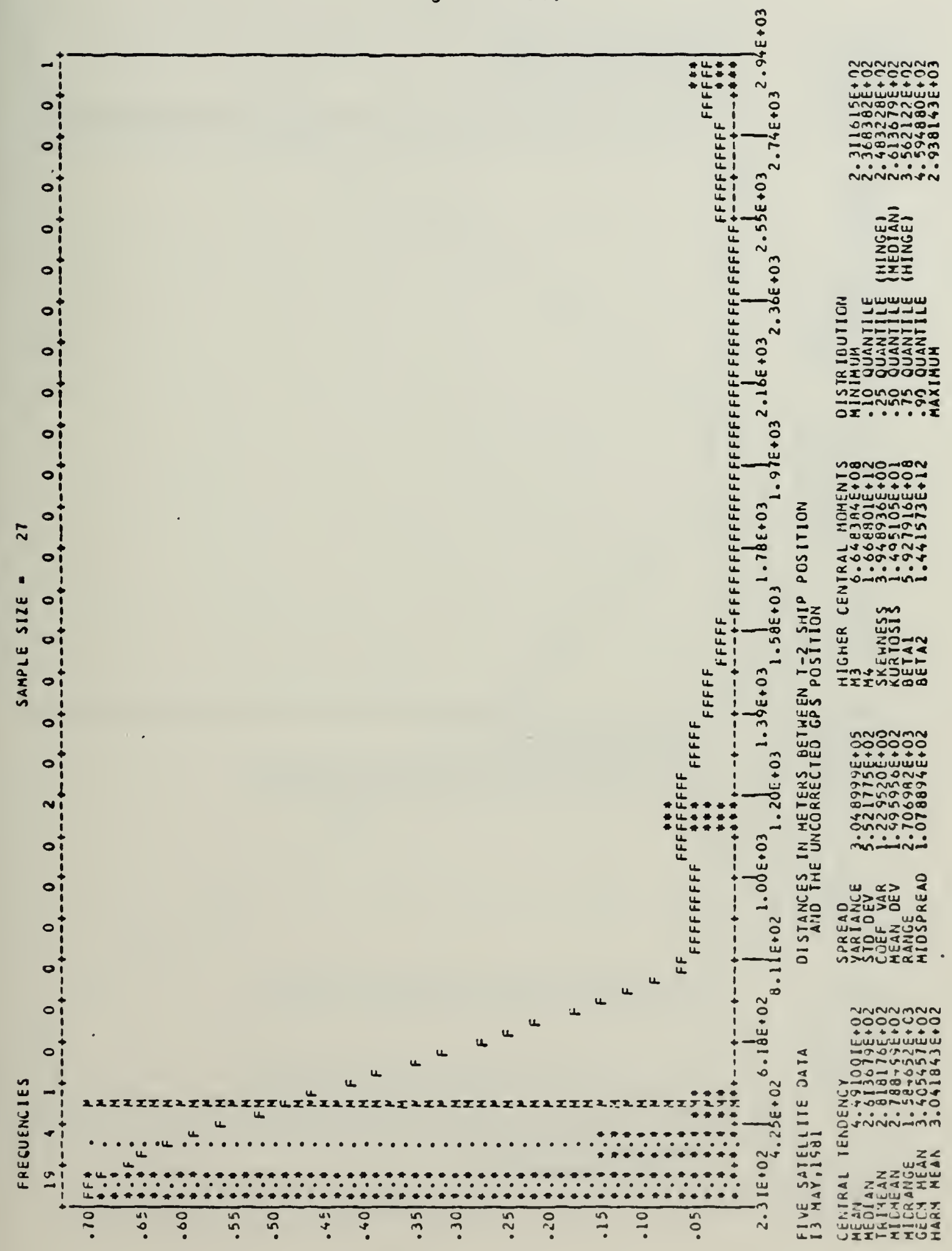




10 and 52 meters. The large standard deviation for 15 May is apparent in the bimodal empirical frequency curve (fig. 7.35) and is caused by the NAVSTAR upload (fig. 7.17). In this case, the GPS Ieceiver did not obtain the new ephemeris until halfwal through the time period of the observations. The data for 13 May (fig. 7.34 ) reflects frequent MArSTAR 1 uploads and the resulting high oRE values (fig. 7.16) for that date.

C. DIFPERENTIAL GPS EVALUATION NITH STATIC CORRECTION The results of the evaluation of the data of 12 May (sets 1, 2, and 3 ), computed using the differential GPS positions and the static corrections, are shown in figures 7.36, 7.37, and 7.38. Mean difference between positions for the theodolite ship position and the GPS position are 29.1, 27.4, and 64.8 meters, with standard deviations of $7.7,7.5$, and 22.7 meters. These distances are larger than those determined for the theodolite ship position and the differential GPS position (fig. 7.39, 7.40 and 7.41). This bigher mean distance indicates that the static correction, as applied, results in a larger error in the differential GPS position. Therefore, further evaluation of differential GPS with static corrections were not conducted. 
Figure 7.36 .

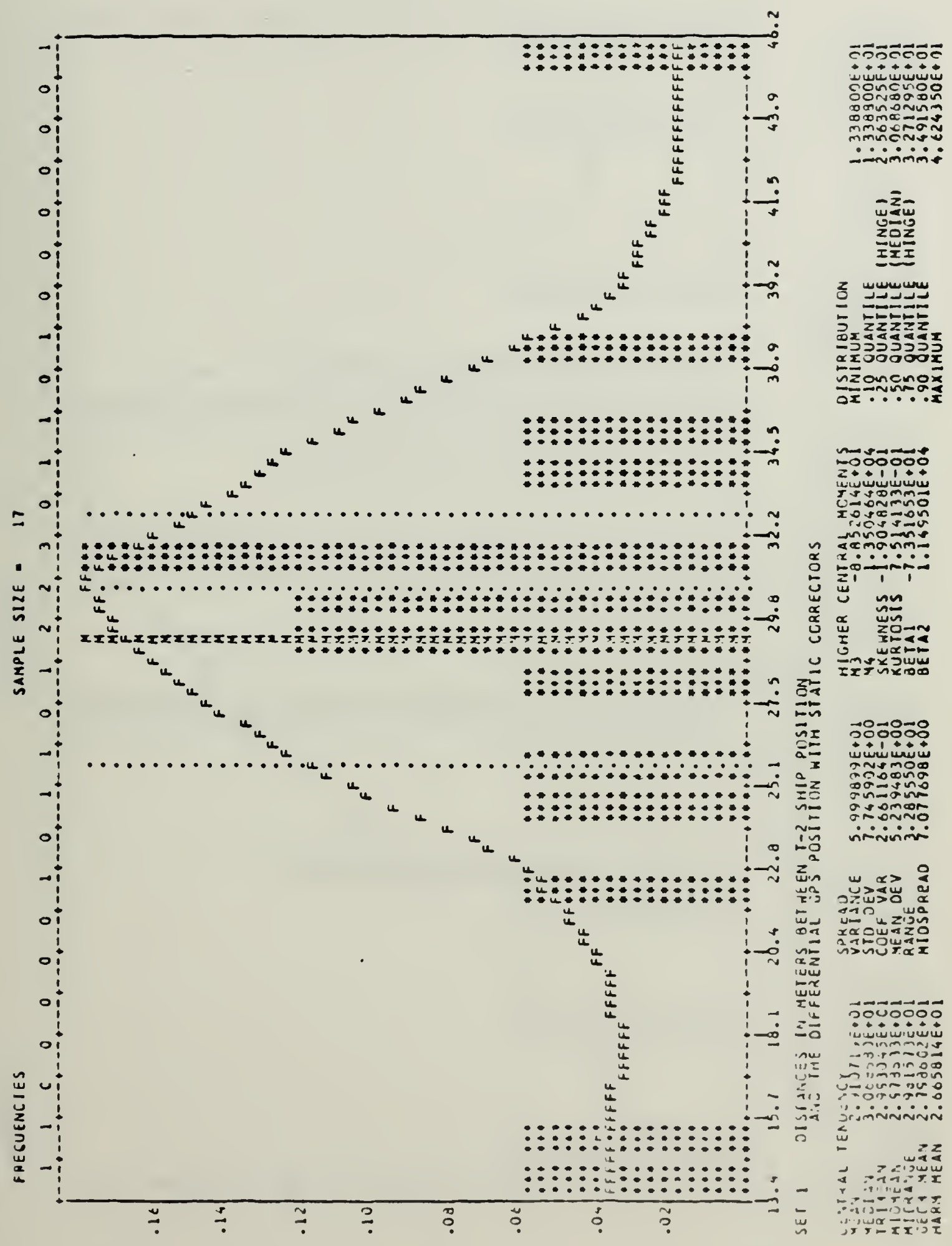


Figure 7.37 .

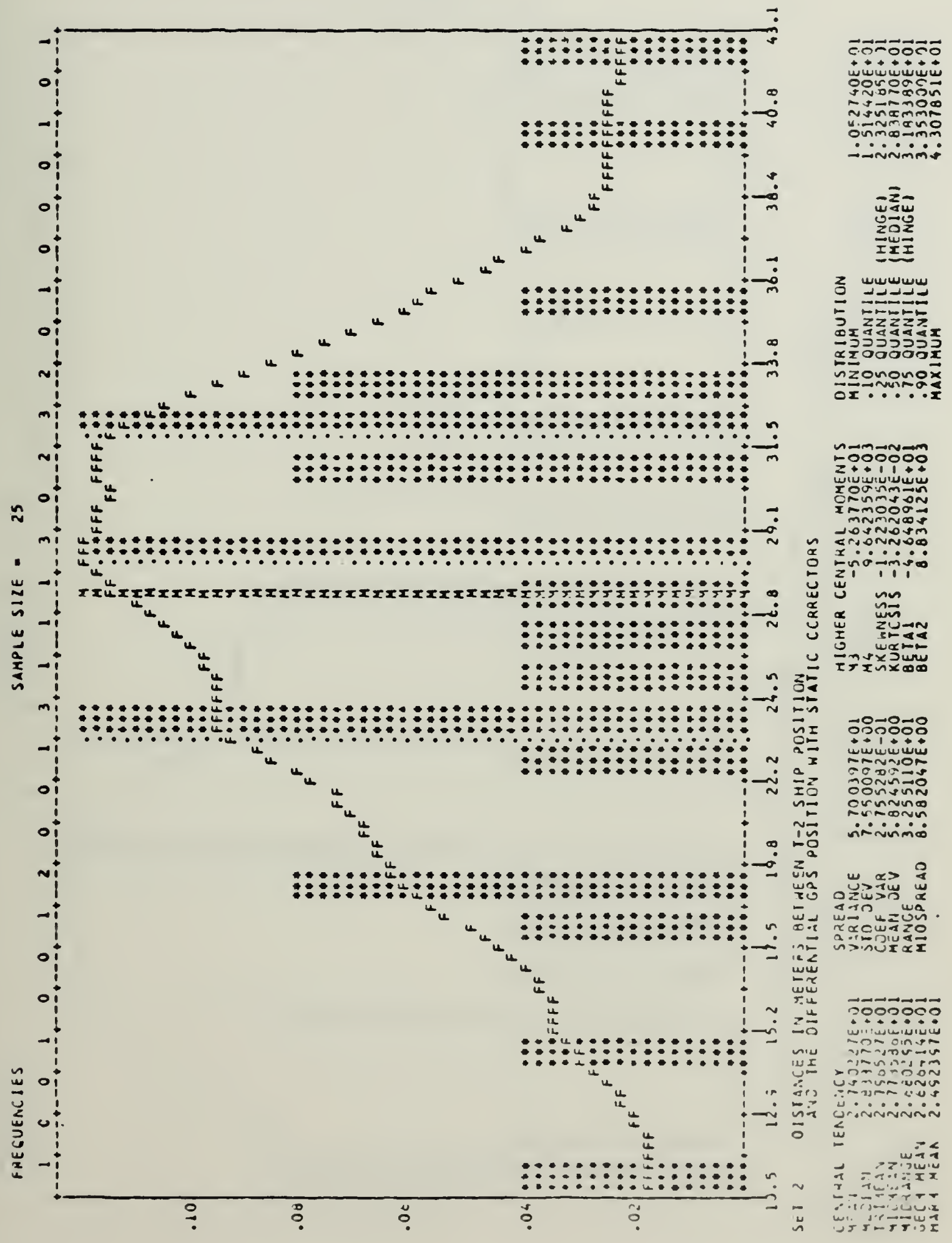



Finure 7.28 .

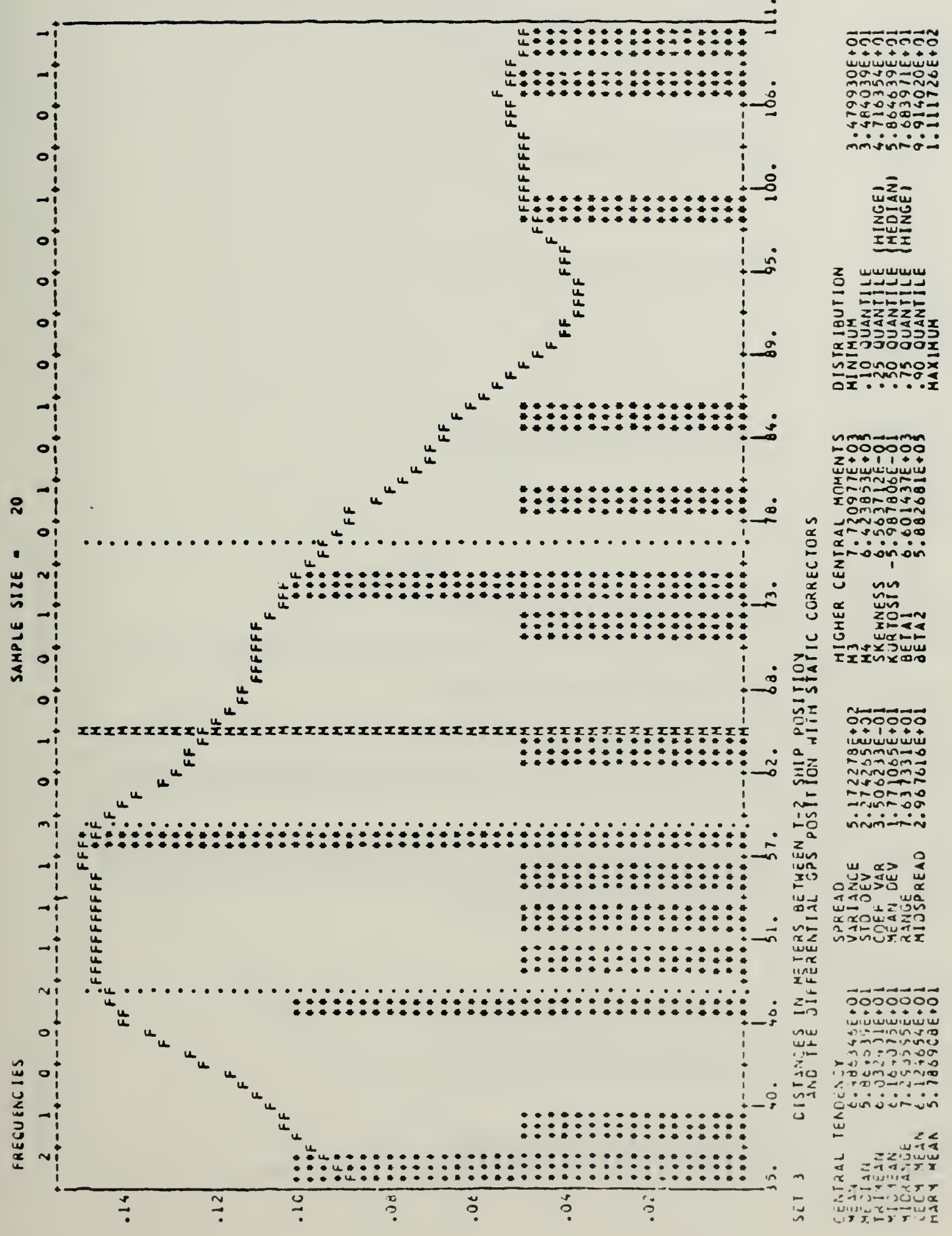



Figure 7.39.

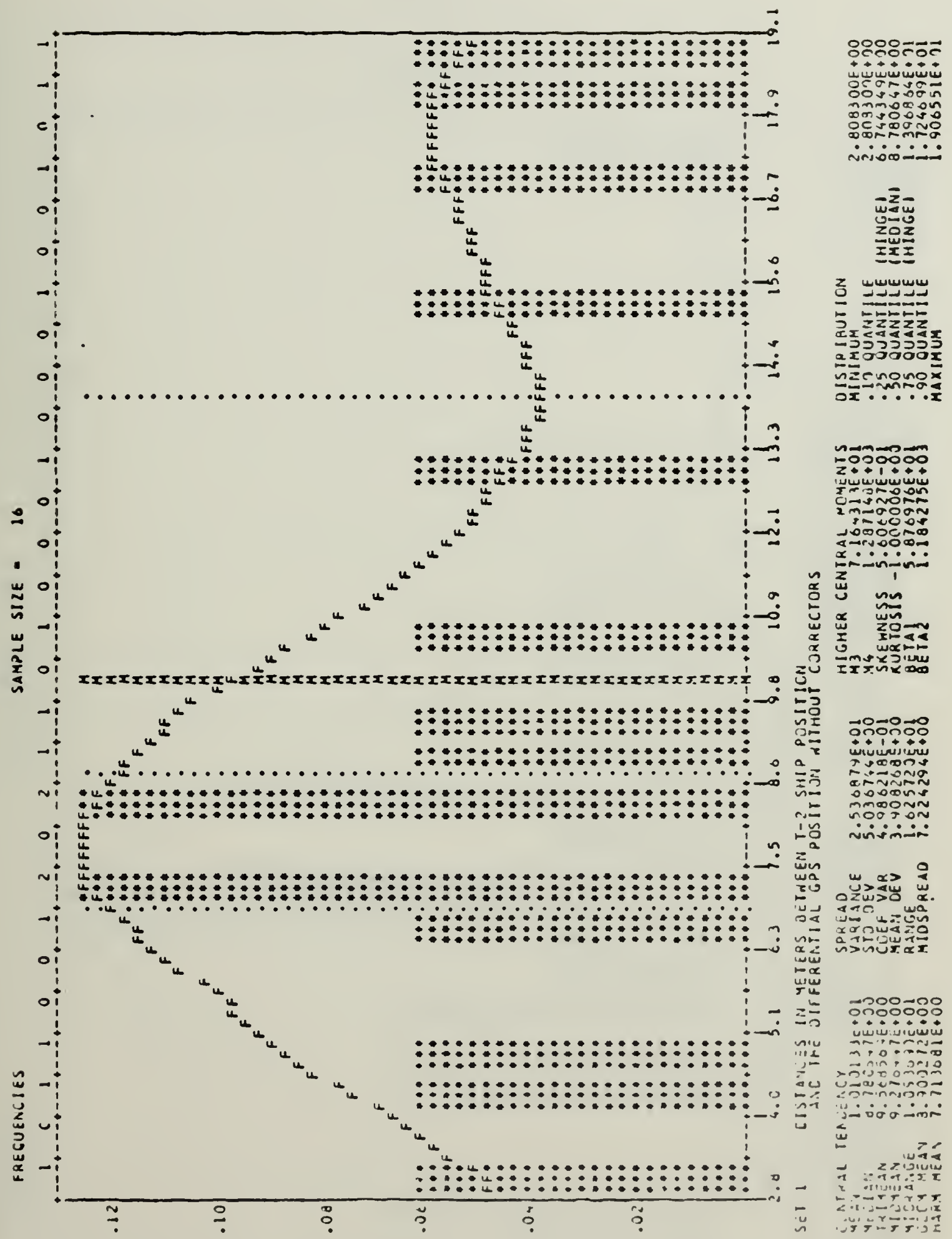


Figure 7.40 .

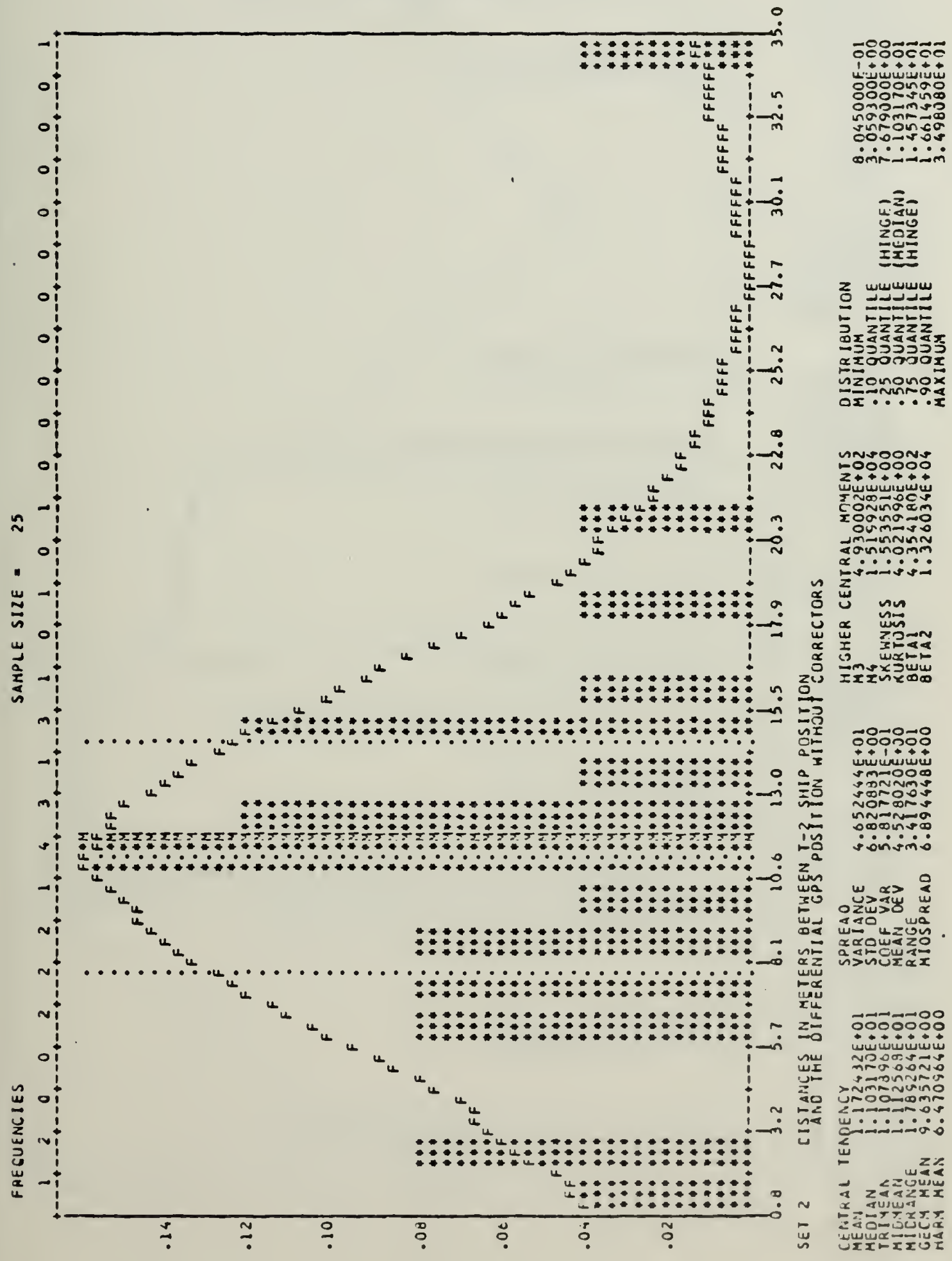





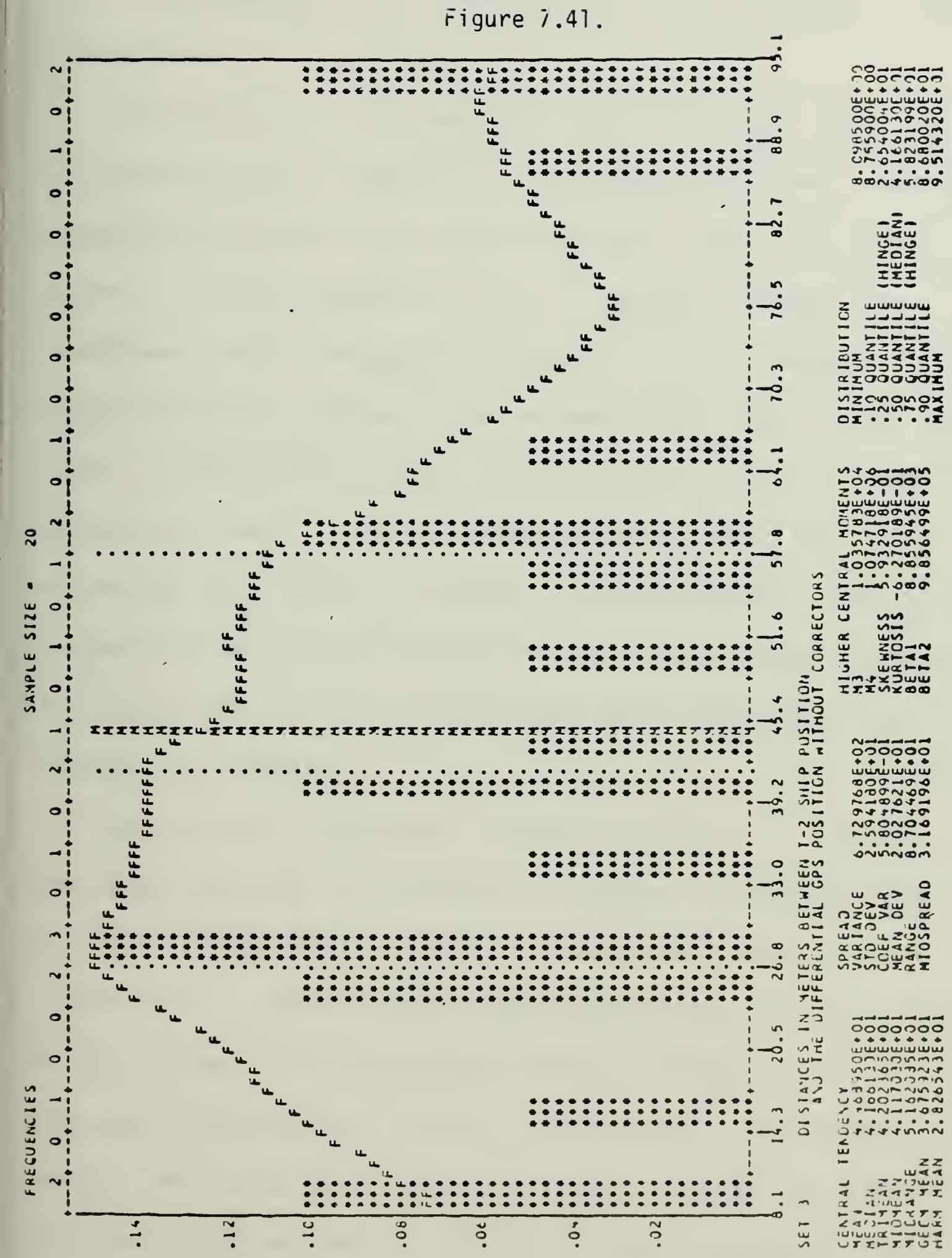



D. EVALUATION OF DIPPERENTIAL GPS hITHOOT STATIC CORRECTIONS

Evaluation of differential GPS without the static corrections vere computed by sets for the five satellite constellations for each day of testing. Set 1 (fig. 7.39) shous a mean distance of 10.1 meters between the tro positions and a standard deviation of 5.0 meters. The median azimuth between the two was $257^{\circ}$ from south (fig. 7.42). Which also was the approximate course of the vessel during the test. These values indicate that the error is caused by the bias, or alias, in GPS position due to the Manpack 24-second fixing interval and positioning algorithm. For this set, the GPS position was obtained after the theodolite position.

During set 2 the mean distance difference between the two positions was 11.7 meters, and the standard deviation was 6.8 meters (fig. 7.40); the median azimuth was $71^{\circ}$ (fig. 7.43). These values were slightly greater than those of set 1 due to the increased URE for NaVSTAR 1 during the set (see 0700 on Eig. 7.32) Additionally, the azinuth vas nearly $180^{\circ}$ Erom that computed in set 1 , with the vessel on the same track as set 1 . Onlike the error obtained from the 
Figure 7.42 .

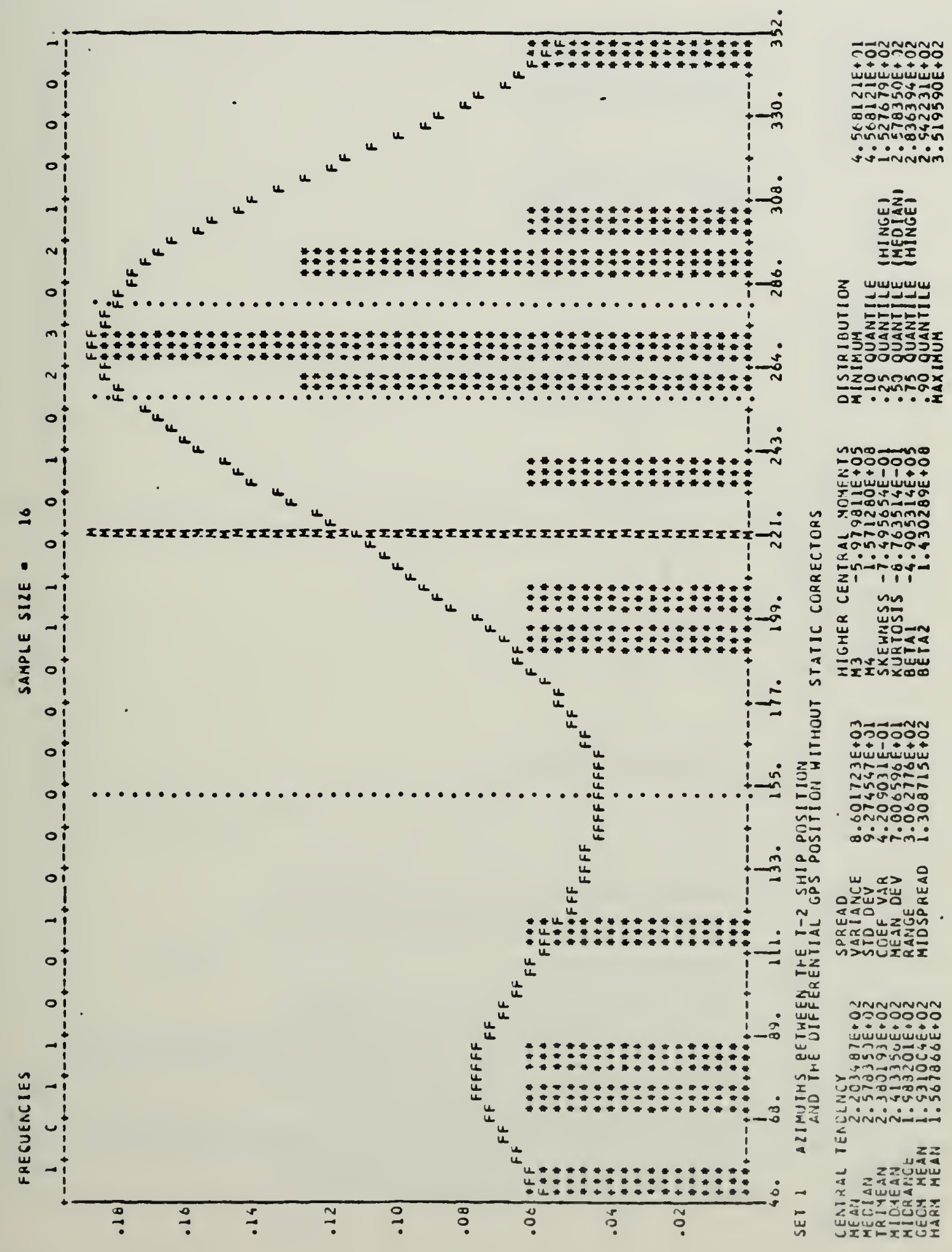



Figure 7.43 .

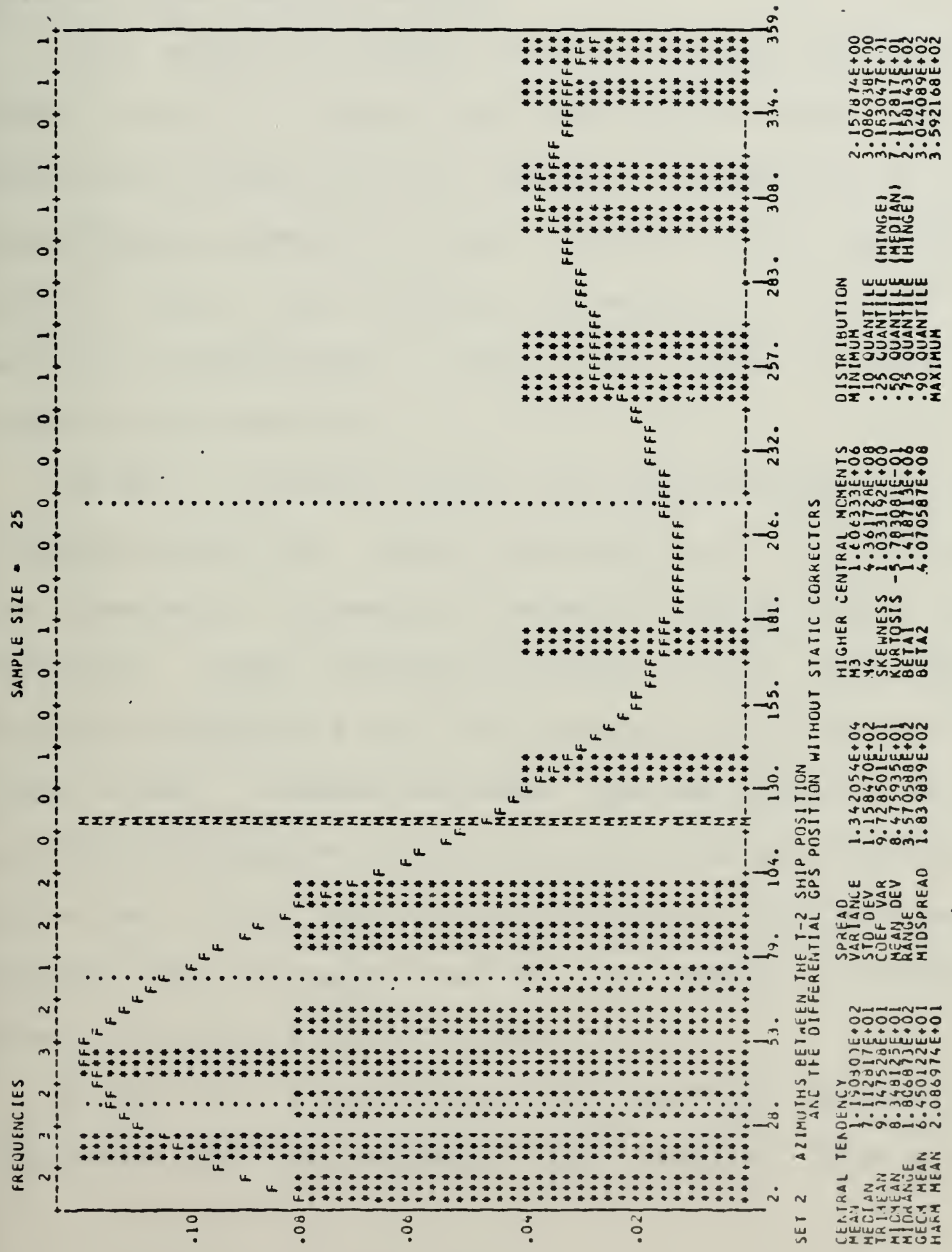



Manpack bias on set 1 , the error in set 2 was due to a similar time delay bias because the theodolite position was obtained after the GPS position.

Set 3 values on figures 7.41 and 7.44 are similar to those of set 2, except the mean distance values were greater- -44.7 meters for set 3 versus 11.7 neters for set 2 . Mean distance increases for set 3 were due tc the upload of NATSTAR 1 (fig. 7.32) and the zvailability of only a four satellite constellation. Set 2 had a fire satellite constellation available.

For set 4 , figures 7.45 and 7.46 show the distances and azimuths for the set. These histograms fail to illustrate the constantly increasing distances betueen the two positions. These increasing distances result from the uploads of NATSTAR's 5 and 6 and the large URE for NavSTAR 1 (fig. 7.16). Onboard the vessel the new ephemeris data uploaded for NAVSTAR's 5 and 6 was not obtained until late in the set. Also near the end of the set, NAVSTAR 1 was uploaded with the result that the last several distances were very large, as shown in figure 7.16 .

In set 5, a very high oRE value for NavSTaR 1 contributed to the extremely large position difference 

Figure 7.44 .

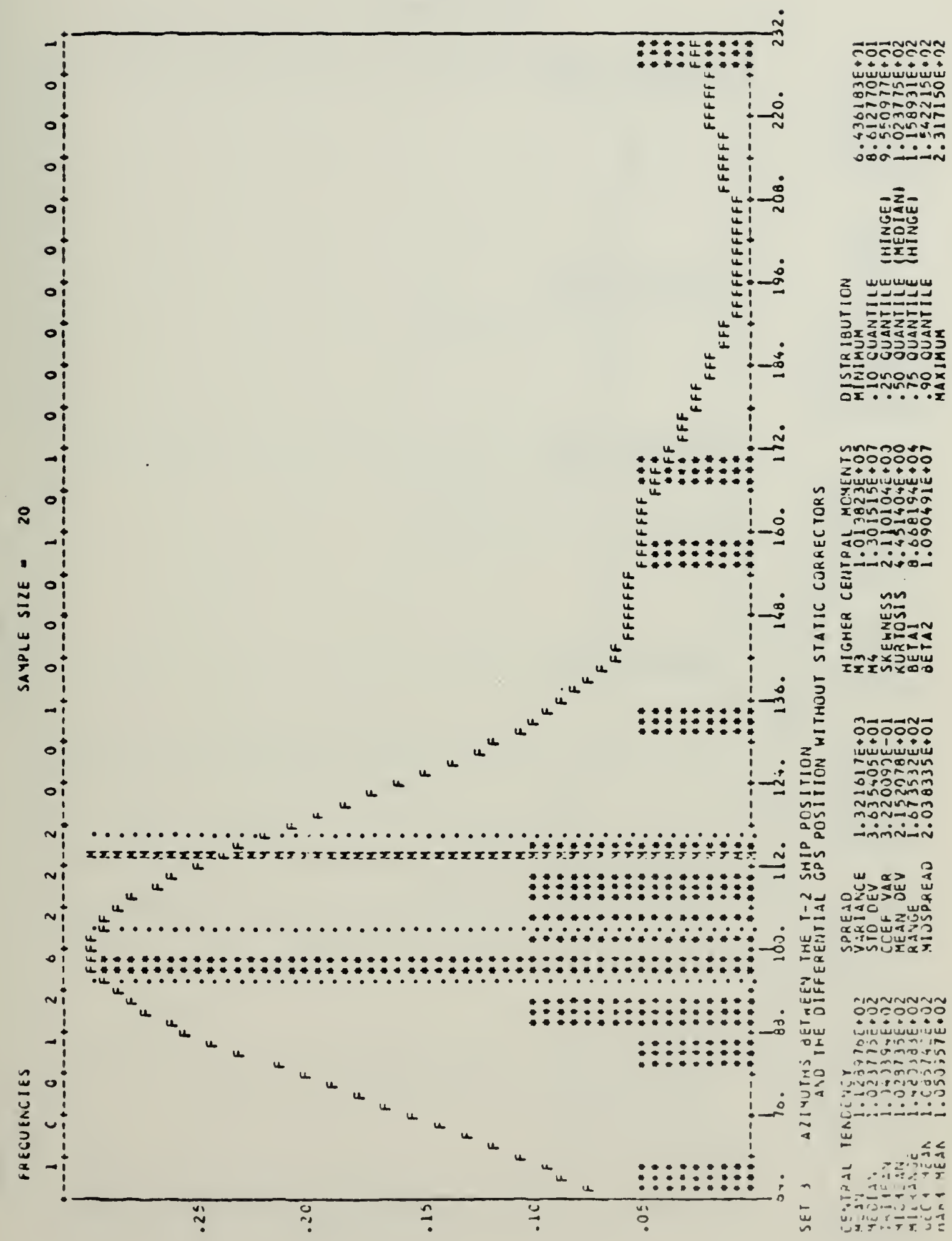



Figure 7.45.

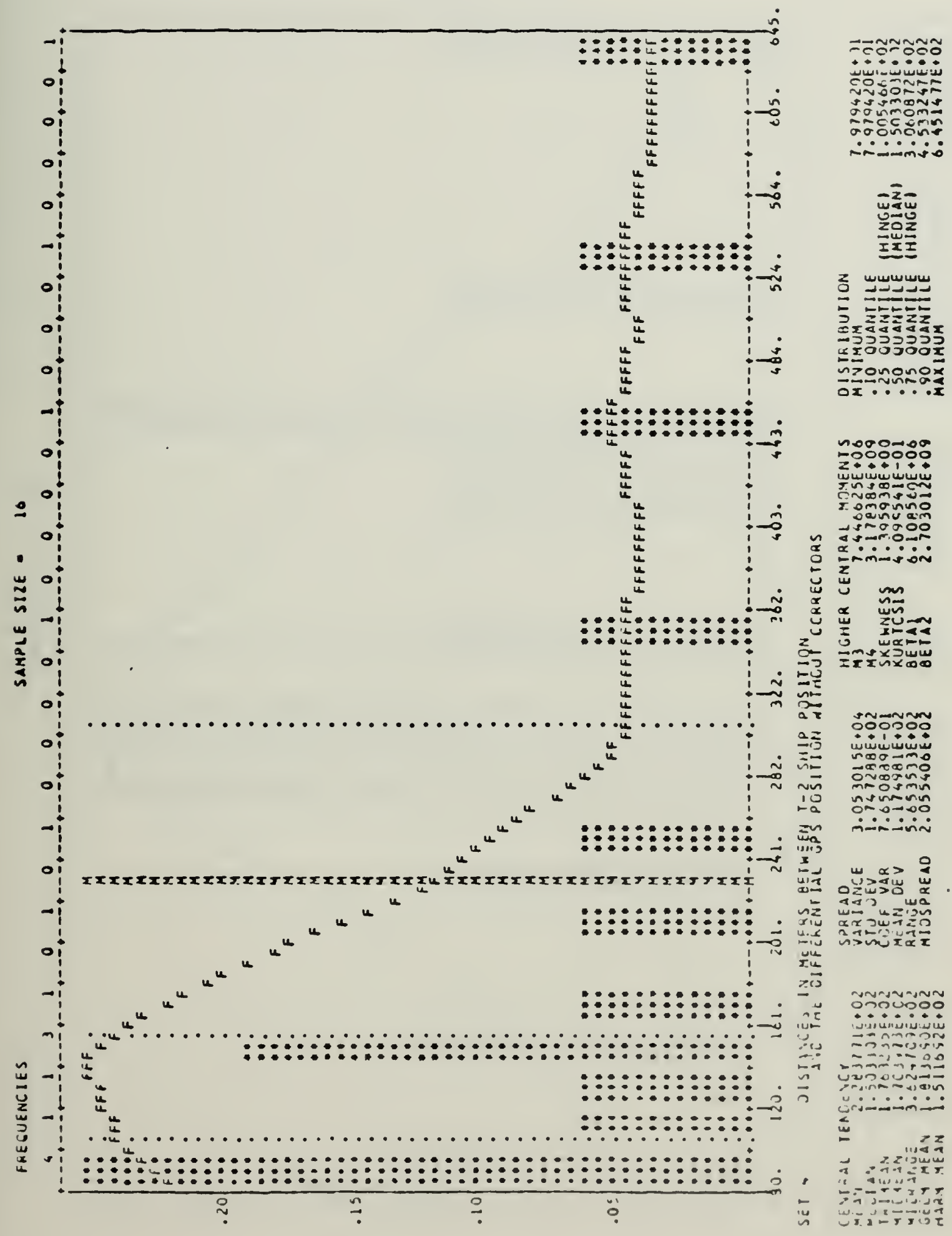



Figure 7.46 .

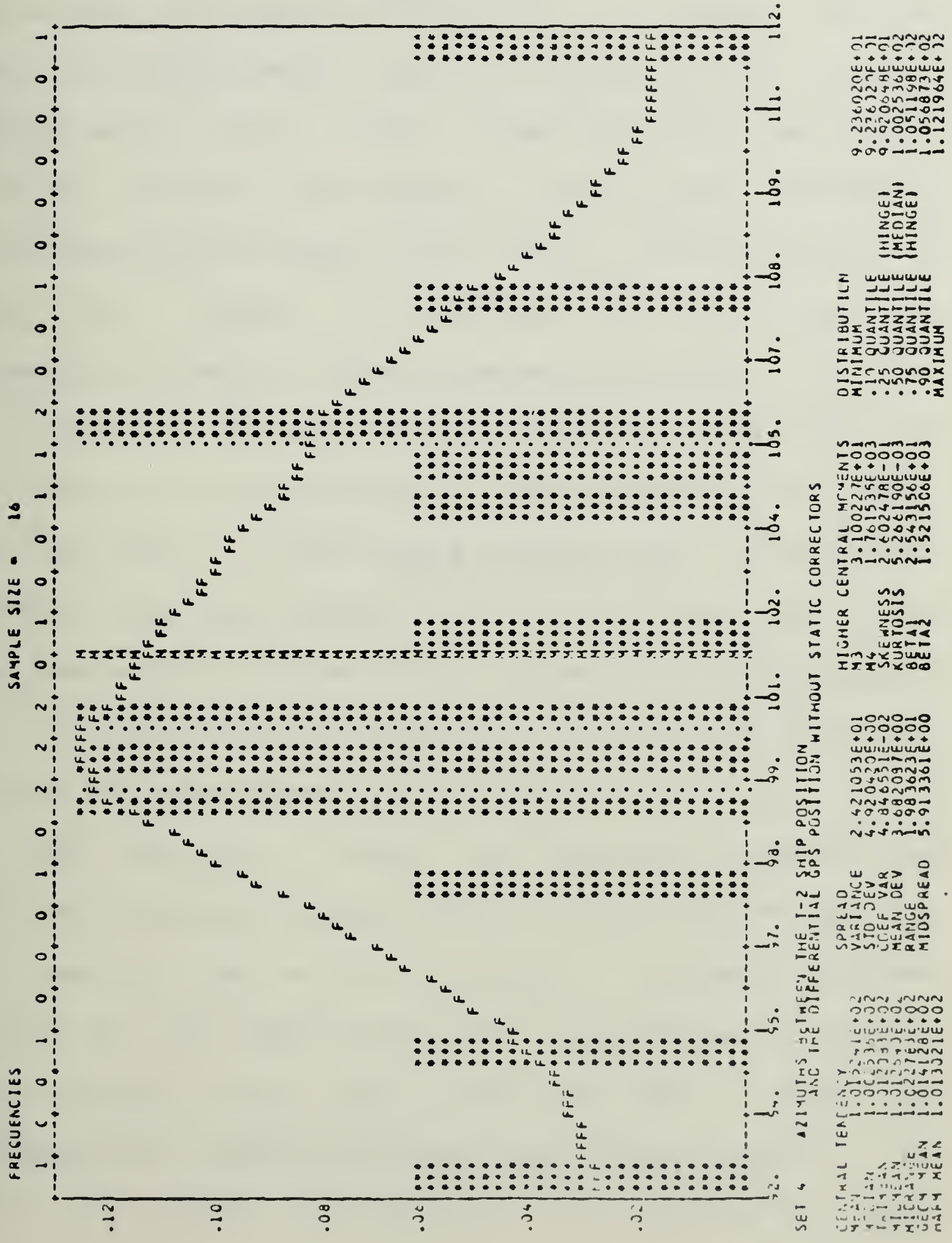



between that determined by the theodolites and that for the differential GPS position (fig. 7.47). The azinuth remained nearly constant between the two positions with a median azimuth of $43^{\circ}$ (fig. 7.48). These values for set 5 show that the large ORE for NATSIAR 1 was the most important contributing error source (fig. 7.16). The large URE may have been caused by activation of the hydrazine stabilization jets to dampen momentum on NAVSTAR 1.

Por set 6 , the mean distance difference between the two positions was 60.0 meters and a median azimuth of $93^{\circ}$ (fig. 7.49 and 7.50$)$. These values indicate that the upload of NAVSTAR 1 near the beginning of the set (0715 on fig. 7.16) was zeceived and utilized in the Manpack position algorithm, but the higher distance between the positions also indicates a large JRE (also shown on fig. 7.16).

Data from set 7 were not evaluated because the stationary Manpack receiver did not record the GPS position for each fix due to radio failure. The mean distance between the tyo positions for set 8 was 121 meters with a mean azimuth of $68^{\circ}$ (fig. 7.51 and 7.52 ). Both the distances and azimuths show that the URE for NAVSTAR 1 at 0530 (fig. 7.17) was increasing in magnitude and thus 

Figure 7.47 .

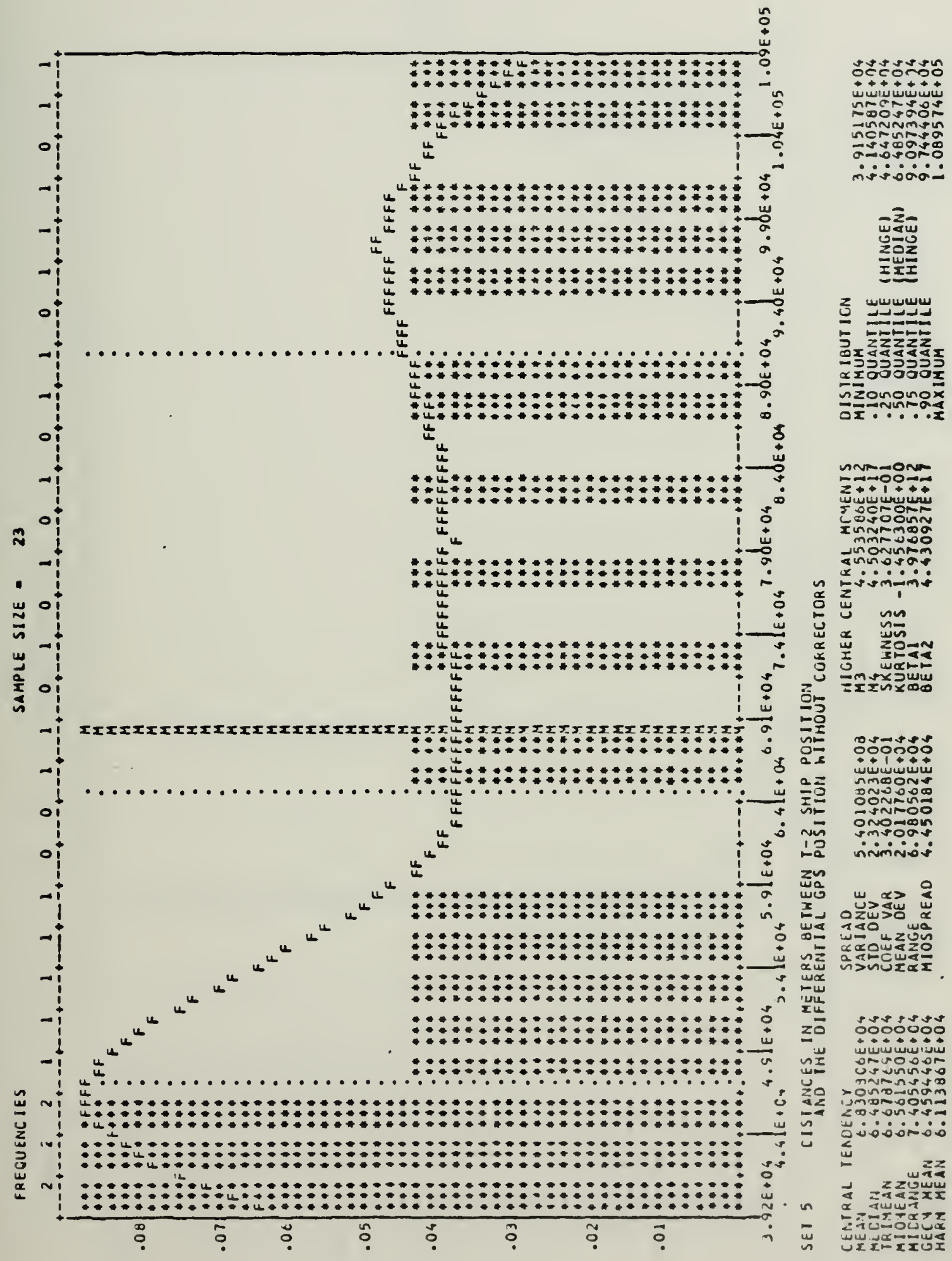



Figure 7.48 .

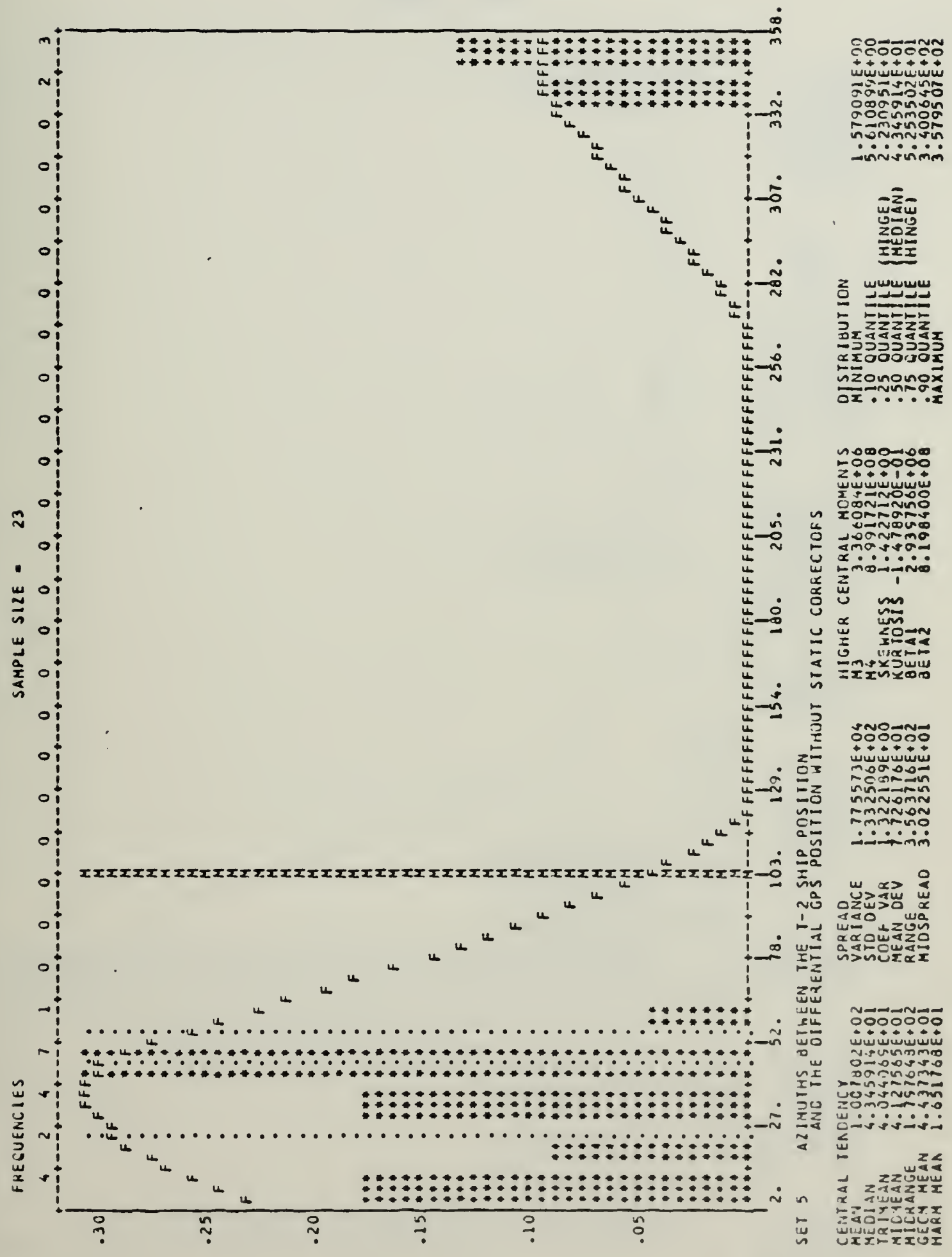


Figure 7.49.

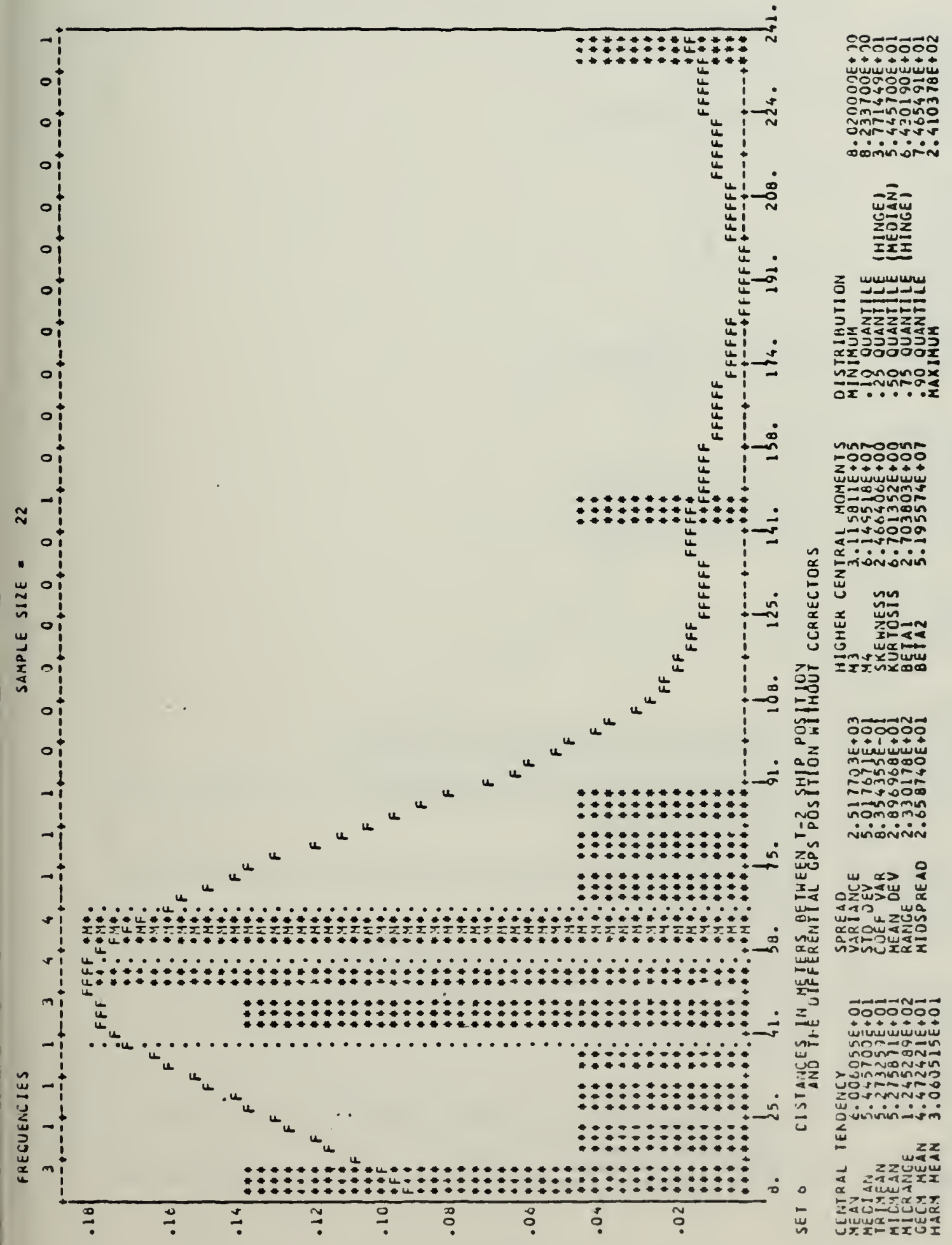



Figure 7.50 .

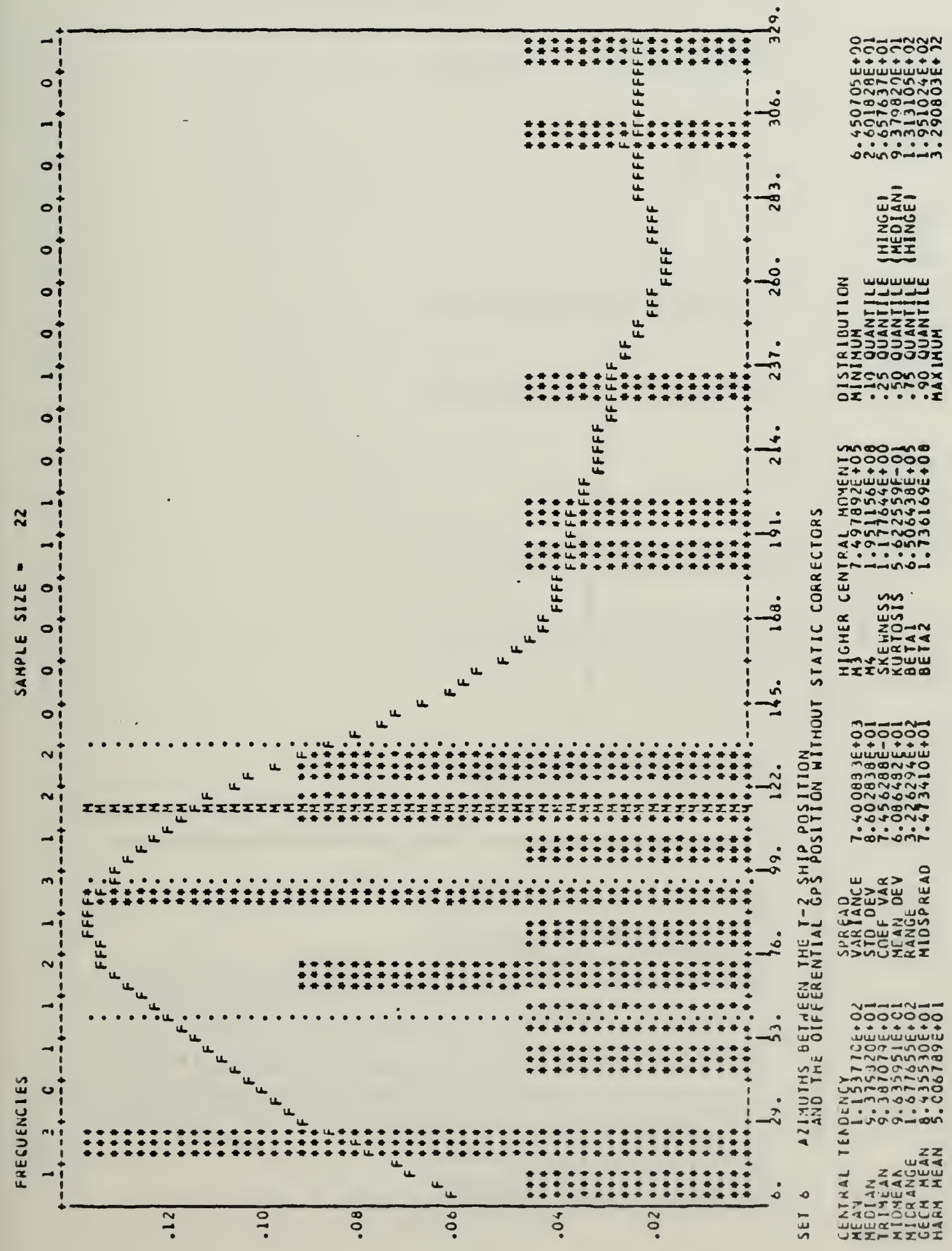



Figure 7.51.

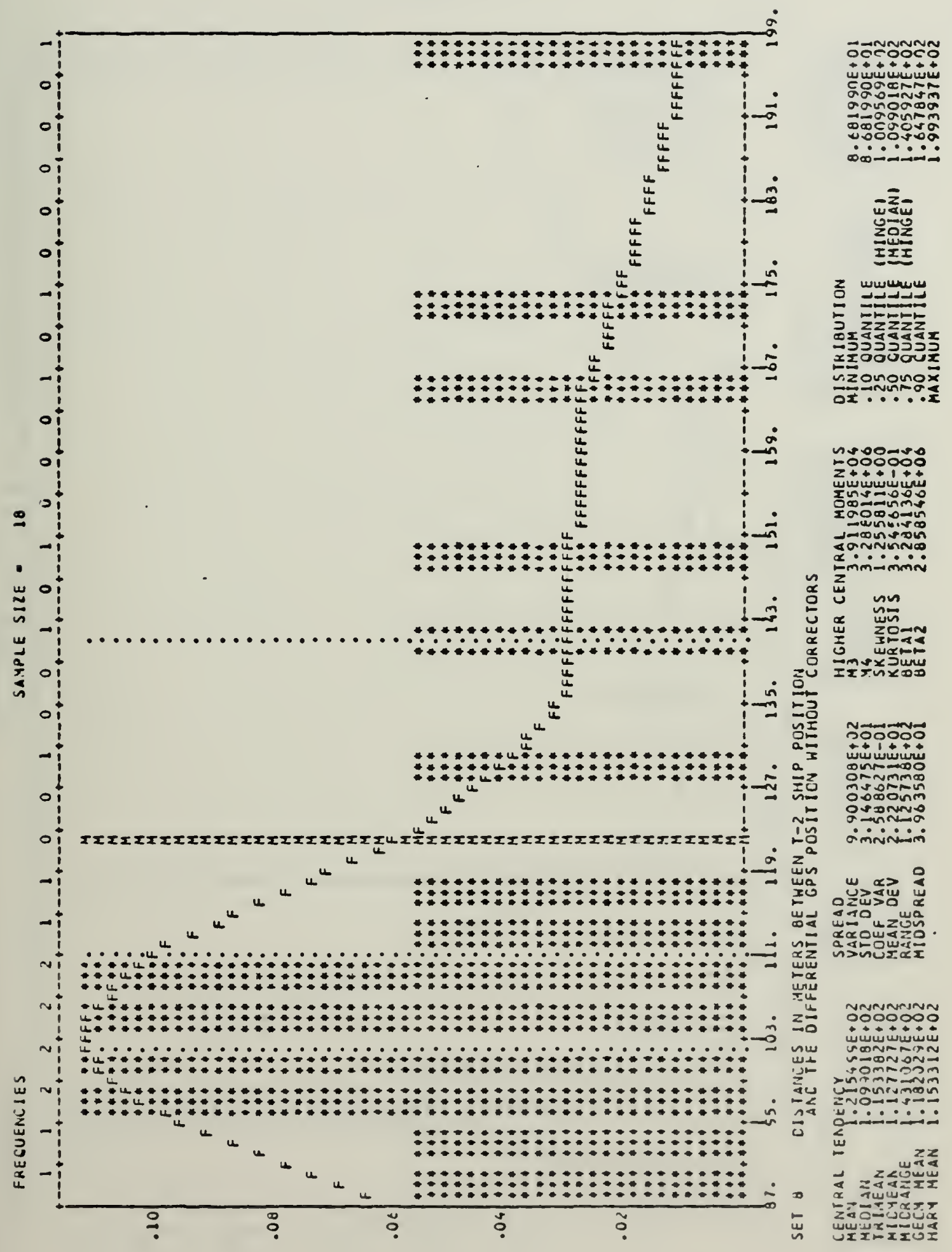



Figure 7.52 .

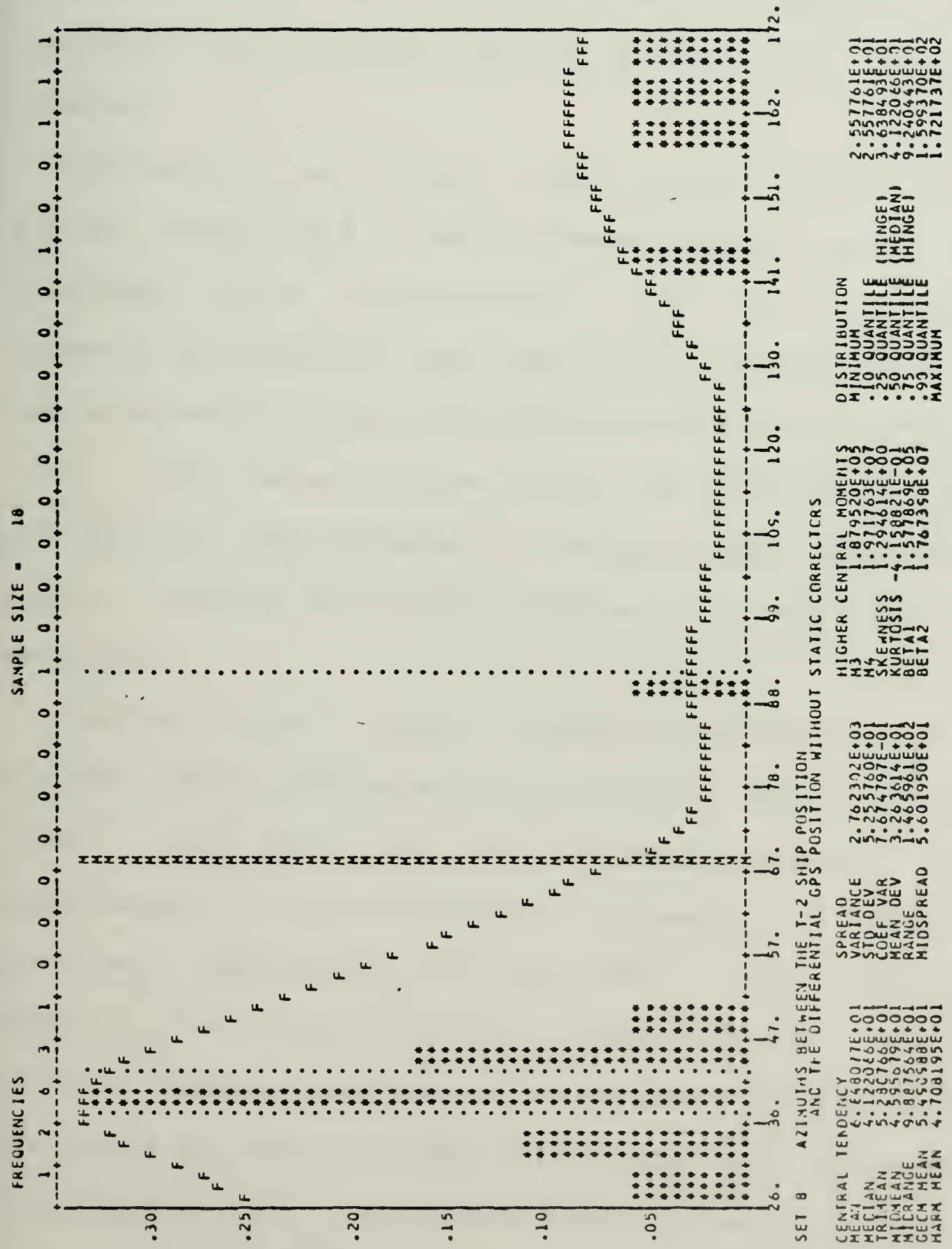



resulting in a greater positional difference. Another factor was the bias introduced by the ranpack 24 -second reception period. This is evident in the azinuth for the theodolite ship position obtained from the GPS shipbcard receiver.

The data for sets 9 and 10 were combined for evaluation and the rèsults were a mean distance between positions of 241 meters and an azimuth of $267^{\circ}$ (fig. 7.53 and 7.54). Values of that magnitude show that the ORE for NAVSTAR 1 vas the error source. Data were sampled from 0600 to 0640 (fig. 7.17). Thus the corfelation betyeen the high NAPSTAR 1 ORE and the high mean distance difference between positicns. Again, receiver bias also introduced an error into the evaluation.

Analysis of set 11 shows a bimodal distribution in both the tyo position differences and azimuths (tig. 7.55 and 7.56). The peaks on the distance histogram are approximately 133 and 160 meters; the peaks on the azimuth histogram, approximately $220^{\circ}$ and $236^{\circ}$. Both peaks are caused by the upload of NaVSTaR 3 halfway through the set and the increasing wagnitude of the VAVSTAR 1 URE just after the upload as shown by figure 7.17. The total positional difference for set 11 was approximately 154 meters. 
Figure 7.53 .

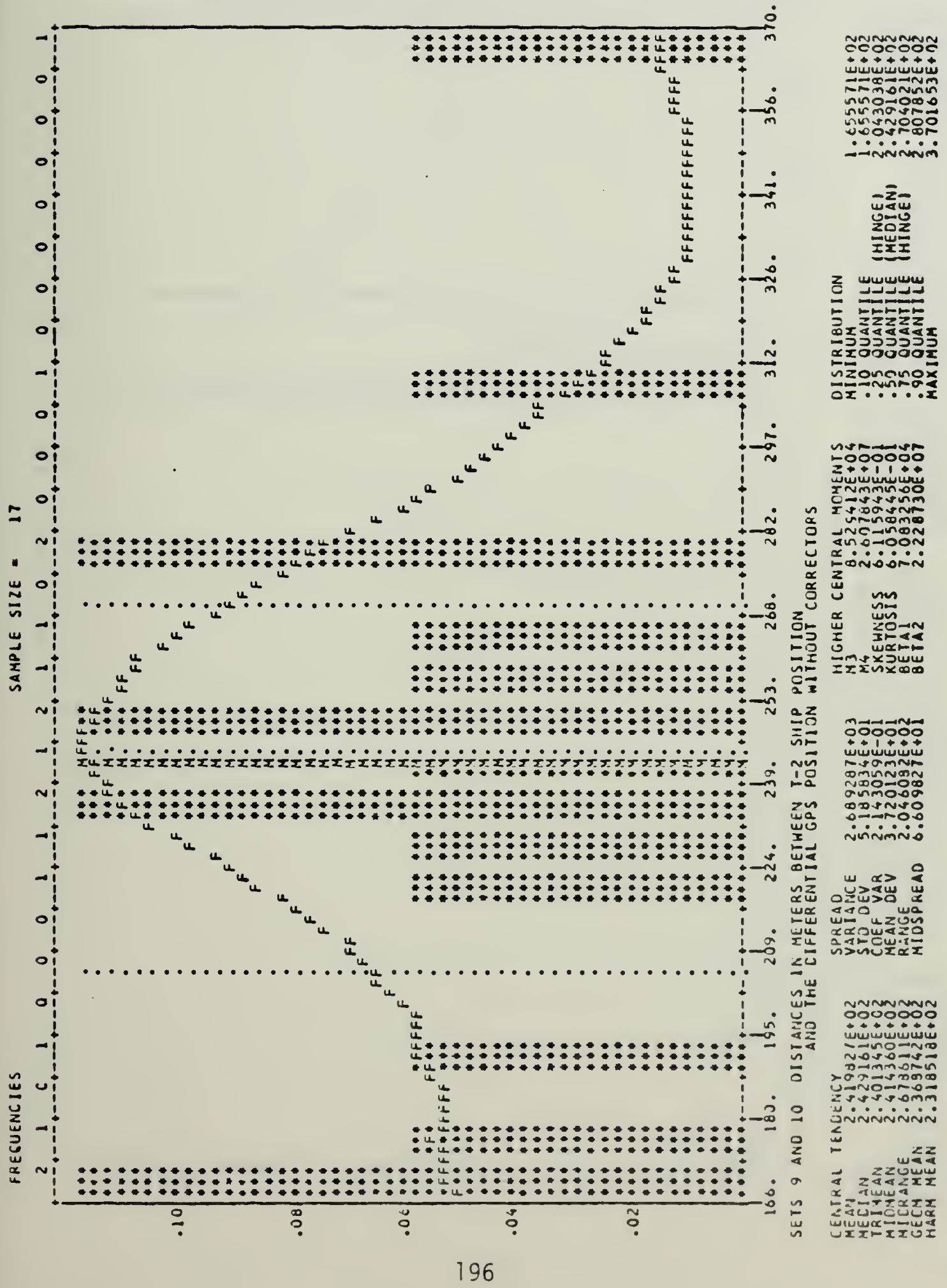


Figure 7.54 .

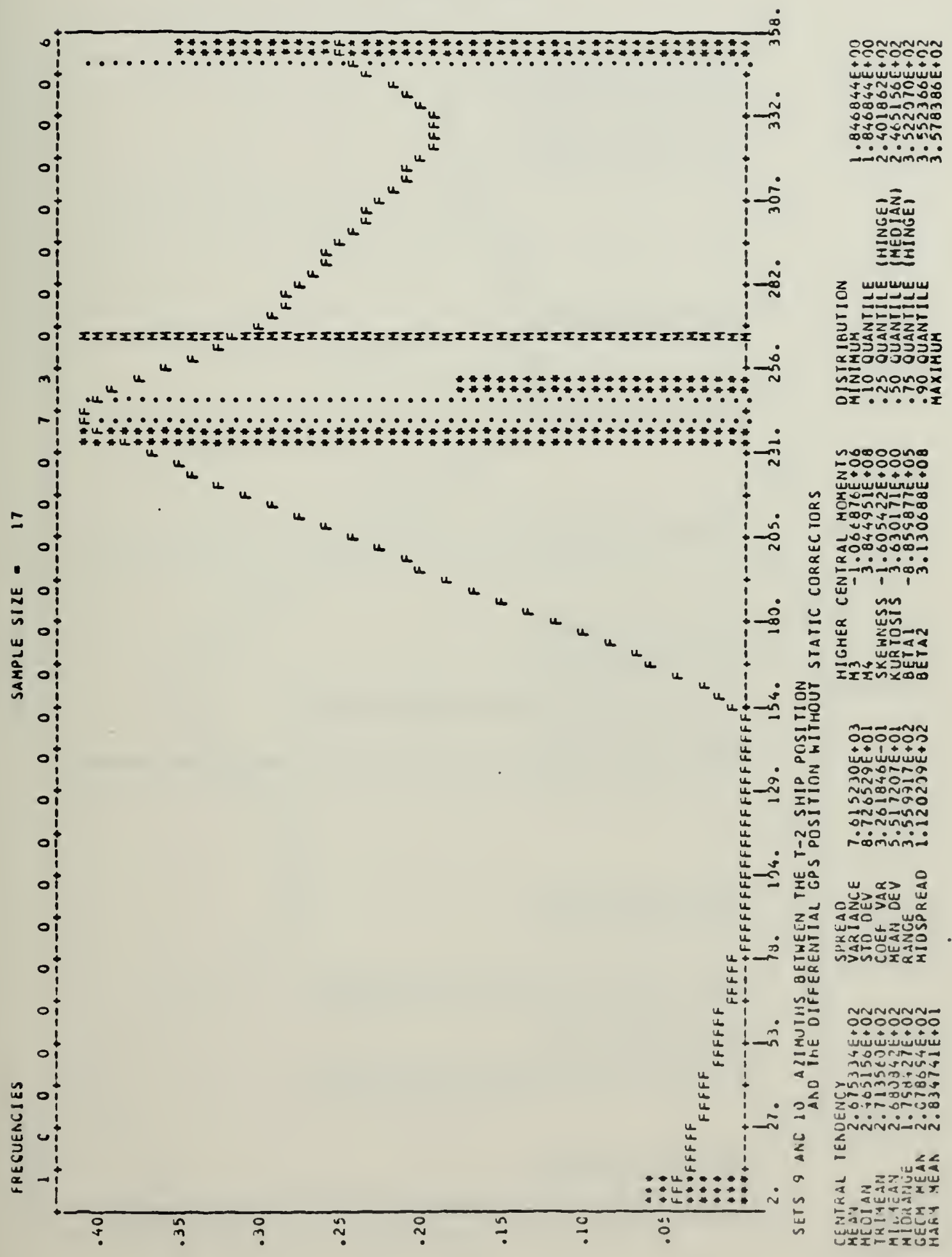


$-1=$ 
Figure 7.55 .

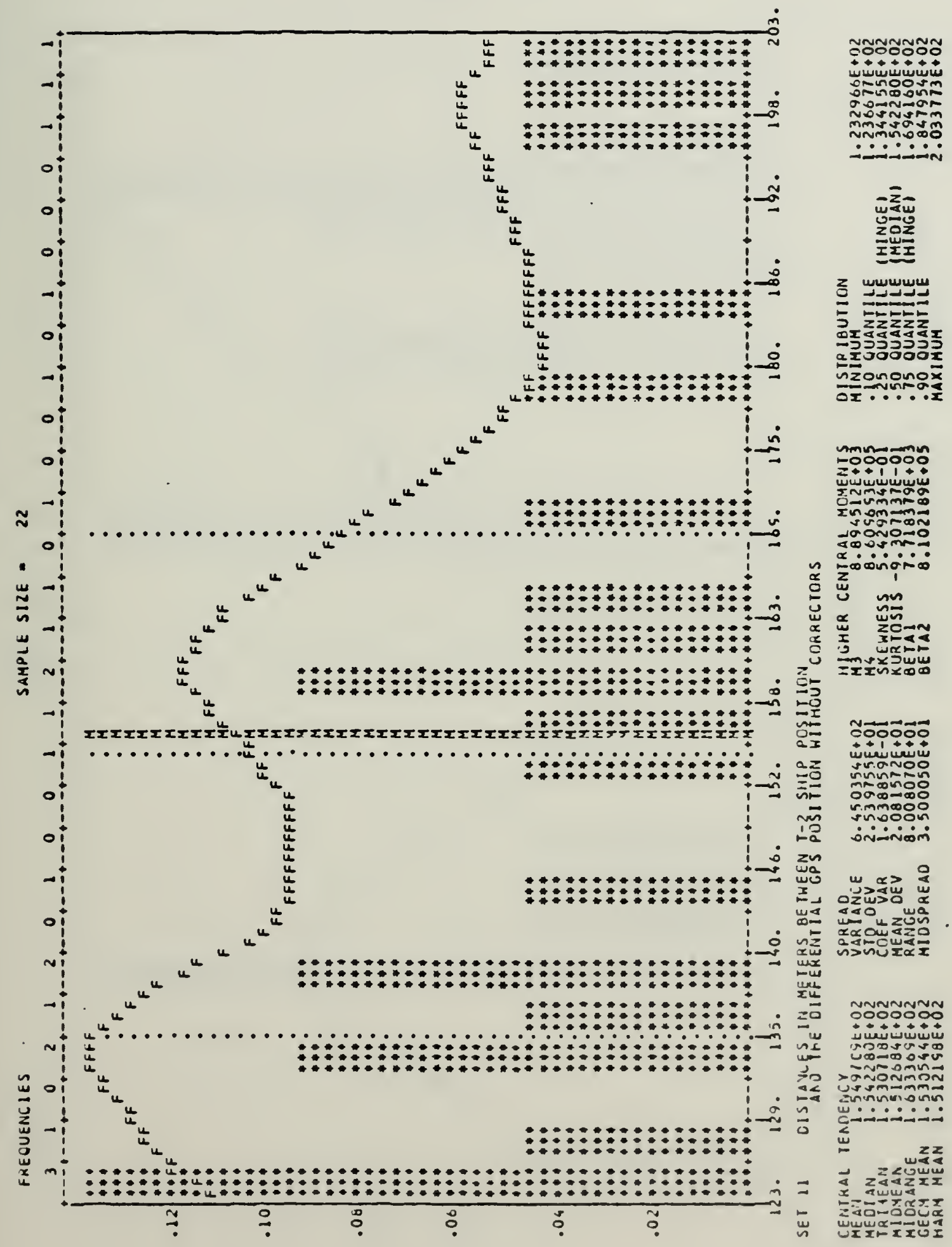



Figure 7.56 .

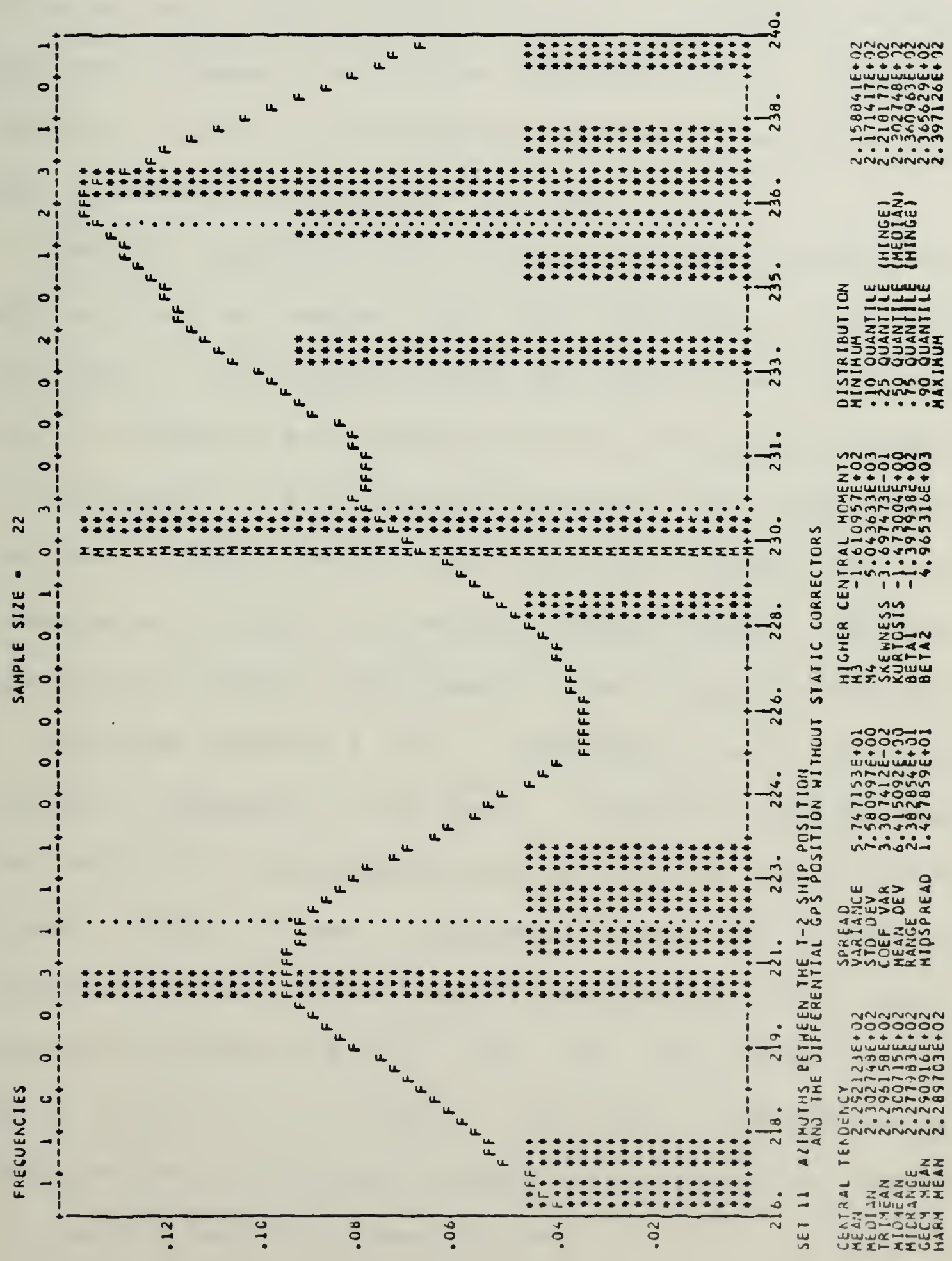


Evaluation of the combined sets 12 and 13 (fig. 7.57 and 7.58) Iesult in a mean distance between the two positions of 172 meters and a mean azinuth of $262^{\circ}$. The mean distance was large because of the large magnitude of the NATSTAR 1 ORE (fig. 7.17). A contributing source of error was the bias introduced by the Manpack receiver.

overall. the data using a five-satellite constellation were as good or better than the data using only four satellites. The results for 12 May using five satellites (fig. 7.59) show a mean distance of 11.4 meters and a median of 10.6 meters. This compares favorably with the results from sets 1 and 2 (fig. 7.39 and 7.40 ). which had mean distances of 10.1 and 11.7 meters, respectively. The five satellite data from 13 May showed a very large variance due to the large NATSTAR 1 URE. Therefore, data were not compared to remaining 13 May data. Data on 15 May for the five satellite constellation had a bimodal distribution because NAVSTAR 1 was uploaded. Once the uploading occurred, the peak distance was 137 meters (fig. 7.60) which compares favorably with 121, 241, 154, and 172 meters for sets 8,9 and $10,11,12$ and 13 . Thus with a Eive-satellite constellation, positioning results were as good or better than the four-satellite constellation. 

Figure 7.57 .

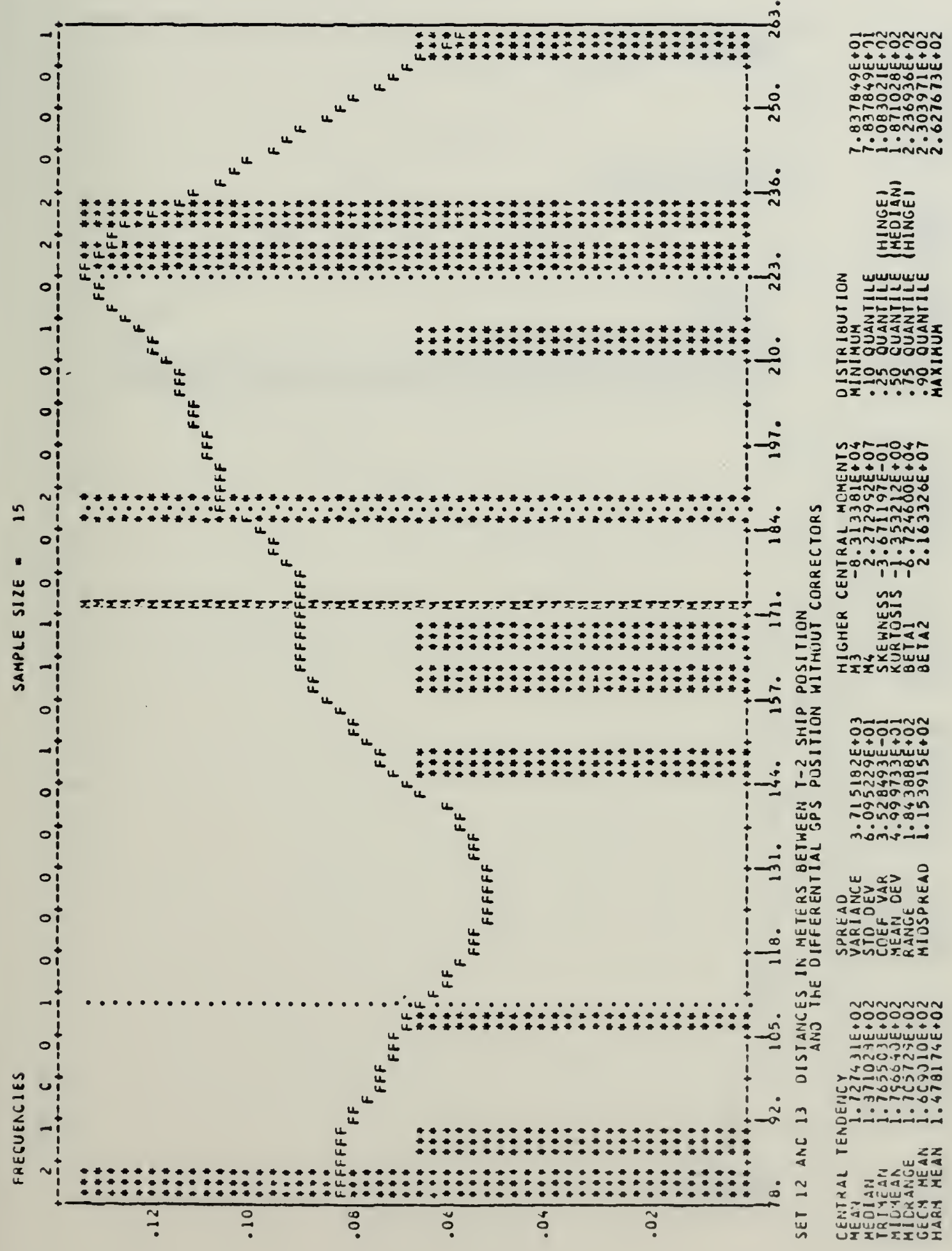



Figure 7.58 .

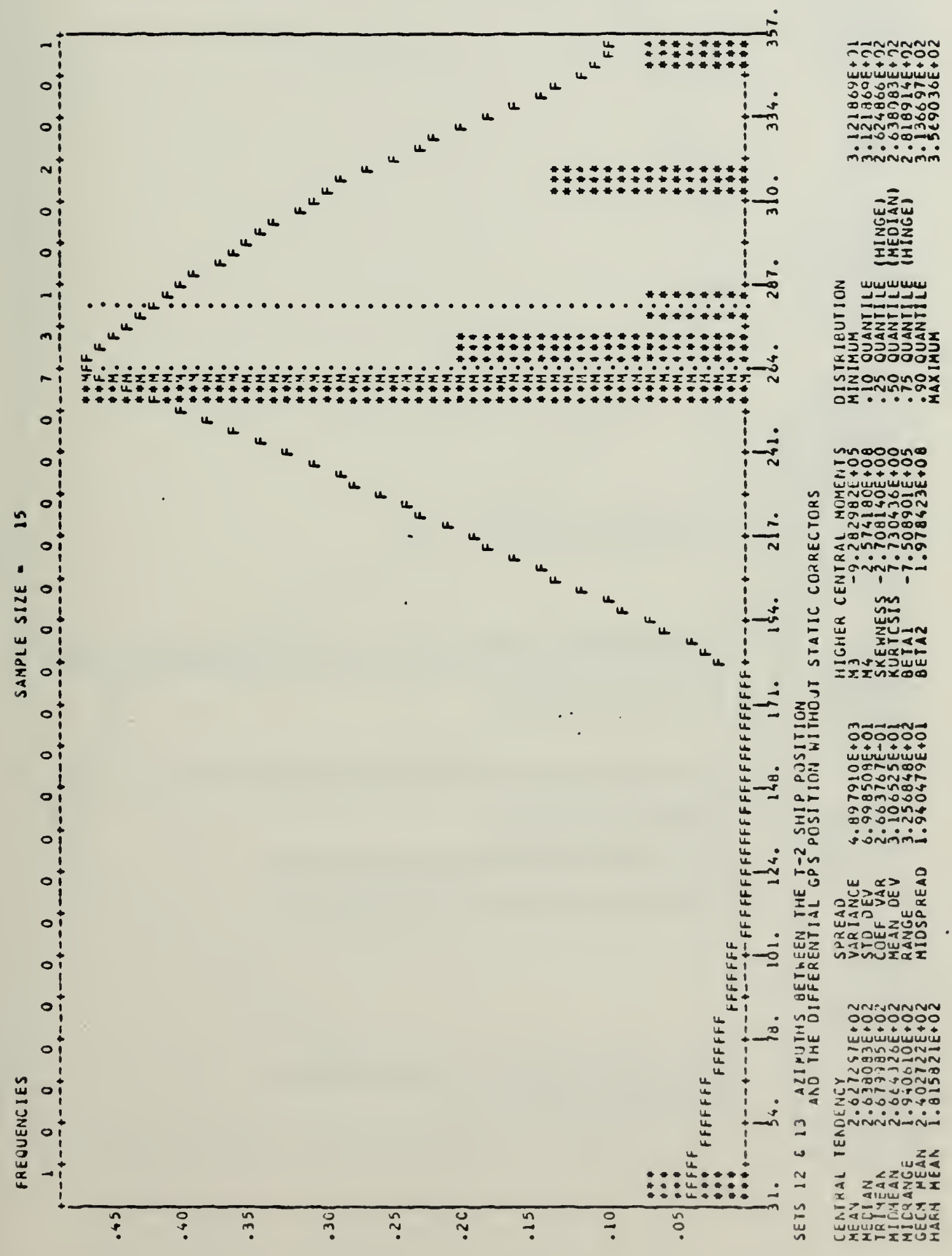



Figure 7.59.

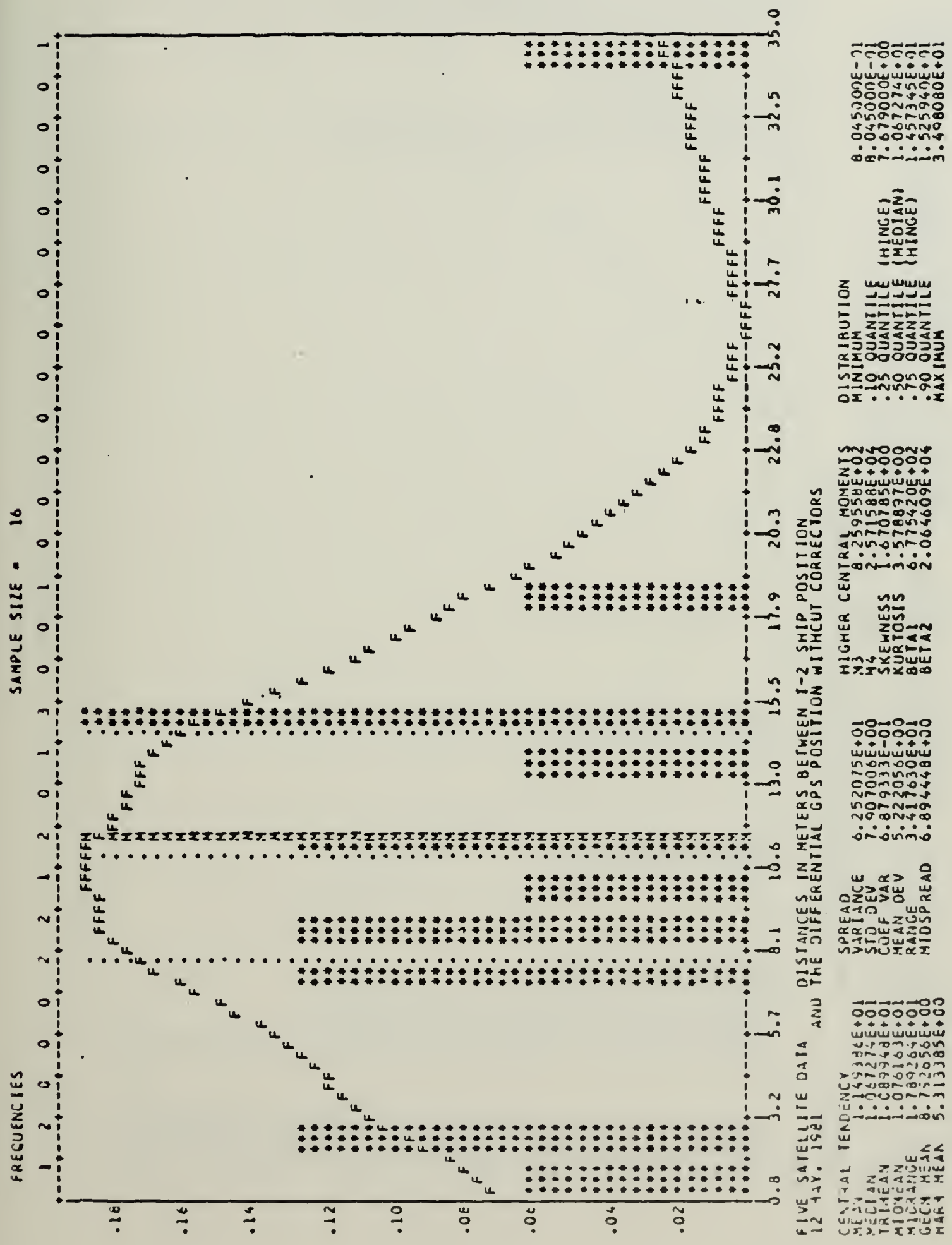


Figure 7.60.

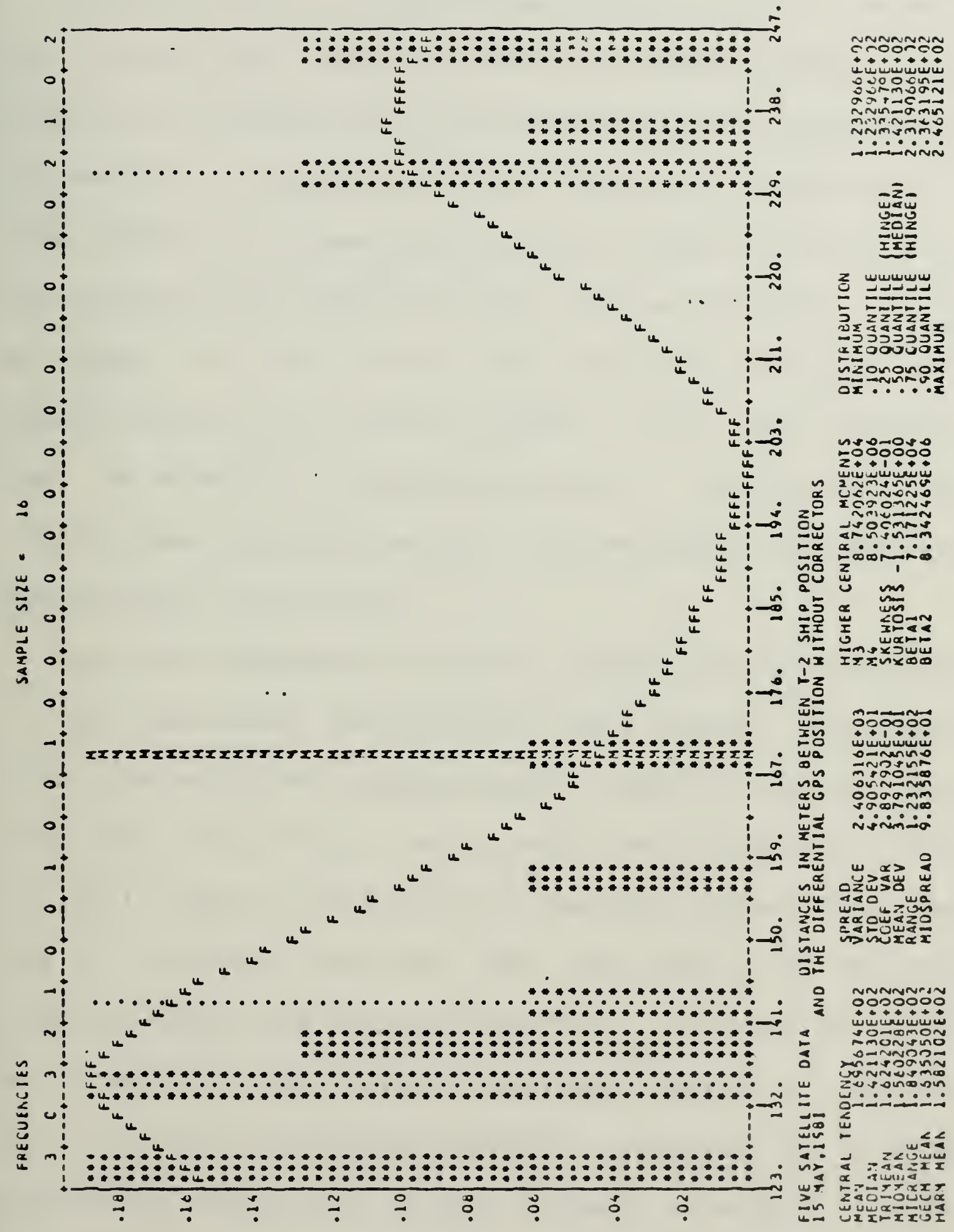



Rigures 7.61 to 7.74 show the difference by fix between the latitude and longitude plots of the theodolite ship position, the differential GPS position, and the uncorrected GPS position. During most of the testing, the longitude of both methods of GPS positioning was in closer agreenent with the theodolite ship position than was the latitude. Shoun on figure 7.9 and 7.10 are the satellite elevation and azimuth data for the testing period. This data indicates that the satellite constellation had a larger effect on latitude than longitude because the predominant ranging was computed from one quadrant.

The large differences between the GPS position relative to the theodolite ship position were easily identified during the shipboard testing period. Latitude and longitude plots (fig. 7.65,7.66,7.69 through 7.74) for sets 4, 5,9, 10. and 12 show the deriations of the GPS receiver positions from the predicted positions that were obvious to the GPS operators during the shipboard testing. For sets 4 and 5 . the stationary GPS receiver positions began to deriate greatly frcm the geoceiver position, resulting in a large differential correction to the GPS ship position. These large differential corrections caused the differential GPS 

LATITUDE COMPARISDH SETS 1,2

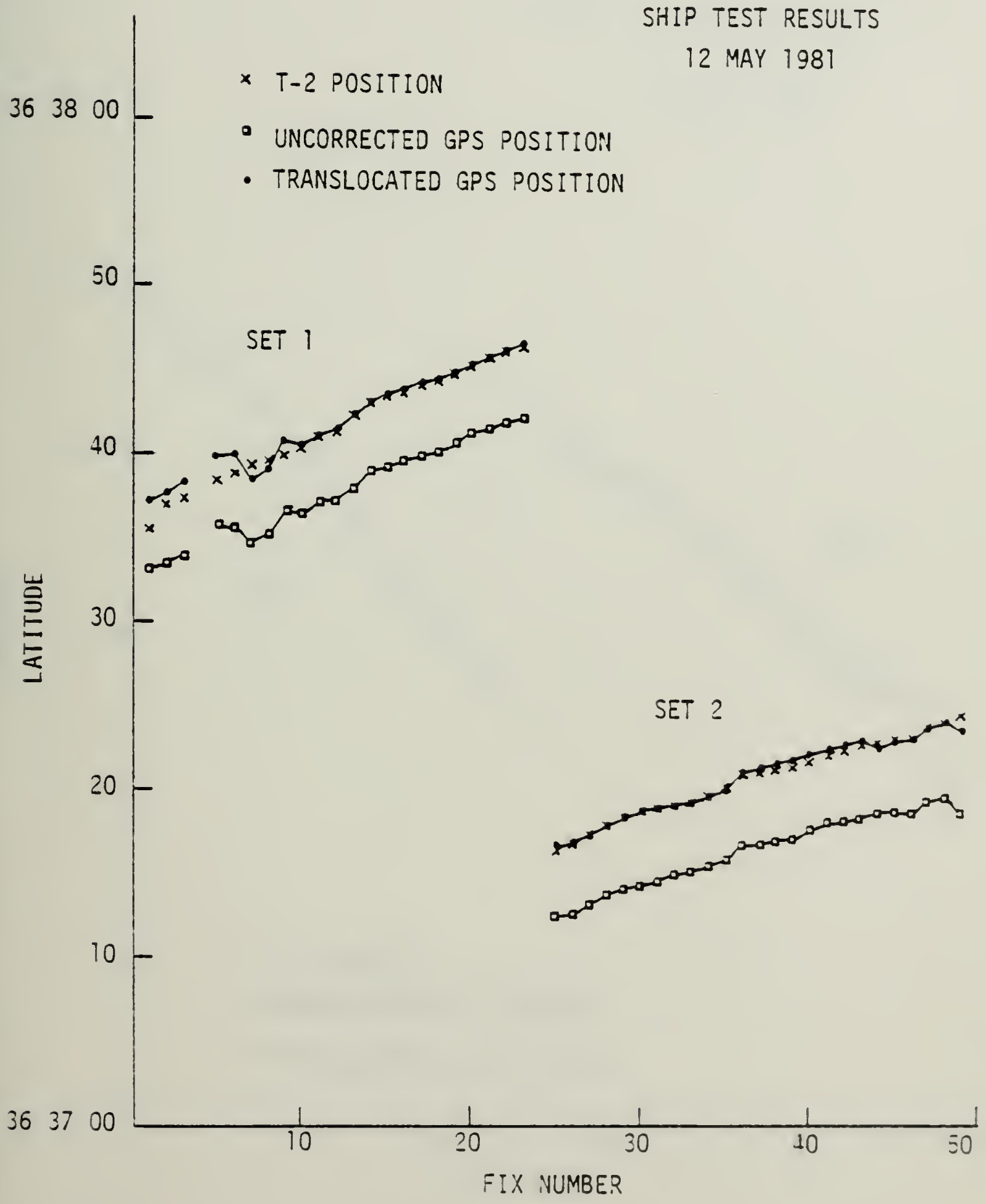

Figure 7.61 . 

LONGITUDE COMPARISOII SETS 1, 2

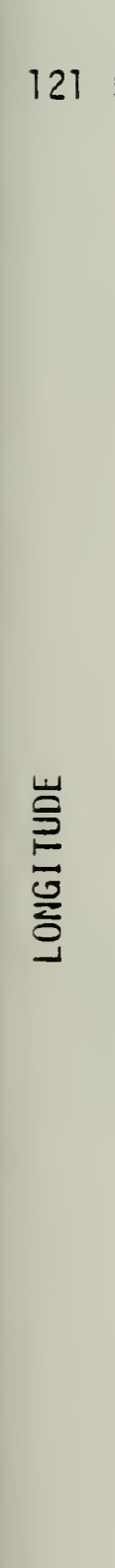

SHIP TEST RESULTS

12 MAY 1981

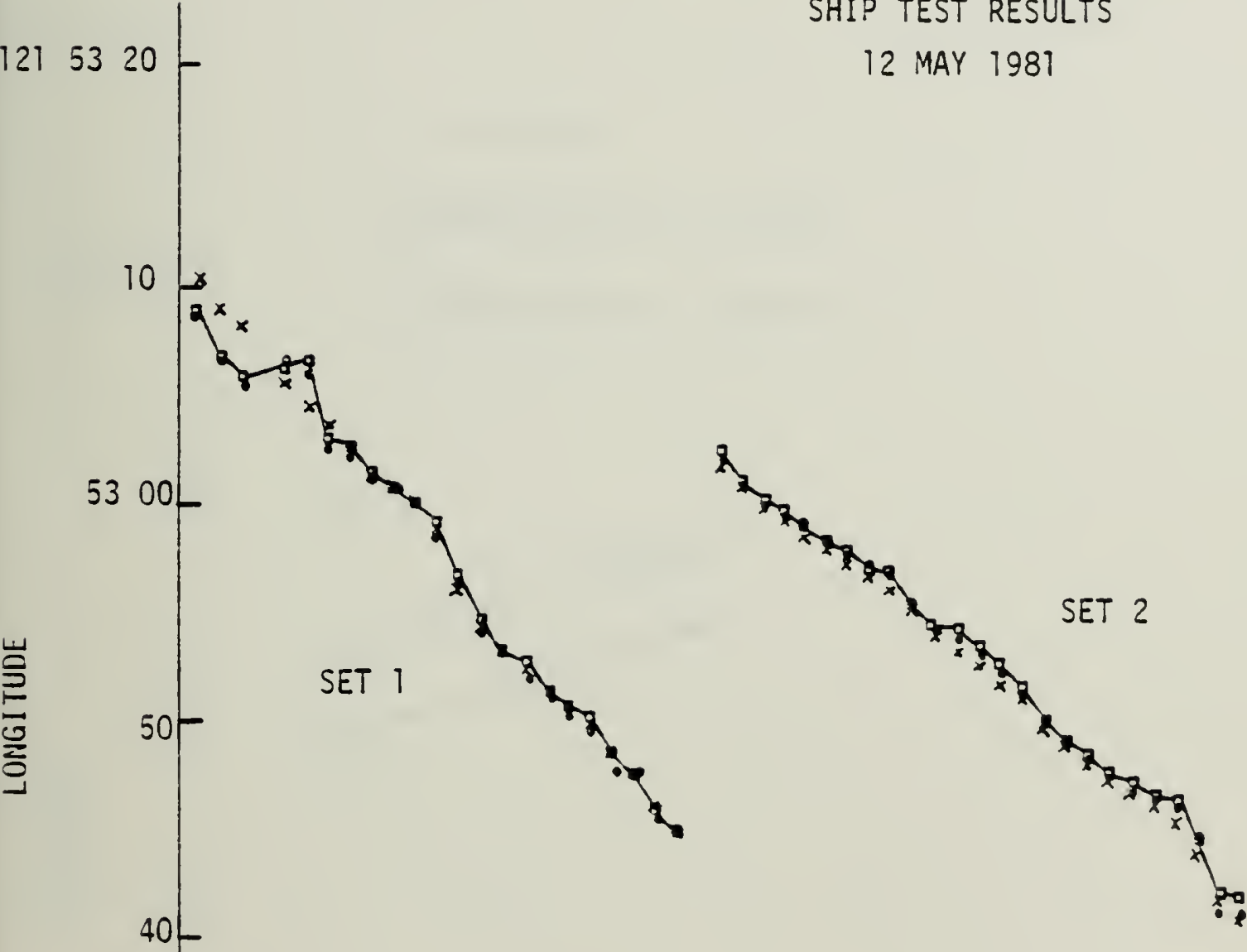

121 

LATITUDE COMONRISON SET 3

SHIP TEST RESULTS

12 MAY 1981

$\times T-2$ POSITION

- UNCORRECTED GPS POSITION

$36 \quad 3750-$

- tRANSLOCATED gPS POSITION

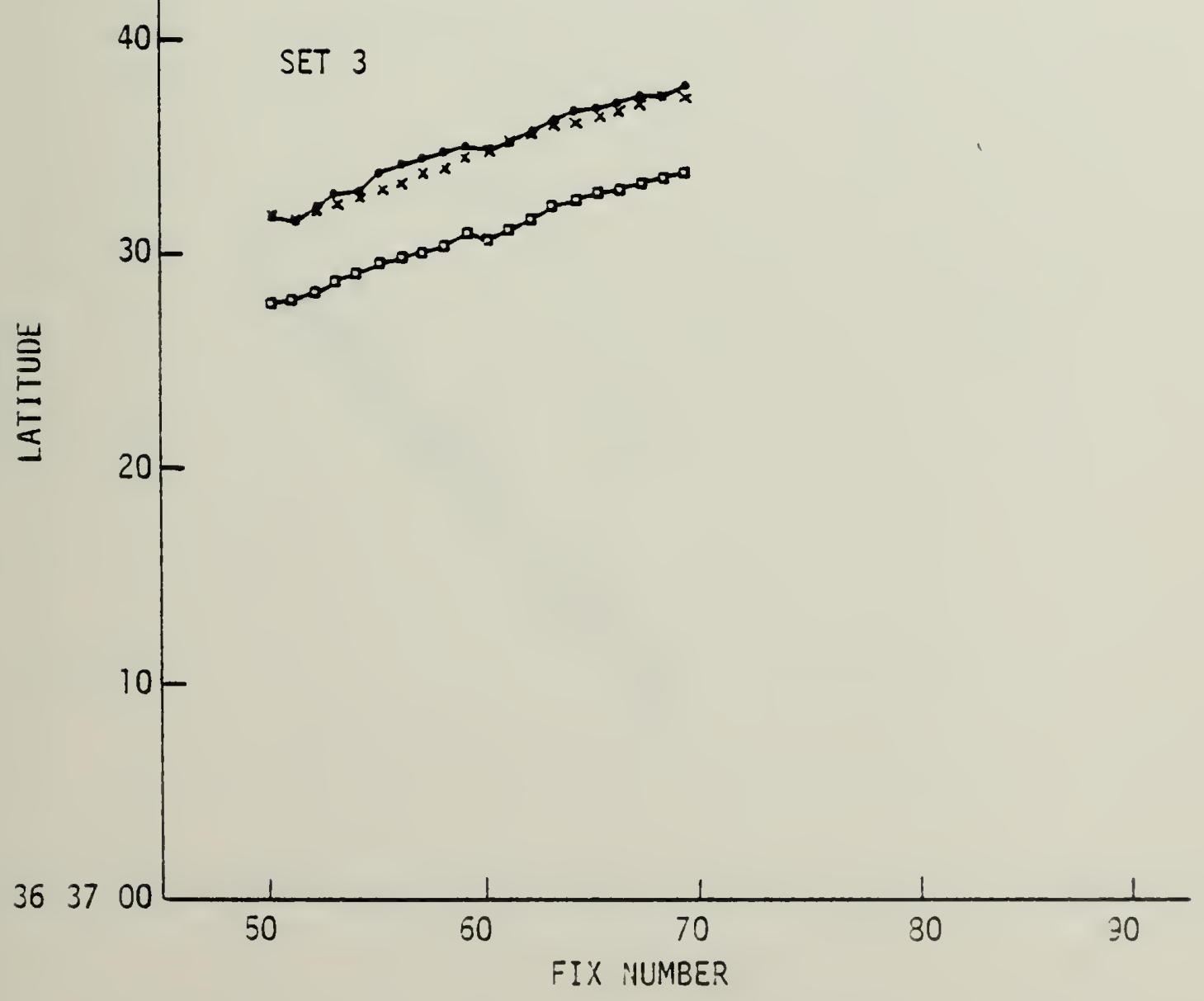

Figure 7.63 . 



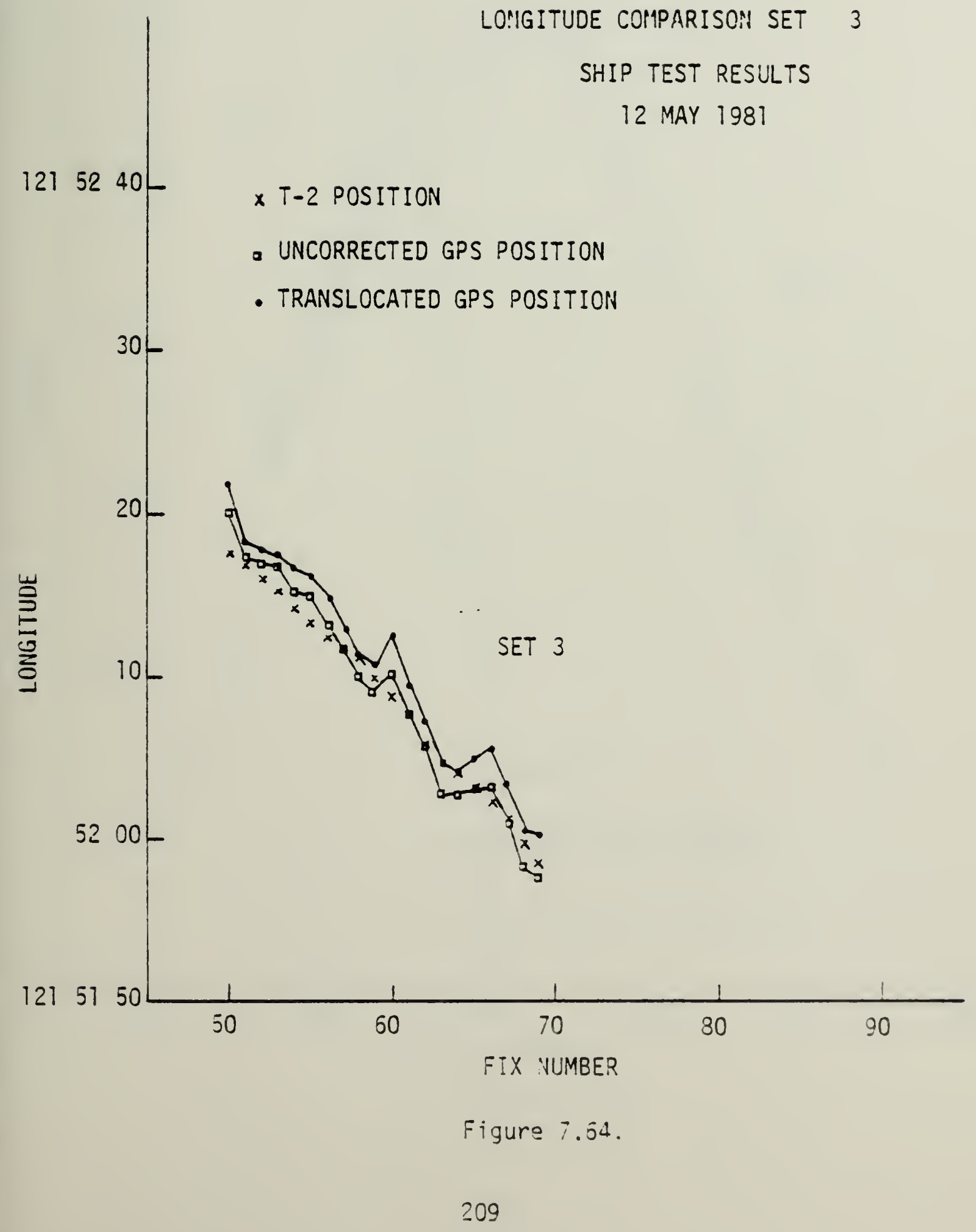




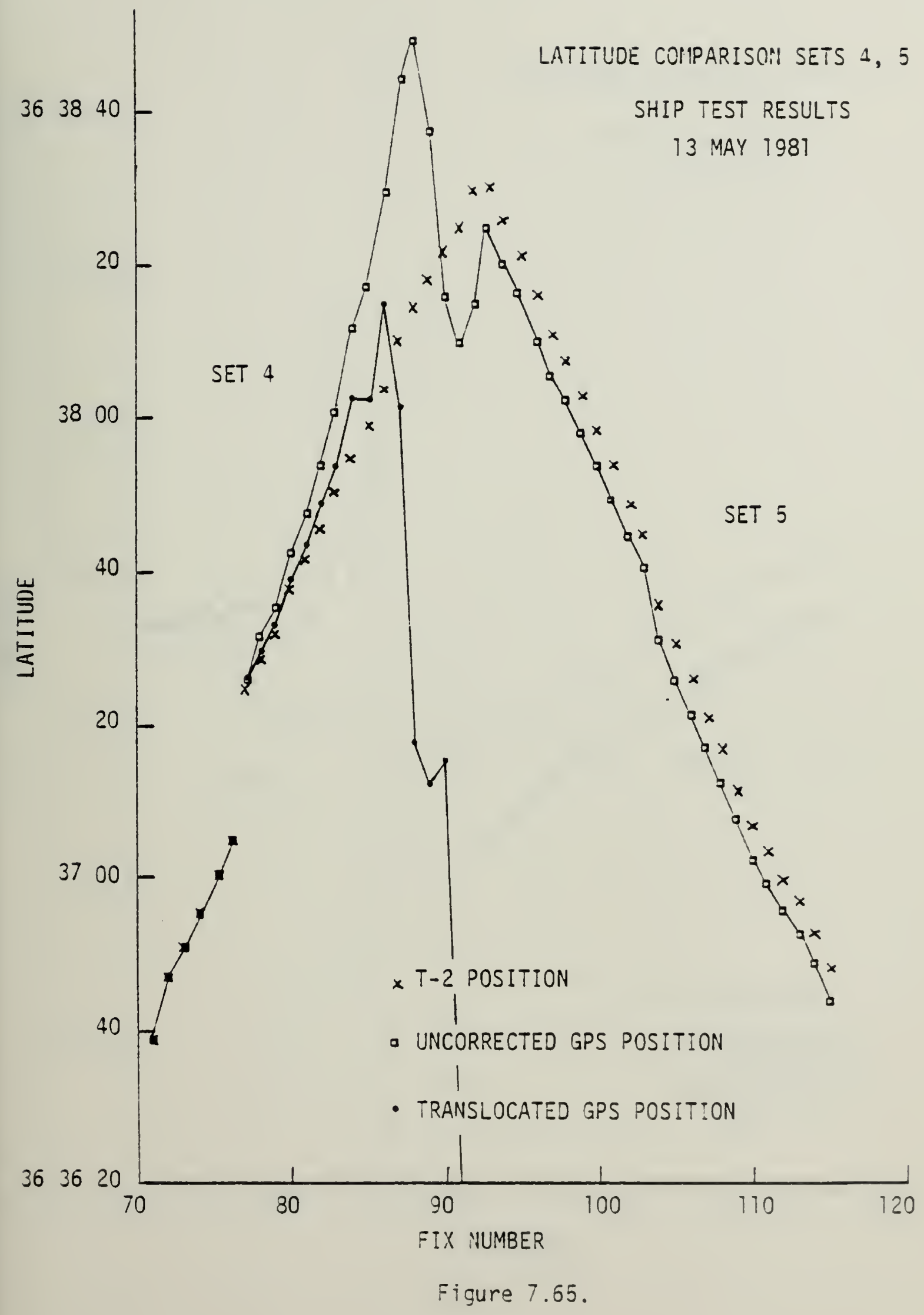





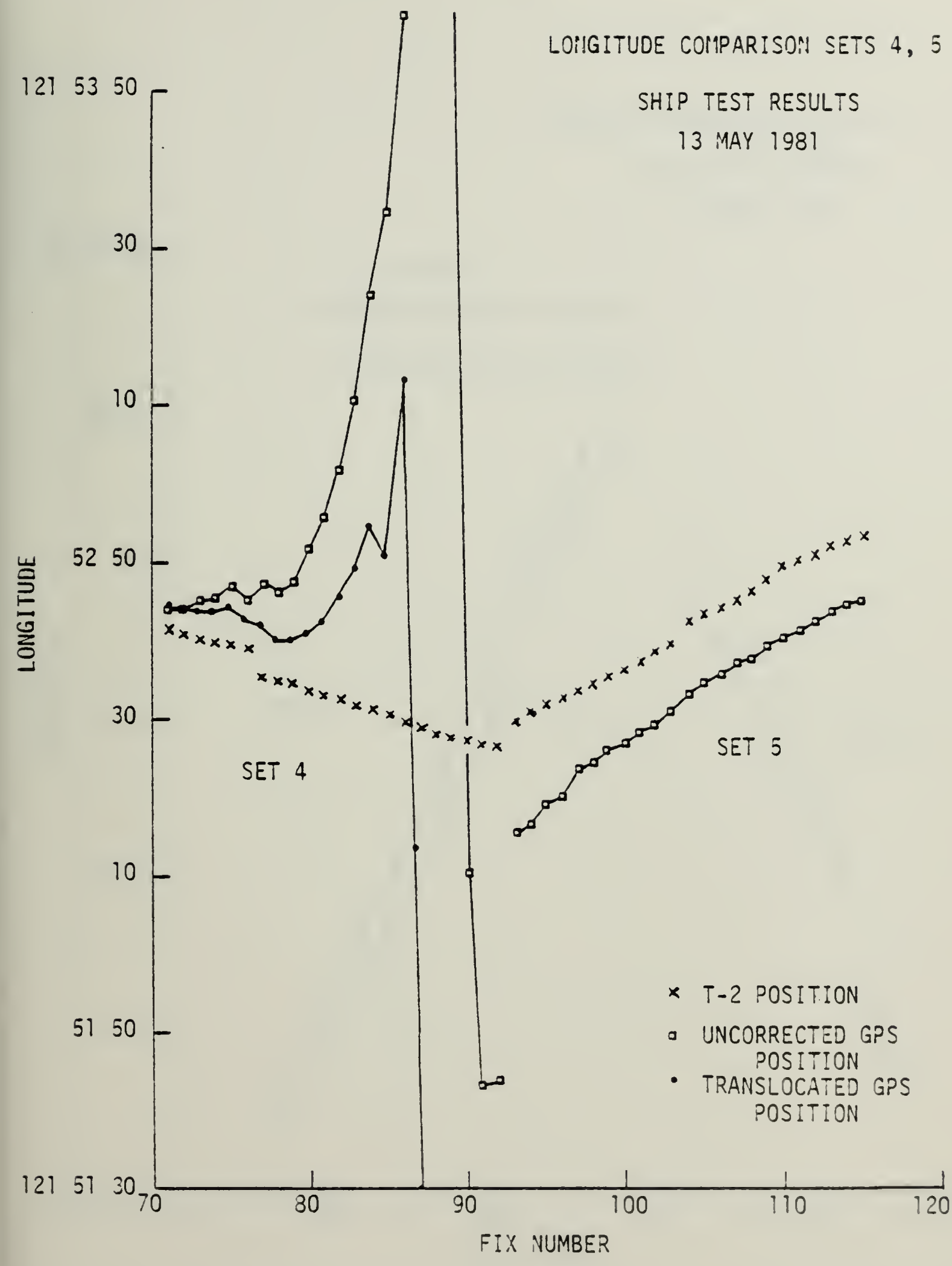

Figure 7.66 . 

LATITUDE COMPARISO: SETS 6,7

SHIP TEST RESULTS

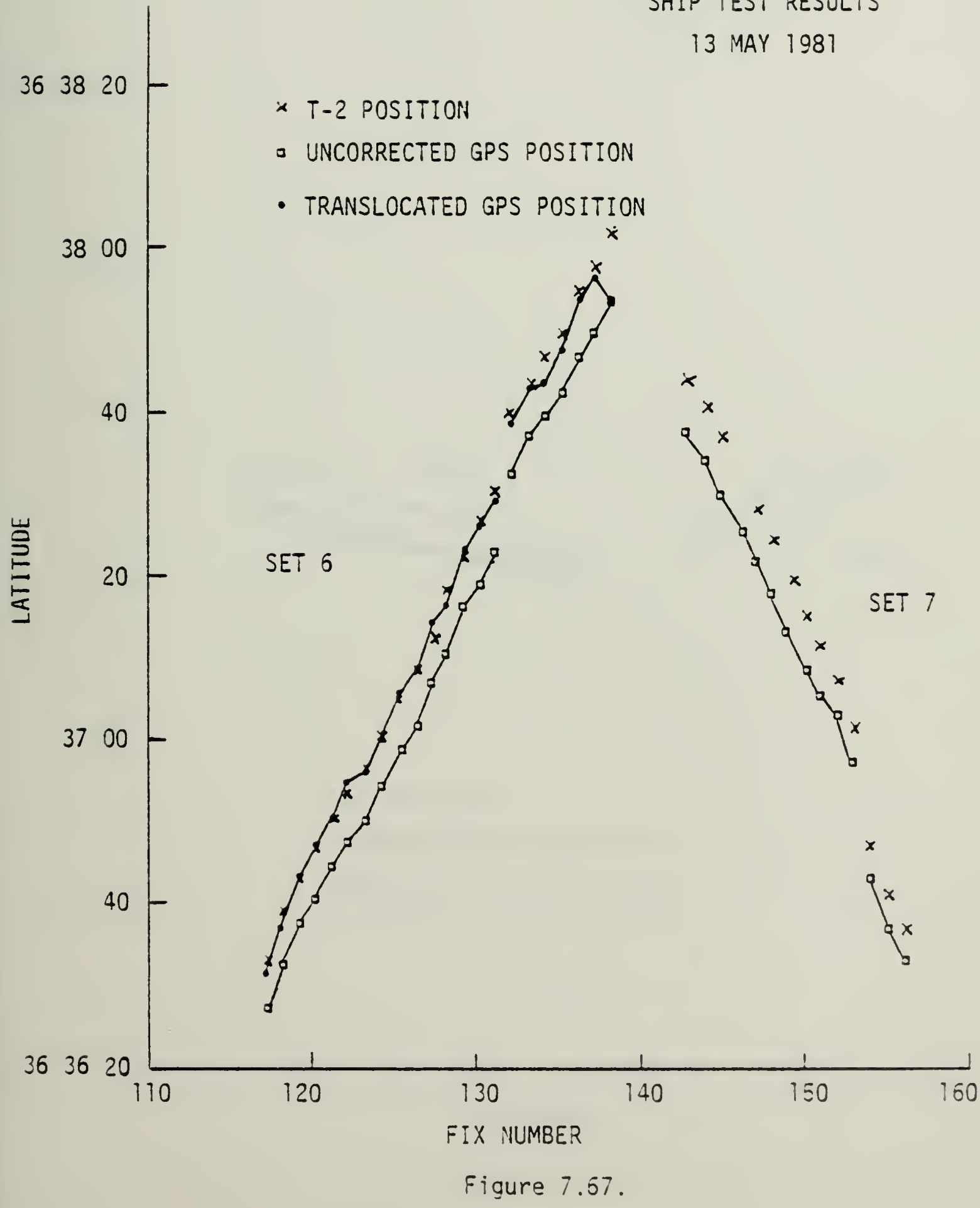

$\begin{array}{lll}36 & 38 & 20 \\ 38 & 00\end{array}$

$\times$ T-2 POSITION

- UNCORRECTED GPS POSITION

- TRANSLOCATED GPS POSITION

13 MAY 1981 



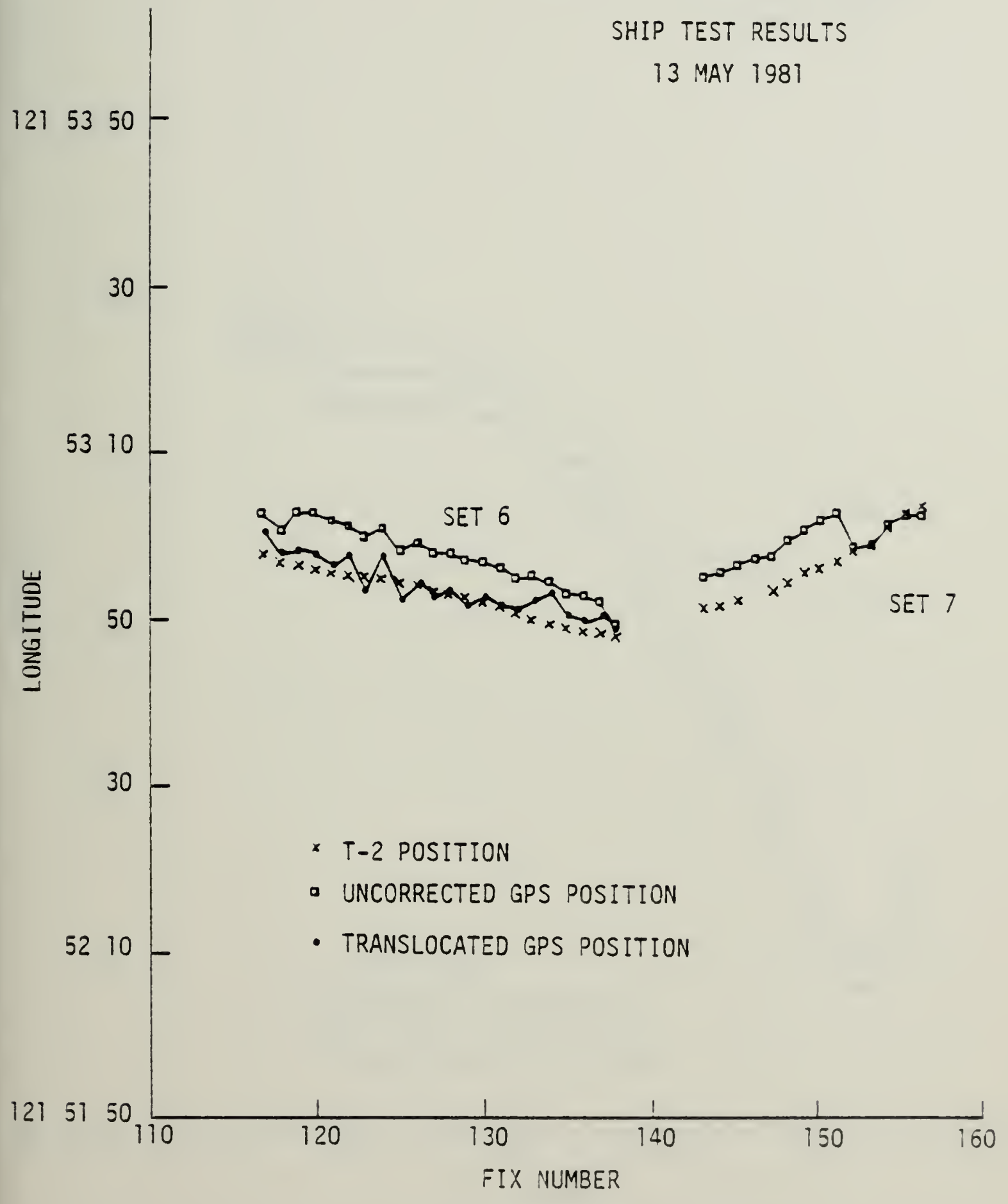

Figure 7.58 . 

LATITUDE COMPARISON SETS 8,9

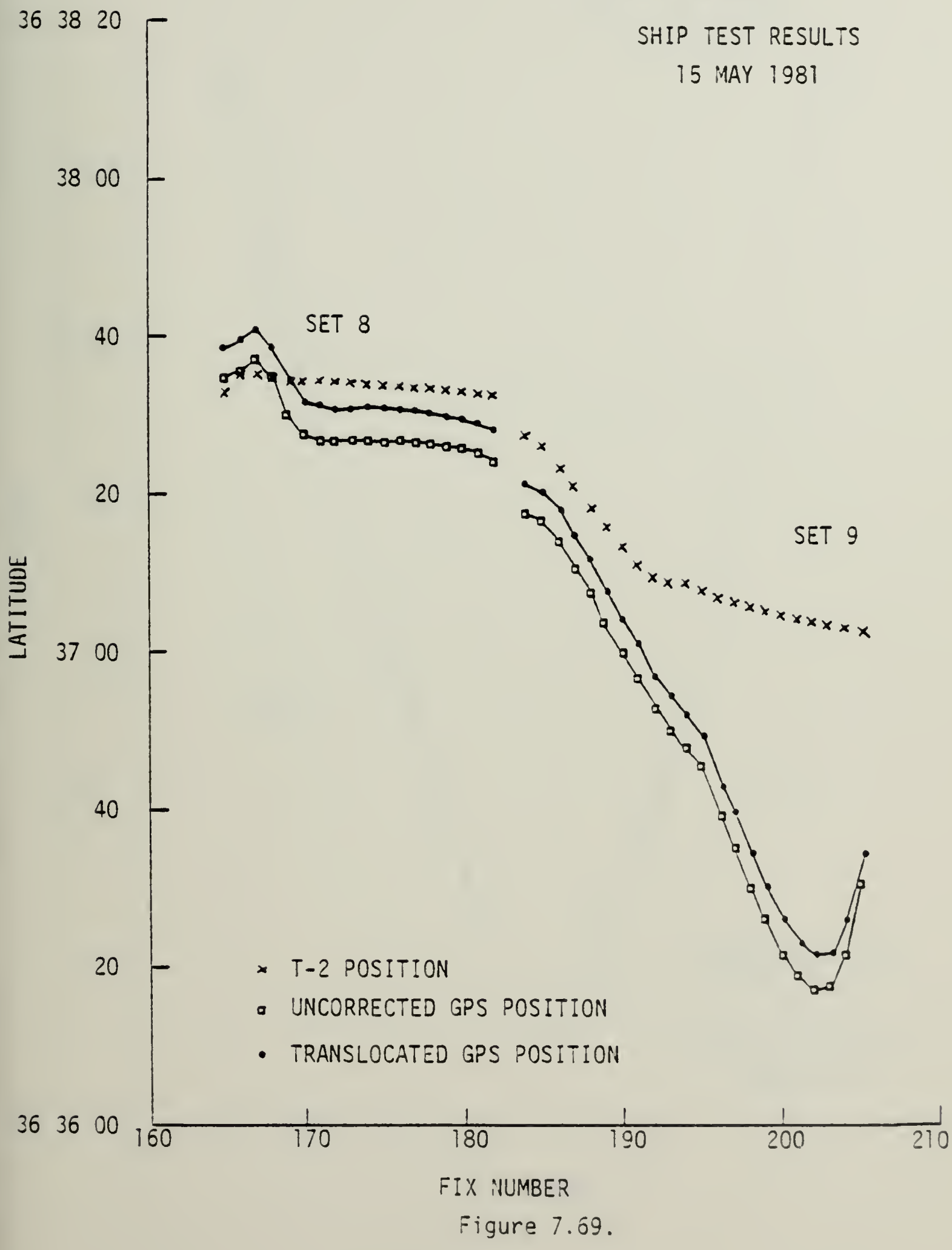





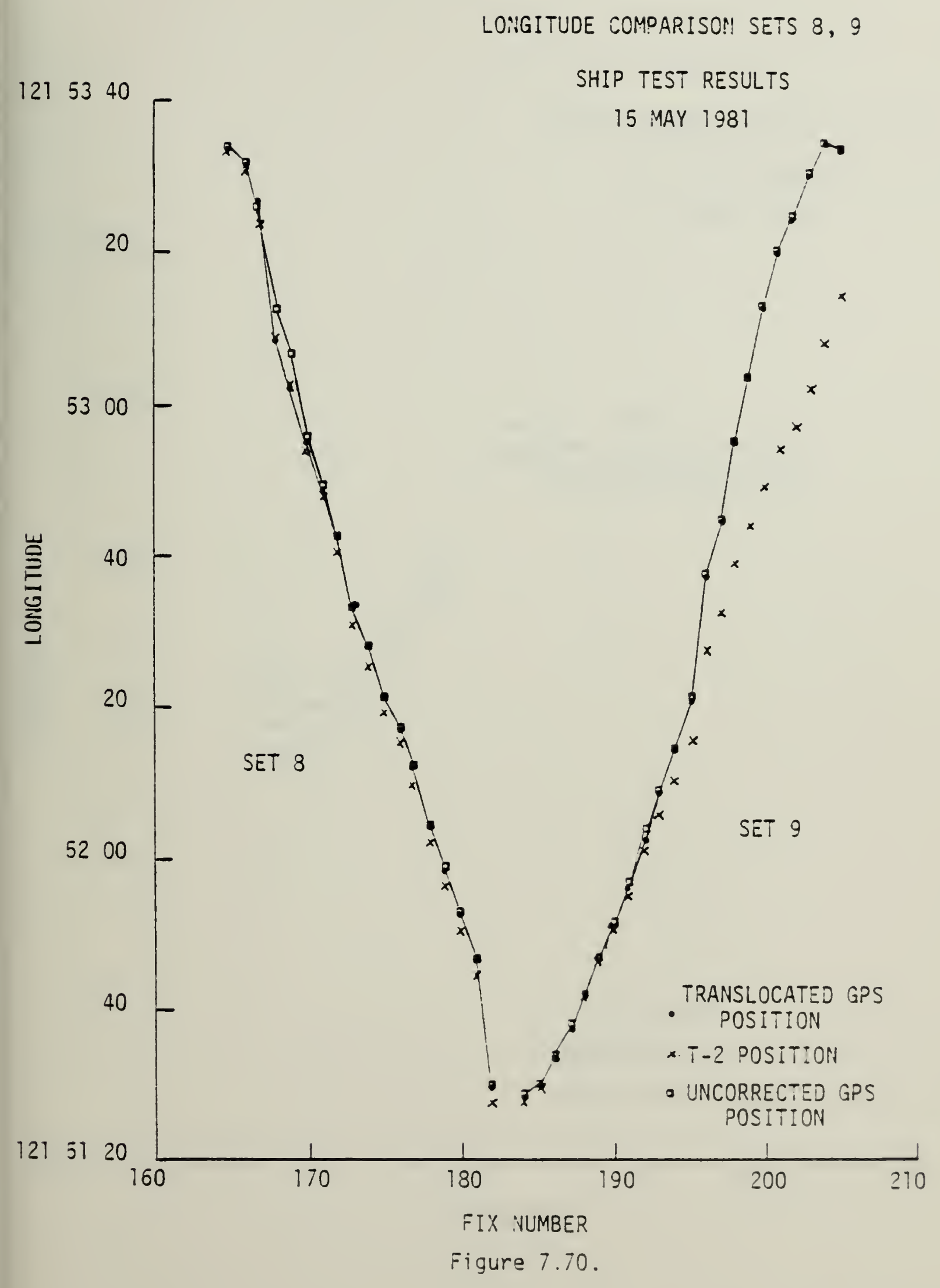



LATITUDE COMPARISON SETS 10,11

SHIP TEST RESULTS

15 MAY 1981

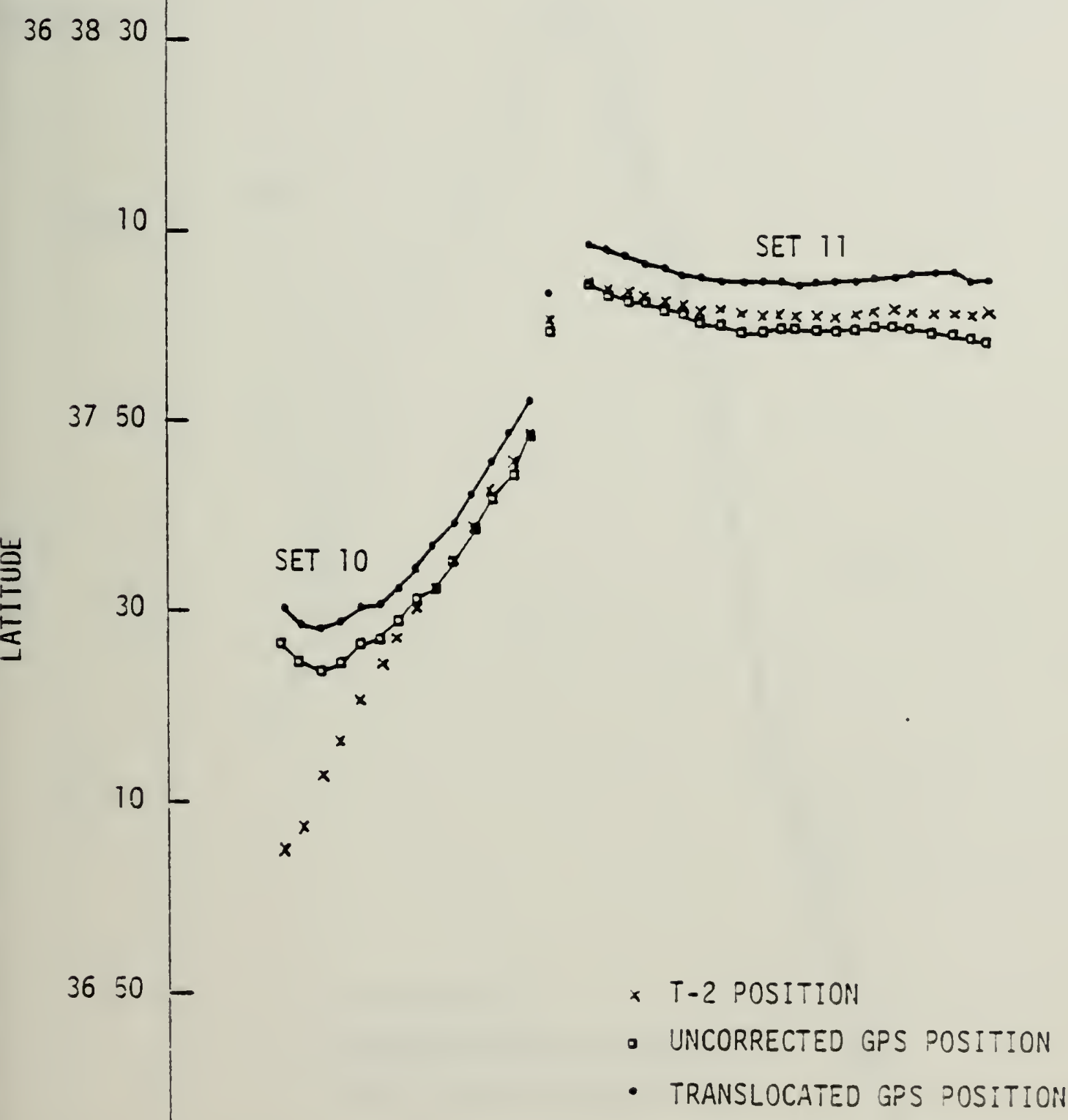

\begin{tabular}{lllllll}
36 & 36 & $30_{20}$ & 1 & 1 & 1 & \\
\hline
\end{tabular}

FIX IUMBER

Figure 7.71 . 

LONGITUDE COMPARISON: SETS 10, 11

SHIP TEST RESULTS

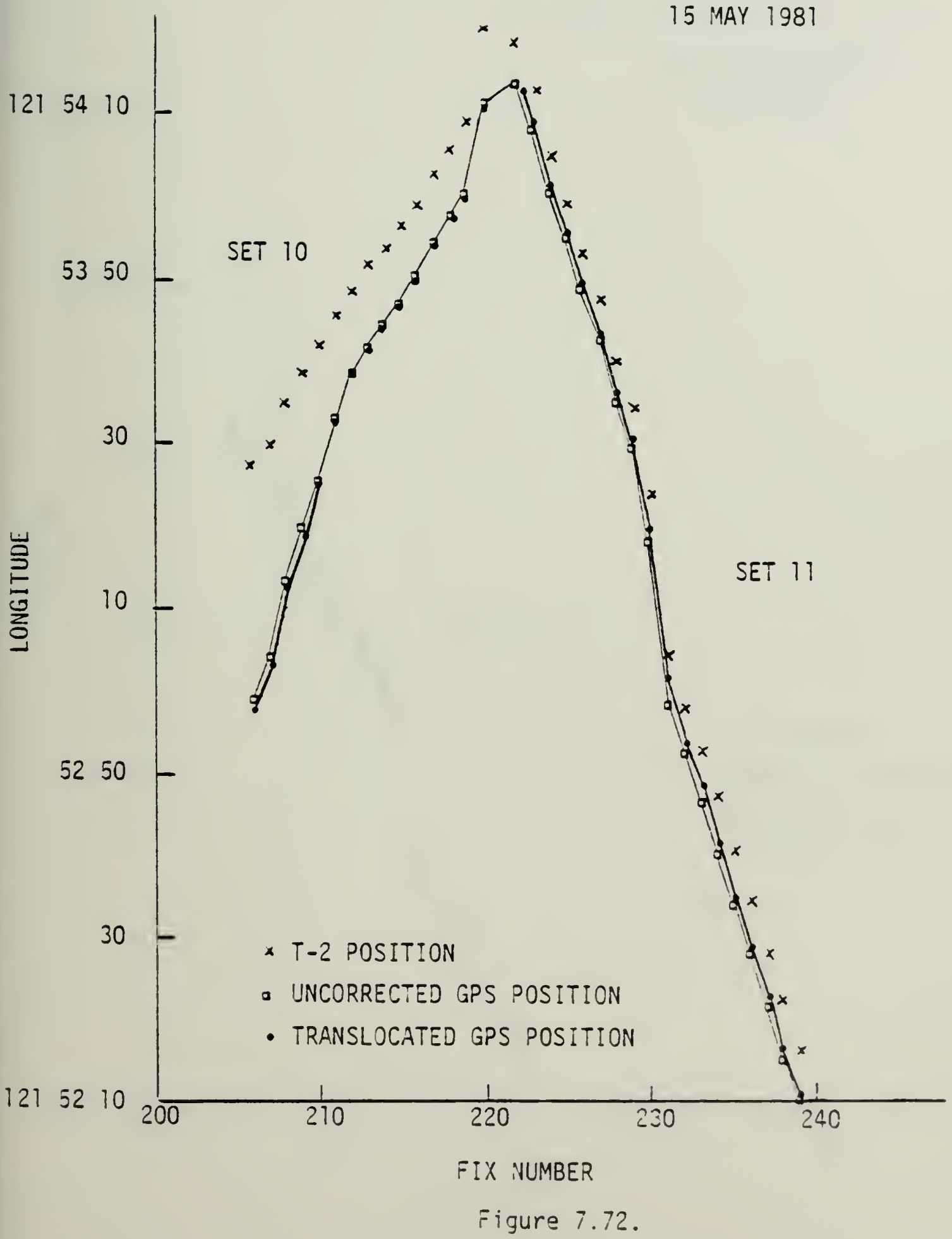





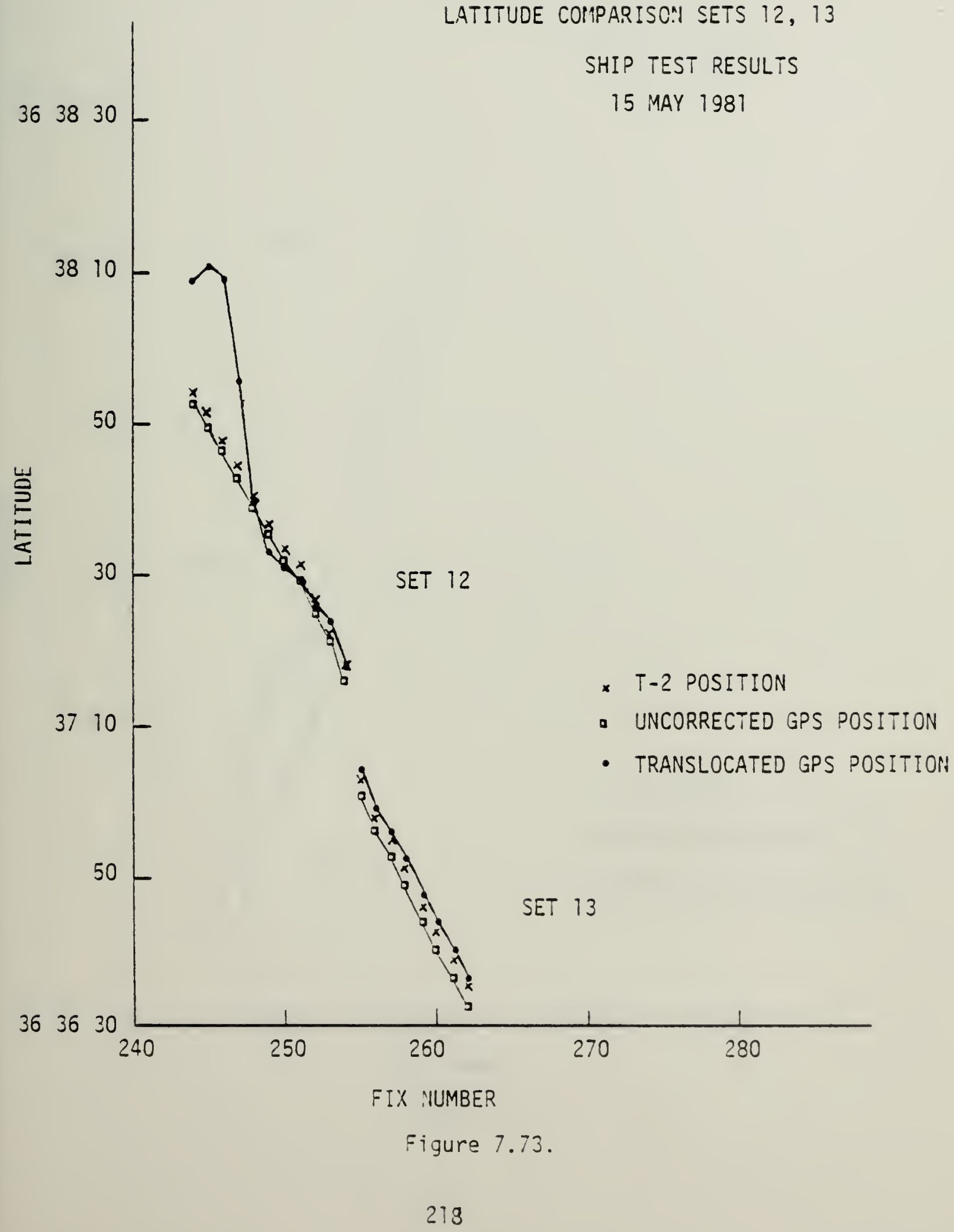



LONGITUDE COMPARISON SETS 12,13

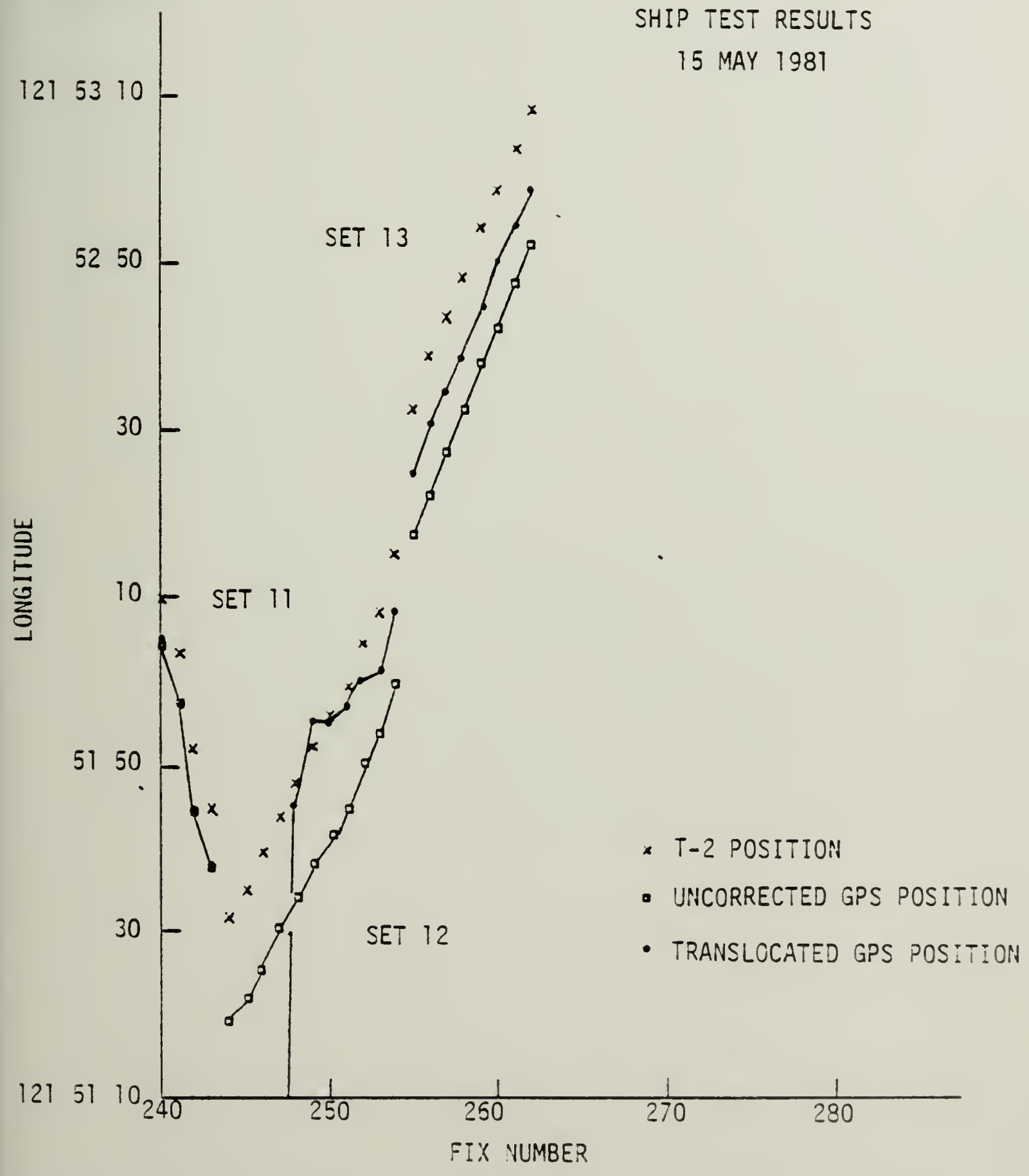

Figure 7.74 . 
position shown on figures 7.65 and 7.66 to deviate a large amcunt from the theodolite position and the uncorrected GPS position. 



\section{CONCLO SIONS}

The objective of the study was to determine whether the application of GPS in a translocated or differential mode provides sufficient position accuracy for near-shore hydrographic surveys. Several assumptions were made prior to the test: (1) two GPS receivers required for the differential mode performed the computations similarly, so that in the worst case a constant bias would be displayed if both receivers were colocated; (2) the process of updating the ephemeris information would not contribute a significant positional error to GPS in the differential mode: reasonable accuracy could be obtained by using the output from the receiver control display unit, that is, sophisticated processing methods were not reguired; and (4) the Manpack receiver results would not differ when used in stationary or low-dynamic environments (shipboard at 4 knots).

None of these assumptions proved to be valid. It was originally expected that the two receivers would produce similar positions if both sets were operating at the same time over the same location. One limitation of these receivers, however, is that current ephemeris infornation is 

not received unless the receiver has been activated prior to the update. [Ref. 66] For a period of time after the receiver is activated, the portion of the satellite message that contains the updated ephemeris is not acknowledged. Therefore, position degrades rapidly when a NATSAR is updated and the current ephemeris information is not utilized by the receiver. For this study, unfortunately, the initial times of activation of the two receivers were not recorded. Hence, the effect on position caused by this receiver parameter was not defined.

The URE plots illustrate that the ephemeris updates did contribute significantly to the range error and, consequently, the resulting position error. The position determined by the Manpack receivers was not affected as seriously by the clock error in NavSTaR 1 wher a five-satellite constellation was used. The inaccuracy of pseudo-ranges received from this satellite required frequent updates from Vandenburg, especially on 13 May. A receiver that had the option of totally eliminating the erroneous pseudo-range would have given the best results for the study. Since the receivers operated independently, and the ephemeris information was not concurrert, the differential mode was effective for only a fer cases. 

A simple correction was applied to the values output or the control display unit of the Manpack receiver. This did not permit application of tropospheric or refraction error corrections, other than that applied by the receiver during computation of the position. a more sophisticated prccessing method, resulting in greater accuracy, would Iequire acquisition of the pseudo-ranges and subsequent postprocessing to determine the receiver positions.

The best results during the onboard portion of the study were obtained when the ship was allowed to drift at approximately 1 knot on 12 May.

In conclusion, use of two phase I Manpack receivers in the differential mode meets the required accuracy of 10 meters only if the ship speed is less than 1 knot and other parameters such as ephemeris information and the number of satelites used for the position computation introduce a minimum amount of error. Further testing using differential GPS should incorporate more sophisticated processing wethods and more advanced receivers to achieve the survey accuracy required for nearshore hydrographic surveys. 



\section{APPENDIX A. DESCRIPTION OF ERROR THEORT}

Prom application of error theory in the evaluation of positional information, it is possible to establish a meaningful accuracy statement subject to uniform interpretation. To provide a logical and acceptable basis FOB COMPOTATION AND COMPARISON, POSITIONAL ERRORS ARZ assumed to follow a normal distribution. The assumption is valid because positional error components generally follow a normal distribution pattern when sufficient data is available.

The statistical treatment of errors utilizes measurable errors obtained in the sources of positioning information. Analysis of the linear components provides a tro-dinensional expression of the accuracy of the positioning system in the form of an error ellipse. The use of an error ellipse is complicated by the problem of axes orientation and propagation of elliptical errors. Therefore, the ellipse is commonly replaced by circular form which is easie= to use and understand. The linear standard errors are combined and converted to a circular distribution and the final accuracy statement is expressed in terms of circular errors. 

The circular form assumes the circular probability distribution function. This function expresses the probability that the radial error will be equal to or less than the radius of the probability circle. The dispersion of errors within the distribution is measured in terms of precision indexes, each of which represents the error which is unlikely to be exceeded for a given probability. The preferred circular precision indexes are the circular standard error $(\sigma)$, the circular probable error (CPE or CEP), the circular map accuracy standard (CMAS), and the circular near-certainty error, or 3.5 sigma $(3.5 \sigma)$. For each precision index, the given probability is $39.35 \%, 50 \%$, $90 \%$, and $99.78 \%$, respectively.

Each of the precision indexes can be converted to one of the others by using the following table:

Circular Error Conversion Factors

\begin{tabular}{l|cccc} 
& $39.35 \%$ & $50 \%$ & $90 \%$ & $99.78 \%$ \\
\hline $39.35 \%$ & 1.0000 & 1.1774 & 2.1460 & 3.5000 \\
$50 \%$ & 0.8493 & 1.0000 & 1.8227 & 2.9726 \\
$90 \%$ & 0.4660 & 0.5486 & 1.0000 & 1.6309 \\
$99.78 \%$ & 0.2857 & 0.3364 & 0.6131 & 1.0000
\end{tabular}



The rapid approximation for determining the circular standard error is

$$
\operatorname{csE}=0.5000(\sigma x+\sigma y)
$$

where $\sigma x$ and $\sigma y$ are linear standard errors obtained from the sources of positioning information, and therefore are the axes of the error eliipse. For a truly circular distribution, where $\sigma \mathrm{c}$ is identical to the circular standard error, $\sigma x$ and $\sigma y$ are equal and the angle of intersection between the two is $90^{\circ}$. In all other cases, a normal circular error distribution is substituted for the elliptical distribution. The substitution is satisfactory for an analysis within specifiedomin/omax ratios, where $\sigma$ min is the minor or smaller linear standard error of the two. Distortion in the error distribution between elliptical and circular forms at lower $\sigma$ min/ $\sigma$ max ratios limits the use of the circular concept to ratios greater than 0.2 .

The cuas is the precision index used as the 0.5 . National Map Accuracy standard. It is interpreted as limiting the size of error which $90 \%$ of the positions will not exceed. CMas is computed from circular standard error as follows:

$$
\text { CMAS }=2.1460 \sigma \mathrm{C}
$$



The two-dimensional error distributions for positions determined by the ARTEMIS system and the cheodolite network are described by cyas. The accuracy of the specific positions is expressed by a statement of probability and error magnitude. The accuracy statement does not mean that the error in position is exactly the value shown in figure 5.1. rather it expresses the probability that the error in position will not be larger than the error given. 



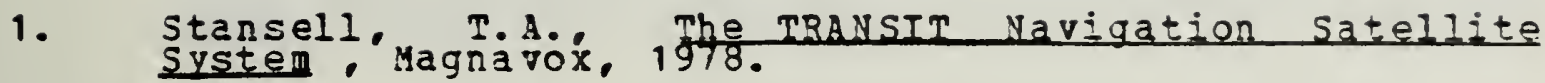

2. Denaro, R.e etal, "GPS Phase I User aguipment Field Tests": Näigation: v.25. No.2, Summer 1978?

3. Personal communication, Lt. T. Bulon, NOAA, 2 Pebruary, 1981.

4. Munson. R.C. RADM NOAA
on the Hork of Positioning systems--pepert

5. Durn Po and Rees J. Hydrographic Applications of the Global Positioning sys

6. Ibid.

7. Van der Ree, A.. The ARTEMIS position Fixing system. A Range Beárinǵ systzm. paper presented beforethe Caradian hydographic Conference, Halifax. N.S.. 1980.

8. Op git., Stansell, 1978.

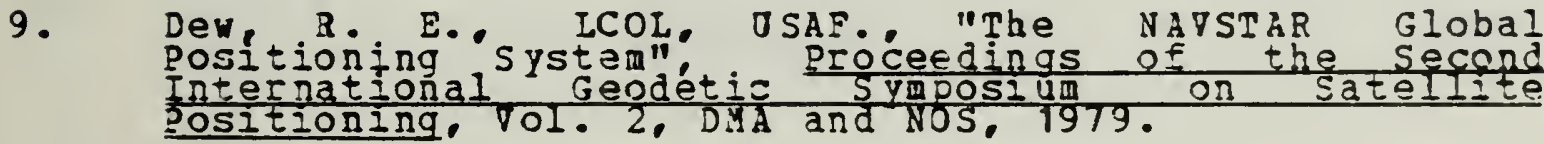
10. Henderson D. N. and Strada, J.A.: "NAvSTAR Fiold Test

11. Easton R.I. and Buisson, J.A. "The Contribution of Navigation Technology Sateliftes to the Global Positioning system" procedings of the second International Geodetic symposium on satellite voppleI

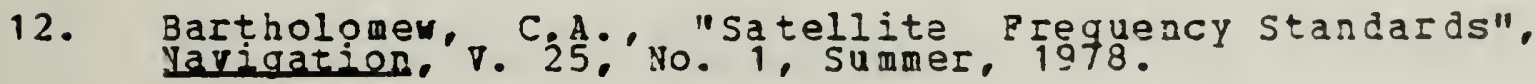

13. Ibid.

14. Qgeit. Dew, 1979.

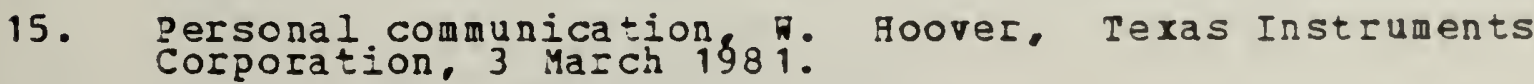



16. Jorgensen, P.S. "Combined Pseudo-Range and Doppler Positicning for " the Stationary NAVSTAR DSern, IEEE plans 80 position Location and Navigation symposium RecoId, 1980.

17. Book S.A. et al, "The Nonuniform GPS Constellation", IEEE Pajis 80 position location and vavigation

18. Milliken R.J. and Zoller c.J. "Characteriple of Operation of NAVSTAR, and System Characteristics",

19. Qp Eit, Dew, 1979.

20. Apiation Heek and Space Technology, 10 rarch, 1980, ?. 21. Op git, Book, 1980.

22. GPS Diagram, Rockwell International--space Division,

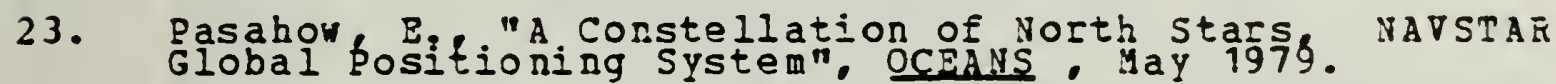

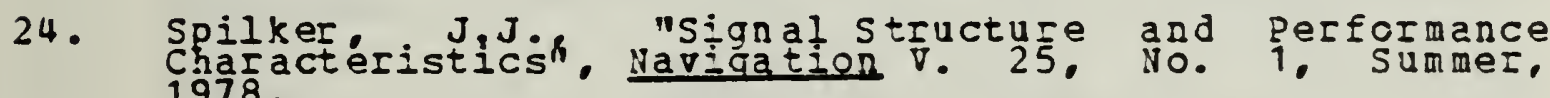
1978 .

25. Ibid.

26. Op cit, Milliken and Zoller, 1978.

27. Op cit, spilker, 1980. 28. Van Diererdonck, A.J.

29. Russell S.S. and Shaibly. J.H." "Control Segment and oser PeIformance". Navigatien, $\forall$. 25, No. 1, sumer.

30. Op eit, Dew, 1979. 31. Personal comanication, CAPT E. Gonzales, USAF, 5 May

32. Op cit, Van Dierendonck, 1980 

33. Global positioning system Manpack/Vehicular ogser

34. Ibid.

35. Op cit, Spilker, 1980.

36. Op cit, Milliken and Zoller, 1978.

37. Teasley S.P.\& et al "Differential GPS Vavigation", Symposium Record. 1980 .

38. Qp cit. Muason, 1977.

39. Umbach, M.J., CAPT, NOAA, Hydrographic Manual, Fourth Edition, NoS: 1976:

40. Gossett, F.R., Manual of Geodetic Triangulation, Nos, 1950 .

41. Poling, A.C., Tellurometer Manual, NoS, 1961.

42. Mueller. I.I. and Ramsayen

43. Hodgson C. V.á Manual of second and Third-order

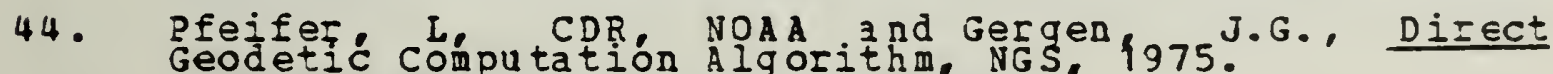

45. Pfeifer, Ĺ, CDR NoAA, Intersection Computation

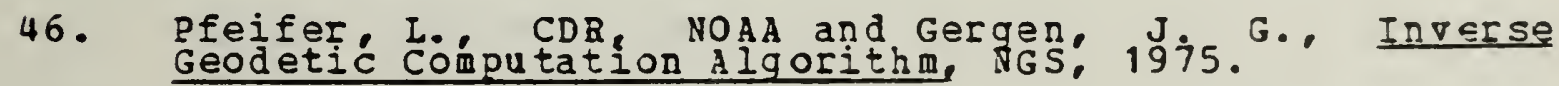
47. Library Program, NONIMSL, IBM 3033, Naval Postgraduate

48. Op Cit, Van der Ree, 1981.

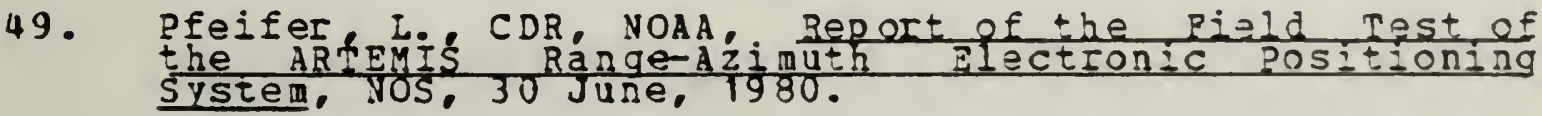


50. Nevell, V. LT, NOAA and Winter, D., LCDR, NOAA, ARTEIS TESt RESUlts, MS. 1989.

51. Personal communication, R, Melby, PMC, NOAA, 5 april,

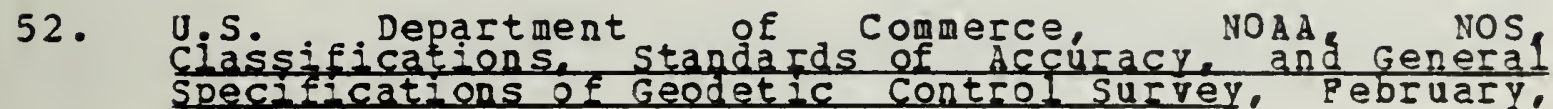
Speci.

53. U.S. Department of Commerce NoAA, NOS Specifications to support classification standards of Accuracy and Generat specilications of Geodetic control surveys. July 1975, Revised June 1980 .

54. Admiralty Manual of Hydrographic surveying. Vol. 1. Hydrographer of the vary. 1965.

55. Op cit, Admiralty Manual, 1965.

56. Op cit, Stansell, 1978.

57. Qp git, Milliken and Zoller, 1980.

58. URE plotted data received fron SAMSO, May, 1981.

59. Goodman J. ". "The Environment and Earth-Space

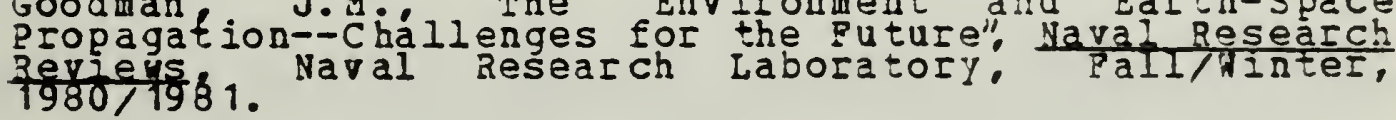

60. Op cit, Milliken and zoller, 1980.

61. Ibid.

62. Q2 eit, Spilker, 1980.

63. Op cit, Van Dierendonck, 1980.

64. Op eit, Henderson and strada, 1980.

65. 2p cit, Teasley, et al, 1980.

66. Personal comunication, 1981: Porter, Yuma Proving 

Air Porce ACIC Technical Report Number 96 fy Principles of Shultz, Pebruary, 1962.

Air Force Systems Command Test and Evaluation Master plan Number J-190, NATSTAR GIObal Positioning System fer Navy Annex, by headquarters, Space Division, JuIy, 1980. Army Map Service Technical Report Number 477 Integration
orbits

Army Map Service Technical Report Number 61, Pre-orbiter Investigation, by R. H. Harpe and others, 1967:

Bossler, J D. Interagency Coordination plan for Development of the Appi ication of the MAVSTAR Global positioning system (AES) tor Geodetic Surveying paper distributed to the ational Academy of Sciences committee on the panei for Global Positioning systems and members of the Interagency Group. Rockvilie, Maryland, 31 October, 1979.

Bowditch N American Practical Navigator, 2 vol.. Defense Mapping \&gency. Hydrographic Center, JMA Stock 'Number NV PUE97I. 1977.

Christiaan Ruygenslaboratorium ARTEMIS Manual, operation and Instaliation ganual for the ARTEMIS position Rixing System. तर III-S, 1972.

Cnossen, R Row Cost GPS Receiver for General Aviation, pacer presented at the 32nd Annual Helicopter Association of im-13 February. 1980 .

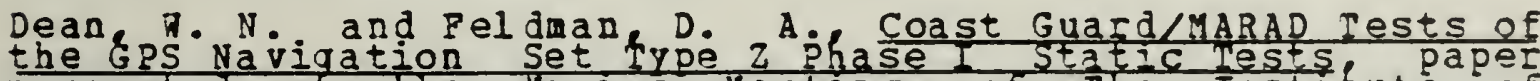
presented at the Marine leeting of The Institute of Wavigation, Yorktown, Virginia, 1980.

Defense Mapping Agency, Availibility of Data as of 15 July, portáble Tracking zquipment. Sateliste Records Desk, is Ju1 1979 .

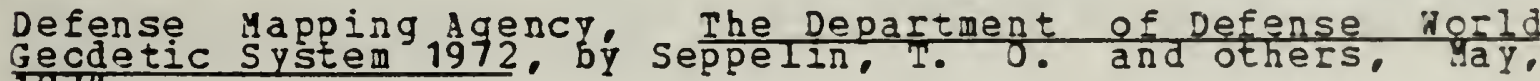
1974.

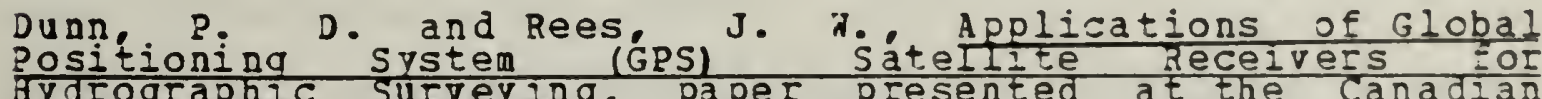

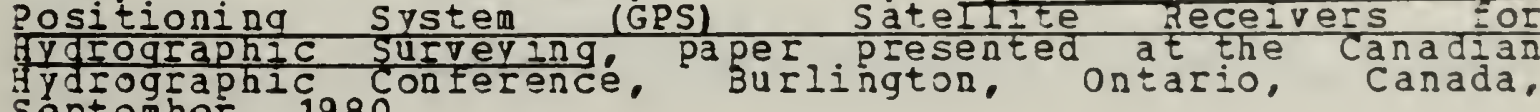
september. 1980 . 
Euler, N. C and Jacobson, L J. A Perspective on civil Ose of GPS. paper presented at rhe fnstitute of Navigation $36 t h$ dnnual Meeting. Monterey. California.23-26 June, 1980

Prancavilio J." "NAVSTAR New Stars in the Sky." SuIface WaIfare, February. 1979.

Heinzen, M. R. Hydrographic surveys: Geodetic EIIor PIcpagation, unpublished paper. United states Naval oceanographic office. NSTL station: Mississippi. 1981.

Henderson, D. 7. and Strada, J.A. NAVSTAR Field Test Results paper presented at the Institute of Navigation National A erospace symposium, Springfield, Virginia, 8 March, 1979.

Ingham, 1975. Sea surveying, 2 vol.. John riley and sons, Jacobson, L ${ }_{\text {Sositioning }} \frac{\text { User Equipment for the NAVSTAR Global }}{\text { paper presented at the vational }}$ Positioning system 1976 .

Jacobson, I. and Huffman, L." "Satellite Navigation With GPS," Satelíte Communications:" JulY. 1979.

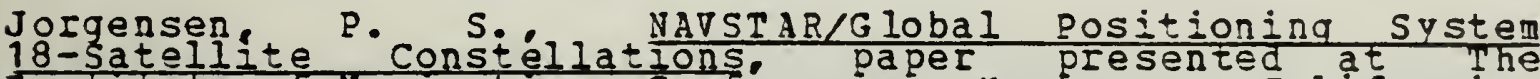
Institute of Navigation Coniérence, Monterey. California. $25-29$ June. 1980 .

Joseph K ${ }^{\prime}$ ipp and others. VAVSTAR GPS Receiver for Satelizte Applications. paper presented at AGARG sist kingdom, 14-17 october, 1980.

Kaplin, A. Error Analysis of Hydrographic positioning and the Application ot least squares. lasters mhesis. NavaI postgraduate school. Monterey. California. 1980.

Logistics Review Group Report
System (GPS) Audit Sumary. 26 A pril. T979.

Magnapox Technical Report MX-TM-3324-80, Absolute and Relative positioning Accuracy of Integrated satellite/omega

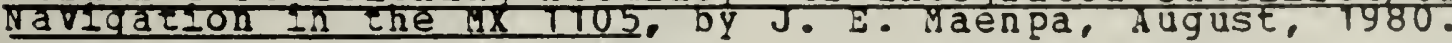

Magnavox Report 14043, Global Positioning systems 2hase I User Sets Descriptions: october. 1980.

Mils. G. Analysis of Random Jrrors in Horizontal Sextant Angles, Masters Thesis, Naval postgraduate School, yonterey. California, 1980. 

Moses. J.its for the GPS Manpack parion paper presented at the 30th annual symposium on Frequency control, Atlantic City. $N \in W$ Jersey, 2-4 June. 1976.

Moses. J." The Application of the NAVSTAR Global positioning System to the ivaluation of the Next Generation long Range Ballistic Missiles. paper presented at the International Telemetering conference, hyatt House Hotel, Los Angeles, california. 18-20 Octobér. 1977 .

National Aeronautics and Space Administration Contract Numer Nas 6-2173. Hallops Island Tropospheric Refraction study and Analysis; by C. Goad, 12 July. 1974.

Naval Ocean Systems Center Pield Test operations Plan PTOP-PF-1052 NATSTAR GIobal Positioning system on Figate $\angle P E-1052,301 Y .1978$.

Naval Ocean Systems Center Field Test operations Plan Contract Number N00123-77-C-0046 NAVSTAR GIobaI Positioning System on IVTP. by SAI COMSISTEGS Corporation. Tovember. 1979. Naval Ocean Systems Center Technical Regort Number 417,
NAVSTAR Global Positioning System Shipboard Antenna Tests: by R. H. AkIta and R. H. HajoI. May. 1979.

Pfeifer. L. ' RepoIt of the Field Test of the ARTEMIS ange-Azimuth Electron IC positioning system, paper presented at the National ocean Survey fydrographic conference, Norfolk, Virginia, 17 January. 1981.

Rockuell International 3eport, NAVSTAR Global positioning System. Collins Government Avionics DIVISIOn. 6 February. Space and Missile Systems Organization CS/OE Definition by General Dynamics, Electionics Division, 28 February, 1974:

Space and Missile Systems organization cs/0E Contract Definition P04701-73-c-0298. Jse inal keport for Giobal Dositioning systen control Use segments 1974 .

Space and Missile Systems Organization NAVSTAR Global positioning system Contract Number CID-ADUS-101A. PIime Item product Function lor the Global positioning system ranpack/vehicular positioning and Narigation set rypecla. With lexas Instruments Incorporated, 3 June, 1975.

Space and Missile systems Organization Report IR-79-79.

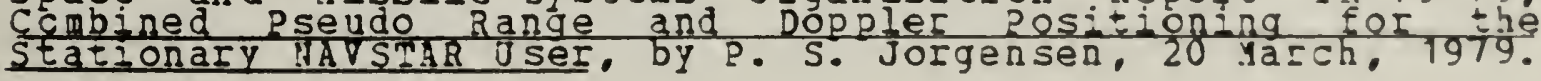


Space and Missile Systems organization Final Pield Test operations, 1 June. 1979.

Space and Missile Systems Organization Major Field Test value: Photomapping/p hototargeting, Tyay, 1979.

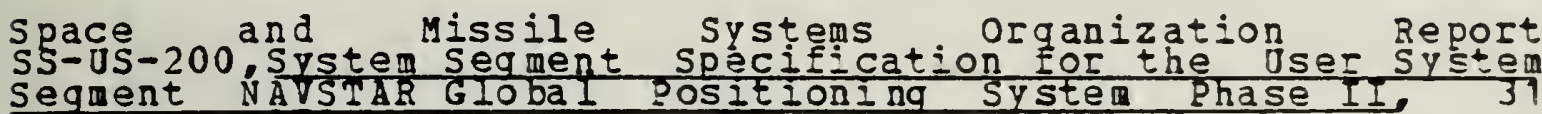
January. 1979.

University of Tezas at Austin Bid Invitation Number 0088,2
Global positioning Receiving System (GPS). Pield Portable, 2 July, 1981. 
NO. COPIES

1. Defense Technical Information Center

Cameron Station

2. Library, Code 0142

Monterey, California 93940

3. Department Chairman, Code 68MI

Department of oceanography

Naval Postgraduate School

vonterey, California 93940

4. DR. G. Sackman

Department of Electrical Engineering, Code $625 a$

Naval Postgraduate School

Monterey, California 93940

5. MR. T. Stanton

Department of Oceanography, Code:68sa

Naval Postgraduate. School

Monterey, California 93940

6. Professor G. Schacher

Department of Physics and Chemistry, code:61 Sq

Naval Postgradua te School

yonterey. California 93940

7. CDR D. Puccini

Department of Air ocean Sciences, Code: 35

1

Naval Postgraduate School 190

8. DR. K. Davidson

Department of Meteorology, Code:63Ds

Monterey, California 93940

9. CAPT. R. Reynolds

Department of Oceanography, Code 68

Monterey, California 93940

10. Professor J J Pon Schwind

Department of oceanography, code $68 \mathrm{VS}$

Nonal Postgraduate School 

11. Professor T. Garwood Department of Oceanography, Code: $68 \mathrm{G}_{9}$

Nonterey. California 93940

12. Associate Director, Marine Operations, C7

National Ocean Survey

vational oceanic and Atmospheric Administration

Bockrilie, Maryland 20852

13. Director

Office of Ocean Technology and Engineering Services. National oceanic and Atmospheric Administzation

bockrilie, Maryland 20852

14. Director

A tiantic Marine Center, NOAA

439 West rork street

Norfolk, Virginia 23452

15. Director

Pacific Marine Center NOA

1801 Fairview A venue East

Seattle, Mashington 98102

16. Director

Enqineering support office, TE3

office of Ocean Technology and Engineering Services

National oceanic and atmos pheric administration

Rockville, Maryland 20852

17. Chief, Operations Division

National Ocean Survey (NOAA)

oA/C71: Attn: CDR PideIT. Smith

Bockvilie, Maryland 20852

18. NOS Iiaison for Radio Prequency Managenent

National Ocean Survey (NOA A) Moore

Bockvilie, MaIyland 20852

19. Chief, Sensor Test Division

OAngineering Suport Office OTES/YOAa

Bockvilie, Maryland 20852

20. Office of Marine Surveys and Maps

National ocean Survey, NOAA

oa/C35x3: Attn: Mr. Jáck t. Rallace

Rockvilie, Maryland 20852

21. Engineering support office

OTES/NOAA

oA/TE31: Attn: Mr. Rnute A. Berstis

Rockvilie, Maryland 20852 

22. Engineering Support office

OTES/NOAA

OA/me31. Attr: Mr. Gary Rhitsell

Rockvilie, Maryland 20852

23. LCDR. G. B. Mills, NOAA

Department of Oceanography, Code 68yi

Nonterey. California 93940

24. IT. T. BuION, NOAA

NOAA NOS

Code: C734

6001 Executive Blvd.

Rockvilie, Maryland 20852

25. MI. T. B. Smith

Assistant Regional Director Hydrography

Bedford Institute of Oceanogra phy

P.0. Box 1006

Dartmouth, N. S., Canada

B2 14 A2

26. IT. Hector soldi

Direccion De Hidrografia y

Navegacion De La Marina

Esq. Roca I Gamarra

Chucuito-callao

Peru

27. ITCDR Nalter Garcia

Direccion De Hidrografia y

Navegacion De La Marina

Esq. Roca Y Gamarra

Chucuito-callao

peru

28. LT. D 2068 Minkel, NOAA

Naval Postgraduate School

yonterey. California 93940

29. Mr. ${ }_{S}{ }_{2} 873$. Peters.Esq.

Naval postgraduate school

Monterey, California 93940

30. Director

Defense yapping Agency

Hydrographic/Topographic center

Code: HO

6500 Brookes Lanes

Washington, D.C. 20315

31. Director

Defense Mapping Agency

Hydrographic/Topographic center Code: STr

6500 Brookes Lanes

Nashington, D. C. 20315 

32. Director

Defense Mapping Agency CY Od IOgrapt 6500 Blookes Lanes Hashington. D. C. 20315

33. Director Defense lapping Agency 6500 Brookes Lanes washington. D.C. 20315

34. Director Defense Mapping Agency Hydrographic/Topographic center Code: GSGS 6500 Brookes lanes Washington. D. C. 20315

35. Director

Defense Mapping agency

Hydrographic/Topographic center Code: SD

6500 Brookes Lanes

Mashington, D.C. 20315

36. Director

Defense yapping agency

Code: $\mathrm{PPH}$

3ldg 56 U. S. Naval Observatory

Wasbington, D. C. 20305

37. Director

Defense Mapping agency

Code: SST

$31 d g 56$ O. S. Naval Observatory

Washington: D: C. 20305

38. Director

Defense Mapping School

Code: PSD-MC

Bt. Belvoir, Virginia 22060

39. IT. 7. Newell, NOAA

NOAA Ship Davidson

Pacific garine center

1801 Pairview Avenue, East

seattle, washington 98102

40. ICDR. D, D. Minter, voAA

YoAa Ships Rude $\varepsilon$ Heck

atlantic Marine center

439 Hest roIk Street

Norfolk, Virginia 23510 

41. Naval Research Laboratory

Code: 5110 (John Brozena)

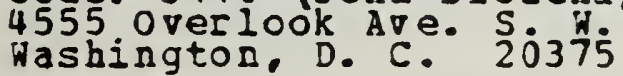

42. Mr. Mohan

4800 Oak Grove Drive

91109

43. MS. P. D. Dunn

Naval Oceanographic office

Code: 8412

NSTL Station

Bay st. Louis, Mississippi 39529

44. C comander

Naval Oceanography Command

NSTI Station

Bay st. Louis, Mississippi

39529

45. Commanding officer

Naval Oceanographic office

NSTI Station

Bay st. Louis, Mississippi 39529

46. Commanding officer

Naval Ocean Research and Development Activity

Attn: Larry Gronmeyer, Code: 302

NSTL Station

Bay st. Louis, uississippi 39529

47. Comanding Officer

Oceanographic Unit one

OSNS BÓWDITCH (T-AGS21)

Fleet post office

New YoIk. New YoIk 09501

48. Commanding officer

Oceanographic onit Two

USNS DOTTON (T-AGS22)

San Prancisco, California 96601

49. Commanding officer

Oceanographic Unit Three

USNS H. H. HESS (T-AGS38)

leet post ofice

San Prancisco, California 96601

50. Commanding officer

Oceanographic onit Pour

USNS CAAUTENET. ( $\bar{T}-$ AGS29)

Pleet post office

San Prancisco. California 96601 
51. Commanding officer

Vaval Oceanographic office
Code: 8400 Atti: D. Ouellette
NSTI Station

Bay St. Louis, Mississippi 39529

52. Commanding officer

Naval oceanographic office

Code 8100 ; Attn: Hart

NSTL Station

Bay st. Louis, Mississippi 39529

53. Commanding officer

Naval Oceanographic office

Code: 800; Attn: R. Higgs

NSTI Station

Bay st. Louis, Mississippi 39529

54. Commanding officer

Naval oceanographic office

Code: 6000 ; Attn: C. Getmen

NSTL Station

Bay St. Louis, Mississippi 39529

55. Commander

Naval Oceanography command

Code N53: AtEn: J. Reshew

NSTI Station

Bay st. Louis, Mississippi 39529

56. Commanding officer

Naval oceanographic office

Code 02: Attn: A. Beck

NSTI Station

Bay st. Louis, Mississippi 39529

57. Director

Naval Oceanography Division

OP-952: Atta: CDR J. Chubb

Department of the Navy

Washington. D. C. 20350

58. Defense Mapping Agency HQ

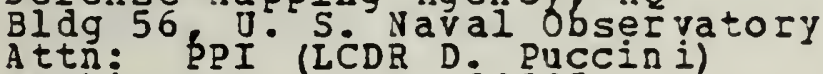

Washington. D. C. 20305

59. Director

Naval Air Development Command

Code: 4031; Attn! N. Yelling

Narminster, Pennsylvania 18974

60. Mike sims

Code: $K-13$

Vavai Surface Meapons Center

Dahlgren. Virginia 22048 
61. HI. BIuce Hermann

Naval Surface Meapons Center

Dahlgren. Virginia 22408

62. Texas Instruments

Attn: hoover

2501 South Highway 121

P.O. Box 405

Lewsville. Texas 75067

Mailstatión 3418

63. MI. T. Calhoon

Department of oceanography. Code $58 \mathrm{Cu}$

Naval postgraduate School

Monterey. California 93940

64. LT. Rिं Parsons, NOAA

Naval postgraduate school

Monterey. California 93940

65. CDR. A. Durkee

Deputy Project Manager, DOT

APSC. Space Dirision

Code $Y$ E $-D O T$

P. O. Box 92960

Los Angeles. California 90009

66. MI: Stilianos Mertikas

University of jew BIUnswick

Surveying and Engineering Depa rtment

Canada $33 \mathrm{~B} 5 \mathrm{A3}$. Fredericton. N. 3 .

67. HI.J. Hume

Marinav Incorporated

1814 Hest BelE Drive North

Houston, Texas 77043

68. MI. B. GIay

Marinar Incorporated

1814 West BeIt Drive North

Houston. Texas 77043

69. Commanding officer

NOAA Ship Davidson

Pacific larine center, NoAd

1801 Fairview Avenue East

seattle, washington 98102

70. Director

Naval Oceanography Division

Naval observatory

$34 \mathrm{th}$ and yassachusetts avenue $\mathrm{v}$

Nashington, D. C. 20390 
71. Commanding officer Monterey. California $939 y_{0}$ Center

72. Commanding officer

Naval ocean Research and Devel cpment Activity

NSTI Station

Bay St. Louis, MS 39522

73. Commanding officer

Naval Environmental Prediction Research Pacility

yonterey, California 93940

74. Chairman, Oceanography Department

An S. Nolisal Academ $214{ }_{2}$

75. Chief of Naval Research

800 N. Quincy street
AIlington.

76. Office of Naval Research (Code 480 )

Naval ocean Research and Development Activity

NSTI Station

Bay St. Louis, MS 39522

77. Director

National Oceani Survey (OA/C)

sockvilie, MD 20852

78. Chief, Program Planning and Liaison (NC2) Nockville, yD 20852 atmos pheric administration

1

79. Associate Director

Yarine Surveys and Maps $(0 \mathrm{~A} / \mathrm{C} 3)$

National oceanic and Atmos pheric Administration

Rockvilie. MD 20852

80. Chief, Hydrographic surveys Division (OA/C35)

National Oceanic and Atmospheric administration Rockvilie, YD 20852

81. Commanding officer

oceanographic Ũ

USS HARRNESS

Fleet post office

NeW YOIX, NY 09573

82. Ino/PIG International Advisory Board

International Hy drographic Bureau

Avenue President J. Z. Ken nedy

Mon te-Carlo, Monaco 
83. Hydrographer of the Navy

Hydrographic Department

Taunton. Somerset

TA $129 \mathrm{~N}$

England

84. Hydrographer, Royal Australian Navy

Box $13 \frac{3}{3} 2$

North Sydney

New South yales - Australia

85. Dominion Hydrographer

Canadian Hydrographic Service

615 Booth Street

ottawa. Ontario

Canada

KiAOE6

86. Kapala Jawatan Hidro Oseanografi

Jalan Gunung Sahari-87

Jakarta, Indonesia

87. Direccion General De Oceanografia

Departmentc De $\mathrm{Hidrograficia}$

A ve COYOACAN 131

Hexico $12, \mathrm{D}$. F.

88. Director

Instituto Hidrog rafico

I is boa

Portugal

89. Director De Hidrografia y Navegacion de la Marina 1 Direccion de Hidrografia Naregacion de la Marina Calie Saenz pelia - 5ta cuadra-La Punta Callao-5 peru

90. Civil Enqineering Department

ports and lighthouses Administration

Ras Eltin-Gate 1

alexandica, ggypt

91. הydrographic service

A thens BST 902

Greece 



Thesis 195491 N4494 Newell

c. 1

Application of the global positioning system to nearshore hydrographic surveys.

\section{Thesis}

N4494

C. 1

NeweII

$30: 494$

Application of the global positioning hydrographic surveys. 


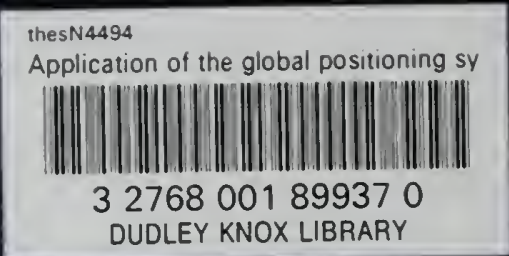

